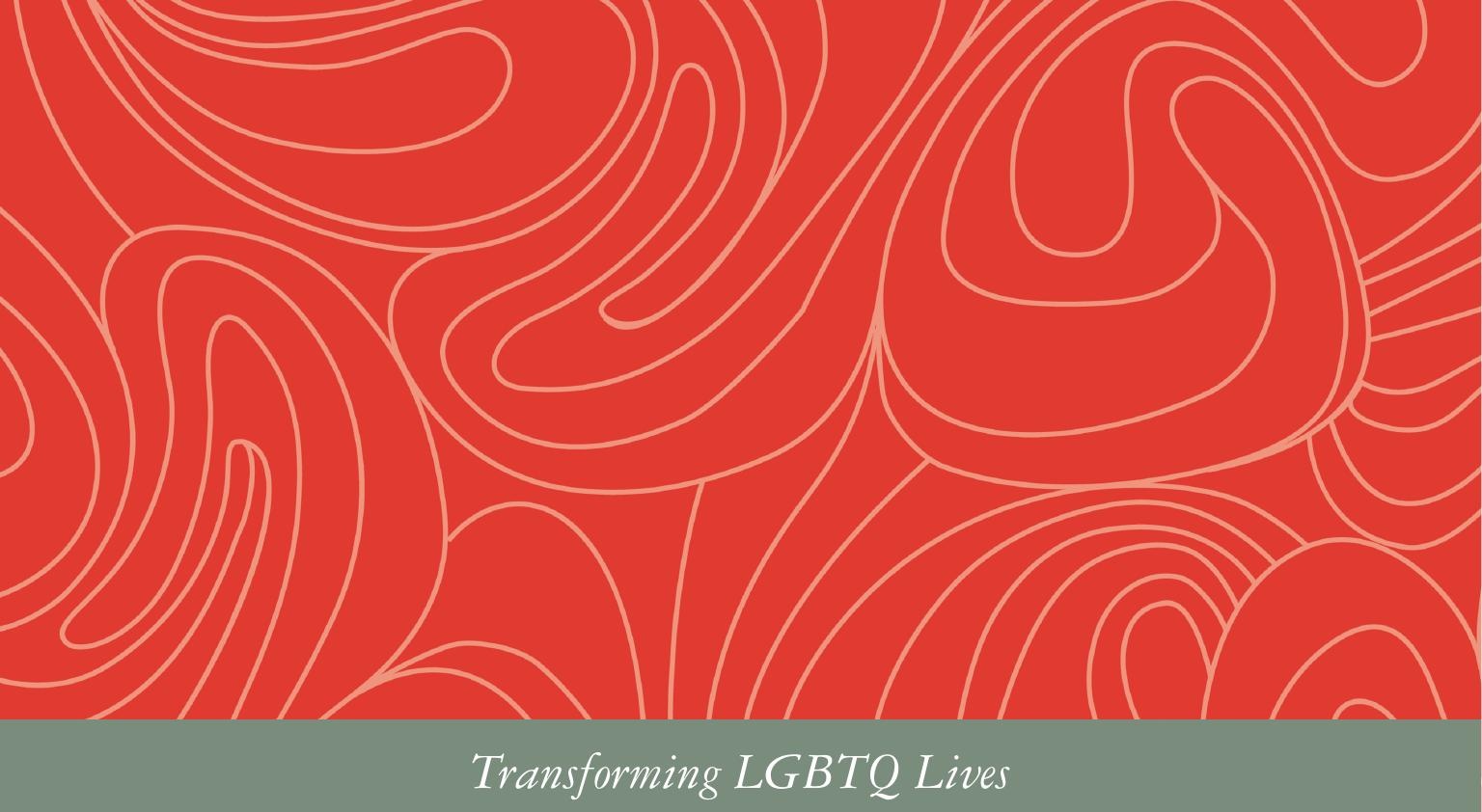

\title{
THE EVERYDAY LIVES OF GAY MEN
}

\section{AUTOETHNOGRAPHIES OF THE ORDINARY}

\author{
Edited by
}

Edgar Rodríguez-Dorans and Jason Holmes 


\section{The Everyday Lives of Gay Men}

The Everyday Lives of Gay Men draws on the expertise of 12 contributors from different countries and fields, writing from an autoethnographic firstperson approach.

Putting the power of personal stories at the centre of the construction of sophisticated narratives of gay men's lives, the accounts draw attention to the limits of traditional perspectives to gay men's studies that look at gayness through a sexualised lens and explore how gay men make sense of their identity in their everyday lives. Together they present a complex, nuanced understanding of gayness and challenge the conception of 'being gay' as a sexual orientation because it describes in sexual terms an identity that is not only, not always, and not predominantly sexual. The authors come from a variety of fields, including counselling studies and sociology, to communication, religion, and education.

The innovative approach of The Everyday Lives of Gay Men makes it ideal for students and scholars in gender studies, sexuality studies, sociology, mental health, and research methods.

Edgar Rodríguez-Dorans is a qualitative researcher and mental health practitioner interested in the study of identities, sexualities, the everyday lives of LGBTQIA+ people, and the use of performing arts in research. He completed a PhD in counselling studies at the University of Edinburgh. $\mathrm{He}$ is a lecturer in counselling and psychotherapy at the University of Salford.

Jason Holmes works as a psychotherapist and writer. His research examines the ways gay male friendship groups can take on qualities commonly associated with cults and the emotional harm such groups can inflict on their members. He completed his doctorate in psychotherapy at the University of Edinburgh and is a member of the British Association for Counselling and Psychotherapy. 


\section{Transforming LGBTQ Lives}

Series Editors: Katherine Johnson (RMIT University, Australia) Kath Browne (University College Dublin, Ireland)

Transforming LGBTQ Lives hosts the best international scholarship on contemporary lesbian, gay, bi, trans and queer (LGBTQ) issues. Innovative, interdisciplinary and intersectional, the series showcases theoretical and empirical research that fosters debate, pushes disciplinary boundaries, and shapes activism. Extending feminist and queer scholarship through attention to a wide set of disciplinary influences (sociology, psychology, human geography, media and cultural studies, social policy, leisure studies, sports studies, political science) topics address the diversity of LGBTQ lives.

Recent titles in series:

The Everyday Lives of Gay Men

Autoethnographies of the Ordinary

Edited by Edgar Rodríguez-Dorans and Jason Holmes

\section{Queer Roma}

Lucie Fremlova

For more information about this series, please visit: www.Routledge.com/ Transforming-LGBTQ-Lives/book-series/LGBTQLIVES 


\section{The Everyday Lives of Gay Men}

Autoethnographies of the Ordinary

Edited by Edgar Rodríguez-Dorans and Jason Holmes 
First published 2022

by Routledge

2 Park Square, Milton Park, Abingdon, Oxon OX14 4RN

and by Routledge

605 Third Avenue, New York, NY 10158

Routledge is an imprint of the Taylor \& Francis Group, an informa business

(C) 2022 selection and editorial matter, Edgar Rodríguez-Dorans and Jason

Holmes; individual chapters, the contributors

The right of Edgar Rodríguez-Dorans and Jason Holmes to be identified as the authors of the editorial material, and of the authors for their individual chapters, has been asserted in accordance with sections 77 and 78 of the Copyright, Designs and Patents Act 1988.

The Open Access version of this book, available at www.taylorfrancis.com, has been made available under a Creative Commons Attribution-Non Commercial-No Derivatives 4.0 license.

Trademark notice: Product or corporate names may be trademarks or registered trademarks, and are used only for identification and explanation without intent to infringe.

British Library Cataloguing-in-Publication Data

A catalogue record for this book is available from the British Library

Library of Congress Cataloging-in-Publication Data

A catalog record has been requested for this book

ISBN: 978-0-367-67683-4 (hbk)

ISBN: 978-0-367-67946-0 (pbk)

ISBN: 978-1-003-13350-6 (ebk)

DOI: $10.4324 / 9781003133506$

Typeset in Sabon

by Deanta Global Publishing Services, Chennai, India 
To those whose life stories allowed us to be ordinary 
$\Longrightarrow$ Taylor \& Francis Taylor \& Francis Group

http://taylorandfrancis.com 


\section{Contents}

Contributors ix

Foreword: Transforming everyday gay life xii

KEN PLUMMER

What is conjured when we talk about the everyday lives of gay men? 1 EDGAR RODRÍGUEZ-DORANS AND JASON HOLMES

117 Times a day I think about being gay DAVID LOWBRIDGE-ELLIS

2 Shower thoughts - of loss and queer love RANDALL C. LOPEZ

3 Christmases past and present: A Phet tee saam lamb's search for their flock

PANU SAHASSANON

4 Sunday: An intimate self-dialogue about loneliness

CINÁED THOMAS

5 On (not) living past 30

TONY E. ADAMS

6 Going back to the glory hole: An (extra)ordinary story of meeting shame, doubt, and arousal in the therapy room

SEAMUS PRIOR

7 Becoming (in)visible: A performative autoethnography on mental health, help-seeking, and missing connections 
viii Contents

8 Lack of ordinary privileges in a gay man's life: Navigating through privileged systems

YASIN KOC

9 I dreamt of a stranger

JULIAN TRIANDAFYLLOU

10 Testing proximity and intimacy: An everyday reappropriation of private and public space

EDGAR RODRÍGUEZ-DORANS

11 In my Latinx gay shoes: Work, discrimination, immigration, and polyamory

OSCAR PANTOJA GUZMÁN

12 Planetary times and queer times: A critical planetary romanticism for the earth

WHITNEY A. BAUMAN

13 Notes on the contributors' experiences: Insights into autoethnographic research

EDGAR RODRÍGUEZ-DORANS AND JASON HOLMES

14 Conclusion

EDGAR RODRÍGUEZ-DORANS AND JASON HOLMES

Index 


\section{Contributors}

Tony E. Adams, professor and chair of the Department of Communication at Bradley University, USA. Prior to Bradley, he was a faculty member at Northeastern Illinois University, USA (2008-2017). He has (co) authored and (co)edited several books including Narrating the Closet: An Autoethnography of Same-Sex Attraction (Routledge), Autoethnography (Oxford University Press), and the Handbook of Autoethnography (Routledge). He is a co-editor of Routledge's Writing Lives: Ethnographic Narratives book series (with Carolyn Ellis and Arthur Bochner) and founding co-editor of the Journal of Autoethnography (University of California Press).

Whitney A. Bauman is an associate professor of religious studies at Florida International University in Miami, USA. He is also co-founder and codirector of Counterpoint: Navigating Knowledge, a non-profit based in Berlin, Germany, that holds public discussions over social and ecological issues related to globalisation and climate change. His areas of research interest fall under the themes of 'religion, science, and globalisation'. He is the recipient of a Fulbright Fellowship and a Humboldt Fellowship. His publications include: Religion and Ecology: Developing a Planetary Ethic (Columbia University Press 2014) and Environmental Ethics and Uncertainty: Tackling Wicked Problems (Routledge 2019), co-authored with Kevin O'Brien. At the time of writing his chapter, he is working on a manuscript about the 19th-century German romantic scientist Ernst Haeckel.

Oscar Pantoja Guzmán obtained his bachelor's degree in psychology from Universidad del Valle de México in 2015. He migrated to the USA in 2017, where he aims to continue his studies. He collaborates in this book with the aim of sharing part of his story of discovery and self-exploration.

Jason Holmes works as a psychotherapist and writer. His research examines the ways gay male friendship groups can take on qualities commonly associated with cults and the emotional harm such groups can inflict on their members. He completed his doctorate in psychotherapy at the 
University of Edinburgh and is a member of the British Association for Counselling and Psychotherapy.

Yasin Koc (he/him) is an assistant professor of social psychology at the University of Groningen in the Netherlands. His research benefits from the social identity approach to help improve the low status and wellbeing of disadvantaged groups, particularly in the case of multiple conflicting identities. He uses mixed methods in his research and aims to make his research findings relevant for the members of the communities involved in his work.

Randall (Randy) C. Lopez is originally from a small city called Corpus Christi in South Texas. They completed their undergraduate degree in psychology at Texas A\&M University prior to moving to Austin, Texas, for work and graduate school. Randy earned an MSc in health psychology from the University of Central Lancashire, UK, and an MSc in counselling studies and MSc education (research) from the University of Edinburgh, UK. Being a Hispanic, non-binary queer individual has stimulated their counselling and education research interest in working with the LGBTQ+ community and people of colour, especially where there is intersectionality between the two. They focus on the influence of education, mental health, resilience, and social justice for these communities. It is Randy's hope that their academic path provides a voice for marginalised communities, sharing their own journey from being part of a marginalised community. An academic journey mixed with their culture and their international community has allowed Randy to explore academia on an unprecedented level. It is their hope to continue this work not only for personal benefit but for the benefit of all those who inspire them.

David Lowbridge-Ellis has more than 17 years' experience as a secondary school teacher and has been a senior leader for most of those. His work has been featured by Schools Week, SecEd, the Key for School Leaders, the SSAT, Teacher Toolkit, the National Carnegie Centre of Excellence for Mental Health in Schools, the Centre for LGBTQ+ in Education, the BBC, ASCL, LGBTEd, and the DfE and on various podcasts. David has put his master's degree in educational management and leadership to practical use, supporting many schools in the UK and worldwide in helping them improve in various areas, particularly assessment, well-being, inclusion, and curriculum design. His academic interests are varied and often intersect with his personal interests. When not teaching or leading schools, he runs an online hub for queer readings of James Bond (www .licencetoqueer.com) and writes a travel blog with his husband. He can be found on Twitter@davidtlowbridge.

Seamus Prior is a senior lecturer in counselling and psychotherapy at the University of Edinburgh, UK, where he trains on professional programmes and teaches health care ethics. He is a psychodynamic therapist 
working in community mental health and private practice. His research focuses on the experience of therapy from both client and practitioner perspectives.

Edgar Rodríguez-Dorans is a qualitative researcher and mental health practitioner interested in the study of identities, sexualities, the everyday lives of LGBTQIA+ people, and the use of performing arts in research. He completed a PhD in counselling studies at the University of Edinburgh. $\mathrm{He}$ is a lecturer in counselling and psychotherapy at the University of Salford.

Panu Sahassanon was born in Thailand and lives in Bangkok, working as a lecturer in the faculty of psychology at Chulalongkorn University, where he earned his master's and bachelor's degrees. Outside of lecturing, Panu works as a counselling psychologist in the university's Center for Psychological Wellness. At the time of writing his chapter, Panu was on study leave in the UK, completing his doctoral degree in counselling and psychotherapy at the University of Edinburgh.

Willem J. Stander completed his $\mathrm{PhD}$ at the University of Brighton, where he also lectured across a range of core psychology curriculum areas. $\mathrm{He}$ currently works as a research fellow at the University of Birmingham on a project which aims to improve LGBTQ+ young people's experiences of social care. His research interests and expertise relate to how LGBTQ people seek help for mental health problems and the use of digital platforms for community outreach. Originally, from Namibia, he currently lives in Brighton and Hove with his partner, Max, and their two imaginary dogs - Chewie and Yoda.

Cináed Thomas is a mental health professional and researcher who is interested in when what goes on between gay men turns toxic. Outside of these identities, Cináed calls himself a procrastinating baker (he wishes he had the patience to make sourdough bread), a cabin porn addict (he drools over images of shacks in forests), and, because of what is sitting on his coffee table, a book-based traveller. If there was a playlist for his life, Cináed's list would include classics by Prince, in addition to more recent tracks by Christine and the Queens.

Julian Triandafyllou is a filmmaker working in creative documentary. He graduated in Fine Arts from Central Saint Martins, London (2008), before completing his MA in film direction from the University of Edinburgh (2019). 


\title{
Foreword: Transforming everyday gay life
}

\author{
Ken Plummer
}

\begin{abstract}
We always live at the time we live and not at some other time, and only by extracting at each present time the full meaning of each experience are we prepared for doing the same thing in the future. This is the only preparation which in the long run amounts to anything
\end{abstract}

John Dewey Experience and Education 1956

(1938) page 51 MacMillan

The book you are reading provides a wonderful collection of stories about the everyday personal experiences of being a gay man in the early 21 st century. Here are autoethnographies of the everyday: tales which give insight not just to biography and life but also to culture and history. All the tellers were born after the anti-gay laws changed in 1967; many were born after the AIDS pandemic killed many lives in the 1980s. Here they reflect on the plurality and problems of human experiences today: ageing, commerce, disability, health, loneliness, loss, marriage, monogamy, religion, teaching, therapy, time, and transcendence. Sometimes, the story mode is explicit and strong with stories of past lovers, of desire, of abuse, of Christmas, of the death of a father, of a dark sexuality, a glory hole, and despairing loneliness. Sometimes the stories are dramatised. All the stories engage with storytelling at an angle - they do not focus on being gay in and of itself; nor do they create conventional narratives. And they touch on movements across different cultures: Mexico, Thailand, the USA, the UK, Turkey, Namibia.

When I was first approached by the editors to engage with their book, I puzzled a little on the very idea of 'Gay Men'. The year 2020, and the era of COVID, is a time when, for some, the whole idea of clear gender and sexual identities is being challenged and rendered fluid. That said, for many people, their identities may be puzzling for a while, but they do not usually remain forever fluid. They gradually solidify. Most of my gay friends today are pretty clear who they are, as am I. There is often a struggle to get to this place. And most commonly, this takes place when they are young. I expect many of the authors in this book are engaged in a struggle to get where they are now. But that is not the story they tell here. I can recall (rather embarrassingly) once pronouncing at a conference for lesbian and gay scholars in 1989 that I was 'post-gay' (I puzzle now a little at my pretentiousness then and wonder now 
just what I actually meant by that!). Many eventually achieve some kind of more solid identity, and life becomes for many a much more stable affair - as it did for me. But, of course, this itself will bring new everyday problems.

On reflection, I decided that the preface of the book just might be an occasion for a little more autoethnographical reflection on such matters - a key difference being that I was not going to tell a tale of everyday life in 2020 but draw instead from an earlier period: my coming out period, over 50 years ago, between 1965 and 1970. I will touch a little on times both before and after, but I want to capture a few narrative memories of my 'troubled' everyday life as it was a half-century ago. It can be seen as a kind of scene setting for the stories of today. ${ }^{1}$

Everyday life resides in narrative and storytelling, always shaped by time and space. Our everyday lives become contingent upon shifting grounded historical moments as they get lived in particular places and told in particular personal biographies, transformative generations, and evolving histories. It is our personal and human actions that breathe life into the structures of the everyday world we inhabit. My little scene setting from a recent past suggests a world of the changing everyday. ${ }^{2}$

\section{Conversations with an earlier self: Coming out stories once more}

Although, in 2021, it may sound very quaint and old-fashioned, central to my understandings from 50 years ago was, and is, the narrative of coming out. An early challenge of my life was to move from the everyday darkness of gay stigma into the light of a functioning everyday life. Coming out is a powerful narrative of trouble, repair, and hope. It depicts a core, but messy and gradual, movement from an inner struggle with self, an engagement with others, on to a finding of a community of like-minded beings and towards an eventual becoming that is able to publicly and visibly and politically declare being gay, queer, or whatever. Ultimately, it is a coming to terms with oneself in a public world. ${ }^{3}$ Today I can see this as part of the much wider process of coming to terms with life: how people are engaged with the search for meaning and charged to make sense, giving story form to

1 In these notes, I suggest connections to some earlier writings for the interested reader. I have discussed some of these earlier personal moments in Cosmopolitan Sexualities: Hope and the Humanist Imagination. Cambridge: Polity, 2015, part 4; 'Foreword: Falling in Love with Johnnie Ray: Sixty Years of Telling Sexual Stories' in Waugh and Arroyo, I Confess: Constructing the Sexual Self in the Internet Age. McGill-Queens University Press, 2019, p1x-x; and in 'On the Infinitude of Story Telling: Still Puzzling Queer Tales after All These Years' in "Queer Autoethnographies" Spring 2017 issue of QED: A Journal in GLBTQ Worldmaking. Vol 4 No 1 p189-197.

2 For my wider analysis, see Ken Plummer Narrative Power: The Struggle for Human Value. Polity, 2019.

3 I have discussed my coming out in Telling Sexual Stories (1995, Routledge) where it became a central metanarrative in sexual storytelling. Nowadays, of course this process has become central, I think, to the emergent western narrative of 'trans'. 
their everyday existence on this earth. Sometimes this experience is kept very general, but often it is linked to the unearthing of early worries and problems which need some kind of resolution. When I was young, this focused a lot on sexuality, being gay, finding a partner, settling down; nowadays - 50 years on and having lived with my partner for over 40 years - it focuses much more on illness and dying. This search for meaning is always historically specific and bound up with both the conditions of the times and the stage of a life cycle, even as it gradually pushes us into the transcendental.

I could go back to my earliest childhood memories and worries for a very slow Proustian unfolding of a dialogue with self about difference and queerness. But in a short preface I will start with very specific memories of being in the first year at my secondary school and falling in love with a very handsome sixth form 12th-grade prefect. I remember trying to tell my father about this boy at school and my feelings towards him, and soon learned such things bring a negative, even hostile, response. Some stories were clearly not to be told in public. So I started keeping this side of life to myself and embarked upon a series of relationships with girls - after all, that is what boys were supposed to do. I had quite a few of these relationships and enjoyed them. Indeed, my nickname became 'Romeo'. Something, however, was not quite right. Something was missing. The girls would desert me. I think they expected that little something more, something I wasn't remotely interested in.

At the same time, I was turning out to be quite a religious little boy. Joining a local youth club at the age of 11, I became a Methodist. First, I would go to Sunday school, and then I would teach in it, becoming a church member. And I would progressively worry here about the sins and darkness of the flesh. I listened attentively to the stories of sin that led me to think about my private desires and indeed my own masturbatory fantasies. I struggled with this over a long time until I was nearly 20 . I remember many long personal self-discussions in which I weighed up the pros and cons of being gay or being Christian. For me they became a stark binary divide - even as I was beginning to become dimly aware that there was such a thing as gay Christians (a little later I was to go to hear a Troy Perry meeting in Conway Hall). Gradually, I was making the decision that to be gay meant to leave behind the condemnatory, moralising, and hate-filled world of religion. This was repressive and destructive to life. No good could ever come from such devastatingly negative beliefs. I decided to be gay and not a Christian.

\section{Finding self through others}

And so, I went in search of finding the like-minded. At this time, there was no acceptability - and no Grindr! It was certainly not easy to find people in the 1960s. For a little while I struggled by going to public toilets, where messages scrawled on walls seemed to indicate a chance of meeting somebody. And I did. But it was risky, dangerous, and threatening. I know some people loved that risk. But I did not. It was not going to be easy to meet people that 
way, so I pursued another route. I had heard that there may be such things as gay bars, and I decided to try to find them. After all, I lived in London, and if there were any, they were surely going to proliferate here. Looking around, I discovered there were gay male model magazines, and I bought a few (furtively from the back of a bookshop in Soho). Putting myself at what I saw as a great risk, I wrote to one of the photographers and asked if he could tell me where these bars were (there were no gay guides or gay magazines then). He speedily replied, inviting me to have dinner with him at his Chelsea home, where he would introduce me to a few of his younger friends. Panic! What to do? I decided to go. But before going, I wrote myself a letter saying exactly where I was going and what I was doing so that if perchance I was murdered, the letter would arrive at my home and contain the details of where I had gone! Such was the scariness and fear of that time.

Momentously I went to have a Sunday-style lunch with full silver service on a Wednesday evening with a very kind, smart, and elderly gentleman (but probably much younger than I am now!) who introduced me to a couple of guys roughly my age. Here I was not just being introduced to the gay world but also to a different world of social class - a much posher, much more middle-class world than I was used to. And after the meal, the young men took me out and about, showing me around the night life of Soho: up narrow creaky stairs to small upstairs clubs and down winding steps to tiny cellar bars. All secrecy and caution. I got to know these guys, and in a short while found myself having some of my earliest sexual experiences - a very long way from satisfactory but at least I was on my way.

\section{Finding a self on the way to the loony bin}

In 1966 I decided it was time to move out of the darkness. I was going to tell my parents that I was gay. This was going to be far from easy, but I did not want to live a double life. (This proved a very important decision for later everyday life.) My parents were loving and caring, but I guess they had hardly ever thought about such matters as homosexuality in their life! The only kind of awareness they had of it was that it was a terribly wrong thing. It was very difficult to tell them. I recall bursting into tears and throwing them a Penguin book of the time by Donald J. West (with a bold title HOMOSEXUALITY), ${ }^{4}$ shouting 'that's me!', and then running out of the room, sobbing and desperate. There was silence for a little while. Then my father tells me he has arranged for me to visit our local general practitioner doctor to see what can

4 Later in life, I was to meet Donald West (1924-2020) on a few occasions. His book was by far the most influential of its time - it was an accessible Penguin paperback and provided a full academic overview. Donald was gay but did not make it public till much later in life. The same was true of Michael Scofield (1919-2014), who went on to become a close friend. He wrote several earlier works under the name of Gordon Westwood. Only in 1965 did he use his real name as the author of Sociological Aspects of Homosexuality. 
be done. I did not want to upset them further, so I agreed. But, of course, my doctor knew nothing about it either and was clearly awkward and embarrassed with the conversation. He decided to arrange for me to have an appointment with the local psychiatric hospital - the local loony bin. It was based in New Southgate, the county psychiatric hospital, which housed over 1000 patients. ${ }^{5}$ I approached it with nauseating trepidity. What will happen to me here? I had three meetings. The first was with a young psychiatrist, a trainee possibly, who again seemed very embarrassed by the whole topic. She could make little sense of me, and I could make little sense of her! I had a second appointment - this time with a man who felt it necessary to arrange for me to have a physiological examination. I was forwarded to a psychological centre for a brain scan. My brain must have been pretty alright because I never heard the results of this at all. On my third visit, I encountered a psychiatrist who tried much more analytically to make sense of me. Finally, I was asked whether I wanted to change or whether I was content with my being gay. Saying I was content, the psychiatrist replied there was nothing more that could be done. I returned to my home and family, from that day stamped with a sense of approval, vindicated, able to live the life I had chosen. I have often thought about how precarious this moment was for my life. If that brain scan had reappeared, it could have meant electro-shock therapy, popular at that time. That would have been severe damage and set back. As it was, step by step, I was moving on.

\section{Finding a self politically}

The background to all of this was my becoming a student of sociology at Enfield College between 1964 and 1967 and then moving on to the London School of Economics (LSE) (1968-1973) to do a PhD on 'homosexuality'. It was at Enfield that I did the painful bit of my coming out - feeling confused, seeking others, telling others. But it was here that I was also able to write a major essay on homosexuality for my inspirational teacher, Stan Cohen, who encouraged me to take my studies further. At that time, this field of study was wide open - there was a lot of medical stuff, but that was of no use to me. My thesis was registered; I was to look at the impact of the changing law on gay life. My coming out socially became heavily my research project!

Very important at that time was the Homosexual Law Reform Society (HLRS), which was busy changing the law around homosexuality, due to come into effect in 1967. I initially visited the organisation based at 32 Shaftesbury Avenue to seek advice: I ended up being a volunteer, hanging around for some three years. Here I met dedicated, serious-minded but

5 Friern Hospital was formerly Colney Hatch Lunatic Asylum (1851-1993) in New Southgate, London. 
largely closeted gays, working quietly but effectively for change. I helped out in the office, and it became something of a little home for a while. I met a lot of wonderful people but especially Antony Grey (1927-2020), who was the secretary and the key influential reformer. I became involved in a few projects, including a major attempt to discuss what should be done after the law. What were the social and personal needs of this newly found group of legal people? I was introduced to the politics of pressure group lobbying and middle-class caution.

All this was to change while I was at the LSE. Here I met a young sociology student Bob Mellors (1950-1996), who had been to New York and witnessed the Stonewall Liberation in 1969. He came back with his friend, Aubrey Walter, with a passion for establishing a Gay Liberation Front (GLF) here in the UK. They called a meeting at the LSE on 13 October 1970. A small group of us gathered in a seminar room - I cannot remember much of the detail, but this was the beginnings of huge and escalating energy. A larger meeting in a big lecture hall was called, and the following week, 100 people or more came. The next two or three months was a whirligig of excitement and passion as everyone started to 'come out', coming out in the gatherings and on streets; campaigning, marching, organising 'out' balls, writing pamphlets. I met many really exceptionally radical, energising people. I even 'fell in love', meeting my first serious partner. It was the lifechanging experience of my life: and helped to establish a strong sense of a future self for the everyday world to come.

I could go on but will end this fragment of my tale here quickly. The 1980s was dominated by HIV and AIDS and the death of friends and large numbers of gay men throughout the world. The everyday life of gay men at this time was one of dying, death, and grieving. For a while, I really believed it was likely to bring about the end of gays: a gay genocide of sorts. It certainly brought a new kind of professional activism around HIV. Anyway, HIV dominated every aspect of life for nearly a decade - and yet, these days it is pushed away from memory (recently, Russell T. Davies's It's a Sin has brought it all back). During the 1990s, gayness gradually became part of the academy, as writings and courses started to appear, and a new publishing boom of books on gayness emerged - with new gay bookshops and widespread interest. There was a backlash - Section 28 (a 1988 UK law that prohibited the promotion of homosexuality), but then a renewed movement took hold: in the UK, Stonewall emerged as a new and well-organised campaigning movement (alongside the more radical Act Up). Gradually gay marriage was put on the agenda, becoming an organising mantra for the next decade or so.

\section{Transformative everyday gay life}

Time moves on. That was then. And this is now. Living a life is necessarily an everyday business lived in the moment. But it is also always just a moment in the vast, perpetual flow of historical - and generational - human 
creative actions. Eventually, later, today may become a narrative memory. In the phenomenology of everyday life, what is significant at one moment can recede to zones of insignificance in later life. ${ }^{6}$ But what we call everyday life does not mean it has always to be routine and banal (though this must be for much of the time - in what William James once called 'the flywheel of habit'). It can also be transformative. For those who find their world rendered oppressive, painful, discriminatory, and dehumanising, then everyday life can take on a different shape. It can be, indeed has to be, creatively resisted. And so, the everyday life that I experienced in the 1960s had to be resisted as I went along. I have given a few little examples of them, but all of them suggest modes in which an underground subterranean world of negotiation and resistance was being set in place for me to create new counternarratives to the dominant conformist everyday narratives of the day. ${ }^{7}$

This is part of what I can now identify as a process of narrative resistance. Throughout history, but especially in modern times, many people and groups experience a painful world out of which new forms of social life emerge. And as one generation comes to shape out its stories and actions in the everyday world in which they live, they come to anticipate new lives and future possibilities for others to live in. We might speak of a generational hope by which the lives of each generation bear some caring responsibility for the lives of the next generation to come. There is some kind of responsibility to act in the world for 'the horizon of the future'. Fifty years on from my little tales, the everyday life of gay men has been transformed by a multiplicity of struggles grounded in the recent past and with a vision of future hope.

This is the new world 'we have won', as my friend, the gay historian, Jeffrey Weeks, has written. ${ }^{8}$ A lot of everyday politics has gone into bringing about a new everyday gay reality, which is generally better than it has been in the past. It is quite a profound change, and it did not just happen by chance. Quite the contrary: I am reminded of Margaret Mead's famous remark that 'Never doubt that a small group of thoughtful, committed individuals can change the world. In fact, it's the only thing that ever has'. These were the really dark days of the early stalwarts of the HLRS; the radicals of GLF; the activists around HIV facing ubiquitous death, dying, and

6 See Alfred Schutz: On Phenomenology and Social Relations, edited by Helmut R. Wagner, University of Chicago, 1970 part 5 p 111-122.

7 For a fuller account of this, see Ken Plummer, 'Whose Side Are We on?' Revisited: Narrative Power, Narrative Inequality and a Politics of Narrative Humanity. Symbolic Interaction, 2020 Vol 43, No 1, p 46-71.

8 I met Jeffrey Weeks at both GLF and the LSE in 1970, and we became good friends. He has recently written a wonderful biography of a life that parallels mine. See Between Worlds: A Queer Boy from the Valleys. 2021, Cardigan, Parthian Books.

More abstractly, see Hans Jonas, The Imperative of Responsibility: In Search of an Ethics for a Technological Age. Chicago, 1984. 
suffering; the Stonewall and Act Up campaigners formed in 1989 to battle initially against the regressive Section 28; and a million miniscule actions by everyday folk doing everyday things that have shifted reality. A long history of ghosts from the past has brought us to the everyday world we now inhabit. Gay life now has its own distinctive and complex history. New everyday worlds are created in part through a resistance to dominant ones. This is indeed a very different world from half a century ago. ${ }^{9}$

I can see many striking creative changes to everyday life in the UK since my coming out in the late 1960s. Most notable for me is the sheer public visibility and widespread everyday acceptance by many in a country like the United Kingdom. There has been a major change in public attitudes and much higher levels of public acceptance for gay and lesbian life to flourish in everyday life. Many now come out publicly, and there are even annual awards for service to the gay community. At the same time, a language of human and social rights has emerged with the development of an equality before the law. Built into legislation, it includes an equality of the age of consent and an equality training in the armed forces. Back in the 1960s, it would hardly have entered the gay imagination that there would be an equality for same-sex marriage - indeed, the GLF was strongly opposed to the oppressive family and would not have countenanced such a reactionary idea. But now there is legislation that recognises gay marriage in 28 countries of the world. But still only 28 , which is also to remind us that this story of partial progress is not to be found all over the world. Indeed, in most parts of the world, it is clear that for many, the everyday world of same-sex relationships is still one of stigma, secrecy, and shame. Indeed, in six countries it is still met with the death penalty.

\section{Everyday gay hope: making creative futures}

Always lodged in shifting times and spaces, different generations move in new ways and directions. As we move on, we necessarily face the new problems of our lives lived in the everyday of today. As this book shows, many of the stories told today are not happy ones. They do not suggest that the changing world has brought contentment and joy to all. As if any world could. And so, I do not want to suggest a rosy or even necessarily a progressive picture. And we now face anew our personal troubles against a background of the world's environmental crises; a life-threatening pandemic; widening inequalities; a resurgence of hostile, fundamentalist religions breeding new

9 I have documented some of this more fully in two articles: Ken Plummer 'Afterword: Liberating Generations: Continuities and Change in The Radical Queer Western Era' in David Paternotte and Manon Tremblay, eds. Companion to Lesbian and Gay Activism. 2015. Ashgate; and 'Generational Sexualities, Subterranean Traditions, and the Hauntings of the Sexual World: Some Preliminary Remarks'. Symbolic Interaction, 2010 Vol 33, No 2, p163-191. 
$\mathrm{xx}$ Foreword: Transforming everyday gay life

authoritarian populist regimes, and so forth. Worldwide, there is a continuing war over sexuality and gender, frequently linked to the growth of different religious fundamentalisms. On a wider world scale, many countries look like they are in serious trouble. ${ }^{10}$

The challenges ahead then remain enormous. But when the world works well, a narrative hope has to emerge across the generations that suggests stories of possible better worlds to come. Everyday life has to generate new everyday stories that will help move us ahead. We actively work to imagine and create new and powerful stories of a kindlier, more open, caring, and just life and world for all across the world - maybe a cosmopolitan sexualities? Here is ultimately a passion and mission for what might be called a connective humanity: a creative, caring existential being that can link narratives of our humanity to the earth and planet, relations and community, being and world - one which resists the current trend to celebrate a kind of anti-humanity, one which pursues instead a worldly care for all. ${ }^{11}$

January 2021

Ken Plummer is Emeritus Professor of Sociology at the University of Essex, UK. His website/blog can be found at https://kenplummer.com/.

10 As I write this preface in late 2020, the International Lesbian and Gay Movement (formed in 1986) published its annual report, State-Sponsored Homophobia 2020. This documents the changing world situation for lesbians and gays. See: https://ilga.org/downloads/ILG A_World_State_Sponsored_Homophobia_report_global_legislation_overview_update _December_2020.pdf. But it is not just homophobia: many reports issued from the United Nations indicate the failure of many states across the world alongside the growing inequalities of wealth.

11 I discuss these closing ideas in Cosmopolitan Sexualities: Hope and the Humanist Imagination (2015); Narrative Power: The Struggle for Human Value (2019); and Critical Humanism: A Manifesto for the Twenty First Century (2021). 


\title{
What is conjured when we talk about the everyday lives of gay men?
}

\author{
Edgar Rodríguez-Dorans and Jason Holmes
}

[Edgar] Most of the ideas for this introduction were developed while washing dishes in a flat in Edinburgh. Most of the actual typing of those words happened in the living room of that same flat, where I live with my husband. The flat is in a modern building, located on the ground floor. At the back there is a door leading to a patio and garden, which gives it a feel of a house, in contrast to how I envision an "apartment" - that is, many floors up in a tower block. The interior is all painted in white, and it has various windows that offer different views, some of them to the garden, some into other flats, but without feeling intrusive. My favourite view is from the kitchen window because it frames a generous portion of the sky that I see change from blue into other colours: from blue into pink, then into orange, and from grey into deep blue. This window deserves acknowledgement, as it affords the everyday activity of washing dishes some reflective qualities.

The above scene-setting paragraph might seem a mere background for what is to come: a series of concepts and themes that form an overview of the book. I must clarify that all elements - the city, the flat, the garden, the sky, my ideas about what a flat is, my husband, the act of washing dishes, my thoughts - are more than a background to the contents of this book; they are an illustration of its core elements. Contributors to this book address themes of personal and cultural significance and engage in critical explorations of their social milieus through narratives of their everyday concerns. These narratives show the different contexts in which gay men live, how these social realities intertwine with our lives at a personal level, and how, in doing so, gay men create, reproduce, question, and challenge the cultures they/we are part of. In my case, the city of Edinburgh is relevant because it is a relatively new place to me, one that has given me perspective: a place I moved to for studies (as did Jason) and the one where I became - without noticing - an immigrant. The flat is relevant because throughout my life growing up in Mexico, I lived in big houses with complex dynamics, which contrasts with my current experience living in Scotland. One of the houses of my childhood was a multi-family house inhabited by nearly 20 people $-\mathrm{a}$ humble construction with a greenhouse full of plants that would be later sold at the town's market in the south of Mexico City. Another house had 


\section{Edgar Rodríguez-Dorans and Jason Holmes}

a wild and lush garden that engulfed the building, creating an exotic feel. I remember that my grandparents would host guests from South America for long periods in that house. Another one was some sort of a mansion with high ceilings and domes that created echoes in its rooms, giving it a church-like atmosphere. Another home was a four-storey house with a view over a small woodland area. My mother and I lived there even though, for two decades, it was an ongoing project, a house constantly under construction. We persisted with the construction partly because it was a dream of autonomy and independence, partly because it was the grounds where generations before us had lived, and we had some family connection with the land. These are just some of the houses I have lived in with peculiar living arrangements. The flat in Edinburgh is the first place I have ever lived that is compact, finished, and 'straightforward'. It is also the first place that I have lived in as a married man. Considering the battles that people have endured to get to this point and the current state of affairs in same-sex relationships around the world (see Mendos, 2019), two men living as a married couple is at the same time an ordinary and extraordinary occurrence.

At the time of co-editing this book with Jason, my everyday life - like many other people's during the global COVID-19 pandemic - revolves around domestic life, and this is something that has surely informed my interest in what happens at the interior of these relational spaces. However, this focus on the intimacy of personal life emerged long before the pandemic. This description of household experiences intends to invite you to pause and stay close to the personal histories narrated in this book and reflect on how these are embedded in a web of inter-personal, social, and cultural dynamics. 'The Everyday Lives of Gay Men' first draws upon Henri Lefebvre's Critique of Everyday Life (2014) to explore ordinary aspects of existence that have been neglected in society at large, but even more in LGBTQIA+ populations. In the context of the series 'Transforming LGBTQ Lives', this book contributes to create and share the stories about gay men's lives that are available as the chapters engage with the psychic, social, geographical, and political dimensions of everyday life from an interdisciplinary perspective. This book looks at the interior of gay men's subjectivities in areas that have not been widely discussed, and, in doing so, it disrupts the common notion that the study of gay men's lives is limited to the field of sexuality studies.

Thus, the different buildings I have inhabited, those relational spaces are more than the backdrop of a life; they are an integral part of life. The different household configurations and the relationships that exist there contributed to and developed my idiosyncrasies. I adapted to periods of life in which we would not have things - for example a fridge - that in other contexts were considered standard; I adapted to spaces where everything would be shared; and I did not question aspects of life I now consider essential - for example, privacy and silence were not a right, but more an occasional luxury when everyone had gone out. Gradually I moved from organic, rural houses 
to what I see as more structured, urban ways of living. Living through these contrasting milieus attuned me to different ways of inhabiting spaces. But beyond my personal experience of the space, these differences were part of a cultural move towards modernism. Flores Rodríguez (2019) writes that domestic life has been one of the main symbols of modernism. My narrative of inhabiting spaces may speak about how sometimes, without noticing, individuals inhabit spaces that are the target of broader social changes led by economists, architects, and urbanists. And if we have the luxury, we may transform those houses into personal spaces, into our homes. A significant part of life happens within the confines of houses, which is why these relational spaces we have inhabited are an element that will be present in this book. As Barak (2019) writes: 'my childhood neighborhood seems to capture a delicate intersection between identity, place, and space, highlighting - as I see it - the role of borders in regulating identities' (p. 667). Domestic life is one of the focuses of this book, not only because relationships, events, memories, and existence itself happen at the crucible of domestic life but also because it illustrates aspects of social, cultural, and political relevance.

From the private spaces of homes, this book also focuses on queer ways of relating to friends, to partners, and to other family relationships, always seeking to look at gayness both as culture and identity, from a close-up perspective, always from a first-hand perspective in which it is gay men who give an account of what it means to be gay; how we make relationships, love, and community; and how we make our worlds at the intersection of other people's worlds. Our gayness is the lens through which we think about culture. 'The everyday' or what happens as quotidian experience is shaped by our individuality; what is mundane and ordinary for me - Edgar - is not ordinary for you reading this text. My everyday consists of waking up at 8 a.m., having my shower, having breakfast, and, amidst the COVID-19 pandemic, going to a little corner in the flat where I listen to people in my online mental health practice, writing notes, writing for academic projects - this very text I'm writing right now is a good example of my everyday life. I have a series of routines like having coffee, watching movies, gathering virtually with friends to dance, joking with my husband, clearing the table so we can have dinner, clearing the table after having dinner so it can double as my office desk the following day, washing more dishes, taking the rubbish to the bins (and worrying about how much plastic we produce), 'WhatsApping' with my mother and my friends. Then I repeat these routines the following day and the day after that. I know everyday life during the COVID-19 pandemic is similarly restrained for Jason too.

In his exploration of the everyday, Ben Highmore (2017) questions:

What exactly is being invoked when we call on the everyday - a terrain of habit, survival, getting-by and getting-on, or going under? Perhaps it presents a sphere of desire and feeling - hopes dreamt of and pursued, or dashed on the rocks of prosaic reality, or a world of pervasive 
and sporadic moods (e.g., anxiety, boredom, elation, barely concealed rage)? Or something more like a quantity than a set of qualities: this much sleep, that much food, this much work, that much money, these many days left...?

In this book, the everyday encompasses the realm of habits and routines a continuous sense of doing - that is conflated with an equally important sense of feeling and thinking. The significance of the everyday comes into play when we realise that the minuscule aspects of experience come together to form the grand narrative that is our lives, such as me writing this and you reading it right now. The events we remember the most are those 'grand' events of our lives: for me, the day I experienced my first gay kiss, the day I left Mexico and moved to Scotland, the day my beloved friend died. What are the grand events of your life? I presume you remember a few. However, we might forget the more mundane aspects of life. It is paradoxical that it is in those ordinary moments, those that seem uninteresting, that we might find unexpected value. This effect, this focus on the milestones, happens similarly at a broader social and cultural level. We remember big dates, big events, big achievements, big challenges. In his book, Queer Domesticities, Cook (2014) writes about his interest in showing:

additional ways in which queer men orientated their sense of themselves - behind closed doors and apart from the more public bars, clubs, toilets, cruising grounds, courtrooms, and protest and pride marches that have more often drawn our attention. It takes queer histories more determinedly indoors, and touches and troubles existing histories of home and family which almost entirely neglect queer lives.

Intimacy is an essential concern of authors writing for this collection. This intimacy takes us behind closed doors, inside the spaces we make our homes, but this same intimacy also goes beyond the materiality of those walls and buildings to address the relationships - with the self and others - that come into being within those spaces. We reveal rare aspects of life, aspects of gayness that have been ignored, sometimes even by ourselves. We emphasise that the point of departure for the essays in this collection is a personal experience and how this is embedded in dynamic relationships in our respective social contexts. Our focus, therefore, is on the large, intricate, detailed life stories and the ways in which gay men give meanings to those stories. Our intention is for these narratives to contribute to the creation of ordinary representations of gayness from an insider perspective.

\section{Narrating 'the everyday'}

[Jason] In offering a description of his household experiences, Edgar conceptualises the everyday as something done and thought. His story of life 
inside his flat offers an activity-based account of personal space and the broader narratives within which his story is told. However, the everyday can also be conceptualised through affective engagement - through feelings and experience.

A key challenge when writing about 'experience' is how we can know about, or generate, knowledge of it. On most understandings, 'experience' is intrinsically elusive and never matches our descriptions. In some framings, for example Gendlin's (1959) privileging of present time 'experiencing', part of its elusiveness comprises the experiencer's own inability to describe their experience without losing core features of it. So, in a collection of personal stories, we can also conceptualise 'experiencing the everyday' as encountering, observing, and taking part in events associated with the ordinary 'through which one has lived and gained learning from' (Tudor and Merry, 2002, p. 52). In so doing, the term 'experience' recognises that the learning taken from the events resides inside the individual as a dynamic fusion of thoughts, insights, perceptions, bodily feelings, and emotional responses. Through participating in and learning from events, individuals experience the experience. Experience is, therefore, a blend of two components: (1) the present, the thoughts, insights, perceptions, bodily feelings, and emotional responses arising when the experience is lived, and (2) the past, namely what is remembered as having been present at the time of the initial event (Tudor and Merry, 2002). Hence, when I recall entering my first gay bar, I remember the nervousness I experienced then, and when writing about it now, I feel a tightness in my chest: thus, anxiety lives on inside me or as something yet unknown. In summary, we can also conceptualise the everyday as the totality of the present and past cognitive, physiological, psychological, and spiritual learning the contributors to this collection, gained from encountering, observing, and taking part in their ordinary, mundane lives as gay men.

Authors in this collection address the everyday - the 'ordinary' - in different ways. Some of them do so with an emphasis on the maelstrom of doings and goings-on of their activities, a constant movement that sometimes allows little space for reflexion. There is personal significance in these activities as they fill our minutes, hours, days, and so on. They fill our years with verbs of varied quality and intensity: waking, eating, drinking, talking, sitting, browsing, exercising, earning, and perhaps also some struggling, hurting, crying, longing, missing. The everyday actions we engage in - you reading this sentence right now - constitute the life we are living. This book brings those small actions into focus, allowing us to examine how they construct what we understand as the overarching narratives of our lives. But in between the steady pace of everyday life, in our daily encounters with routine and monotony, we can also find interruptions to the motion, a pause in which we might reflect, a comma. The interruption might afford 
an engagement with our own feelings and thoughts to interpret what the motions mean.

People use those junctures to reflect on the events and make sense of them. This action is rooted in our narrative capacity: that human ability to communicate our experiences in the form of stories and give meaning to them through narrations of those stories (Bruner, 1986; Ricœur, 1984). In the narrative process, people use different devices which help them to organise the random material that emerges from their daily experience (Mayer, 2014). Turning points, kernel moments, stories of redemption, stories of victory: these are all some of the 'tools' that set a milestone in the individual's life as a way of setting beginnings and endings in the continuity of their lives (Phoenix, 2014). Gay men give meaning to gayness partly from cultural and social dimensions and partly from personal experiences, but the grand narratives that shape cultural understandings of gayness often colour these experiences in a way that neglects to reflect personal experience and personal narrative. In her study on histories of LGBTI rights, Lalor (2018) writes: 'A grand narrative must necessarily privilege some views and voices over others, and it tends to do so in relation to a vector of power, which guides perception of situations, representations, and identities' (p. 24).

One of the 'grand narratives' in the lives of gay people is the 'coming out', which makes reference to the moment when an individual acknowledges to others that they identify as gay. It can be communicated to just one friend (Poteat et al., 2009), to their parents (Lee and Lee, 2006); or it can be a public announcement to millions of followers on social media (Stone, 2013) or to the international press (Neate and Hern, 2014). One of the key features about the narrative of the 'coming out' is the act of externalisation, a social aspect of communicating it to someone. Although it is seen as a moment in which the person tells one or more people they are gay, for the person who is telling it, there is normally a process of self-acknowledgement which involves deliberation and deep thought about when, where, how, and to whom to tell it (Adams, 2011; Bolen, 2014; Carnelley et al., 2011). Coming out can be an important event in a person's life, to the extent that it has become one of the grand narratives of the LGBTQIA+ experience. However, anyone who has come out realises that it is not a one-off event, and we come out in different circumstances and contexts so many times throughout our lives, that at points it may even become demoted from grand to ordinary, 'from ritual to gestural' to the realm of 'habitual repetition' (Lefebvre, 2014, p. 137), and other aspects of life might become more important. Thus, some coming-outs feature in the pages of this book (see the foreword by Ken Plummer) because they form part of many gay men's lives (for an insightful analysis of gay identity and the closet, see Adams, 2010). The nuances of these coming-outs will show the need for diverse representations of gayness, and the multiple circumstances in which they occur will demonstrate that even this seemingly well-known aspect of gay life needs further exploration. 
Unsurprisingly, for gay men, being gay is our everyday. Although sometimes we might not actively think about it, it is brought to our consciousness for different reasons, perhaps through one of the moments that form part of the grand narratives, perhaps through an unprecedented event. This book addresses those narrative junctures that help us make sense of who we are. When we live through the experience of loving someone, of being rejected, of waiting for a call from someone, of crying for the loss of someone, of being in touch with our friends or families, of dealing with discrimination, trauma, or abuse; it is through transforming those happenings into stories that we make culture as we speak.

\section{Approaching gayness autoethnographically}

These essays focus on the premises of autoethnography as methodology and draw on the experiences of 12 individuals who address their thoughts, feelings, and stories about finding gayness in their everyday life. Autoethnography is an effective approach to addressing the everyday because it allows the individual to access aspects of culture and society that are only reachable through the self. Understood as 'narratives of self', autoethnographies are 'highly personalised accounts that draw upon the experience of the author/researcher for the purposes of extending sociological understanding' (Sparkes, 2000). Aiming to understand how gay people construct culture and how culture informs gay people's subjectivities, studies from this approach rely on the authors' voices as 'native experts', as 'insiders' of the gay culture. Ellis, Adams, and Bochner (2011) explain that 'once at the service of the (White, masculine, heterosexual, middle/upperclassed, Christian, able-bodied) ethnographer, indigenous/native ethnographers now work to construct their own personal and cultural stories' ( $\mathrm{p}$. 278). These personal and cultural stories become first-hand knowledge that confers authenticity and authority to these studies.

A personal story is the point of departure to analyse aspects of everyday life at various layers of complexity. Because we are aware that by using the term 'gay men', we are invoking a number of assumptions about gender, culture, history, and geopolitics, we want to open the term for interrogation. We use a queer prism to observe how this identity colours our experiences and makes those experiences specific to gay men. As Spieldenner and Eguchi (2019) write: 'The queer praxis of autoethnography calls out the politics embedded in the narratives: it is a matter of making visible the invisible forces that undergird all social interactions and experiences rooted in heteronormativity' (p. 135). Being gay is political - even when it is not intended to be - and there are many ways of being gay. While there are aspects of gay culture that are widespread throughout the world and are incorporated into our behaviours - some of them even make their ways into non-gay communities - it would be a mistake to think about a universal way of being gay. To better understand what it is like to be gay from 
an ordinary, autoethnographic perspective, contributors write about their reflections of gay identity/culture and its impact on everyday life.

\section{Gay men's lives beyond the grand narratives}

What does 'being gay' mean to gay men? How does being gay manifest itself in our everyday lives? To answer these questions, contributors in this collection focus on the small, the seemingly insignificant, the quotidian; those events, thoughts, and feelings that might go sometimes unnoticed but have the power to affect us, especially when we reflect upon them. Highmore (2017) writes: 'we might do better to treat everyday life as an invitation to consider how we might know the world' (p. 327). That was the approach we asked contributors to take; an invitation to write about something ordinary that had personal significance to them. Their biographical configurations would offer a personal perspective, a way in which they know the world. The exploration of how the everyday might look for gay men living in different cultural contexts would illuminate often ignored aspects of existence. Applying a gay lens or a queer lens to analyse everyday life means that the contents of this book will be familiar to many readers. Authors write about mundane activities - such as waking up and having a shower; travelling in trains, buses, and planes; and going to work, school, or university - and about familiar feelings, such as falling in love, experiencing anxiety, feeling lost. However, these events and feelings will be experienced differently in response to their specific biographical configurations. In other words, what might be ordinary or everyday for Edgar - writing these lines at home in Edinburgh while listening to Paloma Faith and thinking about a loved friend who is gone from the world - might be quite extraordinary for you, who will be reading this book somewhere else in the world while dealing with your own everyday concerns. The expectation is that you find in the experiences narrated in this volume some familiarity, but also that you discover aspects of gay life that you did not know existed.

The 'ordinary' as an angle to approach meaningful discussion presents a problem inherent to the term itself in the sense that something ordinary is something with no special characteristics, something commonplace which, consequentially, does not seem worth writing about. Writing about the unremarkable seems counterintuitive as we wonder who would be interested in reading such text. This is where reflexivity enters into the picture, as the invitation for authors to look into their own experiences and disrupt the familiarity with the events of their own lives has the potential to transform their own understanding of what it means to be gay. Taking a reflexive stance on everyday life invites us to look at the structures that sustain those routines, those common thoughts, and those ordinary effects. On his 'Critique of Everyday Life', Lefebvre proposes an imaginary scene, of a woman who buys sugar, to analyse the interconnectedness of personal life with broader social and cultural issues. The apparently simple scene is 
connected to circumstances that go beyond the woman herself, as the act of buying sugar responds to her individual needs and desires but also to broader social spheres that surround the act. In a similar vein, we propose an imaginary scene of a gay man browsing the LGBT section on Netflix. While the act can be seen as a response to the individual's desire to watch LGBT content, this need is tied to a geographical location and a period in history in which watching lesbian, gay, bisexual, and transgender content is not only possible but perhaps it is also ordinary. This act also responds to a technological revolution that has made it possible for entertainment to be distributed digitally. Commercial implications can also be considered, as these contents are delivered by companies with an interest in profit. Questions of technology and internet access are also relevant. Amidst these broader social conditions, there are individual processes while the man browses that section. He might be thinking that the category 'LGBT' is missing the ' $Q$ ', the 'I', the 'A', and the ' + ' that represent a wider range of identities under that rainbow; he might be thinking that Netflix got it wrong because some of the content does not even belong in that section. Or perhaps the man is just happy to see some relatable content. He might be thinking about his own personal history and how this content was not available when he was a teenager. Perhaps this fictional character is not a 'he' but a 'they'. Perhaps they are not even gay but queer. Perhaps they even question the label 'man'. Perhaps they dread the way in which LGBTQIA+ identities have been commercialised and presented as products to be consumed. Perhaps they worry about how particular stories are largely ignored while others are repeated over and over, mystified and presented as accurate realities of the lives of these populations.

This book engages with those widely accepted 'realities' of the lives of gay men and interrogates the elements that maintain them because, in many societies, gay men have lived under oppressive regimes that have shaped our ways of communication. The 'gay gaze' is perhaps one of those common practices of gay cultures: an act of secret intimacy in plain sight. It starts with delighting in the eye candy, looking at guys who most of the time do not look back. But sometimes they do. And when they do look back, we might experience the power of possibility through an act of recognition, a sense of reciprocal desire - a simple gaze, a mutual encounter of eyes that validates our identities and corroborates our very own existence. I - Edgar - experienced and practised the gay gaze way before I even had a name for it; I would long for that moment when someone would look back at me. That would be my everyday. For years I would look for those encounters of eyes without even knowing that researchers had created a label for it. In contexts where talking about being gay - and even identifying oneself as gay - represents a risk, the act of looking at men and sensing whether they will look back becomes, for many gay men, an essential form of communication. Another common aspect of gay cultures has been centred on night clubs and the activities around them - dancing, drinking, flirting, congregating 
with others who are 'like us'. In many contexts around the globe, there are similar versions of the gay night club, with its rainbow flag on the door and its 'gay music'. While there might be 'global gays' who ascribe to these aspects of culture, it is important to emphasise that gayness is an ambiguous concept for which there is no uniform worldview. What there is, is a set of grand narratives about gayness that have been formed by powerful forces such as the state, capitalism, religion, and science and have shaped people's understandings of what being gay means.

Applied to the field of queer studies, some of the grand narratives describe LGBTQIA+ peoples through perils, conflicts, and suffering (Lalor, 2018). Research has also been complicit in incomplete portrayals of LGBTQIA+ life; sociological, psychological, medical, and legal disciplines refer to LGBTQIA+ people in terms of sexual orientations, sexual identities, sexual minorities, and gender identities. Along with the notion of sexuality being at the centre of LGBTQIA+ life - in particular gay men's lives - there is another grand narrative that creates a false dichotomy between heterosexuality and everyone else who is not heterosexual. This means that the whole diversity of LGBTQIA+ identities is often referred to as 'the non-heterosexual population', as if the term LGBTQIA+ existed only in function of heterosexuality. These grand narratives position LGBTQIA+ individuals in a disadvantaged place, defining entire populations as an ambiguous 'other' and often forcing the focus to sexuality while important aspects of everyday living are neglected. Being gay is about more than sexuality, and the chapters of this collection will show how gayness intertwines with work and employment, migration, globalisation, and climate change. Contributors invite you to look at aspects of gayness that often go unnoticed in dominant discourses.

\section{On the everyday stories of this book and the authors who wrote them}

From an autoethnographic approach, this collection is concerned with how gay men give meanings to their everyday experiences and how, through those meanings, they/we create their/our life story. To create this collection, we invited 12 individuals working in different fields and from different backgrounds to write an essay based on personal experience. Diversity has been a guiding principle of this project. Acknowledging the various ways in which diversity can be conceptualised, we followed Harrison and Klein's (2007) assertion that diversity is 'attribute specific' (p. 1200). This means that a group might not be inherently diverse, but instead a group is diverse with respect to a particular feature or set of features. Thus, we aimed to create a diverse collection in terms of two different attributes: biographical configurations and disciplinary perspectives. In terms of biographical configurations, we sought contributors of various ages and from a variety of cultural contexts. They bring their history with them and touch upon 
aspects of geography, religion, ethnicity, and nationality. They write about their experiences of being gay in the UK, USA, Turkey, Thailand, Mexico, Ireland, and Namibia, and they address, sometimes in very subtle ways, the broader social aspects that shaped their individual experiences. In terms of disciplinary perspectives, we aimed to present a variety of thoughts and disciplines in the collection. Some authors come from a post-humanist approach; some of them come from the arts and humanities, mental health professions, and some from a more general social science background. In some cases, we knew the contributors; in some other cases we only knew their scholarship, and that is how we decided to approach them. However, we are not under any illusions that we are presenting a completely diverse collection; for example, we are mindful that we are still presenting a cisgendered, westernised view of being gay men, but we always aimed to achieve a collection that takes the ordinary, the mundane, the everyday in our lives as gay men as the departure point to address the concept beyond the grand narratives that have dominated representations of gay life. We considered the contributors' expertise and invited them to use that as an angle to approach their writing. However, we emphasised they could take their chapter in any direction they so wished.

The result of these contributions is a collection of 12 autoethnographies and a series of reflective notes on the writing process. The autoethnographies are organised in a way that evokes certain contiguity in their messages; the chapters speak to each other while maintaining the personal and disciplinary imprint of the authors. Organised around the notion that gayness is experienced at intra-personal, relational, and social levels, the chapters move from a more intimate domesticity - the book opens with a chapter that takes us to the moment of waking up, being in bed with the author - and towards a wider social, cultural, and global narrative - the book finishes with a chapter that makes us think of the impact of modern life in the global environment. We resist the notion of thinking of the contributions in terms of abstract themes. Instead, we invite the reader to connect with the individual stories and stay with the people who wrote them. This approach aims to understand individuals and their specific life circumstances.

In the first chapter, David Lowbridge-Ellis presents 17 examples of how being gay infuses his professional, social, and married life, offering a rich narrative of the centrality of gayness in his intra- and inter-personal relationships. The diversity of examples portrayed in the chapter provide some well-known passages of gayness such as 'coming out' from a new angle, making the familiar unfamiliar, such as an understated coming out to an assembly. The chapter gives a rare insight into school life from the perspective of a teacher and articulates feelings that will resonate with a number of gay men beyond a professional perspective.

Randall C. Lopez writes an emotive autoethnography that provides rich descriptions of aspects of love, loss, and grief. Framed within the space of the shower room, the personal experience narrated by Randall invites you 


\section{Edgar Rodríguez-Dorans and Jason Holmes}

to closely examine the processing of emotions in the event of their father's passing and the end-transformation of a romantic relationship. The unfolding of the father-son relationship reminds us of the many family relationships that are still impacted by prejudices and stigmatisation of gayness and, although Randall contextualises it from the perspective of a MexicanAmerican family, this scenario will speak to readers from different cultural backgrounds.

Panu Sahassanon introduces the reader to his personal Christmas as a celebration of togetherness in Thailand. This holiday has links both with his early recollections of family life and also with his more recent friendships, like a festivity that gives the opportunity to integrate all his relationships during the December-January period. Taking us through experiences of different Christmases, the chapter presents an element of Christianity in focus in a predominantly Buddhist country. The chapter also brings our attention to thinking beyond the Western construction of gender and sexuality and reflecting on how Thai culture provides with its own construction and performance of gender and sexual identities.

In 'Sunday: An intimate account of loneliness', Cináed Thomas writes about his lifelong sense of isolation. Using self-dialogue, Cináed tells of the excruciating desolation he often goes through on Sundays, when families and friends are involved in their own domestic lives. Reflecting on recent family deaths, Cináed then ponders on his usefulness to others and himself if, as others have commented to him, 'he doesn't have a family'. In often painful and self-disclosing writing, Cináed reflects on what relatives have said to him at the time these relatives died and delves into his wish not to receive treatment should he develop a life-threatening illness.

In 'On (not) living past 30' Tony E. Adams discusses a pervasive view of ageing amongst gay men, one in which ageing is seen as a negative and undesirable process. Narrated in the second person, the text introduces his relationship with his long-term friend/family/lover Brett to reflect on the cultural and circumstantial forces that have constructed an image of youthful, often tragic, gayness. Through the tragic premonition 'I'll be dead by 30 ' in the voice of Brett, the text illustrates the lack of cultural narratives/ trajectories/scripts for gay men after 30, yet at the same time presents more hopeful alternatives.

In 'Going back to the glory hole: An everyday story from the therapy room', Seamus Prior presents a narrative of the personal challenges faced when working with gay men in the therapy room, in particular when addressing sexual content. It is an example of the subjective experience of a gay male therapist encountering feelings that are never a 'once done thing'. The theme of the glory hole is affective and thought-provoking, as Seamus invites readers to reflect with him on a symbol of gay culture that will be identified by many. This work is of particular interest to an audience of mental health professionals as it demonstrates that, while in theory any qualified psychotherapist could work with gay men, there is certain 
sensitivity and specialised knowledge of gay culture that is required to work effectively with this population.

In 'Becoming (in)visible: On mental health, help-seeking, and missing connections', Willem J. Stander presents a performative autoethnography on the theme of mental health difficulties and the personal, social, and cultural barriers to accessing mental health services. Set in the form of a theatre piece, the stories portrayed are based on embodied knowledge, as we read about knees giving out, holding hands, tearing eyes, fingers interlacing from the perspective of a white, middle-class gay man. These narrated actions provide a wide range of subtle imagery of how the body expresses what otherwise would be private emotions. Within the large group encompassed in the umbrella term 'LGBTQIA+', 'Becoming (in)visible' draws the reader's attention towards the specific circumstances of students in higher education settings and provides a close-up look at the difficulties that are common to gay men in particular. The chapter makes a subtle yet powerful critique on hegemonic masculinities and invites the reader to reconsider traditional notions of being a man.

In his chapter, Yasin Koc uses the concept of 'ordinary privileges' to construct the main argument about the parallels between someone's ethnic background and someone's sexual orientation/gay identity when navigating systems that favour whiteness and heterosexuality. Yasin selected passages of personal and cultural relevance that bring about the ordinariness of life through scenes of everyday interaction - some of them in a striking way and others in a more delicate manner.

'I dreamt of a stranger' by Julian Triandafyllou is an open and vulnerable text on how his childhood experiences of prolonged sexual abuse have influenced and, to some extent, shaped his ways of relating with gay men. Many of the episodes and settings he describes will be familiar to gay readers and will make the ordinary evident. Julian has shared his ongoing journey into discovering and understanding what being gay means to him and how his experiences have been tainted by the events of child sexual abuse. It was sad and unsettling to read that the abuse became 'ordinary'; however his writing shows his resilience and strength. Furthermore, some of the relationships he writes about, both long-term and ephemeral, demonstrate the restorative power of a meaningful connection.

In 'Testing proximity and intimacy: An everyday reappropriation of private and public space', Edgar Rodríguez-Dorans explains that while sexuality in general has been an area of human life that has been the object of social regulation, gay sexualities have been disproportionately disciplined and oppressed in a way that both public and private lives have been punished. This autoethnography addresses how experiences of relational intimacy have been a crucial factor in resisting public oppression against gay people. Through a narration of a coming-of-age relationship, Edgar argues that intimate ways of relating to gay men have been constructed around fleeting opportunities and unexpected places in response to intimidating, 


\section{Edgar Rodríguez-Dorans and Jason Holmes}

persecutory, and unwelcoming experiences of the public space. Harshness helped the author and his partner discover softness in unexpected places and, in turn, create intimate ways of relating that differed from the normative idea that gayness should be restricted to the confines of private life.

In his chapter, Oscar Pantoja Guzmán uses his personal experience as a Mexican immigrant recently settled in the USA to explore aspects of displacement and mobility through his everyday encounters with colleagues and lovers. He reflects on the discrimination and power imbalance he has experienced in different organisational contexts: as an established organisational psychologist in Mexico City and recently as a sales support worker in California. Through narrations of his journey, he offers insight into the inseparability of his gayness from his everyday life, even in instances where he is not the one thinking about this identity. He concludes by problematising monogamy and using his explorations with polyamory to think about the future of gay men's relationships.

'The Everyday Lives of Gay Men' concludes with 'Planetary times and queer times: A critical planetary Romanticism for the earth' by Whitney A. Bauman, a chapter that pushes the boundaries of the sometimes-insular term 'gay'. Whitney offers the term 'critical planetary romanticism' to expand the obvious ways in which people might think of gay and queer topics. The chapter moves the discourse forward, beyond reductionist ways of seeing gayness and queerness. He disturbs the order of things by making us think about the relationship between fossil fuel economies and the lives that are affected by them (effectively everyone's). He introduces a post-humanist way of loving, one in which it is more important to think beyond a human point of view and recognise other living creatures and the environment, a planetary eroticism. The chapter finishes by offering a future-oriented way of relating, one in which people will be (and some people already are) postlabels, fluid, non-binary, polyamorous. Whitney invites readers to think even further and position themselves towards the future through a polyamory of place.

Written by the editors, the chapter 'Notes on the contributor's experiences' is informed by the authors' experiences of writing their texts. It aims to provide some reflective accounts of the writing process itself and how contributors navigated their autoethnographic research. With this combination of interdisciplinary contributions, the work presented here remains deliberately exploratory and invites you - the reader - to think about gayness in social, cultural, and political terms, as well as in its intra-personal and relational dimensions. The study of gay life requires interdisciplinarity and the autoethnographic approaches used here provided it.

As a whole, this book emerges from those grand narratives, from the conflicted history of sexuality and mental health, and the broader social challenges faced by gay men and other members of the LGBTQIA+ populations. Every single one of those challenges has shaped our understanding of who we are. Those sexual relationships that have defined everything and 
nothing, those legal battles that validate or invalidate those relationships, those legal acts that have been fulfilling and emptying. Those derogative terms - queers, homos, puffs, putos - that first made us feel oppressed but then empowered us. This project emerges from all those well-studied aspects of our lives - the coming-outs, the same-sex marriages, the recognition acts - but it goes beyond that by exploring not only the 'drama' of our lives but also the mundane. Sometimes this book also explores when the drama - and the trauma - became mundane. The project might explore more stories of the struggle of first coming out but also the boredom of coming out for the 100th time; it might look at the big event of attending a pride march but also at the aftermath when people return home to have dinner alone or with friends. The project might look at the perils of navigating public services for marriage licences; it might touch upon the celebration on wedding days, but it also looks at what it is like to be married and living together. This book also looks at those moments when we are alone, troubled, or at ease; it explores those experiences of relationships in seemingly uninteresting contexts to understand how we construct our lives 'day by day'.

\section{References}

Adams, T. E. 2010. Paradoxes of sexuality, gay identity, and the closet. Symbolic Interaction, 33, 234-256.

Adams, T. E. 2011. Narrating the closet: An autoethnography of same-sex attraction. Walnut Creek, Calif: Left Coast Press, Inc.

Barak, A. 2019. My childhood neighbourhood: A critical autoethnography. Qualitative Inquiry, 26, 107780041984356-673.

Bolen, D. 2014. After dinners, in the garage, out of doors, and climbing on rocks. In: Wyatt, J. \& Adams, T. (eds.) On (writing) families. Rotterdam: Sense Publishers.

Bruner, J. 1986. Actual minds, possible worlds. Cambridge, MA and London: Harvard University Press.

Carnelley, K. B., Hepper, E. G., Hicks, C. \& Turner, W. 2011. Perceived parental reactions to coming out, attachment, and romantic relationship views (English). Attachment \& Human Development (Print), 13, 217-236.

Cook, M. 2014. Queer domesticities homosexuality and home life in twentiethcentury London. Basingstoke, UK: Palgrave Macmillan.

Ellis, C., Adams, T. E. \& Bochner, A. P. 2011. Autoethnography: An overview. Historical Social Research/Historische Sozialforschung, 36, 273-290.

Flores Rodriguez, C. E. 2019. Sobre el modernismo en la arquitectura habitacional en México. Una reflexión epistémica. Revista de Direito da Cidade, 11, 277-309.

Gendlin, E. T. 1959. The concept of congruence reformulated in terms of experiencing. Counseling Center Discussion Papers, 5, 1-30.

Harrison, D. A. \& Klein, K. J. 2007. What's the difference? Diversity constructs as separation, variety, or disparity in organizations. The Academy of Management Review, 32(4), 1199-1228. doi:10.5465/AMR.2007.26586096

Highmore, B. 2017. The everyday, taste, class. Chichester, UK: John Wiley \& Sons, Ltd. 


\section{Edgar Rodríguez-Dorans and Jason Holmes}

Lalor, K. 2018. Encountering the past: Grand narratives, fragmented histories and LGBTI rights 'progress'. Law and Critique, 30, 21-40.

Lee, M. M. \& Lee, R. E. 2006. The voices of accepting and supportive parents of gay sons. Journal of GLBT Family Studies, 2, 1-27.

Lefebvre, H. 2014. Critique of everyday life. London: Verso.

Mayer, F. W. 2014. Narrative politics [electronic resource]: Stories and collective action. New York: Oxford University Press.

Mendos, L. R. 2019. State-sponsored homophobia 2019. Geneva: ILGA.

Neate, R. \& Hern, A. 2014. Tim Cook: 'I consider being gay among the greatest gifts God has given me'. The Guardian, Thursday 30 October 2014.

Phoenix, A. 2014. Opening speech, troubling narratives. Troubling Narratives: Identity Matters. Huddersfield, UK: The Institute for Research in Citizenship and Applied Human Sciences, University of Huddersfield.

Poteat, V. P., Espelage, D. L. \& Koenig, B. W. 2009. Willingness to remain friends and attend school with lesbian and gay peers: Relational expressions of prejudice among heterosexual youth. Journal of Youth \& Adolescence, 38, 952-962.

Ricœur, P. 1984. Time and narrative. Chicago: University of Chicago Press.

Sparkes, A. C. 2000. Autoethnography and narratives of self: Reflections on criteria in action. Sociology of Sport Journal, 17, 21-43.

Spieldenner, A. R. \& Eguchi, S. 2019. Different sameness: Queer autoethnography and coalition politics. Cultural Studies, Critical Methodologies, 20, 153270861988496-143.

Stone, J. 2013. Tom Daley: A new way to come out. The Guardian, Tuesday 3 December 2013.

Tudor, K. \& Merry, T. 2002. Dictionary of person-centred psychology. London, UK: Whurr Publishers. 


\title{
117 Times a day I think about being gay
}

\author{
David Lowbridge-Ellis
}

I think about being gay from the moment I wake to the moment I go to sleep. I think about being gay hundreds of times a day, every single day. Here are 17 of my most persistent ruminations.

Some of these things happen every day and some don't, but they could happen any day.

\subsection{5 a.m. When I wake up}

Three decades on from realising something was 'wrong' with me, the novelty has still not gone away:

I am sharing a bed with a man.

I think this every morning and I am still mildly surprised by it.

Maybe straight people think this way too. Maybe those who sleep with the opposite sex are just as surprised to find someone else's arms, legs, head, and the rest of 'another person', right there beside them.

I doubt it though. I think most of them take it as a given. Princes only find princesses, or vice versa.

I was six when I realised I was gay - or at least different. One of my friends was 19 when he realised. But it's never a competition, especially when we're all on the losing team.

Whenever I try to explain to a straight person what it's like growing up gay in a heteronormative world, I tell them to remember the last time they walked through a greeting card shop. Birthdays, weddings, new arrivals, condolences ... and everything in-between, the whole panoply of life is (supposedly) right there, on those greeting cards, in binaries: baby boys (blue), baby girls (pink); male teenagers (cars and sport), female teenagers (shopping, shoes and selfies); a man and a woman on top of a cake; and then: a blue or pink crib. And the whole cycle begins all over again, until it ends ... with sympathy.

Only after they've gone is it acceptable to send men flowers, or an image of them at least, tastefully arranged around the words, formatted in a cursive font. And even then, most people avoid the pictures of pink flowers if they can find a card with blue ones on it instead. 
I find the conventionality repugnant, the way it reinforces the idea of what a 'normal' life looks like. That my life, in business terms, is considered a 'niche market'.

The 'scare quotes' are a bad habit - like biting my fingernails - that I've never managed to break. I have to go back through anything I write and trim for the scare quotes. The original draft of this chapter had twice as many. I think they result from being scared a lot. Scared of words like 'romance', 'marriage', 'family', and 'happiness'.

I grew up being terrified of card shops. An odd phobia, I'll grant you, and not one I voiced. Instead, I silently held my mum's hand tightly as she wandered the aisles looking for the right card for the right occasion. I just kept it to myself: a vague feeling of unease. This sharpened into something more as I grew up and realised I was looking at a version of the world I could never fit into. 'Romance' was not possible for people like me, not in the way I saw it represented on the Valentine's Day cards my parents sent each other. 'Marriage' was impossible, a nonsense word just taking up space in my mental dictionary. Best to chuck it out. 'Family' was stability, of a kind, even if I could imagine replicating nothing like that in my own life. I would forever be alone, unable to share in others' definition of 'happiness'.

It sounds so silly now. Now I know I wasn't alone. There were lots of people like me, even if I never saw them on greeting cards, or films, or TV.

So much of gay life is lived in scare quotes, as if the words between the inverted commas are not really the same things enjoyed by everyone else. Similar, but different. Like two versions of the same language.

This morning - today - is a new day. Which language should I speak?

\subsection{7 a.m. When my first waking thoughts recede and I drowsily recall that the man in my bed is my husband}

'Marriage' lost its scare quotes a year to the day that same sex marriage was legalised, when we got married on 28 March 2015. Just a coincidence. We didn't plan much of anything.

Our proposal took place while we were doing the washing-up after dinner one night.

We'd just got back from visiting the new library and were wondering, aloud, if our local city council hired it out for weddings. I offered to phone them the next day to make enquiries.

And that was it.

No proposal on a gondola. No ring dropped into a glass of champagne. No sunset tête-à-tête planned with military precision. Either of us getting down on one knee just didn't seem ... necessary.

I always said I'd never get married, mostly because I couldn't picture it happening. Maybe being surrounded by those billions of words in the 
library helped change my mind. I had to relearn the word 'marriage', modify its meaning - as we all did in England in 2014.

Love had recently won the day, and perhaps, in hindsight, we were riding high, drunk on the idea that anything was possible. This was in late July. Nine months later, as if we'd had to get married for a more Victorian reason, we said our vows. We adapted the words from the books which had shaped us, made us feel better about ourselves. We wore paper flowers made from pages of Nineteen Eighty-Four, quoted lines from X-Men in our personal declarations, threw in a Native American blessing at the last minute because the lovely registrar liked it. Why not bring more persecuted people into it?

It felt like we were making it up as we went along, because, in most ways, we were. We wrote ourselves into each other's lives.

And then: the anniversaries of cotton, paper, leather, linen. This year, our fifth, it was wood. Funnily enough, it's what our rings are made of. Mine is oak. His is maple. We worried they wouldn't last like gold or platinum. But they still look like new, like they did on the day we put them on.

\subsection{8 a.m. When I snuggle into his Nook}

Still in bed, I find myself nuzzled into what we call The Nook, that delve on Antony's right side, between his pectoralis major and his deltoid. More prosaically, his armpit.

I joke that I've made it my own, burrowed out a place where I can slot in, snug as a puzzle piece. He maintains it was already there but waiting for my cheekbone, without either of us knowing it.

For 20 years I couldn't imagine this could ever be done. 1 man +1 man = does not compute. As rational as reaching out your tongue to taste the sun.

\subsection{9 a.m. When I finally go downstairs to make coffee and feed the cats}

The coffee is on the go. Two hits of Nespresso.

The boys are eating breakfast. Our furry babies. We could navigate the surrogacy minefield. We could adopt. We spoke with a social worker once who seemed determined to put us off. Maybe it was just her. Maybe it was us. We have gay friends and family who have sprogs, and we love spending time with them.

And then we give them back.

Two cats are enough for us. At least for now. And in the meantime, I have nearly 1600 children at school to take care of.

\subsection{8 a.m. When I reach for the shower gel}

In our shower there is no LYNX shower gel. 
LYNX, Africa, Aztec, Atlantis ... These were the exotic-sounding scents of 1997. In other countries, LYNX is known as AXE, which is scarcely less hyper-masculine. For me, it brings back the smell of the boys changing room after PE lessons.

On the pitch, I always made a decent show of tackling, holding my own in a scrum, like boys are supposed to. Running hell for leather at a set of posts spelling a badly drawn capital letter $\mathrm{H}$, as meaningless to me as a character in a dead language, like Sanskrit or Akkadian.

Sport made me feel awkward. Aloof.

I wasn't afraid to get hurt. What I was doing to myself, at the time, could never compare with a few scrapes, a few spurts of mud.

I just didn't see the point in sport. But I played along, afraid of being found out.

When the teacher wasn't around, I skipped the showers and tried to keep my eyes down, somewhere near (but not quite at) the ground.

I tried hard not to look, but I didn't always try hard enough.

I remember one lad in particular, a bit older than me. He was, in a very literal sense, cock-of-the walk; the overconfident, supposed alpha male who strutted around like he owned the whole place - with that cocksure grin on his face but sans towel, sans shame, sans any of the concerns that played on my mind. His confidence scared me more than any of his physical attributes.

The smell of 'men's' shower gel always brings this back: a cheaply scented Proustian rush which can still make me feel guilty and unworthy.

I lather up and wash it all away.

\subsection{9 a.m. When I question everything I wear}

\section{Are these socks too gay?}

They're at least a 3 on Kinsey's famous scale, running from 1 ('exclusively heterosexual') to 6 ('exclusively homosexual'). They're probably closer to a 4: 'more than incidentally homosexual'. A French-looking sailor. I think he's supposed to be French, in a borderline-offensive kind of way. The beret gives it away. Only marginally less obvious is the arched eyebrow, a love heart tattooed on his bicep. A Pierre et Gilles fantasy, or (as I first encountered this iconography), a model in an advert for Jean Paul Gaultier. An advert I pretended not to be paying attention to. In reality, I could barely take my eyes away.

Now they sell such men in H\&M, in sock form at least. For men of all persuasions (sizes 6-11).

I end up going with the socks. Why not?

It's only a pair of socks.

Except, it's not, is it?

I remember the frightened little ginger kid who professed not to care what he wore. Who, more often than not, didn't like who he was. Who, at 
least once a week in his teenage years, reached the point where he didn't want to be here anymore.

And if a pair of socks can make all that seem more distant than it really was, please don't turn up your nose at my turned-up trousers. They're like that on purpose. I'm inviting you to look. Look! My socks have 'more than incidentally homosexual' sailors on them! Jealous, aren't you?

\subsection{8 a.m. When I put on my shoes and ready myself for the kiss}

My husband and I don't consciously intend to make a public demonstration on our doorstep. But every kiss comes with questions and considerations: what if someone sees? What will they think of me? Is this a political act? Is there some greater good in this, more than just what we take for ourselves?

A few years ago, in St. Mark's Square, Venice (aka, The Most Romantic Place on Earth), I thought it was obvious. All the straight couples were doing it, but he refused to kiss me. I feel unsafe - he said. I felt otherwise. A rare case of us misaligning. We argued in silence, not talking until the next morning, safe on the plane home.

Public displays of affection still don't always come easily to us. We've been conditioned to think that's not right. My dad used to recoil when he saw men kissing on the TV soap opera, Coronation Street. Even he was conditioned, and he's a liberal, an academic, with a degree in history from Cambridge University. Cambridge with its famous, gay alumni: Turing, the British war hero betrayed by his country who now appears on the $£ 50$ note; Forster, the novelist who wrote 'Maurice', one of the best gay romances of all time but didn't publish it in his lifetime because his friends told him readers would never believe in two men living together happily; McKellen the wizard, the Shakespearean, the activist, the X-Man.

My dad recoiled at men kissing because he was just doing what he'd been carefully taught to do. And, although I find this hard to believe now, seeing men kiss always disgusted me too.

When I kissed my husband in front of everyone at our wedding, I closed my eyes. I was surprised I could open them again.

\subsection{9 a.m. When I deliver an assembly to Year 11}

Today's assembly addresses exam anxiety, so I naturally share with a school hall full of 15- and 16-year-olds some of the things that have threatened my equilibrium over the years. I tell them about when I faced three challenges simultaneously when I was 20: 1 . I was trying to complete my undergraduate dissertation; 2. I was dealing with the deaths of two grandparents within months of each other; 3. I was in love with someone I shouldn't have been in love with. Someone who couldn't love me back. 


\section{David Lowbridge-Ellis}

To my surprise, this elicits some sympathy. Around half the room goes $a w w$, and not in a sarcastic, teenager way.

It's okay, I tell 263 Year 11s about to take their exams; I don't deserve sympathy. Looking back, I don't know what I was thinking. He was an idiot anyway.

And they fall about laughing. Some even applaud, and not in a sarcastic way.

\subsection{2 a.m. After the assembly}

The caretakers are already putting away the chairs, and I only have a minute to get to my lesson on the other side of the building.

But someone is waiting for me.

She rocks, gently, as if she's desperate to dance but unwilling to be the first one to get up on the dance floor.

Can I talk to you about something?

Of course, I tell her, trying not to look at my watch or imagine my class lining up outside the classroom, wondering where I am.

I think ...

For a moment, I don't believe she can go through with it. She can't meet my eyes. Without realising it, I've tilted my head to the side, knowing what's coming. My gay Spidey-sense is tingling. This is the moment her life changes. I want her to just say it. But I also want her to savour this. I want to say all of these things, but now is not my time to talk. This is all about her.

I'm ...

I fight the urge to help her. It is what teachers do every day, after all: coax out existing knowledge, building on it to form deeper understanding. But this is something she already knows and has been burying for some time. She doesn't need my help to excavate it. She doesn't need my permission. She just needs someone to listen.

I've not told anyone this, but I'm ... a lesbian.

'That's great', I tell her, barely pausing, but pausing just enough. I pick my words carefully, without betraying my mental effort (I hope). What I say and do now she will remember for the rest of her life. With gay power comes gay responsibility.

'That must have taken a lot of courage', I say. 'I couldn't have imagined coming out at your age. You're so brave. I'm so proud of you'.

She's a bit teary, and so am I. This is not an ordinary day for her or me.

It feels like results day has arrived several months early. But this is better than any results day.

\subsection{7 a.m. When a pupil asks me about my badge}

Where can I get one of those badges from, sir? The Year 7 girl on the front row is pointing at me. Pointing to the lapel of my jacket. Pointing to the badge with the rainbow on it. 
We only sell those in July, I explain, guiltily. It is currently November. A long time to wait when you're 11.

They're to raise money for charity, I add. I intend it to sound like an apology, but it comes off more like an excuse.

Here, I say, unpinning my own. It's yours now.

She takes it in her hand and immediately pins it to her blazer.

The next day she comes to find me before she goes to registration.

I made you this, she says, handing me a small thing made from a rectangle of paper and a safety pin. The coloured stripes are wobbly, drawn by an eleven-year-old hand with a felt-tip pen, and the whole is held together with Sellotape. But it's the most beautiful thing I've ever seen.

\subsection{2 a.m. When I'm on playground duty and one kid says that's so gay as they drop their bottle of fizzy drink}

Before I have a chance to jump in, one of my straight colleagues addresses it.

How would that make a gay person feel?

The child looks sheepish. I see traces of teenage bravado rising off him, evaporating.

How would that make a gay person feel, comparing them with something you've dropped on the floor?

There's no glance at me. It's unnecessary. It's impersonalised. Nothing to do with me but everything to do with being a decent human being. Instead, my colleague points to the fallen bottle of cherry-flavoured pop, guiltily spilling its bright red E-numbered innards.

That doesn't look very gay to me. Being gay doesn't make someone like a spilled fizzy drink.

The child agrees, promising to think before he speaks next time. I believe him.

\subsection{7 p.m. When someone says I knew he was gay all along in relation to the latest celebrity coming out}

I don't even wait to hear who 'he' is because I'm angry, and I'm not listening, and I'm talking and I'm talking and I'm talking, although I'm careful to stick to the third person, because this is not personal but it is something they need to know. And I don't stop until I've taught them something they really need to know, right now, so they never make this mistake again:

I hope you didn't say this to someone's face because it's the worst thing you can say to a gay person. At least if you call them a faggot, they can deal with it and write you off as a bigot. But when you say to someone's face that you knew they were gay before they came out to you, you rip away all those years of attempted concealment at a stroke. You steal the punchline to their joke, not that it was ever funny for them.

You make that person feel paper thin, as if everyone was watching them all along. As if they were failing all along. As if all that time, all that effort, 


\section{David Lowbridge-Ellis}

all the tears and blood and the 'I-wish-I-was-deads' should be instantly wiped clean. Their innermost secret reduced to the importance of a stain. Look: they're brand new again! And, really important, they are. But all that shame will never quite go away.

And even though they're now out, because they've been brave enough to hold themselves up to the light, you've reduced this important moment in their life to your moment, a petty victory of knowledge over courage, rather than as it should be: their triumph - over everything.

So, before you open your mouth, please think twice. Think more than twice. Think a hundred times. A thousand. A million. And then double it. Because however much you think about them being gay, you've got nothing on them, and it's not your experience. They've been thinking about it every day. They've been thinking about it all along.

\subsection{7 p.m. When a colleague tells me, you don't sound gay}

And then he realises what he's said, and he immediately apologises for thinking in stereotypes. I step in before he thinks there's even a possibility I have taken offence.

It's okay, I reassure him; I know what you mean. I take pride in being a linguistic chameleon. I can sound 'straight' when I want to, or camp it up with the best of them. And yes, most people say my 'real' voice (if I have such a thing) is somewhere on the straighter end of the spectrum.

Maybe this is another reason why I didn't come out sooner. I was hiding in plain sound.

From what I've read, no one really knows why some people sound gay. It's unlikely to be a conscious choice. More likely unconscious. This says to me that, deep down, some gay people want you to find out they're gay, but without having to articulate the words.

\section{What does that mean for you then, if you don't sound gay?}

I tell him I don't know. And then I pause, consider keeping my next thought to myself. Is it too solipsistic? I say it anyway: Maybe I was lost for so long that I couldn't imagine ever wanting to be found.

\subsection{2 p.m. When someone asks me a sex education question}

A trainee teacher stays behind after my training session on LGBT inclusion and asks me what 'chemsex' is, and I confess I don't know, and I tell her I feel like I've failed at being a gay because I don't know all there is to know about sex.

This last part just falls out of me and we both laugh. She says I will just look it up on Wikipedia. As a matter of interest, I ask her, why is she asking me?

Perhaps I didn't stress this last word enough because she only replies: One of my form asked about it in PSHE. 
I want to tell her and state categorically (and a tad over-defensively) we (gay people) are not all sex experts. What we've learned, we've largely had to teach ourselves. School failed us. Parents were clueless. The internet was ... curious and often full-on dangerous.

Later that evening, I Google 'chemsex' myself and learn that, as a nation, we really need to update our sex education curriculum.

\subsection{7 p.m. When I come out for the millionth time (or thereabouts)}

It's potentially hostile territory. Another school. I'm here to see the head teacher, I tell the receptionist. She gives me a lanyard with the word VISITOR emblazoned on it, telling everyone I'm not from around these parts.

I have arrived ten minutes early. I have time to take in the sights, searching the walls for some sign that my kind are welcome here: a poster, a kite mark, a rainbow flag, no matter how small. I find nothing.

Children come and go, stampeding through the foyer on their way to assembly.

And then he appears. The double doors swing apart like they do in western movies of the 1950s.

The first thing he does is shake my hand, but not in a John Wayne kind of way.

As we walk to his office, we make small talk: about my journey, about the weather, about how much work we still have to do before the end of term and how we will not get it all done. My wife says I take too much home with me. I smile and nod, telling him my husband says the same thing.

I say it without thinking.

He doesn't react. His voice doesn't deepen to make it clear he's DEFINITELY STRAIGHT.

In other words, the world does not end because I've come out (again). For 20 years I thought there was a very real possibility it might.

Another novelty that hasn't quite worn off.

So, why is my heart still racing?

I've lost count of the number of times I've come out in the last decade. And it does get easier. It used to be accompanied with a shot of pure adrenaline. Most of the time now, it's like a hit of caffeine.

The head teacher with the firm-ish handshake asks whether I take sugar in my coffee.

'No thank you', I tell him, my pulse returning to normal, my confidence returning. 'I'm sweet enough already'.

\subsection{7 p.m. When he and I hold hands}

We're out of milk, he greets me with, instead of a kiss.

I've not even taken off my shoes yet. I'll go, I tell him. 
I'll come with you. Dinner's in the oven, anyway.

By mutual, silent assent, my husband and I decide to hold hands for the short walk around the block. It's a risk, this holding-hands business.

We all get to know where it's safe and where it's not. It's not really fair that gay people have to carry around a mental map of the places where they live, like a Google Maps overlay showing them which streets they can walk down in the dark and which ones they need to avoid at all costs. But that's the way it is.

Even armed with this knowledge, places that you thought were safe turn out not to be. We've been attacked in Birmingham's Gay Village, just up the road from London's Soho, our own street.

Once, some idiot decided to shout abuse and throw chip shop curry sauce at us from their car as they drove past. This was on the main road, just around the block from our house.

A drive-by saucing. It sounded funny when I described it as this to the policeman on the phone later. But he took it seriously. He sighed: I wish I could say I was surprised. It's the area, I'm afraid. Although it could happen anywhere. And then, when he came around our house to take our statement, he laughed.

I love it, he said, pointing to our bedroom window, pointing to the rainbow flag hanging defiantly down, only faintly ruffled by the breeze.

\subsection{8 p.m. When my husband kisses me goodnight}

He's usually in bed before me and I'm the one to put out the light.

As tired as he might be, I don't have long to wait. In the darkness, I feel his lips searching for mine. Sometimes they graze my ear, or an eyebrow, or a nostril, before they drowsily find their home.

In these moments, the seemingly intractable 20 -year problem of being gay flutters away. What remains are the thousand natural shocks of the every day. Sometimes they keep me awake. Sometimes I'm just too tired to pay them much mind.

But his kiss tells me he'll be there if I need him. His kiss tells me he won't be overjoyed by my waking him up at 4 a.m. if I need him, but he'll be there, anyway.

There is a man in my bed.

Someone who loves me.

Someone who helped me love myself.

I know the novelty will never go away.

\section{Making sense of this experience/reflections on my writing}

We're all defined by what we are not. We all compare ourselves with other people, especially if we're in a minority. But I don't think a lot of straight 
people realise how many times a day gay people are reminded (or we remind ourselves) of our differences.

For this piece, I chose a typical school day. I have taught (if my calculations are correct - I teach English, not maths) over 3000 pupils. And as a senior leader in a large secondary school, I have helped to shape the lives of over 30,000. Only one has ever asked me, 'Sir, are you gay?'

I lied.

I wasn't even fully out to myself. I'd barely been teaching a year. I was only three years older than some students I was teaching, fresh from university. So why do I still, as I type this, feel a degree of guilt about lying to that kid?

We all remember things teachers have said to us, both the good and the bad stuff - but especially the bad stuff.

Sometimes it may appear to teachers that our words fall on deaf ears, especially if those ears belong to the most recalcitrant pupils. But just replying 'Yes, I'm gay' in that moment could have had a life-changing impact on everyone in that room. And I don't just mean the queer kids. I also thought my being honest could have had a positive impact on the straight kids, most of whom had only experienced gay people on TV or the internet (I would specify 'social media', but this was 2005 and it wasn't really a thing yet, unless you count Myspace, which makes me feel old, so we won't).

There are some who argue a queer teacher's identity is irrelevant to learning. ${ }^{1}$ It may, they say, even be a distraction. Some ${ }^{2}$ maintain that gay teachers should categorically not share details of their 'personal lives'. ${ }^{3}$ But would they disagree with a straight male teacher referring to their wife? I doubt it. What about if a gay male teacher was to refer to their husband? These same people would be up in arms. I don't know how anyone can summon the mental energy to teach effectively ${ }^{4}$ if they're also wasting

1 I am loathe to dignify any of the keyboard warriors who express such views by referencing them (just Google 'too young to learn about LGBT' to find a depressing number of these stories). However, the particularly venal 2019 protests which targeted primary schools in Birmingham, 20 minutes from my house and the school I teach at, are of particular note and received plenty of mainstream media coverage and comment, e.g. Hobby (2019). The long overdue update to Sex and Relationships Education, which became mandatory in the 2020/21 academic year, provoked similar reactions.

2 My experience has taught me that this ignorance stems from three main misconceptions: 1 . Sexual orientation is all about sex; 2. Gay people are sex pests 3. Gay people choose to be gay. I have explored these and the steps school leaders can take to overcome them elsewhere, e.g., Lowbridge-Ellis (2018a, 2018b, 2018c, 2019, 2020).

3 More scare quotes. As I explore early on in my piece, I've long had a tendency to rely on these punctuation marks to make it clear that I don't accept things at face value. Recently, I was delighted to find a resonance in Susan Sontag's Notes On 'Camp' (1964): 'Camp sees everything in quotation marks. It's not a lamp, but a "lamp"; not a woman, but a "woman". To perceive Camp in objects and persons is to understand Being-as-Playing-a-Role'.

4 The literature on the link between pupils trusting their teacher pupil motivation is wellestablished. For a succinct summary see chapter 4 of Mccrea (2020). 
a sizeable chunk of cognitive energy ${ }^{5}$ on concealing such a fundamental part of their identity. ${ }^{6}$

Well, that last one I do know about, because I did it. For those first four years I was a teacher until I came out at the age of 26.

I'm a much better teacher now that I don't have to refer to the man I love as 'the person I live with' or avoid saying the personal pronoun be.

I never conceal who I am anymore. The past decade has been by far the best of my life so far. Being openly gay is nowhere near as exhausting as being closeted. And yet, I still think about being gay many more times than would be necessary in a supposedly more inclusive society. ${ }^{7}$

I'm sure I'm not alone in this?

\section{References}

Hobby, R (2019) 'Teaching children about LGBT issues is not brainwashing - It equips them for life.' The Guardian, 9th June. Available at: https:/www.the guardian.com/commentisfree/2019/jun/09/teaching-children-lgbt-issues-parents -teachers-government

Lee, C (2019) 'How do lesbian, gay and bisexual teachers experience UK rural school communities?' Social Sciences, 8, 249.

Lowbridge-Ellis, D (2018a) 'Unacceptable in the 80s.' LGBTQ+ In Education, Leeds Beckett University (February 2018 edition). Available at: https://leedsbe ckett.ac.uk/-/media/files/research/lgbtq-volume-2-feb-2018.pdf?la=en

Lowbridge-Ellis, D (2018b) 'The importance of being open in the classroom.' Teacher Toolkit. Available at: https://www.teachertoolkit.co.uk/2018/07/18/b eing-open/

Lowbridge-Ellis, D (2018c) 'This knowledge organiser is here. It's queer/get using it.' LGBTQ+ In Schools, Leeds Beckett University (June 2018 edition). Available at: https://leedsbeckett.ac.uk/-/media/files/research/lgbtq-working-paper-seies-june -editioncx.pdf?la=en

Lowbridge-Ellis, D (2019) 'Teaching gay stuff: Let's get this straight.' Teacher Toolkit. Available at: https://www.teachertoolkit.co.uk/2019/04/24/lets-get-this -straight/

Lowbridge-Ellis, D (2020) 'Be LGBT inclusive.' Association of School and College Leaders. 'Leader' Magazine (June 2020).

Mccrea, P (2020) Motivated Teaching. Available at: Pepsmcrea.com.

5 Cognitive load theory has been around for over three decades but has only become common parlance in most schools quite recently. See, for instance, Muijs (2019).

6 And let's not overlook the detrimental impact on the mental health of queer teachers themselves. A recent study (Lee, 2019) showed that nearly two-thirds of LGBT teachers have experienced serious anxiety or depression linked to having to conceal their sexual or gender identity, and those in rural schools are disproportionately affected.

7 In 2019, the Organisation for Economic Co-operation and Development (2019) declared that the UK was only 'halfway to full social acceptance', appearing at just over 5 on their 10 -point scale (10 being fully socially accepting). The USA appeared slightly below the UK. Countries which were more accepting included Germany, Australia, Sweden, and Iceland. 
Muijs, D (2019) 'Developing the education inspection framework: How we used cognitive load theory.' Department for Education. Available at: https://educati oninspection.blog.gov.uk/2019/02/13/developing-the-education-inspection-fra mework-how-we-used-cognitive-load-theory/

OECD (2019) 'Society at a glance: A spotlight on LGBT people. How does the United Kingdom compare?’ OECD. Available at: https://www.oecd.org/unit edkingdom/sag2019-united-kingdom.pdf

Sontag, S (1964) Notes on "Camp”. Partisan Review, Fall 1964. 


\title{
2 Shower thoughts - of loss and queer love
}

\author{
Randall C. Lopez
}

The hot beads of water hit my body as I relish the steamy shower, feeling every bit of warmth, seeking some sort of gentle comfort. I get lost in my lucid imagination and thoughts that offer beautiful distractions from the darkness that creeps on me. I'm in the shower for five to ten minutes before feeling that melancholy, though I try my best to put up invisible liquid barriers. I continue in the shower, losing track of my time in this blissful heat, though it's a steamy charade. The sadness begins to fill the void like clockwork, though the hot beads ease the feelings that are beginning to lurk in my mind. I think about how my sleeping schedule got utterly fucked during this pandemic. There are no rules for sleep, so I do what I think is reasonable in terms of these chaotic times. With no work or school to keep me in a routine, I sadly drift into a depressive state hovering above a quiet existence. My friends and family know me to be colourful, vibrant, and that sort. I'm always doing something, especially putting much effort into whatever job that I am holding or university that I am attending. But my world has gone quiet. Not even the crickets chirp, making the sadness in my soul rise up to tears listlessly stuck to the edges of my eyes. I go back to the warmth of my shower as I think about this pandemic, but other thoughts rise up.

I knew being gay was a difficult journey, but I found it even harder when dealing with my last relationship which exposed my deep-rooted loneliness knotted with loss and love. Yes, the relationship carries weight in both loss and love, but the issues go deeper than what I had encountered with my exboyfriend Ryan. As I sit in the shower, it comes to me again in a sad, wispy voice from the obscure corridors of my mind. I feel it as though clutching a wooden rosary in my hand, absolving whatever sins that I hold. I silently pray to divine spirits hiding in the downfall of water. I hope they hear me. The hot water continues to furiously beat down, and it's here in this glorious warmth of the shower that my mind slowly wanders to a black veil. I feel the lingering aura of death in my presence. The loss of my father creeps from the back of my mind. I am reminded that he will not be physically present for the rest of my life. I am reminded that he will not be around to meet my same-sex partner, meaning that he is not around to fully embrace my queer identity. I am reminded that he is gone. The shower thoughts come in 
full force, leaving only the warmth as a shield in what feels like chaos raging in my mind.

My father's death cheated me out of fully coming out to him, and that opens deep emotional wounds that have been repressed. A flashback to me getting a call from my mom while I was living abroad enters the stage of my mind. She tells me that it's time for me to come home to say goodbye to my dad. He's on life support and there is talk of removing his breathing tube. I give a sad, hopeless sigh in response to the news. He was dying, and there was nothing that anyone or any medical miracle could do. Returning to Corpus Christi, Texas, was difficult. I don't know whether this place is a town or a city, it just sits on the coast. But thank god I left. There I was rushing my mother to be at the hospital by my father's side with my mind feeling heavier every second. The world felt like a blur in my eyes, a tunnel vision that only sought to be in my father's presence. I got to the hospital, which felt very familiar at this point given that my dad was in and out throughout the majority of my life. All the diabetic seizures, amputations, blindness, and kidney failure scares led to this final, tearful episode. It was nearing midnight when I finally saw my dad in his hospital bed. I remember the beeping sounds from machines indicating my father's vital signs. It became very real knowing that I would never fully be myself as an out, proud, queer individual to my dad. There was so much to say, but my dad was leaving us.

The shower blazes on with warm water hitting my face as though tears are forming. I can smell the peppermint from my Harry's shampoo wash over me, caressing my brown skin as it finds its way to the drain. I feel myself in my body with the roundness of my stomach feeling heavy. I embrace my curves under the lather of the soap in some sort of comfort, as though hugging myself. I feel the heartache as I continue to remember. It came time to remove his breathing tube, which caused a commotion of tears, pain, and sadness in the eyes of my family. The removal was quick and easy, but it made the air around my dad's hospital bed difficult to breathe. I was choking on my own tears and sobs. I stayed by my father's side till the very end, feeling this surreal trauma as though rose thorns were piercing my bleeding heart. I remember crying and chatting with him as if he was still there. He stared at me with such focus but couldn't utter any words. When I asked him if he could hear me and he responded yes with a blink, I broke down crying because I had so much to say before he left. My father passed early on a cool January morning with the sun shining gloriously over the glistening bay. I stared at my dad resting in eternal sleep. His body, the hospital bed, the blue walls, all became a portrait that sits in my mind. I still hoped that maybe this wasn't real - that maybe, just maybe, he would wake up. So much was left unsaid, but there was no changing the hard truth. It was a scratching thought that found a corner of my mind in which to fester. I had barely been comfortable with being out to my father, not fully knowing if he was accepting of my queer identity. Later, my mother would console me and say that my dad loved me no matter what. This made the sentiment even 


\section{Randall C. Lopez}

harder because I also realised that my dad would never have the opportunity to meet a boyfriend of mine. It feels as though I have been robbed of some affirmation of my gay identity, knowing that my dad will not be introduced to any of my potential partners. I was closeted for the first 19 years of my life, barely feeling free when I had the chance to go to university in a different city. My father and I grew distant for various reasons, especially because of my fear that he would not come to terms with my sexual identity. Our Hispanic culture was riddled with toxic masculinity and machismo complexes that were harmful towards men if they show emotions or anything that hints at femininity. Not being a 'man' would ostracise me from my culture and have me ridiculed by my family and friends. It was only a couple of years before he passed that I could openly talk to my dad about my problems with dating men. It wasn't until after he passed that I met my first boyfriend in a country far from home where I could somewhat escape the reality of losing my father. But that loss left an impervious stain on my soul, and there is no removing that.

My dad's absence left a void in me and my queer identity. However, it didn't take away my chance to be vulnerable with someone and capable of having an intimate relationship with another individual. True, this was a painful loss, but I could feel something else enter the space as the warm shower droplets expressed past events. I find my ex-boyfriend in the mix of warmth and steam. My mind focuses on a guy who made my heart feel joy with his radiant smile and vibrant eyes. I know Ryan to be sincere and warmhearted with his delightful boyish manner. He is definitely the compliment to my dark, witchy, vibrant self. Ryan brought balance as though we were the sun and the moon, creating remarkable feelings of euphoria. I can't help but get giddy whenever I'm around him. He was my second boyfriend that I had the chance of being with when I returned from living abroad. I had known Ryan prior to my departure, and a year later, he was still around. I left him with a kiss which was heartbreaking, but now we had a chance to be together. Things were fantastic during our happy relationship, but I could feel the distance between us growing. Our relationship was filled with much laughter, humorous sarcasm, academic wittiness, many lovely hugs, outdoor walks, and memorable dates. His passion for his field and future in his career were a driving force that gave him the undeniable spark to succeed. It was admirable to love someone who cared so much about their work. Then, Ryan told me that he was moving away from the city that we shared. This news shattered me and left me in an almost inconsolable state when I saw the text message.

Ryan and I began to grow distant at an alarming rate. One day I was utterly infatuated with him, and then the next I was planning on breaking up with him. It finally came in the form of a text message that I created. It was alarming for me as I didn't expect myself to choose to break up with my partner via text. I prefer to communicate in person regarding these personal matters, but Ryan was beyond distant from me. We didn't talk for 
two weeks prior to my breakup message. It was a difficult time for me as it felt like I lost the air in my lungs. Breathing felt heavy when I thought about making contact with Ryan. I put off messaging Ryan with excuses, but the silence was growing into this monster that was strangling me. It was time to end the stillness between us and address the broken hearts. This was all horrible, even more so as the pandemic had just started isolating me in my apartment where I would sit with these thoughts of heartbreak and loneliness. The steam in the shower becomes heavy, just like my thoughts.

The COVID-19 pandemic was like Pandora's box being opened across the United States. I live in Austin, Texas, and wow, did things take a turn for the worse. One could feel the uneasy nature of fear and anxiety lingering in the air. There was too much noise on social media and from untrustworthy sources that only heightened the intensity of the situation. The world was not safe outside my cosy walls, yet my world was not inviting due to the venomous feelings that remained. I felt loneliness, anger, and so many other dark feelings when I broke up with Ryan. I was a mess because I felt like I wasn't enough for this person who I poured my heart into. I already have this self-conscious, self-loathing perception of myself that mostly focuses on my body image. This is especially true with my relationship to the gay community. In this context, I allude to the gay community that exists here in Austin. This occurs as I've had most of my experiences in gay culture in this environment, though this is not to say that these experiences have been limited to here only. Furthermore, I would like to make clear my use of the words 'gay' and 'queer' in relation to my gender and sexual identity. These words within my identity are fluid in adapting to where I find myself. It is okay to be me in the way that I see fit and feel comfortable with, depending on the space and place.

In my perception, the gay culture that surrounds me in Austin seems to heavily focus on body image in an almost unhealthy, toxic manner. This does seem universal when I see social media posts regarding the issue from various other perspectives, and in this case, I am sharing my own experience with my own voice. I scroll on gay apps such as Grindr and Growlr that are centred around the various body types of gay men. The applications themselves let you advertise your body type in order to draw attention from other men that are attracted to what you have to offer. There are even labels that help define gay men from 'twink' to 'masc' and from 'otter' to 'bear' (with the likelihood of the whole animal kingdom in between). There are so many labels and cliques that I can clearly see the divide in the community. It's the divide that I feel uncomfortable with, as it pressures me into creating and finding a gay label that will define me. But I don't want to be defined by those labels. I am myself.

I think about how exhausting gay dating apps can be for a person like me. Gay apps reinforce men to be highly superficial in selecting a guy as though they were a prime choice of butchered meat from the market. I would suggest picking candy, but I see many of these men dare not touch the sweetness 


\section{Randall C. Lopez}

for the sake of glorified fitness. Yes, innumerable gay men are obsessed with ripped bodies with glistening abs as the hard-driven sex appeal gives them a boner for the thoughts of physical activities engaged in bed or wherever their pleasure can be met. It reminds me of my investigation into sexual objectification that gay men encounter, where our bodies are objects in the eyes of men. It's almost as though our lips are shut, our voices are silent, our thoughts are ignored, and our eyes stare vacantly. The gay culture surrounding me craves the sweat of the dripping hot body of an Adonis thinking only of the physical aspects of the man, leaving him nothing more than represented as a piece of meat. They all want that hard succulent meat. This objectification reminds me of a grand marble statue, smooth to the touch and beautiful to gaze upon, but not offering much of the splendours of the soul, or perhaps a mind, to connect with. I also sadly think that this sexual objectification of gay men leads us to being boy toys that can easily be tossed when our usefulness has met its end. I want to break this cycle. I want to break this negative thinking. But then, I wonder if this was true of gay relationships? Did Ryan find me useless as our relationship came to an end? Was I expendable? I feel my heavy breaths in the heat of the shower as my mind sinks. It's a thought that haunts me, given my low self-esteem. I want to be validated for my presence and how much I matter to this person, but it's hard thinking that way when I feel that I am not worthy to be in a relationship, given my own doubts of body image.

I'm tired of debasing myself for the sake of forming an attachment with a man. It feels as though my gorgeous brown love handles were a big fat 'no' in a community obsessed with looks. I would be defined as a chub, and in some cases, that is too fat for chat - or even friendship - in the gay culture around me. I wasn't some beautiful chiselled gym rat with a six-pack. I wasn't some beautiful, blue-eyed white boy. (Oh yes, racism also exists in the gay community.) The shower feels intense as my thoughts rage on. Shockingly, I thought Austin, Texas, would be more at ease and liberal, but the gay community was just as harsh. I've been beaten by so many words that it's hardened me to where I don't seek to fit in. I sadly avoid the community because I don't want unnecessary battles, especially living in a world where so many other issues call for my attention. I know what I've felt and experienced. It leads me to feeling othered by the gay community. This isn't necessarily bad, as I've been inspired to find my own following, my own love, my own circle, my own culture, and my own family. This path has allowed me to explore my own queer identity where I feel comfortable. Despite the lack of connection with the gay community, a part of me identifies as gay, in that I want to be with a man. And that man was Ryan.

The heat of the water feels like the fire that I have for him. I yearn for Ryan's warmth and love as I didn't think I would find a guy to love me for my body and my winning personality. I remember being intimate with Ryan and I was afraid of showing him my body as I told him, 'I'm fat'. Ryan looked at me lovingly and responded that he didn't care. He wanted me. 
Do you know how it feels to be wanted like that? I feel like it's hard for someone trapped in a body like mine to find romance and that real love that makes your heart rightly skip a beat. I felt undeserving of love given that I didn't care about my body like all those Instagram male models posting their thirst traps of their rock-hard bodies in sensual poses. In all honesty, I find pleasure going through Instagram hitting the 'like' button on these very sexual and seductive photos. It's captivating, as these men are horribly attractive, but it comes to my realisation that all these 'likes' are for validation and even for monetary gain to have people support them, such as on OnlyFans (a job marketplace that has emerged for social media influencers during the global pandemic). I give these men my validation that their bodies are beautiful and worthy of my attention, but I wonder if the reverse would be true for me. I then think that this type of validation is stupid as I begin to unfollow the Instagram pages belonging to these men. It's unhealthy and toxic. But I find myself following new pages and giving new 'likes', as I am stuck in a cycle of worshipping men. My depression beckons me that I will never have someone because I don't have the muscles, the six-pack, nor do I post my efforts in the gym on social media. I feel truly and utterly hideous at times, but then I show a goofy, carefree smile in the mirror or in my frontal camera on my phone to show that a part of me still has life to give. In that, I find comfort, and I feel the love that Ryan once gave me.

A month and a half into quarantine, I finally reach out to Ryan as the pandemic seems to spin in a very dangerous direction. I worry about Ryan, as my love for him did not waver. He responds to my text that he is elated to hear from me. We set up a date to talk in person in a safe socially distanced manner. The day comes and I have butterflies in my stomach. I kept thinking if I looked cute enough for Ryan. I hadn't seen him in person for months. Would he still like me? Would he still care? When he arrives, it's as though nothing had really changed when things were good. My nervousness fades in the warmth of his aura. We were back to being our goofy, lovable selves before the breakup. We have the healthiest talk we ever had in expressing our feelings. No longer fearing the emotions that came from the breakup, we became reconnected in a way that strengthened our relationship with each other.

Communication is vital to a relationship, and we both failed that aspect towards the end of our relationship, but now we are able to use our words to be there for each other in this moment. The loneliness faded when I was in Ryan's warm presence. Truly, I was giddy once again when I saw the flash of his eyes and heard his laughter. I didn't feel any of the toxic nonsense that came from the standards or pressured norms of the gay community. All I felt was Ryan in that moment, and that felt eternal.

Nothing is ever truly perfect, but the feelings are euphoric in the moment. It's like a drug that keeps you wanting more and more till you can't feel anything but the high of happiness. I wanted to stay in that high. My connection to Ryan is blissful, though it is not impeccable. Sometimes, I don't 
get responses from Ryan, which makes me feel inadequate and less than myself. Silence hurts. Though I know he is busy, and we have our own lives to live. He's not my boyfriend currently and he may never be again, but our bond does have warmth and a cute, queer love. My thoughts circle back to Ryan meeting my mother. This was the first boyfriend that my mum met. It was truly a happy moment for me, but in my mind, I still wished that my dad had been around. I don't know if wanting my dad around is to help me validate my identity, or to have him around because I miss him, or a mixture of both. It's hard to process these feelings and thoughts because the interpretations are lucid at times, but then they are muddled in darkness at other moments. This is even more relevant now as I deal with higher levels of loneliness inspired by the current pandemic. This state of isolation has become a mirror of facing hard truths, tough self-reflections, and ugly thoughts that have been repressed due to the distractions of life that were present before COVID-19 decided to wreck 2020. I grow weary of the oncepleasurable shower. I still smell the peppermint from my shampoo. It's time to get out.

It's nearing 4 a.m. and I'm staring at myself in the bathroom mirror. Steam covers it from the hot shower where I've been getting my warmth. The shower did help to alleviate and ease my emotions in turmoil as I often find myself feeling the pressure of my anxiety encircling my head as though it was being poked by a crown of rose thorns. I feel all right, but I see something that wouldn't indicate that. My eyes are red from crying. I look at myself loathing my body image because of the toxic stigmas that gay culture feeds me. But that's not completely it. I harbour pain from feelings of loneliness and being unwanted from my last relationship. But no, I dig deeper. Tears well up in my eyes. I feel it now. I am haunted by this void that pierces my soul. I feel the loss of my dad as well. To lose my dad was to lose a part of myself where the connection has been severed. There is an unexplainable emptiness that I can't grasp that has an inexplicable power to muster all the negative emotions. It becomes a faint stabbing in the heart. The tears are streaming down again.

I look in the mirror with my brown irises and skin. I sweep my hair to the side instinctively. I see myself broken, staring at this reflection. But at least I see myself. Loneliness, depression, anxiety, and loss are one hell of a cocktail that causes a lot of harm if left unchecked. It doesn't help that a pandemic is existing at this moment. The world I know is changing, but in these tears, I find hope that maybe something good will come from all this unprecedented upheaval. Despite feeling the daily exhaustion of my dance with loneliness, love, loss, and pain, I know that I will persevere. Even if this fearful darkness surrounds me, I am a fire not easily extinguished. I have resilience in my bones. It also helps that Ryan is still in my life with regular communication that combats loneliness and aids with some self-affirmation. That thought warms me. A little smile appears on my face in this mirror. I'm reminded of those good feelings of love with hints of laughter. Caught 
in this moment of bliss, I find the strength to look at this reflection of myself and see that maybe I am enough.

\section{Making sense of this experience}

This writing process was a reflective journey that captured pivotal moments of my life, along with the emotions intertwined with those events. It took time to envision the course of connecting these events together. One night I had an epiphany before a shower. In this moment, I was drawn to discuss the loss of my father along with my relationship experiences during the pandemic. The shower became my safe space to connect my various episodes and emotions while being at ease when discussing difficult topics.

The focus on my father's passing is significant to me as it allows me to connect to my culture. Death is honoured in my Hispanic traditions through holidays, festivals, and shrines where the dead are celebrated and remembered (Desai, 2020, p. 775). Personally, death has become easier to cope with in the respect that my lost loved ones are still being kept alive in spirit. Research has shown that Mexican-American families maintain a bond with the deceased through 'dreams, storytelling, keepsakes, a sense of presence, faith-based connections, proximity connections, ongoing rituals, and pictorial remembrances' (Doran and Hansan, 2006, p. 206), where there is no mention of closure or moving on from those lost. I resonate with these findings, as I still dream about my father and find myself asking for his spiritual guidance on decisions. He still feels very much here in my presence, allowing me to connect with that loss.

Culture also influenced my gay/queer identity through the lens of being out to my dad and dealing with machismo. Traditional machismo marginalises queer Latino men (Duran and Pérez, 2017, p. 1151) with threats of non-acceptance and negative reactions from the family (Gattamorta et al., 2019 , p. 157-158). This was a fear that I had, with my father potentially rejecting my queer identity leading to this coming out crisis and the dread of not having him meet my partner. This is a fear that lived with me until his passing and still has a hold over me.

Beyond the scope of loss and culture, I discuss my feelings of being othered in the gay community where I find myself disconnecting from the scene where gay apps glorify sex and labels (Zervoulis et al., 2020, p. 97) and encourage sexual objectification (Kane, 2010, p. 315). This leads into my relationship with Ryan, where exploring the queer love between us felt invigorating in that it was a first for me discussing a personal relationship with such intimacy in writing. The work by Harris $(2016$, p. 34) helps me explain how genderqueer experiences such as mine break out of the traditional mould and 'surrender to unfixity' whereupon I transcend beyond the binary with my queer love for Ryan. It's like seeing myself adapting to spaces with my identity, shifting to what is comfortable at the moment and feels appropriate to me. 
In conclusion, the process of writing this piece was surprisingly refreshing, as I was able to reflect deeply about what had occurred. Throughout the development, I acknowledged that my feelings gave me inspiration to write and view this journey as a self-portrait that according to Nuñez (2009, p. 57) is a 'particularly powerful way of expressing feelings and emotions'. With reflection, I allowed myself to let my emotions guide me in seeing that even a simple shower could turn out to be so much more.

\section{References}

Desai, S. R. (2020) Remembering and honoring the dead: Dia de los Muertos, Black lives matter and radical healing. Race, Ethnicity, and Education. Aheadof-print, 1-17.

Doran, G. \& Hansen, N. D. (2006) Constructions of Mexican American family grief after the death of a child: An exploratory study. Cultural Diversity \& Ethnic Minority Psychology, 12(2), 199-211.

Duran, A. \& Pérez, D. (2017) Queering la Familia: A phenomenological study reconceptualizing familial capital for queer Latino Men. Journal of College Student Development, 58(8), 1149-1165.

Gattamorta, K. A., et al. (2019) Hispanic parental experiences of learning a child identifies as a sexual minority. Journal of GLBT Family Studies, 15(2), 151-164.

Harris, A. (2016) Love has a body that feels like heat: (Extra)ordinary affects and genderqueer love. Departures of Critical Qualitative Research, 5(4), 24-41.

Kane, G. D. (2010) Revisiting gay men's body image issues: Exposing the fault lines. Review of General Psychology, 14(4), 311-317.

Nuñez, C. (2009) The self portrait, a powerful tool for self-therapy. European Journal of Psychotherapy \& Counselling: Phototherapy and Therapeutic Photography, 11(1), 51-61.

Zervoulis, K. et al. (2020) Use of 'gay dating apps' and its relationship with individual well-being and sense of community in men who have sex with men. Psychology \& Sexuality: Preaching to the Choir 2018: An International LGBTQ Psychology Conference, 11(1-2), 88-102. 


\section{Christmases past and present A Phet tee saam lamb's search for their
flock}

Panu Sahassanon

\section{Christmastime in 2019}

It was the first Christmas that a tanned-skin guy with black hair celebrated while living outside of Thailand. That guy is Panu. He came to Edinburgh to complete a doctorate in counselling. He was walking along the busy, iconic Princes Street lined with shops, looking for a Christmas gift for his mother. He admired the vibrant Christmas market across the street, crowded with visitors and locals soaking up the festive atmosphere. Envisioning himself walking with the snow falling, a freezing wind and occasional raindrop replaced his imagination. Amidst this cold and the feeling of being alone, his heart was still warm and enthusiastic about finding the proper gifts for family and friends. Nine thousand kilometres away, almost halfway around the world, he had been missing those times of the year with them. He was longing for those times while wavering between buying a lipstick or makeup gift set. What has Christmas meant for him?

Living at the rural border of Bangkok, when Panu was a young boy, he grew up with a mixture of two religions. Panu's father was Protestant Christian and his mom a Theravāda Buddhist. His paternal grandmother, a devout Christian, also lived in their house. On Sundays, grandmother always urged her son and grandchildren, him and his younger sister, to attend the church activities: the bible class for children and the liturgy for adults. Faced with reluctance, torpidity, and the distance between church and house, their father brought them there twice a month. They kept up this routine until his grandmother passed away. After that, the frequency of attendance dropped dramatically to once a year - at Christmas.

Annually, the Tawan Church, near the heart of Bangkok City, had held Christmas worship whose pattern was quite similar. Never remembering when worship started, by the time they arrived, around 10.30 or 10.45 , most of the Christian members had already congregated in the chamber of worship and were listening to the pastor's sermon. A performance by some children who acted and sang on stage, bringing smiles and laughter to the audience, followed this. Each year the theme of the play would revolve around the love and history of Jesus Christ. A tall, skinny boy, compared 
to his peers, Panu had never been on stage. The songs of worship sung by members of the choir - some of whom he recognised - would be the sign of the approaching end of the Christian ceremony. At noon, members went down to the ground floor, which usually served as a carpark, but at this time of year, it was filled with tables and chairs instead. He received coupons to trade for food at the food kiosks. Menus regularly included fish maw consommé, and grilled chicken with sticky rice. At this gathering, his father gave white meringue cookies with almonds (bought and managed by his mother) as the family's traditional gifts to friends, the pastor's family, and the relatives who accompanied them. Unexpectedly, the boy also sometimes received chocolate or cookies from his sister's friends. He was happily surprised by their kindness, spoke briefly with them, and then left so that his sister would be free to have some private conversations, while Panu sat waiting.

He was a quiet and polite boy who had never made any close friends to share Christmas presents with. At church he felt uncomfortably different and scared of the consequences that would follow if the people there knew he was gay; that is, attracted to another guy. In grandma's room, there was a thick, old cartoon Bible, drawn and coloured beautifully, standing on her wooden bookshelves. Often borrowing it to read for enjoyment, he was curious why he could not find gay characters in the Old or New Testaments. In the book of Genesis, when God first created man and woman, Adam and Eve, there was no room for Adam and other guys. At church, he was the odd one out. Feeling different and isolated from others, he decided, then, to hide, using taciturnity to protect himself from others. He considered himself the black lamb, wondering what underlying reason God had for creating him. For Christians, this symbolic animal is normally represented in pictures of Jesus as the shepherd, but the black colour is also rooted in the Thai proverb that portrays the one who is different or deviates from others.

Despite considering himself a black lamb, every Christmas Panu was unhesitant to go there. When he was born, his father was working as a sailor and could only come to visit on weekends. His grandmother had a major role in supporting his mother. When at night a storm hit the house with rumbling thunder and lightning, or when he was scolded by his mother, he would run into grandma's room. Her hugs and comforting words were an important source of solace. One day, she shared with him a story about her eight miscarriages and how, in her ninth pregnancy, she converted to Christianity. Miraculously, she gave birth to a boy: his father. Since then, she had dedicated herself to God.

Grandson Panu gradually absorbed her loving faith in God. He never spoke explicitly with her about his attraction to guys. Maybe he was unsure of the consequences or was too young or too scared. And then she died. He cried a lot. After her passing, whenever he prayed, he believed that she already knew; he felt more certain of her acceptance and believed that her love for her grandson would be the same. Although she was physically 
missing, her warmth and love remained within him, like a Winnicottian good internal object. Her good image of care, attention, and presence was internalised, instilling him with hope and strength. Every Christmas day, when all the Christians were gathering at the top floor of the church, he looked for one of the empty rooms and sat there silently. In that peaceful room, he prayed directly to his holy spirit with his grandma nearby. It was the place in this living world where he was most closely held, cherished, and empowered by them. He considered himself the black lamb, but at Christmas, he always had his dearest grandmother.

\section{Christmastime in 2009}

Panu was a sophomore at a university situated amid luxury shopping centres. During Christmas and up to the New Year, it was one of the busiest districts, where Bangkok residents and visitors came to buy gifts from shops that were unanimously promoting their end-of-year sales. A giant Christmas tree with sparkling decorations shone as the perfect setting for photographs. Fancy restaurants were booked, and when dusk fell, alleviating the temperature from 32 to 24 degrees Celsius in December, it was a time for celebrations as a sea of people arrived.

Panu's school was nearby, so he and his gang promised to experience this vibrant and warm festival as a yearly excursion. His first boyfriend joined the group to savour this atmospheric Christmas vibe. Panu could not remember where they started and finished their saunter, but he remembers they were sitting on a brown couch when his boyfriend gave him two presents. The first one was a teddy bear dressed in a Santa Claus costume. He named him Ping-Pong, which rhymed with the giver's name. He gave the second present when Panu turned his face away: it was a quick peck on his cheek. Embarrassed and blushing, Panu looked around with concern in case others had seen this public display of affection. His boyfriend giggled. This second-year student thought his boyfriend was a gift from God.

Although gay people might be seen as mainly concerned with sex (Rodriguez, 2016) there was nothing related to sex at that moment when his boyfriend's soft lips landed on Panu's cheek. Like a fragrance, feeling embarrassed and blushing worked as the top notes, the first reaction to the kiss. The heart notes later emerged as a warm feeling of bliss. That kiss significantly symbolised an intimacy that bonded him and Ping-Pong's buyer more closely as a couple.

For the base notes, however, uncertain feelings rooted in his childhood memories formed the last impression of the fragrance, making him tremble inside. A long time ago, while he and his mother were watching a TV show hosted by an effeminate gay celebrity, she said: 'He will never successfully find his true love, only a deceitful one'. Having not yet come out, Panu pondered whether 'She might feel concerned about me being gay'. But these deceptively simple words had impacted somewhere inside, making him 


\section{Panu Sahassanon}

doubt the existence of gay, true love. 'Will gay people like me be able to find long-lasting love?' he asked himself. This question could imply that gay love was inferior and temporary compared to a straight couple's love. Growing older, he encountered similar curiosity from others in the Thai internet forum 'Pantip'. There were many posts asking 'Rak thae khong gay mi ching rue?' or 'Thammai rak thae nai mu gay ha yak chang?' (Does true love exist between gay people? Or why is gay, true love so difficult to find?). Panu was carrying this doubt as he sat next to his boyfriend, touching his ankle through black slacks. This guy might provide evidence against his mother's words. With the future unknown, this Christmas brought something romantic, something new, and something uncertain. He considered himself the black lamb, but this Christmas, the black lamb experienced his first romantic love.

\section{Christmastime in 2014}

Panu met his friends in a quieter and less crowded district, which was recognised as Bangkok's hipster hangout. For merriment, they wore Santa hat hairpins. Six girlfriends and one gay man had formed a group called TGIF girls (Thank God It's Friday). They had known each other for years and aimed to celebrate significant occasions together: members' birthday parties, excursions, and of course, Christmas.

'How was your life, how was your love?' was the common question at the table, although they had a brief overview of some stories via the group's instant messages.

\section{Christmastime in 2010}

This student was again strolling in familiar surroundings, from the Paragon department store en route to Central World, without Ping-Pong's buyer. He had broken up with Panu three months earlier, nearly a year into the relationship. It was devastating. Panu was sitting with friends in a giant plastic snow globe, holding a Santa Claus cardboard stand-in with cats placed inside; they were waiting for their picture to be taken. Although he was still hurt inside, Panu smiled for the picture. Less than two months earlier, he was sobbing, witnessed by mom, who asked in frustration: 'Why do you cry so much for him?' 'Because he was my boyfriend', he shouted back with tears covering his face. It was the first time he had openly confessed that he liked men. Silence fell, and she never mentioned it again; their conversation faded away like his own memory after that confession.

During that time, when he was looking at his reflection in a mirror, with puffy crying eyes and teardrops rolling down, the thought of Granny came to him. 'She would be sad and downhearted seeing her grandson crying in pain', he thought. Knowing that she would always want him to be stronger and to get through this adversity with God's help, he slowly wiped away the tears. 
Since then, he has been better. They further explored the Christmas vibe in Central World square, taking a picture of themselves from the reflection of a red Christmas ball. Before leaving, he hugged and held hands with his friends as they had done with him when receiving the heart-breaking news. Panu was thankful to have friends in his life during this festive moment together.

\section{Back to Christmastime in 2014}

Waving goodbye to his TGIF gang, he walked swiftly across Ari Road to a nearby café where two old friends from his Catholic school were arriving. They had known each other ever since primary school.

In an all-boys school, other students mocked them with the name 'dtut', an insult aimed at someone who displayed effeminate characteristics. Despite being defined by this unwelcome word, they grew up exploring and crystallising who they really were. Among Panu's friends, there were some who dreamed of wearing long hair and makeup so as to become women; some who yearned to acquire a ripped six-pack; and some who were undecided about their gender identities. Later, 'kathoey' and 'gay' were their specifically given names or the way they perceived themselves. Panu witnessed the genders in his group diversifying like the branches of a tree. Despite the differences, they, like others, were essentially on their journey of life, hoping for a successful career and finding love.

After finishing school, Panu's gang grew apart. Here they are in a restaurant, putting on Santa hats after being seated. One of them brought a camera and took Polaroid pictures, rotating the mouth-watering dishes for the best photogenic angles and holding their favourite fruit beers. Panu looked into their eyes, witnessing with glee the physical and mental changes they were going through. While waiting for the pictures to emerge, they spoke of the same topics: jobs, love, life, and other members of the gang.

When with them - the student gang, the TGIF group, and his gay friends - Panu showed his quiet and polite persona, in the same way as he had done at church. However, he also allowed himself to share his other sides: he showed himself as lively, amusing, diligent, and gay. He opened himself and felt accepted and loved in return.

These recollections from 2010 to 2014 were significant examples that he would carry through life, making Christmas time a special occasion of togetherness and celebration. This line from Pose's main character in the Christmas party would fit beautifully: 'The men will come and go, but we [family and friends] are always here for you' (Pose, 2018). He considered himself the black lamb, but at Christmas, this black lamb experienced companionship and love.

\section{Christmastime in 2017}

He had been working as a lecturer - his first job. Earning income was symbolic of maturity which seemed to bring on a splurge, tempered by the need 
to make ends meet. With his extra savings, he intended to buy gifts for his mother and sister. Two silver bracelets, with a white primrose charm on the first and a blue star charm on the second, were meticulously matched with their skin tones. He did not choose these for his father, who was not a fan of jewellery. Planning to surprise them with these gifts at the resort where members of both families spent the night together, he hid the gifts in his suitcase. When they were opening their boxes, curious to discover what was inside, he was excited too, wondering whether they would like these bracelets.

'Whether they would like it' would consistently echo the question of whether they would love and accept him as who he was. Why? Panu pondered. It could be related to television shows and movies he had watched in what was once a daily assemblage of family members in Thailand. The queer characterisations in Thai movies such as Kungfu Tootsie (2007) or The Last Song (2006), often featured exaggerated outfits, makeup, and body language. These characters embodied effeminacy through their voices and speaking style; they were selected to provide humour or tragedy, as in 'The Last Song', whose principal character ended up with a broken heart followed by self-annihilation (Taweewuttichai, 2016). Whenever these actors popped up, an awkwardly silent atmosphere arose in the room. In this world centred on gender binary and heteronormativity, he wondered whether his parents thought, if their children had deviated from the proper societal and gendered expectations, what it would mean for them. Bad parenting? Or, what else was on their minds while watching those characters?

'Did I disappoint you that I might never get married with a woman or give you grandchildren?' He had not asked them directly, and, despite their rarely spoken concerns after all these years, his parents still supported his education and provided sufficient love. They needed to be financially savvy to raise and support him because Panu's family came from the lower-middle class. He was grateful for their love and dedication and promised himself that he would make them proud of him by being a good person and a diligent student. Diligence and excellence in education, he believed, was the key to success in life. To be a lecturer at one of Thailand's renowned universities, therefore, was his passionately desired and achieved goal. It was time for him to play a part in supporting his family and to occasionally purchase something they had never dreamed of, like these Christmas gifts.

As the gift boxes disclosed what lay inside, surprised faces beamed with delight. Witnessing their joy, he grinned. Beneath Panu's broad smile was a hope. His lifetime achievements - membership in a respected profession and the ability to help his family, as symbolised by the bracelets - could manifest itself in their perception that their own son, whatever gender he might be, could make them proud and happy. From the black lamb, this Christmas he considered himself as the black sheep, living and taking care of his family, hoping to make them accept and be proud of him. 


\section{Back to Christmastime in 2019}

Finally, Panu chose a gift set for his mother. 'Mom would like it', he thought, watching the sales assistant skilfully wrap his present. His mother had a major role to play in celebrating Buddhism's religious days. Occasionally offering food to the monks, making a libation, and carrying a candle around the statue of the Buddha were practices that made him feel fortunate to be growing up in a bi-religious household.

Theravāda Buddhist practice has long been circulating in and permeating Thai society. Its central theory of karma (Keyes, 1983) is stated simply in Thai, as: 'Tham di dai di; tham chua dai chua' ('Do good, receive good; do evil, receive evil'). In popular Thai culture, karmic theory could explain physical and social differences among humans. For example, some people are rich or poor, attractive, or unattractive as the result of their acts in previous existences. We believe the karma accumulated in the present life can potentially determine the quality of the rebirth that follows.

Panu could not fathom what karma or what things he had done in past lives that had brought him into this current world as a gay person. Curiously, he searched in Vinaya Pitaka, the Buddhist scripture, and found that genders are not just male and female but include two others: ubhatobyanjanaka and pandaka (Jackson, 1996). Ubhatobyanjanaka is interpreted and described as the combination of male and female biological characteristics, and pandaka is described as a man who does oral sex with another man and gains sexual arousal and satisfaction from it. These two terms can be understood partially as referring to homosexual behaviour, showing that gender is not limited to binary categories but is diverse, like Phet tee saam. Meaning 'the third sex/gender', this broad and diverse term in Thai culture is used to encapsulate being gay, kathoey, lesbian (tom \& dii), bisexual, or transgender.

Now he was outside Jenners, a Renaissance building in Edinburgh, pondering whose presents were still missing. His academic pursuits had brought him to that city. On Princes Street, he walked back to TK Maxx, intending to buy Calvin Klein's low-rise trunks for his two gay companions from Catholic school. His editor, Edgar, later enquired, 'Why did you choose these particular gifts for your friends?'.

Some gay people might buy small, light underwear that was nearly transparent when wanting to reveal their bodies (Cole, 2000). But for Panu, giving underwear symbolised close, trusting friendships in the same way as his girlfriends purchased sexy lingerie for their besties.

While striding along Princes Street, the grandest street where the gardens now turned into a vibrant market, Panu was thinking 'Is there a Christmas market like this in Bangkok?' In Thailand, Christmas is interlinked tightly with the New Year as the entrance to the year's long holiday. It is a special time to go shopping and dining with friends or lovers and to return home to their loved ones on New Year's Eve (see Figure 3.1). 


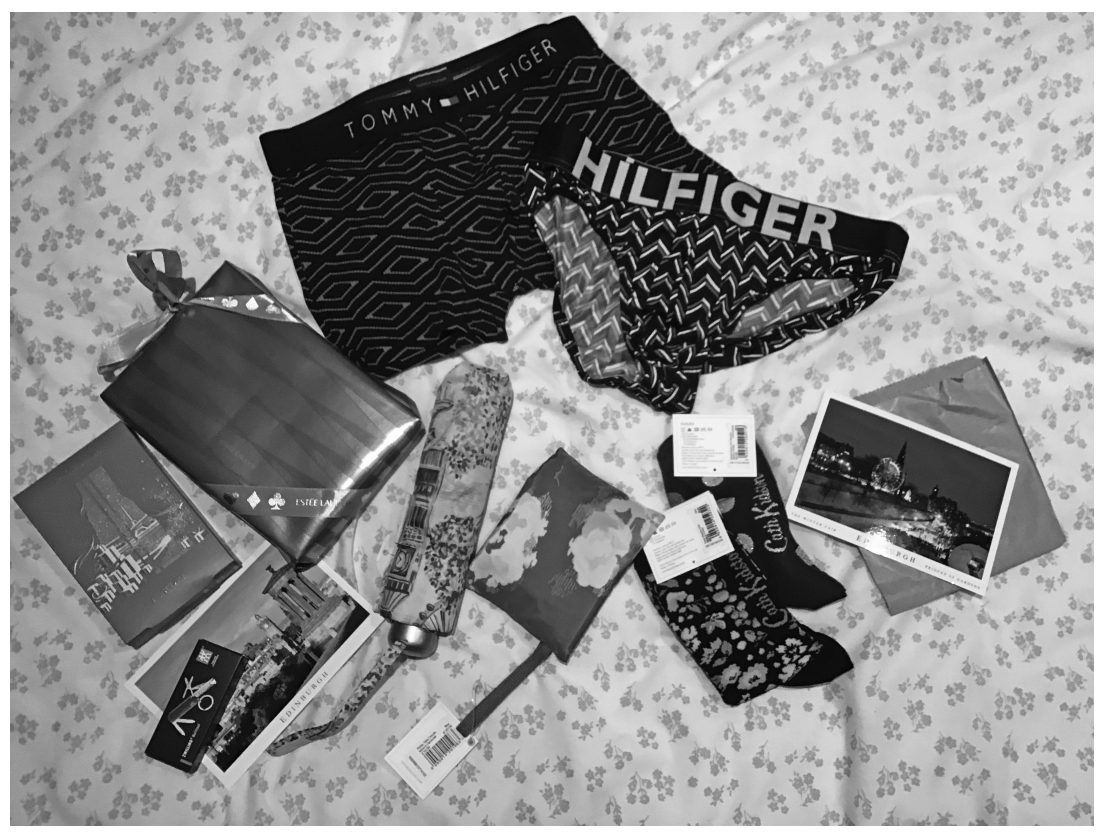

Figure 3.1 Underwear for friends

Despite the long distance, he continued sending Christmas gifts. Luckily, one of his close friends would come to the UK and promised to deliver these gifts to others in Bangkok. That was why he was here in his eventual destination, having a rummage through the undergarments. He ended up with an acceptable second choice, Tommy Hilfiger. He looked inside his shopping bags, smiling knowingly. All these gifts would symbolise his love and nostalgic feeling for those people who were like the threads of love woven through his life. Christmas, his all-time favourite festival, is the time to reminisce about his grandmother; to value his friendships that were respectful regardless of gender differences; to become an adult capable of supporting his parents. Still, be might not fully answer the question of why God created him as a black sheep/gay, but throughout this paper and his everyday life, he was never truly alone.

\section{Christmastime in 2020}

To end this paper, Panu asked: What would Christmas in 2020 be like since the world is still facing the COVID-19 pandemic? There were two issues, however, arising in Panu's mind after editing his chapter. One author, Cináed Thomas, wrote a chapter called 'Sunday: An intimate self-dialogue 
about loneliness' (this volume). His line 'Even within the intimacy of a family Christmas when growing up, I felt lonely' portrayed the loneliness of middle-aged gay people. In addition, during the time Panu was drafting his chapter, the draft Civil Partnership Bill was initially approved in Thailand, recognising same-sex partnerships and providing some significant rights, such as child adoption and inheritance claims (Regan and Olarn, 2020).

Thomas's quote about Christmas raised Panu's concern about the sense of permanency of supportive relationships. After he flew to Edinburgh, one of the TGIF girls got married. Eventually, the baby showers or the upcoming weddings would queue up. His parents and he would inevitably age. As a result, the time of joy for him in the Christmas celebration would inevitably change. Also, the civil partnership draft, though not considered equal to marriage and still in the process of ratification, could be a significant development for Thai Phet tee saam people, affecting their lives and Panu himself.

The future, like the blank pages waiting to be written, was unknowable. He would not know how his perception of himself and relationships with others would change. The same is true of autoethnographic work, which is resistant to closure and finality because social life, identity, and relationships are not static but fluid and open-ended (Anderson and Glass-Coffin, 2013).

'You never know what will come first, tomorrow or the next life': indeed, even the next Christmas. His mother's words were distasteful to him but undeniably true. Possibly, the only time people have is this moment; to go on and cherish with our own threads of love ...

\section{Black sheep is existing}

Christmas is arriving

Love \& support is surrounding

Time is fleeting...

\section{Making sense of this experience}

This 'making sense' section is the most challenging part of writing my chapter. I am left wondering what the essence of my piece is. You, the reader, may have noticed I, Panu, wrote the first section in the third person. Doing so was intentional: I wanted to create a space for the unknown or the psychic distance for readers (Wyatt, 2006), and I thought it would be useful to see this narrative of myself in the third voice. Now, I use the first person to be in closer contact with you.

Throughout my chapter, the black lamb (and later the black sheep - Gae Dam) is the backbone about which I depict sexual and gender identities my identity. It is the metaphorical symbol I give to my gayness, that is, my being part of the Phet tee saam world. In Western countries, the definition of gender and sexual identities (e.g., homosexual, heterosexual, and bisexual) 
are constructed differently than they are in Thailand, where the cultural, traditional, and local discourse should be acknowledged. Therefore, echoing Storer (1999), I too argue against 'the uncritical application of Western paradigms to the study of Thai sexuality' (p.142).

Being gay, in my understanding, is not only the sexual attraction to someone of the same gender, but it also includes a sense of identity characterised by what I consider masculine and feminine characteristics. I am not just a man - Phuuchai - or a woman - Phuuying - but Phet tee saam. Maybe, for me, being born Phet tee saam is common. However, the binary gender identities of male and female somehow have tainted these genders away from who I really was. Being outside of the gender norm, I was afraid of being rejected or hurt by family members. Or in school, I might experience harassment or mockery from schoolmates and question the longevity or permanence of true love.

As I moved from childhood to the University of Edinburgh, the reader can also witness the gradual change from the lamb to the sheep, the mature one. The maturity I portray here is an achievement in life through an academic career, which could be one way for the black sheep to alleviate the inferior feeling inside, to nourish his life with some esteem, and secure his place in the heteronormative world. The sense of self, especially for Thai people, is closely related with the adoration of family members. As I write about becoming an adult - that is becoming a sheep - with some success in life, therefore, might make me - as a Thai gay man - prouder, accepted, and loved in my identities. Maybe this is when the internalised black sheep found his internal flock.

Christmas scenes meticulously interweave throughout Panu's story. The Christmas in the church is the birthplace of my internalised black sheep. Here I felt the shame and inferiority that would haunt me for Christmases to come. But more importantly, I portrayed Christmas as evidence that gay, Phet tee saam people can love, find companions, friends, or someone who loves us regardless of what gender we identify with. This festival of joy and love for Christians reminds us - me - of the flocks of support we - I - have. Research from Fingerhut (2018) corroborated that receiving support, especially from friends, statistically predicted and related negatively with depression in gay people. So, I, Panu, and the Phet tee saam, black sheep people about whom I think about, are never alone because we can search for our own flock, which might consist of diverse metaphorical animals (e.g., black or white sheep or any type of animal). We can find our own sanctuary - a Phet tee saam flock.

Finally, Christmas is a repeated annual festival, giving each year fresh memories to cherish and celebrate with friends and family. Still, the implicit message is that change is inevitable. Life for many gay, black sheep - indeed for many in this world - can be transient. They can be here today and gone tomorrow. Living in the here and now and spending life in every moment as best and meaningfully as we - I - can probably be the ultimate contribution of my chapter. Merry Christmas, everyone! 


\section{References}

Anderson, L. and Glass-Coffin, B. (2013) 'I learn by going: Autoethnography modes of inquiry', in Jones, S. H., Adams, T. E., and Ellis, C. (eds.) Handbook of autoethnography. New York: Left Coast Press, pp. 57-83.

Cole, S. (2000) 'Down to basics: Swimwear und underwear', in Eicher, J. B. (ed.) Don, we now our gay apparel': Gay men's dress in the twentieth century. Oxford: Berg, pp. 131-40.

Fingerhut, A. W. (2018) 'The role of social support and gay identity in the stress processes of a sample of a simple of Caucasian gay men', Psychology of Sexual Orientation and Gender Diversity, 5(3), 294-302.

'Giving and receiving' (2018) Pose, Series 1, episode 3. Directed by Nelson Cragg. Written by Ryan Murphy, Brad Falchuk, and Steven Canals. FX, 17 June 2018.

Jackson, P. A. (1996) 'Non-normative sex/gender categories in the Theravada Buddhist scriptures', Australian Humanities Review. Available at: http://www .australia nhuma nitie sreview.org/archive/Issue-April-1996/Jacksonref.html (Accessed 29 July 2020).

Keyes, C. F. (1983) 'Merit-transference in the kammic theory of popular Theravada Buddhism', in Keyes, C. F. and Daniel, E. V. (eds.) Karma: An anthropological inquiry. Berkeley: University of California Press, pp. 261-86.

Kung Foo Tootsie (2007) Directed by Jaturong Mokjok [Film]. Bangkok: GTH.

Regan, H. and Olarn, K. (2020) 'Thailand could become the first Southeast Asian country to legalize same-sex civil partnerships', CNN, 9 July. Available at: https:/ /edition.cnn.com/2020/07/09/asia/thailand-same-sex-union-bill-intl-hnk/index.h tml (Accessed 12 August 2020).

Rodriguez, E. (2016) 'There's more to being gay than anal penetration'. Available at: https://www.opendemocracy.net/en/transformation/theres-more-to-being-gay -than-anal-penetration/ (Accessed: 11 August 2020).

Storer, G. (1999) 'Rehearsing gender and sexuality in modern Thailand: Masculinity and male-male sex behaviours', Journal of Gay \& Lesbian Social Services, 9(23), 141-59.

Taweewuttichai, P. (2016) The representation of kathoey characters in Thai commercial films. M.A. Thesis. Assumption University.

The Last Song (2006) Directed by Pisan Akaraseranee [Film]. Bangkok: Sahamongkolfilm.

Wyatt, J. (2006) 'Psychic distance, consent, and other ethical issues: Reflections on the writing of “A Gentle Going?', Qualitative Inquiry, 12, 813-18. 


\title{
4 Sunday
}

\section{An intimate self-dialogue about loneliness}

\author{
Cináed Thomas
}

Hate it when the only friend I have that does a few things with me, makes me feel like Sunday leftovers. \#lonely \#bored \#depressed \#gay

Anonymised Twitter User

Cináed: I dread Sundays. They are the days when I feel the loneliest. As I lie in my bed on a Sunday morning, I hear the screams and laughter of family life outside, and I wonder what noises my home would make if it were filled with family. I ask myself why those families want to be together and why I am not with mine. On Sundays, as I wander to the kitchen and pour milk onto a bowl of cereal, I fantasise about homemade muesli and freshly squeezed orange juice; that's the breakfast I see Jamie Oliver prepare on TV whilst surrounded by his many children. Friends are always encouraging me to make my fantasy breakfast. Often, they are mothers who live in homes like Jamie's, filled with the noise of family life: people who struggle after a couple of hours of solitude, let alone a whole weekend. However, as my mum says, 'What's the point of cooking for one?'

Sundays have a tempo unlike that of any other day of the week. Sunday time moves more slowly. Minutes turn into hours, and hours become tortuous stretches of solitude, almost as if time itself struggled just as much as I do to pull itself along from dawn to dusk. On Sundays, time is my torturer, dangling its existential sword cruelly above my soul. They are the days of the week when the mobile phone pings the least. On Sundays, hardly anyone messages me. I'll often wait all day for the mobile to show signs of life. On Sundays, the excitement of a numbered red dot appearing on the screen cannot be overestimated. But when the hours go by and no red dots appear, the loneliness I experience can be crippling. On Sundays, time tries to break me, but I hold on to the idea that, one day, Sundays will be full of pleasure rather than pain. When you experience life alone, Sundays are hell.

Sometimes I prostitute myself online: not for sex, but for conversation to fill the emptiness left by the people who I feel have abandoned me. I'll message a guy on Grindr multiple times who I know isn't 
interested in me and provoke him into maintaining a chat. Sometimes I'll ask questions, too many questions, to keep him chatting for as long as I can. I know who I am, what I have become. As one Twitter post said, 'Please, God, let me find love before the age of 30, so I'm not a creepy, lonely old man on Grindr'. He isn't alone; another post reads, 'my biggest fear in life is not finding a husband and becoming one of those lonely 40-something-year-old men who spend their time harassing twinks on Grindr'. No wonder I find it hard to look in a mirror. Some want to see 'body pics', but I can't show them because I have the average body of someone in their mid-forties. As Shield ${ }^{1}$ writes, 'By centring on the user photo, Grindr's interface hyper-valuates visual self-presentations'. So, within Grindr, there's nowhere to hide. It's different for my straight friends or my gay friends in long-term relationships. They don't worry about having a flabby belly, or having to keep themselves toned like I do. Sometimes I get blocked, because they find me too persistent. Gay men can be cruel. They can inflict the same degree of emotional pain as any straight person. As one Twitter user said, 'Is there a rule in NYC that says all \#gay men must not be seen in public on Sundays until afternoon? I'm \#lonely'. Maybe that's why we are experts at spurning those who repel us. Occasionally, I'll introduce long, artificial pauses to make myself appear busy. After all, what 'normal' person would be on Grindr on a Sunday morning? In 2014, Grindr claimed, 'nearly 10 million users in over 192 countries' of whom over two million were 'daily active users' (Grindr, 2014); by 2017, Grindr reported that its three million daily active users averaged about an hour a day on the platform (cited in Shield, 2018). ${ }^{2}$ I wonder how many of those men are looking at their screens, like me, longing for a connection. Three million is a big number, but despite the enormity of the statistic, I am alone. At a time of my life when all I want is to eat a family-type Sunday roast dinner surrounded by loved ones, I still have to keep myself sexually attractive to other men. In the gay world, being in my mid-40s makes me the equivalent of a cow put out to pasture. I'm over the hill - a desexualised pensioner. Being middle-aged and gay only adds to my loneliness.

C: Have you always felt lonely?

Cináed: Probably. Even within the intimacy of a family Christmas when growing up, I felt lonely. Christmas cards depicting heteronormative family life lay strewn across my mother's sideboard. Even the television showed straight, newlywed couples buying furniture in the New Year sales. Occasionally, I am asked whether I have a 'special friend', but that's it. For the rest of Christmas, my gayness remains unspoken.

1 A. Shield. 2018. Grindr culture: Intersectional and socio-sexual. Ephemera, 18(1), 149-161.

2 Ibid., p. 150, 2018. 
Hence, tucking into Christmas dinner surrounded by my parents, my brother, and his family, my loneliness makes me feel like an outsider in the only home I know. Even amid 'family', I've always felt the odd one out. And somehow, the common wisdom of the 'families of choice"3 doesn't feel so comforting, I still find, as many other gay men $\mathrm{do}^{4} \mathrm{my}$ family of origin pulls heavily on my fibres of being; what they do affects me, probably more than I would like to admit.

I feel ashamed to admit that I feel lonely. It's yet another coming out, in a lifetime of coming-outs. I'm worried I'll be judged as a failure, as someone to avoid. Anybody glancing at my life would not necessarily see loneliness. I have friends and a family forged from blood. However, over time they have found others, predominantly spouses, who fill the space once occupied by our friendship. Some have children and others have busy work lives, but one by one, they have abandoned me. Time spent with me has fallen into the cracks of life's pavement. Text messages aren't replied to, or a birthday card stops arriving. I'm no longer useful or as relevant as I once was. No longer do they need a wingman to distract them during their free time, or someone to listen to their troubles. I am the toy everyone picked up and played with when the noise of family was missing and then dropped when it was there again. I have served my purpose, and now I am alone.

I've never felt that I fitted in: not with family, friends, or even within 'gay culture'. People often assume that if I were in a relationship, then my persistent loneliness would evaporate. However, the emptiness I feel is not partner-shaped. I don't know what would fill the void I have inside me, but the loneliness I refer to isn't about having an empty bed. It's subtler than that. I am part of a family held together by genes but have never created one based on love alone. I know my writing will break my mother's heart. But my persistent feelings of loneliness are not a result of anything she or anyone else in my family has done. The best word to describe it is 'aphasic'. I have always felt out of sync with everybody else. I've never felt I belonged to anything or anywhere and being gay feels like a large part of that.

$C$ : Why are you writing about it now?

Cináed: I feel lonelier than I have for a long time, and I know I am not the only gay man who feels this way. There are others too. I spoke to one guy on Grindr who hadn't left his bed all weekend. And there's the friend who speaks of the crucifying heartache he puts himself through when decorating his Christmas tree. The simple act of placing baubles on every

3 J. Weeks, B. Heaphy, and C. Donovan, eds. 2001. Same sex intimacies: Families of choice and other life experiments. London: Routledge.

4 A. Ocobock. 2013. The power and limits of marriage: Married gay men's family relationships. Journal of Marriage and Family, 75(1), 191-205. 
branch kills him a little inside. He's tried different tactics over the years to make it less of an ordeal. He's bought expensive ornaments and invited friends over for mulled wine, but nothing has worked. You see, even if we make these events full of laughter, inevitably everyone leaves. So many men in empty houses looking at Christmas trees decorated with a home in mind. I know of others, many in their 40s and 50s, who are gregarious and well-connected, some who even have partners. However, we all seem to share that innate sense of never finding others willing to walk alongside us in life, people who vibrate at the same frequency. I read an article on middle-aged gay men and loneliness, and I found myself disheartened, as if they were writing about me, 'Given the heterosexist, homophobic, and ageist attitudes that render some midlife and older gay and bisexual men vulnerable to feel sexually undesirable and invisible, and that gay men lack external resources available to heterosexual men, it could logically be expected that these factors would have an influence on the loneliness of gay and bisexual men over $40,{ }^{5}$ It seems we all harbour a lingering loneliness that walks alongside us in our everyday lives.

What's made matters worse is that I've lost six or so elderly relatives to cancer in as many years, and I have four more who are terminally ill. The only family I have known is fading away. Watching them endure years of sickening chemotherapy is weighing on my mind. What will happen if I get cancer? Who will be there to nurse me? My godchildren and nephews have their own lives. I cannot impose on them. I don't want to die alone, but it's increasingly likely to happen.

Most recently, I lost an uncle whose beloved wife had died some years earlier. He was utterly lost without her. After her death, life drained from his soul. To hear my mother tell stories of him struggling to cook tinned food in the microwave, or of spending his days riding the bus and eating alone in the cafés he frequented with my aunt, broke my heart. For the first time in his life, at 82 , he was alone and with no understanding of how to look after himself. He was the embodiment of a broken man.

Within a year of his wife's death, he developed cancer, first in his bowel and later in his bones. Limping and struggling to get the morphine down, he told me he regretted not having a daughter to look after him and that all he wanted was to die. That was the last time I spoke to him. A few weeks later, he was dead. Unbeknownst to everybody, he had refused life-extending treatment, seemingly because he didn't see the point of prolonging his agony. At his funeral, I recall conversations about how wise his decision was to withhold radiotherapy because, as one relative said, 'He had no family to live for'. That statement stabbed

5 R.J. Jacobs and M.N. Kane. 2012. Correlates of loneliness in midlife and older gay and bisexual men. Journal of Gay \& Lesbian Social Services, 24(1), 40-61. 
me to my core. Does that mean I don't have a family? If it does, then my life is meaningless.

C: Fuck, Cináed, that sounds heavy.

Cináed: I've concluded that if I get cancer, I will refuse treatment. What's the point? Why would I put myself through that? If I don't have kids who need to see me grow old or a partner who needs me, I'm not putting myself through months of nausea and deteriorating health. I saw aunts and uncles wither away because of gruelling chemotherapy. They became living skeletons, trapped in makeshift downstairs bedrooms and nursed by their children. I can't become a burden because I have no one to look after me, which concerns me to the extent that I've become paranoid about falling ill. I eat healthily, I exercise, and I have the flu jab every year. I cannot fail. I've had times when I've lain on my bathroom floor ill from food poisoning. The fear of choking on one's vomit while being alone is terrifying. If you've always had intimate others in your life, someone you can shout out for in times of desperation, I don't think you can comprehend these moments. So much of everyday life centres on family. I know the term can be problematised, and that families come in different shapes and sizes, but when you are lying on the bathroom floor choking, that debate is terrifyingly distant.

C: I'm worried about you.

Cináed: There's no need. I've never felt any different. I've always felt lonely. Of course, we typically associate loneliness with being old, but there is an inherent heteronormativity within that belief. It assumes that a man will marry a woman and that they will have a family, which will stave off any feelings of isolation. I am one of the gay men of Generation X - men squeezed between illegality and gay liberation. We are the men who grew up just before the tsunami that was the Internet took hold of our lives and drowned them in a sea of chat rooms and dating apps. It was a wave of freedom and of connection that came after we had internalised the shame and fear of our parents' generation. We are the boys who grew up being told that gay sex infects and kills. We are the sons whose only gay role models were 'poofters' on TV or men banished from our communities.

Now we are expected to be in healthy relationships and to have worked through the trauma that dogged our childhoods. How can I be in a long-term intimate relationship when it wasn't modelled as a child? How can I be vulnerable and truthful in adulthood when those things could have killed me as a child? A therapist told me that I should get a dog, as it would help me to have a sense of what it's like to be in a relationship. But the commitment frightens me. How can a dog love me unconditionally if a partner never has? How the hell can I expect a dog to come back to me and want to be with me when no human ever has? All I knew as a gay boy was loneliness and isolation. It's natural to me; I'm accustomed to it. But now that I am old, what kept me safe 
has become my enemy. Unless I do something about it, and I'm not sure what that is, then loneliness will kill me. Of that I am sure.

C: How old are you?

Cináed: I'm 42.

C: You sound like an old man; like one of those elderly people who have stopped cooking with fresh ingredients and turned to microwaving ready meals.

Cináed: Only recently have I realised that midlife existence resembles that of a pensioner. I feel gay and grey; you might not be familiar to this reference, why would you? I'm talking about Gay and Gray in New York City, a documentary of the often-invisible lives of elderly gay people. They state that 'Gays are ten times more likely not to have someone to turn to for support compared to the general population'. ${ }^{6}$ Maybe it's because my parents are of that age, and coupled with the recent deaths of relatives, I myself have aged. For years, not having a family kept me young. I went to bars and nightclubs long after my straight friends stopped. I worry that if I went on holiday with gay men now it would turn into one of those drink-obsessed, innuendo-filled holidays that I enjoyed (or should that be endured) up to a few years ago. I just want a holiday during which I can relax. I am one of those old ladies my mother knows, whose husbands have died and who find themselves solo travellers on a coach trip somewhere nice, not too far away, and with other widows.

Being gay and lonely is killing me. Some days when I don't see anyone else, I only walk 200 steps. I've gone from being young to being old. My sofa has a sag in the middle where I've sat for too long. My grandfather's chair had the same sag. I often sit there sipping a coffee, like an old man susceptible to bedsores, suffocating in a silence that takes away whatever optimism I had. The slump breaks my heart and makes my back ache. Even my furniture has moulded itself to my solitude. Sometimes I forget I haven't done the washing up, and I go to the kitchen where the dirty plates are still piled up at the side of the sink, and I want to weep. Living alone is tough; minor tasks become difficult when you haven't got somebody to help you. A folded fitted sheet is never as neat as when somebody helps you fold it. Everything is always just good enough. Maybe the slightly dishevelled, good enough nature of the folded sheet is a metaphor for my life. Living alone, nothing moves unless I move it. A bottle of shampoo drags on for months, and the first voice I hear on a morning is the DJ on the radio.

Sometimes I feel helpless, lost. I worry that there is a stench of loneliness about me, a flatness, a sense of decay. I worry people can smell my

6 N. Chesla, C. Creager, and J. Englander. 1999. Gay and Gray in New York City. Film. 22 min. Distributed by Fanlight Productions, Boston, MA. 
loneliness. I know they can't, but I worry I give off an odour. Loneliness means life becomes stagnant. If I haven't spoken to someone for a few days, my voice becomes frail and my jaw aches when I speak. It's funny; actually, it's not funny at all, that the muscles in my mouth weaken in such a short time. Now I know why some old people talk that way. I don't spend Sunday mornings watching kids play football or preparing a family-sized Sunday dinner.

C: I wonder how many men feel the same. Surely, you're not the only one.

Cináed: Too many elderly gay men are in the same situation. ${ }^{7}$ However, many men of my own age might feel the same. On Sundays, Twitter is full of muscular bearded men enjoying each other's company while smiling into the lens of a mobile phone camera. However, there are also photos of others lying in bed, clearly using social media to fill the emptiness that Sundays evoke. I know of one man who has spent years living by himself, to the extent that he finds terrifying the thought of somebody else entering his flat. Just the other day I met a man who hadn't left his flat for four days, and although he was clearly depressed, I couldn't bring myself to admit feeling precisely the same way. Last Sunday I was chatting to a guy on Grindr whom I had previously met for a coffee, who described Sundays as the 'dullest day of the week'. To meet him you would think he was the life and soul of the party, full of stories of his past adventures. He's even got a boyfriend. Yet he, too, found Sundays a painful reminder of the loneliness many of us gay men have lived with all our lives. Grindr is busy on Sundays. So many of us turn to strangers online for our first connection with humanity in the morning. Emotionally, we want to feel part of something: a family, a community; and I do this by lying in bed staring at my phone. I dread Sundays. They are the cruel reminder that, for many gay men, our battles are not yet won.

$* * *$

\section{A painful making sense of a painful experience}

I wish you hadn't read this about me. Loneliness is yet another thing about which I feel ashamed. And in sharing a somewhat depressing text, I feel embarrassed. But it feels important to tell you what goes on in what Edgar writes about in the introductory chapter: my personal space, my home. A sometimes brutal, non-scripted intersection of identity, place, and space for which narratives both grand and personal have yet to be created.

7 S. McLaren. 2016. The relationship between living alone and depressive symptoms among older gay men: The moderating role of sense of belonging with gay friends. International Psychogeriatrics, 28(11), 1895-1901. 
I've seen the faces and read the responses of those who have read the selfdialogue you have just read. I see the pity in their eyes and in their words. And while I appreciate the offers of getting together, a new self-aware part of me does not want to expose myself to the emotionally rich everyday experiences that I crave. Call it self-care. What I seek, something I can articulate more succinctly through writing this chapter, is an ease of companionship that Esther Rantzen (a UK campaigner and widow) exquisitely captured when she said loneliness is like having people to do something with, but no one to do nothing with. ${ }^{8}$

It's taken a lot to write this chapter, more than you know. We know loneliness kills, it's equivalent to smoking 15 cigarettes a day. ${ }^{9}$ So, while no one is holding a cigarette to my mouth, one manufactured by a cultural vacuum hangs from my lips. My gayness is literally killing me. There are no stories about single gay men enjoying Sundays that I can follow. I am adrift without meaning. Without scripts, I move my body less and I eat what I put in the fridge. What, I have agency you say? Why don't I go out for a Sunday walk and treat myself to a roast dinner, you ask? Because nobody has told me I can. Someone once said I had an underdeveloped sense of entitlement, but I now realise I've never known what I am entitled to. Others haven't known what to do with me. I've fallen in between the cracks of the grand narratives Edgar and Jason write about in the introductory chapter and it fucking hurts. In fact, the fact that I was raised without stories about others like me will directly or indirectly lead to my death. The musculoskeletal and physiological consequences of living without a script are emerging. Only now, in my early forties, am I realising how much my everyday life has(n't) been shaped by stories about others like me. Every day is hard when there is no script to follow. I am an actor on the side of life's stage waiting for his lines. Others have their scripts; they know their roles. But they or the directors in my life haven't got a script for me, and now I am paying the price. Every Sunday, every day.

8 E. Rantzen. 2021. 'Nobody to do nothing with.' Combating loneliness. [online] Social Care Institute for Excellence (SCIE). Available at: <https://www.scie.org.uk/news/opinions/estherrantzen-silverline> [Accessed 22 January 2021].

9 J. Holt-Lunstad, T. B. Smith, M. Baker, T. Harris, and D. Stephenson. 2015. Loneliness and social isolation as risk factors for mortality: A meta-analytic review. Perspectives on Psychological Science, 10(2), 227-237. 


\title{
5 On (not) living past 30
}

\author{
Tony E. Adams
}

In August 2001, at 22, you began to disidentify as straight and come out as gay. Having repressed same-sex attraction for several years, you began to recognise and embrace its permanence; it wasn't going to disappear, so you had better get used to it. That August, you began dating a cisgender man; the relationship ended in September. In September, you began dating another cisman but stopped in October. In November, you began dating another cisman; that relationship ended in December. The pattern continued for several months.

To complicate the entrance into gayness, you were also, simultaneously, learning about dating, pleasure, and sex. As a product (victim) of extensive Catholic education (ages 5-18), at 22 you still had never had any kind of sex. You didn't know much about sex either. You knew the primary purpose of sex was procreation (not pleasure); marriage was an institution comprised of one cisman and one ciswoman; all methods of birth control (e.g., condoms, pills) were sinful; and penis-vaginal penetrative sex occurring outside of marriage was sinful too. Masturbation was sinful as well - one shall not 'waste his seed'; you didn't learn how to masturbate until November 2001, at 22, with boyfriend three.

In August 2002, you met Brett, a new student in the same graduate programme. He was 26; you, 23. He had been out - had claimed and proclaimed his gayness - for nearly a decade; you, merely a year. You felt a strong connection to Brett and began dating within weeks of meeting. Brett quickly became a good gay friend, mentor, and lover who championed your early disclosures of gayness, especially to (former) friends and family, many of whom reacted poorly. Brett also taught you about various histories and controversies of gay life - about intimacy and commitment, marijuana, sex and pleasure, and open relationships - as well as introduced you to the works of Cher, k.d. lang, Susan Sontag, Madonna, Gus Van Sant, and Judy Garland. 
'I'll be dead by 30,' Brett often said, randomly and flippantly. 'Gays are vicious and live for youth. After 30, you won't be wanted or attractive'. ${ }^{1}$

'Nonsense', you'd say, 'age is just a number'. Sometimes, you'd quip further: 'Besides, you already look 30.'

To this, Brett would laugh, roll his eyes, offer a cutting stare or biting remark, and the conversation would end. Until a few weeks later, when he'd make the declaration again.

Although you wouldn't overtly agree with Brett in this remark, you too contributed to such ageist, specifically youthist, discourse. In your 20s, before and after Brett, on your online dating profiles, you described men over 30 as unattractive and undesirable; men over 40 - hell no. None were worthy of your attention; the aged men felt creepy, worn, desperate.

The intimate relationship with Brett ended in December 2003, yet you remained close. You continued to live together until May 2004, when he moved to New York to pursue theatre, and you moved to Tampa to pursue a doctoral programme. In December 2004, you visited Brett in a travelling theatre production at a dinner theatre in Ohio; you spent the night together at a hotel. In February 2005, you met Brett at the Tampa airport; he had a long layover and asked to meet for dinner, drinks, and laughs. You'd speak on the phone every few weeks. You left Brett a voicemail one week before he died.

Brett was born 27 August 1976. He died 28 February 2006, six months before his 30th birthday. His family reported that he died from diabetic shock - not too shocking, as he didn't monitor his blood sugar well. On some low-blood-sugar nights he would roll in bed and wake you accidentally; unconscious and covered in sweat, he wouldn't know where he was or who you were. Alongside diabetes, Brett also had a history of suicide attempts. When he died, two mutual friends reported that he had killed himself after coming out to his father. Neither the diabetes report nor the suicide report was ever confirmed. ${ }^{2}$

Here, now, you think about Brett's 'I'll-be-dead-by-30' prediction. Was his statement a foreshadowing, a plea for help - or merely a sarcastic remark

1 'I remember thinking 30 was an expiration date', Fox writes (2015, p. 239). One of Goltz's (2009) interviewees explained that in “"gay years”, 30 means you are on the way out' (p. 571). Urban Dictionary defines 'gay death' as what happens when 'a gay man turns 30', and one episode of the series Queer as Folk ('Full Circle', Cowen, Lipman \& Chapple, 2001) centred around one of the main gay character's death-themed 30th birthday party. For more comprehensive discussions of gay youthism and aging, see Bergling (2004), Goltz (2009, 2010, 2011), Harley \& Teaster (2016), Ramirez-Valles (2016), and Simpson (2015).

2 See Holman Jones and Adams (2014). 
intended to generate conversation and laughter? Did Brett plan his death - a plan easier to accomplish with suicide, less so via diabetic shock? The answer is a mystery. You only wonder why someone like Brett, a loving and jovial being, had a fear of living too long; why he subscribed to a tainted view of aging and sexuality; how he predicted a death that happened too soon. You also think about what Brett missed having not lived this long, as well as how you ever did.

The more you read and talked with gay others, the more you realised that gay aging wasn't merely an issue of youth and sexual attraction; additional constraints could contribute to a gay man's desire to die by 30 .

Maybe there were tensions with families-of-origin who, initially in life, were understood and idealised as systems of unconditional love and support. Yet, for some men, once they came out as gay, familial love and support turned conditional and disappeared. The men may have been ridiculed, disowned, cast aside ${ }^{3}$; or required to undergo conversion therapy, prayer, and a pledge of celibacy in order to retain membership in the family, continue as a family member; or exposed to more homophobic remarks, or conversely, unsettling silences about their gayness. And so, some gay men ceased contact with hateful families-of-origin. ${ }^{4}$ How might it have felt to lose a primary support system after a mere disclosure of sexuality? (It sucked.)

One of the first phrases I learned as a gay man was 'he's "family". Gay friends used the phrase to reference another's gayness:

'Do you know Tony?' one gay asks.

'Yes, why?' the other gay replies.

'He's "family"', the first gay says.

Family - a term used by some gays in reference to other gays, to determine members of the/our gay family: others to rely on for safety and support when families-of-origin fail. ${ }^{5}$

3 'Of course, heterosexuals can also be disowned', Weston (1991) writes. 'But when straight people encounter rejection by relatives, that rejection arises on a case-by-case basis, generally in response to something done rather than something fundamental to their sense of self. Self-identified lesbians and gay men, in contrast, experience rejection as an ever-present possibility structured by claiming a stigmatised sexual identity' (p. 74).

4 The entirety of Weston's classic book Families We Choose (1991) details processes and nuances of gay kinship and the development of families-of-choice. Weston also observed how a gay child, if they are the first gay in the family, might assume the sole burden of not only introducing gayness to the family, but also having to explain what it means to be gay (while simultaneously learning what gay means themselves). As such, gay men must often venture 'beyond our biological family to find our logical one, the one that actually makes sense for us. We have to, if we are to live without squandering our lives' (Maupin, 2017, p. 2). Metaphorically, 'blood' isn't always 'thicker than water', and all families should be understood as families-of-choice.

5 In The Queen's Vernacular: A Gay Lexicon (1972), Bruce Rodgers defines the gay use of 'family' as a reference to a 'close-knit group bound together by friendship rather than by 
You think about the homophobic and heteronormative religious discourse that permeated (and still permeates) US cultural life. Some religions espoused hateful mantras such as 'Love the sinner, hate the $\sin ^{9} 6$ advocated for heterosexual 'purity pledges'; ${ }^{7}$ only conducted marriages comprised of one cisman and one ciswoman; adhered to rigid cisgender roles and assumptions; praised two-parent families-of-origin (e.g., 'Honor your father and mother'); and promoted conversion therapy - therapy designed to 'cure' (or at least curtail) same-sex sexual activity. Sodomy laws criminalised samesex sexual relations - laws rooted in the biblical tale about the supposed degenerates of Sodom and Gomorrah. And even the most progressive religions advocated heteronormative values, such as monogamy, marriage, and biological reproduction, and simultaneously disavowed variations of (gay) life, such as praising sexual pleasure, refusing to conform to gender roles and expectations, living in open and polyamorous relationships, and choosing to live child-free. ${ }^{8}$

You also think about the lack of cultural narratives about gay life after 30. You knew the post-30 heterosexual scripts and trajectories - be married (or at least pursue relationships with an 'opposite-sexed' cisgender); have a kid ('start a family'); make money; have another kid; celebrate birthdays, graduations, baptisms, and bar/bat mitzvahs; have another kid; get divorced and married again; encourage your kid(s) to get married and have kid(s); attend family reunions; celebrate retirements; spend time with (take care of) grandkids. What do gays (and straights) do if these narratives don't fit??

blood-ties' (p. 79). Although the use of 'family' perpetuates the privileging of familial discourse and bias, your definition of family is very inclusive, e.g., best friends, companion animal relations, polyamorous arrangements. You are fine with celebrating the concept of 'family' as long as the concept is open, inclusive, and able to be defined by those involved.

6 As Arceneaux (2018) writes, 'If you were under the impression that being gay was inherently wrong, you were operating from the frame of mind that $I$ was inherently wrong' (p. 214). Cunningham (2014) makes a similar claim: 'Hate the sin, love the sinner sounds real good if you're on the loving end of that equation, but if you're on the sinner's side of that prayer it feels dehumanizing and condescending' (p. 53).

7 See Harris (2014) and Manning (2015).

8 Harris (2014) demonstrates how even 'progressive' religions, such as the Metropolitan Community Church and United Church of Christ, are intolerant and anti-gay in their advocacy of heteronormative values.

9 Dustin Goltz has written extensively on gay youthism, aging, and time in an attempt to 'counter limited or tragic stories of gay male aging as isolated, miserable, or depressing' (Goltz, 2011, p. xiv). In one article Goltz (2009) asks, 'What does it mean to exist in a space outside of these blueprints and images, to be denied access to the dominant scripts? What if a person peers into the future and envisions loneliness, isolation, and exclusion? How does this affect living today?' (p. 562). In his book, Goltz (2010) writes, 'Heteronormative temporal perfection tells a story of happily ever after: love conquering all, the blessed gift of children, and a guaranteed slice of the [US] American Dream. Monogamous love, marriage, and procreation provide the keys to the kingdom, the honor of respectful sexual citizenship, and identification with a future worth embracing. On the other side, there is punishment and 


\section{Tony E. Adams}

Maybe HIV/AIDS narratives prohibited gays from living, or thinking they would live, past 30; in the 1980s and 1990s, the diagnosis was often a death sentence. There also weren't many hopeful or serious narratives about gay aging; ${ }^{10}$ common gay tales spotlighted loneliness, struggle, missing youth, and they did not attend to other narratives of the future - scripts and trajectories of possibility, brilliant ones that showed how life might be for those who are estranged from family or who refused heteronormativity, monogamy, and/or biological reproduction. How could gay men conceive of the future? ${ }^{11}$ Where did (do) gays go to die?

Complicating all of these factors was a sedimented and systemic ignorance and disdain for gays. ${ }^{12}$ Gayness could affect a person's perceived competence or likability, and some gays - especially those who were out - faced incessant bullying and persecution. Perceived initially as a 'gay disease', HIV/AIDS treatments - and thus particular lives - were neglected for years. Some banned gays from teaching in primary and secondary schools, bans grounded in the homophobic belief that gays were sexual predators who preyed on children. Gay histories and experiences were absent from many archives, educational curricula, and everyday conversation. Gays could have been fired solely for being gay, arrested for committing sodomy, dishonourably discharged from the US military for engaging in same-sex relational acts (e.g., sex, marriage). You traversed this ignorance and disdain with ease to only then come out and into a youth-centric, $30=$ old (and thus nearing death), gay culture. ${ }^{13}$ You knew some straights would treat you as dead for

misery for those who fail to embrace and perform the assumed rightness of heterosexuality or fail to identify with heteronormative structures for future building' (p. 82)

10 Keith Berry writes, 'Until I was in my thirties, well after I came out of the closet, I never thought about myself in terms of a long-term future for which I had to plan. Perhaps this absence stems from the outlook I conveyed above regarding HIV/AIDS, because I did not think I would last to be a senior citizen. Or maybe it's due to the heteronormative model that continues to shape and often govern lived experience in the US today. There is no model of the LGBQ senior, at least not one widely conveyed and explored' (Berry et al., 2020, p. 152).

11 As Ramirez-Valles (2016) argues, the heteronormative 'life trajectory that we perceive as "natural" takes us from birth to schooling, adolescence, job and career, marriage, reproduction, parenthood, maybe divorce, retirement, and death' (p. 39). Queer time is 'lived outside the narrative of birth, schooling, marriage, reproduction, child bearing, and retirement' and is marked by events, such as coming out, HIV, and same-sex relationships (p. 40). For specific discussions of gay orientations to time, see Goltz (2009, 2021), Halberstam (2005), and Muñoz (1999).

12 See McIntosh (1995).

13 Although age, specifically youthism, is the focus of this chapter, age isn't the only identity that can contribute to 'social death' in the gay community. White gay cismen still shun others for their ethnicity, race, ability, size, gender, and/or serostatus, especially men who do not align with insidious White, able-bodied, thin and fit, and/or cisgender expectations for desirability and attractiveness (see Berry et al., 2020; Chuang, 2020; Eguchi and Long, 2019; Riggs, 2018). 
being gay; you didn't know some gays would treat you as dead for living too long.

Maybe 'with ease' is the wrong phrase. You too had a suicide scare in high school - a nervous breakdown of sorts, a desire to quit your desires. You told your parents you didn't feel well and demanded to see a doctor. You wanted some kind of treatment; you felt confused, peculiar, tired; hated yourself; wanted to relax, sleep, die; the unbearable weight of the everyday. ${ }^{14}$ Fearing others might learn of the mental crack, the parents got you a head scan in a nearby town. The memory of these events - a blur; you cannot recall the conversations with doctors, tests or treatments, or how and why, after this incident, you continued to try to live.

Yet, you did. And you're here, now, writing this chapter, feeling something akin to 'survivor's guilt' for living this long, longer than others living through similar conditions, sad to think about what you've done and what they weren't able to do: finish graduate school; feel loved by boyfriends; write; have sex; marry; have more sex; travel; make friends; work; play softball; create a new family. Every day feels extra, and one never knows when extra will end.

You feel privileged to have survived more than a dozen years of Catholic education; the presence and pressures of heteronormativity; burgeoning same-sex attraction; estranged families-of-origin; anti-gay religiosity; limited scripts for gay aging; pervasive disdain and neglect for gay people; a suicide scare. You think about all of the gay men who didn't survive suicide, or sexual violence, or drug abuse, or HIV/AIDS, or Covid-19. You think about those who have aged into old age, seemingly gracefully, yet behind closed doors are closeted and alone, still fearful about exposing their desire; those who were castrated, shocked, lobotomised, or victims of conversion therapy, and those who subsequently killed themselves after trying such blasphemous 'cures' for homosexuality; those killed by anti-gay hate crimes, including the 49 people killed at Pulse, a gay nightclub in Orlando, Florida

14 As queer artist 'artisthought' tweeted, 'I often think about the closet that queer kids grow up in. How it's not just passive hiding, it's traumatizing. To suppress parts of who you are, to experience your own life as an outsider, to hear the people you love hate people like you, is a trauma you carry your whole life' (20 July 2020). 


\section{Tony E. Adams}

(2016); and those who never had access to appropriate and sustained medical care, or, if they did, were forced to entrust homophobic and transphobic doctors with their lives. ${ }^{15}$ You think about all of the coming-outs that didn't happen, the pleasures cut too soon, the experiences of being proudly gay and loved for it.

Here, now, life does feel better - or rather, different. Pro-gay stories have increased in the last decade; youth seem to come out younger; gays have increased legal protections; and there are social privileges to being gay. ${ }^{16} \mathrm{But}$ still, something's off: According to the Trevor Project's 2020 U.S. National Survey on LGBTQ Youth Mental Health, 40\% of LGBTQ respondents (aged 13-24) 'seriously considered attempting suicide in the past twelve months'; $48 \%$ reported 'engaging in self-harm in the past twelve months'; $10 \%$ had undergone conversion therapy; and 29\% had experienced 'homelessness, been kicked out, or run away'. Several LGBTQ youths questioned their worth, and you wonder if living too long feels unattainable, less than ideal.

Here, now, writing as a 41-year-old gay cisman, you think about Brett's comment about dying by 30, and, more generally, about aging as a gay man. You've lived more than a decade longer than Brett. You'd tell him that your 30 s were fun and your 40s have been okay so far; that your attraction to others, and their attraction to you, didn't end - it merely changed, shifted with age; and you've become a 'daddy', a mentor of sorts, to younger gay men. You'd tell Brett about how your local gay bar hosts nights celebrating 'silver foxes' and 'DILFs' (Daddies I'd Like to Fuck) and other events for 'men over 35 and the men who love them' - all indicative of a growing zeitgeist of acceptance and support for aging gays. You'd tell Brett about your neighbours, a gay male couple in their 50s and 60s; your chosen parents; and your beautiful partner of $12+$ years. (You'd even share that, for more than half of these years together, you've lived openly non-monogamous. Brett, you imagine, would judge you, slyly and sarcastically, for once judging him for refusing monogamy.)

You'd tell Brett about iPhones and Facebook, Twitter and hashtags, sexting and selfies, Tinder and Grindr. He'd be excited to see Judy (the Judy Garland biopic), Rocket Man (the Elton John biopic), and maybe even Mamma Mia (1, not 2). He would mourn Carrie Fisher and George

15 See Raimondi (2020).

16 In 'Things I Don't Have to Do' (Chapter 5) of Living Sexuality, Keith Berry describes practices he no longer has to do as a gay man. For example, gayness allows him to do gender differently and avoid heteronormative relational scripts (e.g., asking for a 'partner's father's "hand" in marriage'; Berry et al., 2020, p. 46). 
Michael, enjoy the Tiger King, and love Lady Gaga and Taylor Swift. Even though you went to Cher's 'Farewell' tour together in 2003, you'd tell him that Cher hasn't said farewell yet; she began her 'Here We Go Again' tour in 2018.

You'd tell Brett about US legal victories in support of same-sex relationships - marriage equality, employment nondiscrimination, bans on conversion therapy - as well as the things he would still have to do as a gay man: dwell in the psychic space of being prepared to lose these victories; deal with the continued presence of a mono- and heteronormative society; be concerned about his safety. ${ }^{17}$ And although churches and states are supposed to stay separate, national debates ensue about whether 'religious freedom' grants religious organisations the right to discriminate against gay employees and customers or if the rights of gay employees and customers precede religious freedom.

You'd tell Brett that you do worry about the future - the medical care you'll need, who will care for you should you fall ill, whether you have lived a well-lived life. You have been out for nearly two decades, but relational rifts continue to plague the relationships with your family-of-origin; and although you feel loved by your partner's family, should something happen to him, you wouldn't expect them to care for you. You've developed a sizable chosen family, and you'd tell Brett about your gay Covid-19 quarantine group who spends many Fridays together, a group who frequently references the idea of 'Fruit Acres', an imagined, utopian gay senior living community. The friends' mention of Fruit Acres suggests a desire to plan for aging, something reminiscent of The Golden Girls, a desire to be campy and gay together later in life. ${ }^{18}$ You worry about having to reconnect with your family-of-origin out of a need for care, ${ }^{19}$ or ever having to move into a non-gay assisted living facility, as you imagine living and dying among similarly aged peers who may still carry the homophobic residue of their (your)

17 As mentioned in 'Things I Don't Have to Do' (Chapter 5) of Living Sexuality, Keith Berry describes practices he no longer has to do as a gay man. Conversely, in 'Things I Must Still Do' (Chapter 15), Berry describes practices he must still do as a gay man, such as hide and tone down his sexuality, as well as dwell in the material and psychic space of being prepared to lose hard-fought legal rights (Berry et al., 2020, p. 148).

18 Ramiro, in an interview for Ramirez-Valles's book, 'Queer Aging' (2016), shares a similar vision of growing old with his gay family: 'It would be nice to buy a building where everyone knows each other. Get a big building, everyone pitch in, and there's your community. It doesn't have to be all gay people. It can be family; it can be people who are supportive of each other' (p. 125).

19 The documentary A Secret Love (2020) tells the story of two lesbians, a couple of 60+ years, who lived apart from their family-of-origin and who, later in life, had to rely on one partner's family-of-origin for end-of-life care. At least as portrayed in the film, one woman's family didn't seem as supportive of, or close to, her partner. The woman's partner lived longer and had to rely on the family-in-law for care. If the family-in-law really wasn't supportive, then this would surely add an additional tragic component to the end of life. 
time..$^{20}$ It takes some folks so long to leave the closet; to think of returning to it near the end of life seems cruel.

You'd tell Brett that you try not to take everyday matters too seriously, embrace irreverence, and poke fun at social mores, often to the chagrin of others. The ensuing laughter carries you through those hopeless days, soothes the pain of not feeling good enough. You wish more people - yourself included - recognised their beauty and worth, and you try to shower others with support and love, tell them that you appreciate them, and, to borrow the words from a gay friend and mentor, that you are 'glad they were born'. ${ }^{21}$

You'd tell Brett you're still friends with many mutual friends. You all talk about him and miss him very much - those cutting stares and biting remarks; the resolute friendship; of being able to call or text, or hear his voice, or see his smile. Your gay life didn't end at 30, and you wish his hadn't either. If he was here, now, you'd tell him that gayness - his gayness - is beautiful; that you love him for loving young gay you; that you are indeed glad he was born.

You finish this chapter in Covid-19 quarantine. For months, you have worried about contracting the virus, getting sick, dying. If you did get sick, you'd think about what you were (not) able to do, about no longer having moments of joy: of being with friends family at a local gay bar; dancing and singing and enjoying draft beer; laughing with each other; saying 'we're still here', 'it's been a good life', and maybe even 'we survived'. You all have survived - survived homophobic families-of-origin, religions, governments; the anxieties of youth; suicide scares; pressure to reproduce, of being taught the primary purpose of life is to make children who make children who make children. You reminisce about past heartaches, relationships lost and gained and lost again, the many others who died innocent and young; and the gratitude you feel for making it this far. You're past 40 and 50 isn't far away. At 60 , and then 70 , and then 80 , you hope to meet at a gay bar with your family, hope to say, again, 'we're still here', 'it's been a good life', and maybe even 'we survived'. Death is inevitable, but you're thinking too much and too far ahead, about factors and situations about which you have little direct control. Here, now, you feel okay; you have a drive to live and still some dancing and loving to do. ${ }^{22}$

20 See White and Gendron (2016) and Wolfenson (2017).

21 Friend, colleague, and gay mentor, Bernie Brommel, would tell you this often. He'd also often ask if you had at least one person tell you they loved you that day. If no one had told you, he sure would.

22 And just to be clear - you too are glad you were born. 


\section{Postscript: On writing 'On (not) living past 30'}

You wrote these reflections to record moments of aging, resilience, and pride, as well as to provide an account of one gay life (two, if you count Brett) as it has progressed through time.

You wrote these reflections to honour gay friends and family, as well as those lost to homophobia, despair, hopelessness, and undesirability.

You wrote these reflections to challenge heteronormative relational expectations, expand definitions of family, and conceive of and embody new scripts for aging while/as gay.

You wrote these reflections as a treatise of support, a pledge to live, and to demonstrate that gay life after 30 is possible, pleasurable.

You wrote these reflections to encourage current and future gays to live and love each other more, likely in ways different than described, but living and loving nonetheless.

\section{Acknowledgements}

I thank Keith Berry, Carolyn Ellis, Edgar Rodriguez-Dorans, Jason Holmes, and Gerardo Moreno for their feedback on this chapter.

\section{References}

Arceneaux, M. (2018). I can't date Jesus: Love, sex, family, race, and other reasons I've put my faith in Beyoncé. Atria.

Bergling, T. (2004). Reeling in the years: Gay men's perspectives on age and ageism. Harrington Park Press.

Berry, K., Adams, T. E., \& Gillotti, C. (2020). Living sexuality: Storying LGBTQ relationships, identities, and desires. Brill I Sense.

Chuang, A. K.-C. (2020). A local gay man/tongzhi or a transnational queer/quer/kuer: (Re)organizing my queerness and Asianness through personal reflection. In S. Eguchi, B. M. Calafell, \& S. Abdi (Eds.), De-whitening intersectionality: Race, intercultural communication, and politics (pp. 101-118). Lexington.

Cowen, R., Lipman, D.. (Writers) \& Chapple, A. (Director). (2001, June 17). Full circle [Television series episode]. In Cowen, R.. \& Lipman, D. (Creators), Queer as Folk. Showtime.

Cunningham, S. (2014). How we sleep at night. Sara Cunningham.

Eguchi, S. \& Long, H. R. (2019). Queer relationality as family: Yas fats! Yas femmes! Yas Asians! Journal of Homosexuality, 66(11), 1589-1608. doi: 10.1080/00918369.2018.1505756

Fox, R. (2015). Gray's anatomy. In D. B. Goltz \& J. Zingsheim (Eds.), Queer praxis: Questions for LGBTQ Worldmaking (pp. 239-240). Peter Lang.

Goltz, D. (2009). Investigating queer future meanings: Destructive perceptions of "the harder path." Qualitative Inquiry, 15(3), 561-586. doi: 10.1177/1077800408329238

Goltz, D. B. (2010). Queer temporalities in gay male representation: Tragedy, normativity, and futurity. Routledge. 
Goltz, D. B. (Ed.). (2011). Our legacies: Writings from Chicago's older gay men. iUniverse.

Goltz, D. B. (2021). Queer generativity: Temporal collisions of Fred Astaire's Dancing Lessons. Text and Performance Quarterly. https://doi.org/10.1080/1 0462937.2021 .1915496

Halberstam, J. (2005). In a queer time and place: Transgender bodies, subcultural lives. New York University Press.

Harley, D. A. \& Teaster, P. B. (Eds.). (2016). Handbook of LGBT elders: An interdisciplinary approach to principles, practices, and policies (pp. 417-437). Springer.

Harris, W. C. (2014). Slouching towards gaytheism: Christianity and queer survival in America. SUNY Press.

Holman Jones, S. \& Adams, T. E. (2014). Undoing the alphabet: A queer fugue on grief and forgiveness. Cultural Studies $\leftrightarrow$ Critical Methodologies, 14(2), 102110. doi: $10.1177 / 1532708613512260$

Manning, J. (2015). Paradoxes of (im)purity: Affirming heteronormativity and queering heterosexuality in family discourses of purity pledges. Women's Studies in Communication, 38(1), 99-117.

Maupin, A. (2017). Logical family: A memoir. Harper Perennial.

McIntosh, P. (1995). White privilege and male privilege: A personal account of coming to see correspondences through work in Women's Studies. In C. P. Harvey \& M. J. Allard (Eds.), Understanding diversity: Readings, cases, \& exercises (pp. 130-139). HarperCollins.

Muñoz, J. E. (1999). Disidentifications: Queers of color and the performance of politics. University of Minnesota Press.

Raimondi, G. A. (2020). Looking at/to/for my (oppressed/oppressor) body: A trajectory through performance autoethnography. Journal of Autoethnography, 1(3), 252-264. doi: 10.1525/joae.2020.1.3.252

Ramirez-Valles, J. (2016). Queer aging: The gayby boomers and a new frontier for gerontology. Oxford University Press.

Riggs, D. W. (2018). The psychic life of racism in gay men's communities. Lexington.

Rodgers, B. (1972). The queen's vernacular: A gay lexicon. Straight Arrow Books.

Simpson, P. (2015). Middle-aged gay men, ageing and ageism: Over the rainbow? Palgrave Macmillan.

Trevor Project. (2020). 2020 national survey on LGBTQ youth mental health. Accessed July 15, 2020 from https://www.thetrevorproject.org/survey-2020/

Weston, K. (1997).Families we choose: Lesbians, gays, kinship. Columbia University Press.

White, J. T. \& Gendron, T. L. (2016). LGBT elders in nursing homes, long-term care facilities, and residential communities. In D. A. Harley \& P. B. Teaster (Eds.), Handbook of LGBT elders: An interdisciplinary approach to principles, practices, and policies (pp. 417-437). Springer.

Wolfenson, D. H. (2017). The risks to LGBT elders in nursing homes and assisted living facilities and possible solutions. Tulane Journal of Law and Sexuality, 26, 123-131. 


\section{Going back to the glory hole \\ An (extra)ordinary story of meeting shame, doubt, and arousal in the therapy room}

Seamus Prior

I keep going back to the glory hole, I'm getting into it more and more, but I'm not sure it's good for me.

John (not his real name) makes this statement a few minutes before the end of a session. We are several weeks into our relationship as client and therapist, meeting weekly for one hour. We have covered many issues, and, while his sexual desires and practices have been consistent themes, he has never spoken this explicitly before.

I am thrown off guard. I have an image of a dirty wooden toilet partition, a hole, John's arse pressed up against the hole, waiting for a cock to find its way into his hole. I have another image of his mouth at the glory hole, his lips parted, waiting to be filled. I feel repelled, disgusted, aroused, confused. These images and feelings flash through my mind in an instant. I see the clock: four minutes left. I retain an outward composure. I speak of the polymorphous perversity of sexuality, of the irrationality of desire, of the moral relativism of sexual acts, of the objectifying nature of lust. I say a lot. I fill the space. I hear myself attempting to convey reassurance and acceptance. I hear the long and erudite words of my therapist jargon, but I know I am in flight. I am in flight from the images, words, and feelings that his disclosure has evoked in me. I know this, and yet I cannot change course. It's too late. The moment has passed. I have moved us back to the safe territory of professional exchange, to a scripted psychotherapeutic discourse. We come to the end of the session and I feel ashamed. I know I failed to meet him in his experience and vulnerability. I failed simply to listen and acknowledge and suggest we could return to this next week when we have more time. I panicked and fled the scene that his disclosure had conjured up. I could not bear to join him at the glory hole.

Chris Jaenicke (2015, p. 59) writes 'each new patient we encounter will trigger aspects of our subjectivities in unforeseen ways that will necessitate a renewed silent self-reflection'. John's disclosure is a stark example of such 
unexpected triggering. I will write into how this incident initiated a significant piece of personal work for me and how I was then able to return to meet him in the next session and repair the rupture caused by my panicked flight in this one. Through the detail of this story, I explore my theme of how the everyday life of the gay male therapist meets the everyday life of the gay male client in both the ordinary and extraordinary moments of the therapeutic encounter.

While the context of therapy is an intersubjective encounter and its work a co-creation of both parties, I will focus on my experience as therapist, rather than on the client's, for a number of reasons. Firstly, this is a collection of autoethnographic writings and the self in my story is the therapist. Secondly, it would be unethical of me to claim to know the experience of another and equally unethical to expose the details of a client's life narrative or therapeutic process. Thirdly, I contest the traditional form of psychotherapeutic writing, which seeks to emulate the objectifying nature of scientific discourse by focusing on the 'case' of the client or patient. And fourthly, aligned to this last, there is insufficient writing by therapists, especially gay male therapists, about their subjective experience of the work, addressing with honesty the personal challenges they encounter and thereby illustrating how the domains of the personal and the professional interpenetrate, integrate, and interweave in myriad ways that can never be disentangled.

\section{The risks of resting on laurels}

The glory hole exchange with John is a recent event. It occurred 20 years into my practice as a therapist. As I sat down to write up my notes that evening, I found myself red in the face like a schoolboy caught masturbating. 'I may have been doing this for twenty years', I berated myself, 'but that was a typical rookie error.'

In my work I pride myself on my ability to initiate and sustain open and frank conversations on matters sexual with my clients - straight, bi and gay, male, female, and transgender, young and old. In fact, only some weeks before, a client had ended a year of work telling me how liberating it was to have been able to talk openly about sex for the first time in his many attempts at accessing professional help. As a consequence, he had experienced our work as profoundly life-changing. While then I may have swelled with self-congratulating pride that evening as I wrote my notes after the glory hole moment, I felt utterly deflated. I had singularly failed John in exactly the domain that I claimed to be especially skilled in. I was a charlatan, a fraud, a fool. I knew then that I had to go back to the glory hole myself, albeit in 'a renewed silent self-reflection' rather than in physical reality, to work through what had so unsettled me about his disclosure, what had made it impossible for me to stay with him in his experience there. 


\section{Growing in soils of hate, fed in fear, watered in shame}

The first place I went in my self-examination was to my experience of arousal in response to John's disclosure, to the shock of its sudden irruption into the therapeutic space and the automatic sense of shame which accompanied it, completely derailing my therapeutic sangfroid. To make sense of this event, I had to go back to the beginning: to my experience of sexual awakening and my first lessons in hating, fearing, and being ashamed of my arousal, of my desire for boys and men.

I came of age as a young gay man in the environment of sectarian hatred and violent paranoia that characterised 1970s Northern Ireland. The only thing which successfully united the two warring communities in that benighted time and place was their shared virulent abhorrence of gay male sexuality and a woman's right to choose an abortion. Sensing my difference from a young age, yet immersed in the culture of homophobic discourse and violence that characterised my school, church, and neighbourhood, I learned to conceal myself and drove my desire underground, policing my every look, gesture, and comment. With the ever-present threats of public shaming and violent assault, I purged from my everyday any hint of effeminacy, campness, or displays of interest in other boys. As a weedy teenager who knew no girls, I was unable to pretend a virile heterosexuality, so I cultivated an asexual, bookish persona, adopting the defensive façade of the intellectual too caught up in matters of the mind to even notice the flesh. Along the way, I experienced the kindness and friendship of a few other boys, who sensed my difference and saw through my dissembling. I now see those boys as the true inheritors of an Irish culture of generosity and acceptance, standing in gentle defiance of the misplaced moralising of the hypocrites and liars, the priests and teachers, who were our appointed guardians.

While my days and time with others were spent in this exhausting cycle of fearful self-policing and self-censorship, my nights and time alone were given over to fantasies of boys and men's bodies, of school friends and neighbourhood lads, and to endless masturbation, equally exhausting, but for completely different reasons. Those formative years cemented this pattern of dissociation between my outward presentation of an asexual self, with all sexual expression eviscerated from my interpersonal relations with others, and my private experience of a vivid sexual imagination and extensive enjoyment of self-stimulation, shrouded in secrecy and shame. It was as if I believed that I could unknow and make disappear my sexuality, so long as I kept it in the realm of the wordless and asocial. Though profoundly impoverishing my sexual and social development, this magical thinking, and its associated tactics of hiding, deflection, and dissimulation, also served me well in keeping me safe through a time of threat and danger, until I reached the safer shores of a different time and place where my constricted sexuality could finally be allowed to breathe. 


\section{Seamus Prior}

I have come such a long way from that 70s Northern Irish childhood, and yet the glory hole moment with John immediately threw me back into defensive reactions of freeze and flight. Here, 40 years later, in the safety of my therapy room, the sudden and unexpected appearance of the sensation of sexual arousal in the professional context immediately triggered acute feelings of shame, fear, and confusion from which I automatically reverted to defensive patterns of dissociation and deflection. In my subsequent personal work, I had to acknowledge the limitations of what I had achieved in terms of my adult sexual liberation. With humility and gentle care, I returned to call out, welcome, and embrace the frightened boy who continued to reside within me, still scanning his environment for danger, still reading threat onto the faces of the others.

\section{Sexuality rampant and relinquished}

My second area of personal work focused on the glory hole itself and, in particular, my relation to dimensions of my sexuality I had chosen not to explore.

After the challenging start described above, I spent my twenties in a protracted and often painful thawing from the sexual deep freeze of my adolescent years. It was only in my late twenties, after the end of a long-term relationship in which I had felt emotionally stifled and sexually thwarted, that I began to explore my sexual subjectivity more freely. I promised myself a moratorium on serious relationships and gave myself permission to play creatively with sex, experimenting with new and diverse contexts and encounters, with fetishes and kink, learning the qualities and tendencies of my desire now that it was finally unchained. I was only six months down that road when I met the man who was to become my life partner. I knew from our first meeting that being with him mattered more to me than continuing on my quest of sexual adventurousness, and I willingly curtailed that journey into the unknown to build a life with him.

Yet over the years I have sometimes wondered about that decision. Not that I regret my choice to become partnered or wish my life had taken a different path, but I do wonder wistfully about the roads not travelled and what might have emerged had I followed one of those instead. I question if perhaps I foreclosed on the potentially challenging process of sexual growth by opting instead for the security of an exclusive and monogamous partnership, so akin to the traditional notion of a heteronormative marriage. I wonder where my political queerness would have taken me had I been able to give longer than six months to my evolving process of sexual flourishing. Rationally, I accept the choices I have made to enter an exclusive, monogamous relationship and to relinquish opportunities to develop my sexuality in other directions, and, simultaneously, I can experience envy of the sexual experiences of peers who have not pursued exclusive relationships. There remains a background hankering for the sexual explorations I relinquished 
when I chose to partner, and while mostly quiescent, even imperceptible, it can emerge at times in powerful and unexpected ways. The glory hole moment was one such occasion.

John's unexpected disclosure of his growing interest in the excitement of anonymous, depersonalised sexual encounters at the glory hole hit me squarely in this place of vulnerability and doubt. Distracting questions about my own experiences and choices ran in rapid succession through my head. Do I want that? Do I find that exciting? Would I have wanted that had I not met my partner? Quickly followed by a curious yet naïve fascination with the idea of the glory hole itself. What do men do at a glory hole? If I were at the glory hole, what would I do? What is it like to meet another man's body part but not the man himself? Why do men do that? I was excited, confused, challenged. I knew that John's experience had nothing to do with me, but my mind was noisy with this stream of questions and associations. Only afterwards, in my silent self-reflection, could I begin to articulate all of this to myself and recognise this aspect of my confusion and distractedness in the moment with John. I had to return again to the dynamic tension I feel between the choice I have willingly and lovingly made to relinquish sexual exploration into territories such as the glory hole, and my hankering after the sexual and erotic experiences, pleasures, and self-knowledge that I have thereby foregone.

\section{Purity and dirt}

In the moment with John, I experienced a complex admixture of fascination and disgust, attraction and repulsion, admiration and disapproval, and it took me some time to trace the origins and sketch in the detail of these feelings and thoughts. As I worked through this complex range of responses and reactions, I realised that my confusion about how to position myself in relation to the glory hole was not just connected to how it interacted with my own sexuality - explored, relinquished, fulfilled, and unfulfilled - but also my personal values about sexuality more generally. I pondered on what I came to see as the paradoxical mix of purity and abjection in the glory hole experience and the knotty questions raised for me about the moral dimension of sexual practices. I do not mean morality in the sense of some abstract concept of absolute right or wrong, with reference to a moral code, but rather in relation to the emotional well-being and psychological health of the individual involved. While recognising I had no authority to act as arbiter over anyone else's sexual choices, I nonetheless found myself identifying a process of evaluation of the extent to which pursuing certain sexual experiences is actually good for someone. I knew I needed to address that if I were to create an open and facilitative space for John to return to the glory hole with me.

On the one hand, I recognised the simplicity of engaging with the sexual parts of another man without his body, face, gaze, any sense of his 


\section{Seamus Prior}

personhood, of giving oneself over entirely to a sensual, physical relation to the body part itself, what it does, and what can be done to it, through the limited space of the aperture. In that space, two men become two 'its' represented only by the sexual organ or orifice that they choose to present to the other. In doing so, they achieve a spare and simple exchange, an exchange between two equals, a bartering of touch and sensation between self-objectified fetishised selves, unencumbered by the complexities of personhood and social relation. I saw a transcendence in that, a liberation, an accomplishment of the enactment of pure sexual desire. Seen this way, the glory hole struck me as an honest space of direct access to an unadulterated physical and sensual act, with no pretence of attraction to a person, their looks, the body's shape or size. It cut to the chase of penetration and orgasm. It distilled the essence of the objectifying force of lust.

Simultaneously, the therapist in me, perhaps joined by the sexually continent lover and the residual good Catholic boy, questioned the psychological health in this practice and the wisdom of pursuing it. To turn oneself into a sexual object, to present oneself to another as this body part, this act alone, to be known only for this bit of self and what it does. Conversely, to choose to engage only with the bit, the sex part, the act offered by another's body part, which one knows belongs to another man, yet another man whom one will never see or contemplate as another man. That struck me as a form of self-abjection, a deliberate debasement of sexual subjectivity. I could even go so far as to conceive of this as a sexualised form of self-harm.

As these thoughts developed, I experienced discomfiting collisions between my therapeutic assessment of healthy sexual development and my queer political commitments. The former is attuned to the knowledge, gained from both personal experience and everyday clinical practice, that not every sexual thing we choose to do is good for us, nor every experience an act of liberation, nor every choice a wise decision taking us forward to greater personal flourishing. The latter prizes and honours diverse sexualities and people's right to choose what they do with their bodies, with whom, where and when, to define for themselves what is good for them or not. It celebrates therapy's powerful potential to contribute to sexual liberation and human happiness through the gift of a non-judgmental relationship, freed from the stranglehold of conventional sexual morality.

I spent the intervening week chewing over these tough questions, examining each, reading into the conceptual and practice territory that John's glory hole disclosure opened up for me. I reached no firm conclusions, but a tentative reconciliation in which I recognised the validity in both trains of thought and the necessary co-existence of both my political and therapeutic commitments. I saw what I was doing as ethics work in which I needed to hold in dialogue and balance the principle of respect for autonomy, my client's right to self-determination, and the principle of beneficence, my obligation to attend to my client's well-being and health. 


\section{Eros enters stage left}

It was not just arousal at the thought of the glory hole, and what men did there, that so unsettled me, it was arousal at the thought of being there with John.

Where previously we had spoken of sexual matters in rather oblique and abstract ways, using terms borrowed more from sexual health textbooks than from the walls of the public toilets that men frequent for sex, John retained his place in my mind as this new young client to whom my feelings were largely professional mixed with a healthy dollop of the paternal. With the glory hole disclosure and the little I knew of his sexual preferences, I was suddenly thrust into seeing him as a sexed body occupying graphic sexual positions. First, I had a bird's-eye view of him at the toilet stall aperture waiting for the next man's cock to arrive through the hole. This was quickly followed by the disturbing idea of me being that next man, taking his place in the next-door stall, to present myself in the way he was seeking. That is the moment when I broke contact with John and took flight from the story he was trying to tell me, silencing him with my intellectualisations and bland assurances, filling the remainder of the session until I could call time and escape my discomfort.

Even as it happened, I sensed the multiple layers of shame under which I was drowning: firstly, shame at the sexual thoughts and images that so forced themselves into my mind's eye; secondly, shame that here I was thinking of my client, this troubled young man who had come to me for help and care, in this degrading and exploitative way; and thirdly, shame at my abject therapeutic failure. In taking flight from the scene, I was failing to help him and, as importantly, failing to honour the courage that it must have taken him to bring me this story so early in our work together. Dwelling in this complex, multifaceted shame was the most challenging focus of the personal work I did in the week that followed. Even to write of it now powerfully re-evokes it.

Days of reflection, self-examination, and reading ensued. I returned to a group of men whom I have never met, yet who feel like friends and mentors. They are openly gay relational analysts based in and around New York, and they write with refreshing candour about their therapeutic practice with gay men in several psychoanalytic journals. With the help of their stories of struggle and dilemma, I came to know and accept my own experience and prepare for my return to the next session with John. Eric Sherman (2002) helped me recognise and accept my fear and avoidance, yet find the courage to enter the challenging terrain of the erotic in the room. Steven Kuchuck (2013) showed me I was not alone in struggling to contain my experience of the erotic and how essential it was to accept my experience and use it in the service of the work. Martin Frommer (2007) reminded me of the tangled web of self and self-other experience implicated in erotic subjectivity and how all lust and desire entail an objectification of the other and the self. 


\section{Seamus Prior}

With the support of their professional wisdom, I came to see the obvious and the inevitable: that a client's talk of sex brings the therapist into the sexual scene, certainly as witness, and when working as a gay man with another, also as a potential fantasied sexual partner. I realised that the thoughts, images, and words that came to my mind in the glory hole moment were not signs of my unprofessionalism, my degeneracy, my exploitative use of my client for vicarious sexual gratification. On the contrary, they were an inevitable consequence of joining my client in the exploration of his experience, a necessary corollary of embracing the manifestation of the erotic. Far from being deviant and dangerous, they were required elements in the therapeutic work; to avoid them was a deviation from the therapeutic task to which John had called me.

As Eric Sherman (2002) argues, to enter the sexual scene in thought and word raises the erotic and emotional temperature within the room which, in turn, necessitates a sensitive, delicate balancing between potential seductiveness and hyperarousal on the one hand and defensive flight into the avoidance of intimacy on the other. In the glory hole moment with John, I automatically reverted to the latter, hiding behind the professional façade of uttering intellectualised abstractions on sexuality. While apparently still commenting on matters sexual, we both knew that I had fled the scene of the four-letter acts that are consummated in the glory hole. I had retreated to the ivory tower of psychosexual theory. As I knew from long experience, when I start quoting Freud, as I did in my very first statement with a reference to the 'polymorphous perversity' of sexuality, I am floundering and clutching at straws. Eventually as I worked through my reactions, I came to laugh at this farcical moment of intellectual grandiosity. Really, who did I think I was kidding? I was like my adolescent self, imagining he was fooling everyone with his lofty bookish pretensions, a classic case of 'the lady doth protest too much'.

While an imagining of therapist and client engaged in sexual activity together conjures up a transgressive boundary violation and, at face value, looks like the first step towards professional ethical misconduct, in the work of therapy with gay men, and with all clients where sex and sexuality are relevant themes, the opposite is true. Whether emanating from confusion or doubt, from fear of excitement and arousal, or from anxiety that thought will be translated into deed and boundary transgressions inevitably ensue, a therapist's refusal to contemplate and work with the sexual scenes that the client's account evokes is an act of withdrawal and professional negligence. It abandons the client to his concerns and distress. To do so in work with gay men is to reinforce the long-held message that their sexuality is shameful, their desire repellent, not to be spoken of in polite circles. It communicates that they must handle their desire alone, in the dark and hidden places of their sexual fantasies and encounters; it tells them that not even their therapist can listen to this dirty, disgusting stuff. In this way, the therapist's flight from the sexual and erotic that emerges in the work is just another 
re-enactment of the homophobic violence that is perpetrated every day on gay men's sexual subjectivities. That, to my mind, is the real act of professional ethical misconduct.

\section{Repairing the rupture}

When John returned the next week, I took the opportunity presented by a lull in the conversation to bring him back to the glory hole moment from the previous week. While not revealing all of what I had worked through in the intervening period, I disclosed that his statement had taken me by surprise, and I acknowledged that I had not responded in an open and facilitative way. I suggested that, now that we had more time, we could go back to his glory hole experience.

John took up this offer, and we worked together on this particular dimension of his sexual life, what it meant for him, the needs that were met, the questions and concerns he had in relation to it. There was a sexual charge through our conversation, relieved at times by the comic aspects of particular stories of meeting men's cocks through the glory hole window. However, I was not troubled by sexual arousal or any concern that I was seeking, whether wittingly or not, vicarious sexual gratification through encouraging him to tell me about his encounters. The details were explored in the service of meaning-making and the sexual was exposed in order to access the emotional. The everyday sexual acts of the present were described in order to trace the unfolding story of his sexual life, linking back to the past and early sexual development and casting forward to the future and where he was going, articulating the kind of man he was becoming.

\section{Reflections on this story}

Elsewhere in this volume authors argue for the importance of de-emphasising the 'sex' in 'homosexuality'. They encourage a prizing of everyday lives that goes beyond a focus on the sex lives of gay men, or the simplistic equation of gayness with sexuality, and thereby resist the colonising force of a myopic sexualised medico-scientific gaze. At first glance, my writing may seem to be supporting a converse position: that at the heart of the therapeutic encounter between two gay men is a meeting of sexually desiring minds and bodies. Yet I would contest that 'Going back to the glory hole' is not so much a story about sex as it is an account of a gay man (the therapist) overcoming his shame and pain and internalised homophobia in order to meet another gay man (the client) in an ethical space of intimacy and care.

In psychoanalytic practice, the journey towards psychological health is characterised by a process of owning and integrating 'split-off' elements of self-experience: the thoughts, feelings, and actions that cause shame, anxiety, guilt, or fear and which we tend to avoid, forget, or pretend do not exist (see Leiper and Maltby, 2004, Chapters 1 and 2, for an accessible 


\section{Seamus Prior}

introduction to this core concept). The everyday work of therapy is about finding safe and creative ways to bring the split-off out of the closet of an enforced enclosure, to dial down the shame, and expand acceptance. For gay men in particular, the toxic legacy of homophobic hate and early humiliation has often blighted the capacity for loving the sexual self. The everyday work of the therapist is to find the courage to travel with each client into this potentially arousing, confusing, and shame-inducing terrain, aware of his own troubled past and present challenges, yet secure in his motivation to meet the client in a non-exploitative relational encounter founded on an ethic of care.

As this story exemplifies, such work is not a once-done thing. It is not the case that, once mastered, the capacity is securely attained, the therapeutic competence accomplished. Conversely, and paradoxically, the task is undertaken anew with each new client. Each new therapeutic relationship, as Chris Jaenicke (2015) observes, throws up new areas for self-reflection, or old areas to be revisited afresh, and the therapist works as much and as hard outside the therapy room, after the client has departed, as he does inside it when the client is present. To meet the client in his shame and doubt, his excitement and arousal, and his meaning-making struggles, the therapist travels the same terrain within himself, facing his own developmental tasks and challenges, including his demons, ghosts, and closeted skeletons. The unravelling of shame is a lifelong work in progress, the development of sexual embodied subjectivity, a never-ending process in which I, as therapist, accompany my clients, as they do me, in a joint endeavour of mutual encounter and relation.

\section{References}

Frommer, Martin (2007). On the subjectivity of lustful states of mind. Psychoanalytic Dialogues, 16:6, 639-664.

Jaenicke, Chris (2015). The Search for a Relational Home: An Intersubjective View of Therapeutic Action. London: Routledge.

Kuchuck, Steven (2013). Reflections on the therapeutic action of desire. Studies in Gender and Sexuality, 14:2, 133-139.

Leiper, Rob, and Michael Maltby (2004). The Psychodynamic Approach to Therapeutic Change. London: SAGE Publications.

Sherman, Eric (2002). Homoerotic countertransference: The love that dare not speak its name? Psychoanalytic Dialogues, 12:4, 649-666. 


\title{
7 Becoming (in)visible \\ A performative autoethnography on mental health, help-seeking, and missing connections
}

\author{
Willem J. Stander
}

\section{Characters}

Willem (the protagonist, sometimes antagonist): international PhD student, gay, male.

Max, father, academic mentor: various ages and sexualities; male; all people who want to help the protagonist (sometimes antagonist) the best way they know how.

A long gone, but not forgotten family member: gay; male; dearly missed.

Incidental characters (e.g., police officers, man at the train station etc.): various ages and sexualities; male; holding stigmatising views towards the protagonist (sometimes antagonist) and others like him; themselves navigating shame and restrictive social norms.

\section{Extras}

Shame: a large family of emotions (e.g., embarrassment, humiliation, and feelings of failure, rejection, or inadequacy) (Scheff, 2000); a relational and judgemental emotion tied to vast everyday social and economic inequalities (McDermott and Roen, 2016) or 'the affective cost of not following the scripts of normative existence' (Ahmed, 2015, p. 107); an often unspoken, repressed, disguised, or hidden emotion that 'goes to the heart of who we think we are' (Probyn, 2005, p. 13); can be transformative in the context of relational reciprocity (e.g., Johnson, 2015; Sedgwick, 2003).

Social norms: often implicit and interconnected social rules, ideals, or expectations that guide everyday behaviour (Cialdini and Trost, 1998); dynamic in nature; regulate, coerce, and enforce narrow modes of sexual and gendered existence (Foucault, 1976), and 'operate as a condition of cultural intelligibility' (Butler, 2004, p. 52); in a neoliberalist and biopolitical framework, these norms privilege a particular type of hetero- or homonormative subject, one who is autonomous, self-governing, and responsible for their own life, health, and wellbeing (Cover, 2012; Foucault, 1977; Rose, 1989). 
Ontological (in)security: the degree of 'confidence that most human beings have in the continuity of their self-identity and in the constancy of the surrounding material environments of action' (Giddens, 1990, p. 92); a continuum along which we all move, rather than a binary distinction (Bondi, 2014); in relation to mental health, a state of ontological insecurity can be experienced as a result of difficulties maintaining social relationships and managing daily activities or routines, and feelings of being judged or stigmatised.

\section{Act I: End of the line}

\section{Finally!}

I spot the lights of an approaching train in the far distance. While I've only been on the platform a few short minutes, it feels much longer, and I am desperate to get to the university's library. My right foot taps irritably as I watch the train's slow crawl into the station, thinking about the mountain of thesis writing still left to do. When it eventually stops, I scramble on and make a beeline for a seat in the farthest corner. I settle down, dumping my backpack and coat on the aisle seat next to me; piling them high on top of each other, building a fort. I want to keep all social interactions to a minimum. I want to hide, to be invisible. I can't stand the thought of being watched. Every stare, every glance feels penetrative and judgemental. All of this is unnecessary, however. The carriage is mostly empty given the early hour with the nearest passenger sat at the opposite end.

\section{Come on, come on, come on.}

I'm anxious for the journey to get underway, checking my watch every few seconds. My heart is racing. It's always racing lately. I try to calm myself, slowing my breathing. At long last the train leaves with a violent jerk, lurching forward as we cross over a viaduct offering panoramic views of a stillsleeping Brighton. I am already waiting by the doors when we near my destination, feeling clammy and claustrophobic - aching for the commute to end. I get off at the end of the platform, holding back until I'm all alone. Every step requires gargantuan effort, exhaustion clouding my body and mind. I try to push through it, increasing my pace into a brisk walk. As I reach the station exit, however, I come to an abrupt stop, transfixed by the scene ahead. Framed by bleak, wintery trees on either side, the exit staircase descends into a pool of darkness (Figure 7.1), mirroring the weariness - the hopelessness, the helplessness - inside of me. And then I spiral, spiral into despair, into distress.

\section{I can't do this anymore, can't feel like this any longer. I need help.}

My difficulties with depression and anxiety had finally caught up with me, now debilitating and seeping into every aspect of my life. This was 


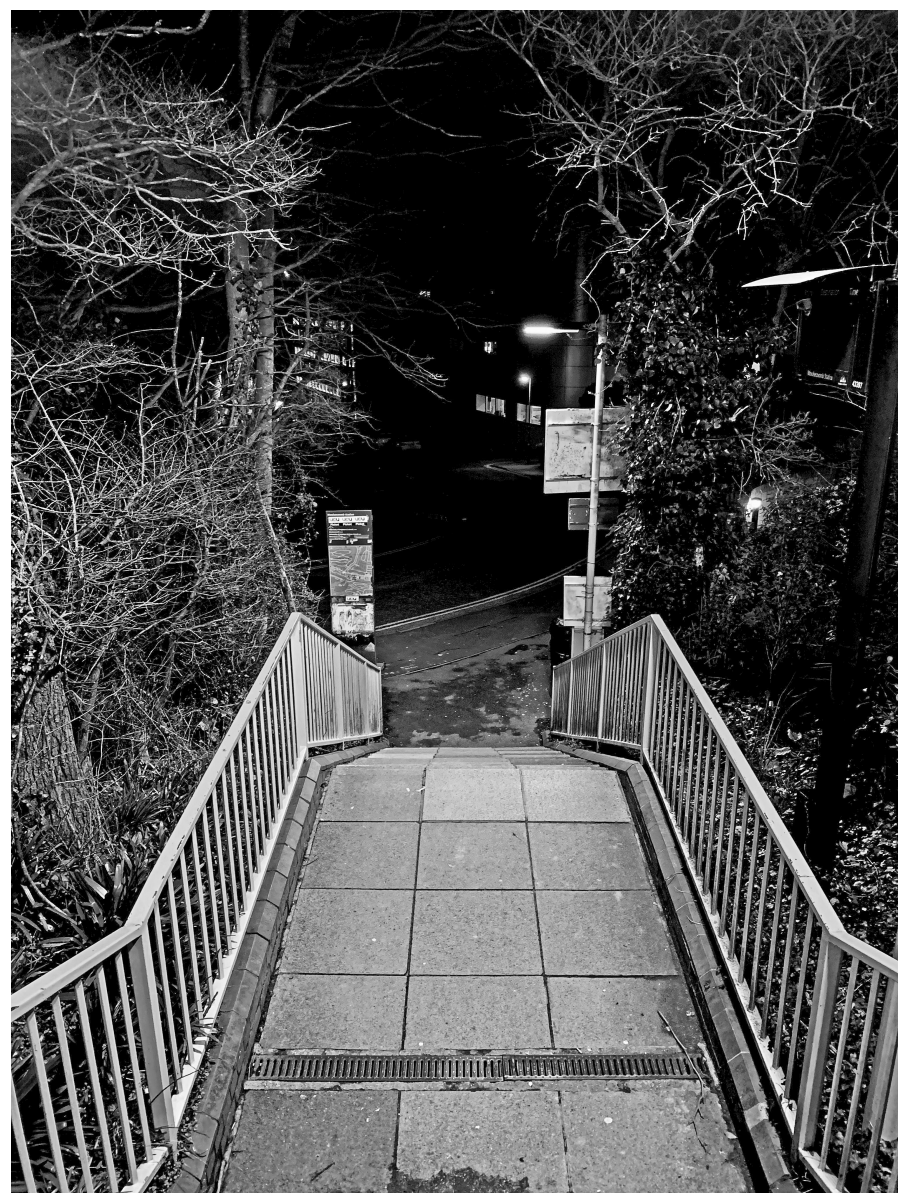

Figure 7.1 Despair on the staircase

in addition to the other life stressors: family ill-health and death back in my home country, Namibia; trying to balance teaching and university commitments; and ongoing financial and visa worries to remain in the United Kingdom (UK), my new home. I was being pulled in a million different directions, stretched precariously thin. Feeling trapped and overwhelmed, no longer able to lie to myself or pretend that I was managing. I sit down on the steps facing an uncomfortable and frightening realisation, knowing I've reached the limits of my ability to cope. Knowing I was hanging on by a thread and in need of support. However, an upcoming deadline towered above all else. It was made clear to me that there would be no more room for delays or extensions regarding my thesis. This deadline was my final opportunity to submit, and I had to meet it. 


\section{Willem J. Stander}

\section{I need to keep going, keep writing.}

I hear the rails behind me rattle as the next train approaches. I stand up and try and wrestle back control over my emotions, not wanting anyone to see me like this. As soon as this is over, I can focus on myself, on my health. I'm overreacting because I'm tired. It's not that bad, others have coped with worse. I lie to myself a little longer, normalising and accommodating my distress. I continue down the steps, disappearing into the darkness.

\section{Act II: Fragmented}

\section{It's all a festering wound, too painful to write.}

I stare in frustration at the blinking cursor, willing it to move - my hands suspended over the keyboard, waiting for the words to come. I've been in the library for a few hours now, but the writing process remains slow and laboured. I keep thinking about my one supervisor's comments and how she attributed my writing anxiety to my desire for perfectionism. Like many academics, I felt like an imposter, an interloper, my best efforts all smoke and mirrors, nowhere near good enough for academia. These feelings certainly contributed to my difficulties in writing, but it was much more than that. Ironically, I was experiencing mental health difficulties while investigating how gay and bisexual men seek help for these burdens. As a result, my research felt increasingly personal and exposing. Through my writing, I was becoming public, visible, and vulnerable - caught in an endless loop of rumination. Always overthinking, over-analysing, and meant to have the solutions to all of my problems but failing. Unable to find peace. My words felt ruinous, an invitation to the judgement or evaluation of others - further proof of my shortcomings.

\section{I should be thriving here.}

I look up from my laptop, searching for some distraction from the panic now clawing up my throat. More students are now filtering into the library, sitting in small groups and whispering softly. I feel lonely watching them, so used to the isolation of postgraduate studies. Outside of my partner and a small handful of friends scattered across England, my Brighton existence has been rather solitary compared to my time in Namibia. Namibia, where same-sexual relations remain illegal under a colonial-heritage law (Hubbard, 2015). Namibia, where the ruling party would routinely employ homophobic discourse to police gender and sexuality during my formative years. Making it known that homosexuality was unnatural, evil, a threat to the nation; that homosexuality needed to be eradicated or, at the very minimum, rendered publicly invisible (Currier, 2010). Although the state doesn't actively enforce this law, negative social attitudes towards lesbian, gay, bisexual, transgender, and queer (LGBTQ) individuals made me keenly 
aware of my distance from the norm at very young age. I was bullied and tormented throughout my childhood for being a 'moffie' - a derogatory Afrikaans term used to refer to or mock homosexual (or effeminate) boys and men - long before I even knew what the word meant or implied. I became hypervigilant about how I walked, talked, dressed, and expressed my interests. Complex, strong female figures in books and other media? Yes, please! Er, no, wait. I'm all about hyper-masculine icons and rugby. For beterosexual reasons, of course. This continued into my early adulthood. I was petrified of coming out to my family and friends, aware, like many of us who fall under the LGBTQ umbrella, that 'love comes with conditions however unconditional it might feel' (Ahmed, 2015, p. 145). Feelings of exclusion, inadequacy, and failure stuck to my negotiations of everyday life. As Eve Sedgewick (2003) suggests, 'at least for certain ("queer") people, shame is simply the first, and remains a permanent, structuring fact of identity' (p. 64).

I did eventually come out, encouraged by the support of a burgeoning local LGBTQ scene. I secretly frequented the short-lived Donna Bella, the first recognised gay bar in the capital. It was there that I found my 'chosen family', that I found my voice. When the venue closed due to financial strain, I was determined to keep its legacy going. Working alongside a group of friends, we arranged a series of events where the city's small LGBTQ community could meet and socialise. My increasing visibility among the gay scene soon extended to the wider public as I started volunteering for LGBTI Namibia, an LGBTQ rights-based organisation. I felt empowered but afraid, reminded often of the violence that comes with (too much) visibility. Yet, I was able to live my gayness openly to some extent, facilitated no doubt by my privileges as a white, middle-class man. Working for a predominantly white and male corporation at the time, I was able to evade some of the blatant homophobia directed at my LGBTQ colleagues. While management didn't block my career development, for example, because of racism and homophobia, they thought it within their right to tell an entry-level employee of colour to 'tone down his gayness' if he hoped for promotion. I left Namibia to pursue my postgraduate studies in community psychology, to learn more about LGBTQ social movements. I left Namibia because I didn't want to die lonely, left because I wanted to be (in)visible.

Lively chatter snaps me out of my reverie. The library is now bustling with activity, loud and claustrophobic. The coronavirus pandemic has dominated the news headlines recently, and seeing everyone packed so close together makes me feel unsafe. I decide to head for the station and work from home for the foreseeable future.

$* * * *$

You were one of the first to discover I was gay. You'd seen my dating profile on a website and phoned to tell me how proud you were, how you'd be there when I come out to the rest of the family. 


\section{Willem J. Stander}

\section{I missed your call.}

You left a voicemail asking if I wanted to meet for a drink. 'Soon', I promised in a text. You caught up with some of our mutual friends instead. They said you were in good spirits, albeit a little lonely. That Windhoek is too small for people like us. They said you were making a conscious effort to catch up with everyone. That you wanted some company.

\section{I missed your call.}

You phoned again soon after, but I let it go to voicemail. I was busy/tired. I promised myself I'd call you over the weekend. The weekend came, and your brother found you. Only then did we find out your difficulties with depression.

\section{I miss your calls.}

$* * * *$

I'm new to Brighton and have signed up to a gay social networking app for some company. To go on a date or to make some friends. I'm on a walk when one of the first messages come through. 'Disappointing in the flesh', it reads. It's come from a blank profile that appears disturbingly close. I look up, searching the area for the source. Unsuccessful, I continue walking. A second message soon follows: 'camper also'.

A few weeks later, I'm on a date with a police officer. He seems nice, but we have very different interests, and the conversation is somewhat stilted. He asks about my research, listening politely. His eyes light up - it appears we've finally hit some common ground. As I finish, he launches into a tirade about the amount of mental health-related callouts the police receive. Words like 'mad' and 'attention-seeking' come thick and fast. 'Time-wasters. The whole lot', he concludes. A second date never materialises.

$* * * *$

We are in a hurry to get to the Brighton station, both needing to get to work. Max's hand slips into mine as we talk about our respective plans for the day ahead. I should be used it to it by now, seeing as we've been together for over a year. Yet, the small intimate gesture still thrills me - still scares me - every time his fingers interlace with mine. I'd never dare do this back in Namibia, but here in Brighton - the LGBTQ capital of the UK - the small, (extra)ordinary gesture feels possible, feels safe. We enter the station and share a hurried kiss before we head our separate ways. I watch Max slip through the ticket barriers, feeling content and brushing my silly trepidation aside.

'Is that really necessary? In public?' comes a voice from behind me. I turn and catch the man's eye as he walks past, his face twisted into a grimace. I 
watch him as he too disappears through the barriers, angry at my stunned silence.

$* * * *$

A meeting has been arranged with an academic mentor from the university to discuss my missed deadlines. To help me get back on track. His office lights are bright, uncomfortable. I feel embarrassed being here, that I let things get to this point. He is distracted at first, hammering away at his keyboard. He finally turns to me, asking me to explain the causes behind the delays. My answers come out in a rush, the lump in my throat promising tears. Perhaps sensing this, he soon interrupts.

'I don't want to hear any of that. I want us to focus on solutions', he says dismissively. We sit in silence for a few seconds, sharing an exasperated look. Our meeting eventually concludes with a solution - an expanding to-do list with additional deadlines, some imminent - and a tension of things left unsaid. I may be struggling, but capitalism marches on.

$* * * *$

I'm on the phone with my family. It's eventually my father's turn to say hello, and we act out the same old conversation.

'How are you?' he'd ask.

'I'm having a really tough time', I'd say.

A short, tense pause usually follows as he thinks of what to say, how best he can help his son. His response is always brief, always stoical: 'Keep going'. / 'Keep at it'. / 'Stay strong'. / 'Get it done'.

The best advice he has, advice his father had given him. And then a hurried, awkward goodbye as we both get back to work.

$* * * *$

Max is at a loss for what to do.

'You don't talk to me anymore', he says with frustrated tears. 'I can see how hard all of this is for you, but you won't talk to me about any of it'.

His concern breaks my heart. He desperately wants to help, to provide some relief. I want to say so much but end up saying so little, the words all tangled and catching in my throat. Overwhelmed by feelings of failure but struggling to voice them because to 'to feel failed is different than saying you are failed; articulation brings the failed subject into being' (p.144). I find words which resonate with experiences much later, wishing I had them in the moment to help fill the silence:

Depression is awful beyond words or sounds or images... It bleeds relationships through suspicion, lack of confidence, and self-respect; the inability to enjoy life, to walk or talk or think normally; the exhaustion, the night terrors, the day terrors. Depression... is flat, hollow, and unendurable. It is also tiresome. People cannot abide being around you when you are depressed. They might think that they ought to, and they might even try, but you know and they know that you are tedious beyond belief: you're irritating and paranoid and humourless and lifeless and critical and demanding and no reassurance is ever enough. You're frightened, and you're frightening, and 
you're 'not at all like yourself but will be soon', but you know you won't (Jamison, 1995, pp. 217-218).

$* * * *$

There is a young man, sitting in a parked car with the engine running. His hands gripping the steering wheel tight, unable to let go. His eyes fixed on the dingy little Windhoek police station in the quiet darkness, unable to enter. He watches the front porch light flicker in and out of existence as he tries to find the words to describe a shame - a violation - that feels unspeakable, unprintable. There are two officers - two men - on duty, both standing on the porch now. Seeing them, he finds that his voice is barely a whisper. He turns his car around, taking the silence with him wherever he goes.

$* * * *$

\section{I need to keep going, keep writing. I need to stay strong, stay on track.}

\section{Act III: Derailed}

Under full national lockdown, everything has changed. Permitted only to leave our homes once a day for exercise, I find myself walking near Brighton station one morning. Perhaps drawn there out of curiosity or a yearning for some semblance of normalcy, I make my way inside. Usually bustling with harried travellers, the cavernous space is now eerily, impossibly quiet (see Figure 7.2). Most platforms are empty as train firms operate under a reduced timetable. Available trains sit largely vacant, looking forlorn. Ghostly figures make their way through the ticket gates, cautious and fearful, giving other commuters a wide berth. There is no frantic platform dash, no waiting crowds; the majority of people have retreated into their homes in a shared loss of safety and predictability, all our plans derailed. The rest of the world now just as anxious - just as isolated - as I am.

\section{I need to keep going, need to stay on track.}

The next few weeks are increasingly blurred, days all blending together. Sleep is minimal as I spend every waking hour writing, trying to meet my new deadline. My everyday life reduced to bare functioning, feeling more insubstantial than substantial; my life reduced to a series of nouns: bed, coffee, thesis, bed, coffee, thesis. Always finding a reason to change or rework another chapter, unable to submit; trying to cross an ever-moving finish line, trapped inside a never-ending tunnel. The threshold for submission for relief, for support - forever pushed to a later date as I continue to ignore and downplay the warning signs. As I (re)negotiate increasing distress, running dangerously on empty. 


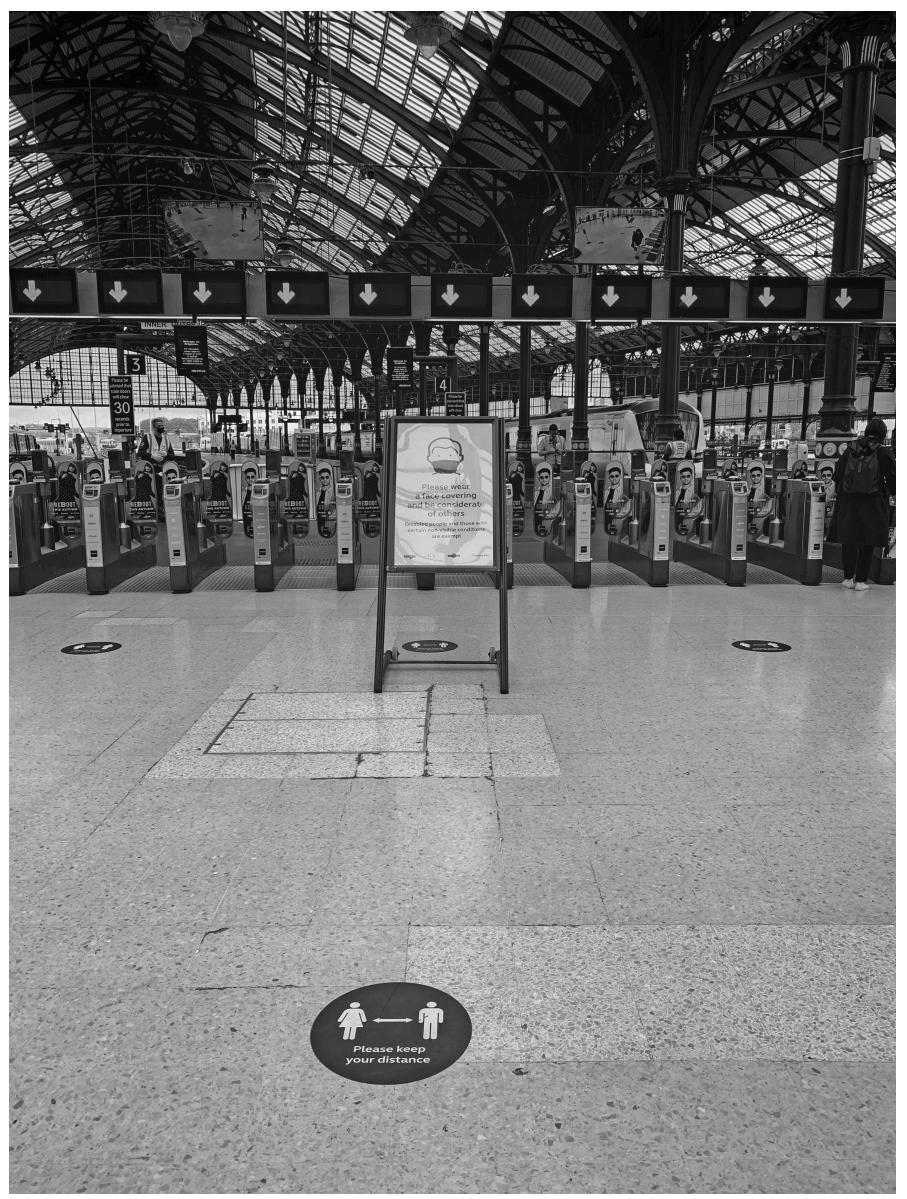

Figure 7.2 Keep your (social) distance

\section{I need to keep going, keep writing.}

The final straw comes early one morning as my Fitbit reveals a dangerous trend. That my heart rate is dangerously high for someone who rarely leaves his desk. I tell this to Max when he wakes, laughing it off as if it's nothing. Only minor transient stress, but I find that I can't meet his eyes.

'You can't keep going like this', he pleads. 'You need to submit what you have and let it go'.

I try to rationalise and justify another delay, that my thesis is nowhere near good enough (that $I$ am nowhere near good enough). I need to keep going, need to keep writing. I need to stay strong, stay on track. Need to stay invisible, need to stay safe. 
I'm not sure what Max says to counter this, but his words manage to cut through the fog of my fatigue. They finally take hold. Reminding me that I am safe, that I am worthy of help, of being seen; that no person is an island. He leads me back to my family and friends, all of them isolated and vulnerable during this uncertain, unprecedented time. All of them are talking more openly, more freely about their mental health concerns and, in doing so, providing me with a space to start untangling my words. A space to begin exploring those norms that keep me from articulating my distress. I realise that I need to submit my thesis, need to let it go. I realise that I need to start telling a story about a young man, sitting in a parked car with the engine running...

\section{Finding the words: Making (some) headway with this experience}

It is important to acknowledge that the majority of gay men are healthy, well-functioning and resilient individuals. Nevertheless, international evidence suggests that LGBTQ people are more likely to report elevated rates of mental health problems compared to their heterosexual counterparts due to increased social (or minority) stressors and diminished coping resources (Plöderl and Tremblay, 2015). Relatedly, LGBTQ people also utilise mental health services at higher rates (Chakraborty, et al., 2011), but can face substantial barriers to accessing care. LGBTQ-specific barriers include fears or experiences of mistreatment and pathologisation, heterosexist language or assumptions, and a scarcity of specialist resources (Hudson-Sharp and Metcalf, 2016; Rozbroj, et al., 2014). This is in addition to more common barriers to help-seeking, such as a preference for self-reliance, discomfort discussing emotions, the stigma associated with mental health difficulties, long waiting lists, and the high cost of private or voluntary healthcare services (Ferlatte et al., 2019; Government Equalities Office, 2018). Furthermore, health and social care workers concede that there is a lack of professional education and training opportunities that specifically address the needs of LGBTQ people (Somerville, 2015). It is not surprising, then, that LGBTQ people report feeling ignored, devalued, dismissed, and invisible within mainstream services (Ash and Mackereth, 2013).

Research specifically investigating the mental health help-seeking behaviour of gay men remains limited (for a similar critique, see Platt, Wolf, and Scheitle, 2018). Help-seeking is an ongoing, interactive process defined and guided by a variety of approaches or strategies (Wenger, 2011). In this chapter, it is perhaps best understood as 'a response to a psycho-social dilemma concerning the desperate need for connection with others in tension with the ... difficulties inherent in that connection'1 (Roen, Scourfield,

1 Although initially offered as a relational understanding or definition of suicidality, I borrow and adapt this phrase to the help-seeking context given how well it resonates with my personal experience. 
and McDermott, 2008, p. 2096), particularly insofar as it involves the transgression of norms. I hope you recognise in my narration how the navigation of multiple sociocultural norms can impact upon gay men's mental (ill) health and (avoidant) help-seeking behaviour: the relentless onus on personal responsibility, self-management, and individualised self-care (neoliberal norms); expectations of stoicism, self-reliance, restrictive emotionality (dominant masculine and emotional norms); and the overt or more subtle workings of homonormativities, heteronormativities, and homophobia. Struggling against all of these normative pressures can make asking for help seem impossible, resulting in attempts to deal with emotional distress alone as the threshold to help-seeking is moved to higher levels of distress (even towards or beyond the point of crisis). These norms act to regulate what emotions are possible to articulate and can intensify feelings of shame, failure, and other negative affects in relation to help-seeking. Thus, for some, shame can remain an isolating, intense, and even deadly affective state if it cannot be released by way of connection and communication with another.

My account also demonstrates significant impacts of social relationships or informal supports (i.e., friends, partners, parents, other professionals) on the help-seeking process and in contributing to a sense of ontological (in)security. The extant literature continues to demonstrate that gay men are among those who most need and benefit from supportive social and community relationships with respect to their mental health (Frost, Meyer, and Schwartz, 2016; Hsieh, 2014). Whether queer or otherwise, these connections provide important 'resources for mediating and reappropriating experiences of shame through affective reconnection' (Johnson, 2015, p. 147). The continued prioritisation of individually targeted interventions and isolated practices of self-care or self-help with this group is therefore questionable. These approaches need to be balanced by a re-emphasis on relationally oriented interventions where attention is paid to fostering helpful relational connections beyond the self. ${ }^{2}$ Such peer-led and community-based initiatives are particularly important - and under significant threat - in light of the coronavirus pandemic (see Stander, 2020).

This chapter highlights the affective and normative dimensions that can impact upon gay men's mental health and help-seeking relations; an area often underacknowledged within the mental health help-seeking literature (McDermott and Roen, 2016). There remain significant gaps in our understanding of how factors such as race, ethnicity, cultural backgrounds, and socioeconomic status intersect with gender and sexual orientation to influence help-seeking. These require greater attention moving forward if we are to better tailor prevention and intervention efforts. As Doolin (2010) - and the works of other contributors in this book - reminds us, 'our words, 
experiences, time, and knowledge (as LGBTQ persons) may be invaluable to those wondering how to deal with some of the same things' (p. 101). My story - and our personal narratives - of mental distress and help-seeking can serve positively as a communal resource within the practice of relational meaning-making, testimony, and witness. I hope my tale encourages questions, identification, reflexion, or reflexivity among gay men, autoethnographers/researchers, and practitioners; as a means for us to find the words, to comprehend these difficult experiences, together.

\section{References}

Ahmed, S. (2015). The cultural politics of emotion (2nd ed.). New York: Routledge. Ash, M., \& Mackereth, C. J. (2013). Assessing the mental health and wellbeing of the lesbian, gay, bisexual and transgender population. Community Practitioner, 86(3), 24-27.

Bondi, L. (2014). Feeling insecure: A personal account in a psychoanalytic voice. Social \& Cultural Geography, 15(3), 332-350.

Butler, J. (2004). Undoing gender. London: Routledge.

Chakraborty, A., McManus, S., Brugha, T. S., Bebbington, P., \& King, M. (2011). Mental health of the non-heterosexual population of England. The British Journal of Psychiatry, 198, 143-148.

Cialdini, R., \& Trost, M. (1998). Social influence: social norms, conformity and compliance. In The handbook of social psychology, volume 2 (pp. 151-192). New York: McGraw-Hill.

Cover, R. (2012). Queer youth suicide, culture and identity: Unliveable lives? Surrey: Ashgate.

Currier, A. (2010). Political homophobia in postcolonial Namibia. Gender \& Society, 24(1), 110-129.

Doolin, E. M. (2010). Bridging the gap for lesbian youth: Making our community their community. Journal of Lesbian Studies, 14, 93-103. https://doi.org/10.1 080/10894160903060457

Ferlatte, O., Salway, T., Rice, S., Oliffe, J. L., Rich, A. J., Knight, R., ... Ogrodniczuk, J. S. (2019). Perceived barriers to mental health services among Canadian sexual and gender minorities with depression and at risk of suicide. Community Mental Health Journal, 55, 1-9.

Foucault, M. (1976). The will to knowledge: The history of sexuality: 1. London: Penguin Books.

Foucault, M. (1977). Discipline and punishment. London: Allen Lane.

Frost, D. M., Meyer, I. H., \& Schwartz, S. (2016). Social support networks among diverse sexual minority populations. American Journal of Orthopsychiatry, 86, 91-102.

Giddens, A. (1990). The consequences of modernity. Cambridge: Polity Press.

Government Equalities Office. (2018). National LGBT survey. London, UK: Government Equalities Office.

Hsieh, N. (2014). Explaining the mental health disparity by sexual orientation: The importance of social resources. Society and Mental Health, 4(2), 129-146. 
Hubbard, D. (2015). Namibian law on LGBT issues. Windhoek, Namibia: Legal Assistance Centre.

Hudson-Sharp, N., \& Metcalf, H. (2016). Inequality among lesbian, gay bisexual and transgender groups in the UK: A review of evidence. London, UK: National Institute of Economic and Social Research.

Jamison, K. R. (1995). An unquiet mind. A memoir of moods and madness. New York: Vintage Books.

Johnson, K. (2015). Sexuality: A psychosocial manifesto. Cambridge: Polity Press.

McDermott, E., \& Roen, K. (2016). Queer youth, suicide and self-harm: Troubled subjects, troubling norms. London: Palgrave Macmillan.

Platt, L. F., Wolf, J. K., \& Scheitle, C. P. (2018). Patterns of mental health care utilization among sexual orientation minority groups. Journal of Homosexuality, 65(2), 135-153.

Plöderl, M., \& Tremblay, P. (2015). Mental health of sexual minorities. A systematic review. International Review of Psychiatry, 27(5), 367-385.

Probyn, E. (2005). Blush: Faces of shame. Minneapolis: University of Minnesota Press.

Roen, K., Scourfield, J., \& McDermott, E. (2008). Making sense of suicide: A discourse analysis of young people's talk about suicidal subjecthood. Social Science \& Medicine, 67, 2089-2097.

Rose, N. S. (1989). Governing the soul: The shaping of the private self. London: Routledge.

Rozbroj, T., Lyons, A., Pitts, M., Mitchell, A., \& Christensen, H. (2014). Assessing the applicability of e-therapies for depression, anxiety and other mood disorders among lesbians and gay men: Analysis of 24 web- and mobile phone-based selfhelp interventions. Journal of Medical Internet Research, 16(7), e166.

Scheff, T. J. (2000). Shame and the social bond: A sociological theory. Sociological Theory, 18, 84-99.

Sedgwick, E. K. (2003). Touching feeling: Affect, pedgagogy, performativity. Durham: Duke University Press.

Somerville, C. (2015). Unhealthy attitudes: The treatment of LGBT people within bealth and social care services. London, UK: Stonewall.

Stander, W. J. (2020, June 23). LGBTQ people urgently need specialist mental health support - But it is lacking. The Conversation. Retrieved from https://th econversation.com/lgbtq-people-urgently-need-specialist-mental-health-support -but-it-is-lacking-141059

Wenger, L. M. (2011). Beyond ballistics: Expanding our conceptualization men's health-related help seeking. American Journal of Men's Health, 5(6), 488-499. 


\title{
8 Lack of ordinary privileges in a gay man's life
}

\section{Navigating through privileged systems}

\author{
Yasin Koc
}

Feeling too close to an undesired possible identity is worse for well-being than feeling far from a desired possible identity.

Oyserman and James (2011, p. 140)

In this chapter, I will explore a number of disadvantages experienced through the lenses of sexual orientation. I call these disadvantages lack of ordinary privileges. The origin of the term 'ordinary privilege' dates back to McIntosh (2012) and has been adapted and elaborated by Greenwood et al. (2017). McIntosh defines ordinary privileges as an invisible package of unearned assets that comes with being a privileged White majority member. It sets the normative way of being for almost everyone based on the lives and experiences of the White majority. It is subtle, constant, and persistent, yet rarely recognised. As Greenwood and colleagues nicely quote from the song of Ani DiFranco: 'privilege is a headache that you do not know that you do not have' (Greenwood et al., 2017, p. 498). Beyond providing a continuous sense of belonging and validation for the White majority, ordinary privileges provide norms and standards according to which minority members feel obliged to establish and maintain their lives. However, these ordinary privileges are often not acknowledged or openly discussed. Therefore, not owning these ordinary privileges certainly has a negative impact on the identity and the wellbeing of the minorities. In this paper, through a life history approach, I want to explore a number of 'lack of ordinary privilege' examples related to sexual orientation, and how they affected my identity, sense of belonging, and wellbeing.

I grew up in Turkey in a big family with traditional cultural and religious values. For me, homosexuality was always incompatible with the two main value structures I was holding. In terms of religion, I thought homosexuality was condemned by God, and all homosexuals were sinners. In terms of cultural values, I knew that being a real man required one to be heterosexual. There were three stages one had to go through to achieve manhood in my culture: circumcision, being a soldier, and marrying a woman, all of which are celebrated with big parties. At the age of 19 , with a very late awakening of my sexual orientation, for the first time, I was confronted by myself on 
my own views. At first, it was a challenge for me to accept this new identity in my life. All I knew was that homosexuality was only about sex, homosexuals were all sinners, and the only visible homosexual men were effeminate men and caricaturised drag queens on TV. When I looked at myself in the mirror, I did not look like one of them. I also knew that most people in my society humiliated homosexuals. It would not be easy for me to accept this new identity. At first, I was in denial. I wanted to hide and change this identity. There was not possibly a way I could accept this. Later on, I did my research, went abroad for studies, met actual gay men in real life at university and elsewhere, and accepted that I was 'normal'.

Unfortunately, as a member of a stigmatised minority, I believe we do not grow up being exposed to any proper representation of our identities. Hence, it is often very hard to figure out where we stand in life. Am I working hard enough for my future? Am I a successful student? Am I a good person? Am I reliable? Am I attractive? Regardless of the reality, the answers to these questions always made me feel like I was a failure. And, now that I think about it, this was because I've always compared myself to the wrong people. Therefore, as soon as I accepted my new identity, two things happened. First, I made sense of a lot of my childhood miseries, and second, I rebuilt myself. Now, I will share several snapshots from my life, and attempt to deconstruct these memories with the knowledge and experience of my today self.

I was probably 15 years old. I visited a female friend for studies. Her father loved me. He always said he saw me like his son and he trusted me to protect his daughter. That day, we were in her bedroom studying, talking about her boyfriend, listening to some music, and then I left to go home. But there was a problem. A group of bullies who bung out in the streets were outside the apartment. With a stray dog. They were smoking, doing drugs, and talking and laughing loudly. They knew me. They always made fun of me and called me names: 'ibne, götveren' (meaning faggot and cock knocker) - some words you would know. They also said 'top, tekerlek' (meaning ball or tire) - which are our local slangs to state that one is round, not 'straight'. I waited in the building for nearly half an hour, but I had to go home, so I left the building. The fear was growing up from my feet to my head and giving me a rush. One of the bullies spotted me, they all started calling me names, and then one directed the dog against me. I started running, the dog chased after me, he attacked me, and I ran into a shop to save myself. I still have some physical but many more psychological bruises from that attack.

Until after I came out to myself, I did not understand what happened that day. Why did the bully boys hate me so much? What could have possibly motivated them to attack me? I went to the same school with some of them, so their psychological attack was constant and pervasive. But why would 


\section{Yasin Koc}

they make a dog attack me physically? For years, I did not know why. My parents and my teachers often told me 'I was special', but they always followed it saying, 'You are very smart'. Nobody was ready to even think about how else I could have been 'special'. But those boys hated me that day because I was not like them. I was not boyish or manly enough. I had female friends. In a traditional culture, I could visit those girls in their apartments for studies. Their fathers trusted me to look after them. I could even go to their bedroom and nobody needed to worry. Deep down, everyone knew why I was not a 'threat' to my female friends. But nobody acknowledged why - neither to me nor to themselves. Therefore, my real identity was hidden from me. Occasionally, it was even denied to me. Regardless, what I took from that day which still continues to prevail in my life is fear. When I see a group of lads, I feel the same fear growing up from my feet to my head. I get paralysed. I expect to be physically attacked and harmed because these things continue to happen all around the world. I have not been able to develop any better way of dealing with this threat. And I doubt I ever will do.

I could not talk about this experience to my family. I knew they would blame me for this. I can hear my siblings' voices: 'You should man up!' or 'Stop hanging out with girls!' or 'If you get beaten up and come back home, expect another round from me'. Imagine being bullied by your peers, feeling the constant fear of encountering them in wrong places, and not being able to ask for support from the people who love you. Because my fear of losing them was stronger than my fear of being bullied and attacked by stray dogs. That's what it means to grow up with an identity that is not recognised. There are no norms or no appropriate representations to learn from. The only ones available for me out there were incompatible with who I was. I am a member of a minority, and this is an example of how the lack of ordinary privileges makes one suffer in life. So, I had to find my own ways to construct my identity today.

It took me nearly five years to reach self-acceptance from first realisation. Looking back, I used these years to update and adjust my value systems. I stopped using the word 'homosexual' because who I was is not only sexuality or an orientation, but it is my gay identity. Yet my next fear was social rejection. Coming out to others is a process that cannot be undone; I did not want to risk losing everything (e.g., my family, my reputation, my dreams) by endorsing one identity of mine. At first, I spent a lot of time dealing with my own homophobia. The most efficient way was through contact. During my bachelor's education, I made gay friends at the university and spent time with them. This helped me reconsider others' position in my life. I decided to keep those who would see and accept me as who I was, and I would let the others go. This was happening because I had just learnt my life was not constrained by the traditions and rules of my culture, which prescribed heterosexuality and derided homosexuality (Eslen-Ziya and Koc, 2016). But there was more, because I believe if people are allowed to make 
their own choices about values, love, life, and work, there is a high possibility that they will select a psychologically rewarding match between their choices and their individual desires. But this was still not easy. How others perceived me set the boundaries of my identity for a long time:

One day I came out to a close friend, and she was not surprised. She was supportive and easily comfortable with my new identity. She asked me how the 'sex' worked. And I said it works as it would normally do. Clearly the question was one of the well-known: are you top or bottom? Then she said, 'I see no point in being a top. If you would be a top, you could as well be straight.' I fully disagreed with her, but I nodded in agreement.

Gay men often get asked inappropriate questions related to their sexuality. Some common ones are: 'Are you top or bottom? Do you use Grindr? Have you had sex with married straight men? Will you tell me if my boyfriend is gay? You use condoms, right?' After my self-acceptance and selective comeout to a small group of friends, I was immediately seen as an expert to answer these questions. For me, however, I was no more knowledgeable than anyone else. All I knew was 'If I would just be a top, I could as well be straight'. That's how the nature of my sexuality was defined for me for a long time: another person telling me how to be and who to be! I was confused though. Even though I felt and wanted things differently, I was not in a position to make sense of this confusion created by the wrong sources of information.

Although confusions can be resolved by seeking the right information, I realised those questions would never leave me alone. After coming out, I suddenly became the token gay man in a lot of straight people's lives, and I had to answer all their curious questions and represent the whole gay community. This is another manifestation of the lack of ordinary privileges: getting one's individual identity ignored and being asked to represent one's whole community at all times. How often do we ask heterosexual people how they have sex with their partners? Who is taking which role in bed? How often do we see heterosexual people's sexuality being underlined on the news in a completely unrelated news piece? The latter reminds me of a debate in Turkey in 2009. After a referee came out gay in Turkey, his contract was frozen by the referee association. A group of middle-aged straight men were discussing the fate of this referee in a sports TV programme, and one commentator said: 'I find it questionable to have gay referees. If they were to make a decision about a handsome footballer, how would we expect them to be fair? I think they will make decisions that will benefit the handsome, strong footballers'. He was wrong about his assumption that a gay referee would base his judgment on footballers' looks, but he was right that the judgment of the gay referee would be questioned based on his sexual orientation. And that was the case for me too. Hence, on top of fearing 
physical harm and social exclusion, I had the fear of being misunderstood in my actions. Would people judge me if a handsome student gets an A in my course, but the average-looking student gets a B? Would people believe that the grades are based on their work and not on their looks? Or how many straight professors experience the same fear? I reckon there will always be an asymmetry in our experiences as long as we, as gay men, are reduced to our sexual identities even while performing our professions, whereas heterosexuality remains to be an invisible factor in straight people's lives.

In an ideal world, I would like to only represent myself, but I have come to the conclusion that this is nearly impossible as long as I continue to interact with other people. My actions are perceived based on sexual orientation or on behalf of a whole community; moreover, their actions are also associated with me. And unfortunately, this is not simply because I come from a traditional background in a traditional society. My experiences were no less disappointing or less stigmatising when I moved to the UK. There were certain sets of behaviours, thoughts, and emotions I was allowed to express. Living accordingly, I was accepted and my identity was affirmed. In other cases, I was not good enough to be a gay man:

It was during the early stages of my PhD when I was planning to spend the weekend in my office to catch up with work. At the time, I was living with a gay guy. He asked whether I would join him to watch Eurovision or had I other party plans. When I said I was not sure if I could because I had work to do, he replied, 'I am not even sure whether you are really gay'.

My landlord struggled to categorise me into his mental box of what it means to be gay. I had to watch Eurovision. I did not know. My identity did not come with a user's manual. Later on, I learnt many other 'rules' that would make me gay. I had to go out every weekend. I had to love Madonna. I had to talk about my sex life openly. I had to be fashionable. I had to know who Marc Jacobs and Alexander McQueen were. I had to enjoy shopping. I had to help my friends shop. I had to look down on religion. I had to check out saunas or other cruising areas. I had to be a fan of RuPaul's 'Drag Race' or 'Queer Eye'. I had to be into hard-core partying and enjoy drugs. I had to hate kids and marriage. I had to drink excessively and die young. I had to find a boyfriend - but first, I had to sleep around.

My landlord was not alone. There were many gay or heterosexual people around who judged me based on the rules above. Often, I was called 'not gay enough'. Sometimes I finally looked or acted gay. I did not have a choice. This time, the emotion I felt was not fear, but it was frustration. Whenever I tried to have a conversation about any of these unspoken rules and personal choice, I was told that I would eventually learn. It is more reasonable to understand that the limits of my identity will be incorrectly drawn by a traditional society who is not familiar with my identity. However, it makes 
it difficult to see why a more open-minded society, or even other gay men, would deny me my own experiences of my identity and try to shape me into what they thought was a correct form of being gay. Perhaps it was to create norms and protect the gay identity, as it was known. They were not ready to accommodate my take on our identity. Because, in a way, they were superior to me when it comes to being gay. With their clearly condescending voice, I was told I would eventually learn because, for them, I had another barrier to understanding all of those: my non-White identity. My White saviours were there to show me the only and proper way to be gay. Coming from a traditional family and culture, I was there to learn and adapt, not find my own ways to express myself. I'd better comply and learn from them if I did not want to be ostracised again. And, that's what I did for a long time.

My intersectional identity of being a non-White gay man was not only a barrier for me to learning the proper ways of being gay: it was also a way others could discriminate against me and put the blame on me:

I was out with friends in a gay bar in Brighton. Late at night after a drag show, we were all dancing waiting for the pub to close so that we could all head to the next one. One handsome guy came closer and started dancing with me. It was a time when I had quite a long beard. He touched my beard and said, 'I really like your beard'. And I thanked him. He asked me where I was from, I replied, we danced more, and he continued, 'Is it Islamic?' I never heard of any beard being Islamic before. I asked back 'What?' and he asked 'Are you Muslim?' And I did not say no. 'Most people from Turkey are culturally Muslim'. And he continued, 'So do you support ISIS?' And this was completely out of nowhere. But for him, having a beard and being even culturally Muslim was enough to be an ISIS supporter. I was certain his behaviour was unacceptable, so I would not encourage him. I said 'This is not okay and I don't want to talk to you'. And his response was, 'Come ' $n$ ! Calm down! We're both gay. Nothing to hide here. Don't be too sensitive. You are not a lady!' Back and forth, this conversation did not go anywhere, until my White British friend came to my rescue and said 'Mate, my friend doesn't want to talk to you'. He left, and I was saved.

The aftertaste of this memory is still very bitter, but, for now, I only want to focus on my emotions and his assumptions at the time. Simply, I was angry. His conversation included sexism, racism, and homophobia altogether. By creating a common identity as gay for both of us, he thought it was okay to ask me such inappropriate questions, but it was my reaction that needed pruning. I was the one who had to calm down because I did not know the etiquette for conversation in a bar. At the end of the day, I was a 'foreigner' who needed to learn ways of being gay from him, as well as integrating into the British culture. He had the right to set the boundaries for my identity. I was used to experiencing or witnessing sexism, racism, and homophobia 
in my life. Hence, my anger did not directly derive from these, but entirely from his insistence on not leaving me alone despite my constant requests. He only respected the wish of my White saviour, and then he left me alone. This made me angry. I was nearly 30 years old, believing that I had rebuilt myself and was living in a free environment. Suddenly, I had to face the boundaries of my identity set by others again.

When I talk about this experience in class or workshops, I typically get one question all the time: do you think he left you alone just because your friend was White? To be honest, it does not matter. That's how it felt at the time, and that's how I still feel reflecting on that experience. And this is not about my experience only. This is an explanation based on identity theories and theories of oppression. On the one hand, I had our minority identity of being gay in common with him. Therefore, one might think he is not in a more privileged position. However, as identities intersect, his White identity gives him the legitimacy to even lecture me on my sexual identity. Therefore, when I asked him to leave me, the identity salient to him was his Whiteness. The way he addressed me, 'Come ' $n$ ! Calm down! We're both gay' was indeed a way to patronise me, instead of finding a common ground. Therefore, he only stopped when he was confronted by another person like him: a White gay man. Ultimately, I felt my agency was taken away from me, and my words had no meaning; so, I felt angry.

Finally, I want to share a recent unpleasant experience during a dinner with some colleagues. I categorise this experience as a moment of unnecessary sensitivity on my side, but I had the opportunity to understand the underlying reasons behind my reaction while writing this piece:

I was having dinner after work with a few colleagues. One of them also has stigmatised multiple identities like me. We do pick on each other a lot. And not all our jokes are always politically correct. One day, we were talking about his children. And he said 'You are not getting anywhere near my children'. They all laughed; I could not. The joke was appropriate, because he was referring to the fact that I often find children annoying, not to my sexuality. But I was suddenly extremely uncomfortable. I immediately went quiet, felt embarrassed, and almost scared. I almost felt like I'd been accused of child abuse, which was not in any other person's mind at the dinner table.

Members of the majority use a variety of strategies to stigmatise minorities. One example is the false association between paedophilia and homosexuality in the 70s. Although this is no longer recognised as a reasonable argument (at least in the Western world), it remains to be one of the driving forces for anti-gay attitudes among religious communities and countries across the world. And as it turns out, given the context, this might also be a trigger for gay men like me in the 2020s. Although I am entirely sure that my colleague did not refer to my sexuality during the conversation that 
night, I felt psychologically threatened once such an association was made in my own mind. Clearly, the heavy burden of the negative stereotypes is much stronger for minorities, and it implicitly persists even though those stereotypes are no longer readily available in the public domain. In the back of my mind, I feel like I am constantly being tested against my sexuality by everyone around me, and I have to be a good person to pass the test. Every interaction at work, with friends, or in shops is a test. The standards are higher for me as a minority member and I am constantly under the stress of my performance to be counted as a good person.

This reminds me of some fantastic research where the effect of meta-stereotypes in interactions are examined. Shelton and colleagues (2005) invited ethnic minority and White students into the lab for an experiment. Half of the ethnic minority students read an article about racial prejudice, and the other half read an article about prejudice directed against the elderly. Next, they had an interaction with White students and finally responded to some questions regarding the interaction. The idea was that the ethnic minority students reading about racial prejudice would be primed to expect prejudice towards themselves. The findings indicated that the ethnic minority students who read the racial prejudice article had more negative affect after the interaction, and they felt less authentic during the conversation. However, White participants who interacted with ethnic minority students reading about racial prejudice liked their partner more, enjoyed the interaction more, and reported less negative affect. This asymmetry in the experience clearly shows how we, as minorities, overcompensate in our daily interactions with the majority members which makes us liked by the majority more yet has consequences for us. Therefore, every interaction feels like I am constantly being tested against my sexuality by everyone around me, and I have to try to be a good person to pass the test.

\section{Reflections on my writing}

Moving forward, I want to reflect on my experiences and analyses above and situate them within the larger context of research in social psychology. McIntosh says privilege is the 'upside' of discrimination (2012, p. 203). Without examining how lack of privileges undermines belonging and selfesteem for the minority, our research into understanding the experiences of the minorities will remain incomplete. We know that the relationship between discrimination and well-being is well established. According to the meta-analyses by Schmitt and colleagues (2014), discrimination is linked to lower levels of self-esteem and life satisfaction - and higher levels of depression, anxiety, and psychological distress. However, these studies almost always focus on direct ways of discrimination that one can easily recognise: not recruiting someone with migration background into the workforce or treating someone badly due to their physical appearance, their age, gender, or race. However, the experiences I discussed are different than easily 
recognisable discrimination instances. They are disadvantages or lack of ordinary privileges, linked to a group membership, which are subtle and not widely accepted as discrimination. Therefore, coping with them is a lot more challenging because first we need to be able to recognise them.

If you witnessed someone being discriminated against next to you, perhaps you would intervene and try to help them. But how would you know about the psychological threat I experienced at the dinner with my colleague? That was a stereotype triggered in my mind out of nowhere. I do not suggest this is unique to me or to the gay community. Anything can be a trigger for someone that we may not be aware of. However, since negative stereotypes for stigmatised groups are more prevalent, I believe we experience this much more frequently. Besides, we are not equipped to deal with these challenges on our own while trying to figure our own identity processes. However, White privilege, male privilege, and heterosexual privilege are the established systems that not only communicate belonging to their members, but also provide tools for being successful and thriving in life. Stigmatised identities do not come with such established systems and tools. Minority members often deal with these challenges themselves.

I believe this is one of the reasons there is a higher prevalence of mental health problems among the gay community. According to Meyer's Minority Stress Model (2015), there is a unique stigma directed towards the LGBT community, and these unique stressors cause mental health issues. However, the model also suggests that, as a response to the stressors, minorities may develop resilience at the individual and community level. Individual-level coping involves building resilience through so-called individual resources and promotes success over adversities. However, this idea is based on meritocracy and ignores the structural inequalities by putting the responsibility on the individual. In reality, people do not have equal access to social, economic, and political structures, and these structural inequalities may limit their opportunities for resilience. Ultimately, minority members feel added stress to achieve resilience given their limited resources. In this way, society feels stripped off from their responsibilities, and we tend to blame the minority for their failure to build resilience. Contrarily, some minority members can also push the boundaries and become overachievers with significant costs to their mental health. I feel this has been one of the ways to cope with minority stress for me: I tried to excel in everything I do, and moreover, tried to do multiple things at a time. If I failed or disappointed someone for being gay, at least I could show that I had other achievements and I was worthy.

There is also community-level coping with discrimination which involves creating social support systems among the minority members and their allies and engaging in collective action to improve their status (Bourguignon et al., 2020; Koc and Vignoles, 2018). Such communities may contain role models to look up to and create norms and values about the identity. It then helps minority members have reference points for their identities and perhaps, 
ultimately, be the basis for compensating for the lack of ordinary privileges in our lives.

At the beginning, I mentioned that two things happened as soon as I accepted my new identity: first, I made sense of a lot of my childhood miseries, and second, I rebuilt myself. I gave some examples regarding several instances of thinking, making sense, and rebuilding. The good news is that it works. I have fewer fears now. I get frustrated or angry much less often about how others perceive me or treat me in relation to my sexual identity. Perhaps, this is because I am better equipped to challenge such negative attitudes and behaviours; perhaps, the world is becoming a better place treating me more like an equal (which is rather unlikely). Also, I have become an academic researching these topics as a form of political activism. This not only helped me learn more and build collective resilience, but also created a knowledge base for the community with academic and practical implications. However, I do not want these experiences to be perceived like a bildungsroman. One's own agency and hard work alone do not improve the situation. Regardless of all the efforts of adapting myself and finding a good fit between who I am and how I live, this progress is not linear. The reminder of an 'old-fashioned' stereotype can easily be a trigger of an identity threat. I am still exposed to questions regarding the intricate details of my bedroom life. I get judged in a conversation because I have not seen the latest (or any) episode of (Ru Paul's) 'Drag Race'. I am still afraid to disappoint my parents. Besides, such experiences can still trigger fear, anxiety, frustration, anger or shame about the situation or myself. Therefore, I continuously look back at the reservoir of tools I have, reinterpret my experience, seek the help and support of others, and find a way to cope with such threats to my identity. Finally, I am feeling closer to a desired possible identity than feeling too close to an undesired possible identity. Yet challenging lack of ordinary privileges is not about me, but it is about challenging the existing structures and improving the status of my community. Therefore, we still have a lot to do.

\section{References}

Bourguignon, D., Teixeira, C. P., Koc, Y., Outten, R., Faniko, K., and Schmitt, M., 2020. On the protective role of identification with a stigmatized identity: Promoting engagement and discouraging disengagement coping strategies. European Journal of Social Psychology, 50, 1125-1142.

Eslen-Ziya, H. and Koc, Y., 2016. Being a gay man in Turkey: Internalised sexual prejudice as a function of prevalent hegemonic masculinity perceptions. Culture, Health \& Sexuality, 18(7), pp.799-811.

Greenwood, R. M., Adshead, M. and Jay, S., 2017. Immigrant women's experiences of acculturative stress: Ordinary privileges, overt discrimination, and psychological well-being. Psychology of Women Quarterly, 41(4), pp.497-512.

Koc, Y. and Vignoles, V. L., 2018. Global identification helps increase identity integration among Turkish gay men. Psychology \& Sexuality, 9(4), pp.329-342. 


\section{Yasin Koc}

McIntosh, P., 2012. Reflections and future directions for privilege studies. Journal of Social Issues, 68(1), pp.194-206.

Meyer, I. H., 2015. Resilience in the study of minority stress and health of sexual and gender minorities. Psychology of Sexual Orientation and Gender Diversity, 2(3), pp.209-213.

Oyserman, D. and James, L., 2011. Possible identities. In Schwartz, S. J., Luyckx, K., and Vignoles, V. L. (Eds.) Handbook of identity theory and research (pp. 117-145). Springer, New York.

Schmitt, M. T., Branscombe, N. R., Postmes, T. and Garcia, A., 2014. The consequences of perceived discrimination for psychological well-being: A metaanalytic review. Psychological bulletin, 140(4), p.921.

Shelton, J. N., Richeson, J. A. and Salvatore, J., 2005. Expecting to be the target of prejudice: Implications for interethnic interactions. Personality and Social Psychology Bulletin, 31(9), pp.1189-1202. 


\title{
9 I dreamt of a stranger
}

\author{
Julian Triandafyllou
}

Will you show face?

Not today.

Age?

Why does it matter? I can just lie anyway. How old do I look?

What are you into?

On a webcam? I assume I'm into jacking off with a stranger.

No, I mean in irl.

But this isn't real life.

To be a successful cammer depends on your willingness to commit to the performance. On some sites, it's about simultaneous viewer counts, on others it's about intimate and 'roulette-based' chance encounters, face or no face attached. It's a safe place for someone like me, afraid of sexual intimacy and the cavernous wound it can create.

There are moments where my eyes meet my companions over the screen and we can really see each other, wondering what connection might feel like. Should I ask for their details, I think? No, this is just a wank, once you've come it will be over; but I can feel it. I wonder if they do too, as we are together, by chance. I like seeing their homes, their cars, their balconies, their lives littering the frame of the screen. In our aloneness, we have created connection without the hazard of physical touch.

See the boy, he's on a plane sitting next to a rounding American man, who's wearing a colourful cartooned Hawaiian shirt. 'Your shirt's fun' the boy says, he isn't shy. The man has a bag of candies to hand and gives him some, the boy accepts. The man's hand finds its way to this young boy's leg, in shorts for the summer, and holds the soft skin.

See the boy, dressed like Mowgli, in a community theatre group production of The Jungle Book. Bronzed head to toe, and wearing a small loincloth, he looks like a pretty little girl. Everyone says so. In one scene he sits on the knee of a man, he knows also as a teacher from school. The boy smells the man's dairy breath wafting over him. Sweat is dripping from the man's brow, falling over fearful eyes, his fingers restrained around the boy's 


\section{Julian Triandafyllou}

naked waist, an awkward and proper grip, 'don't fumble here' the fingers say, the boy can hear them.

See the boy standing behind his desk in school. There was butter under the table and leaning back on his chair it had attached itself to his knee. Someone had put it there. After class, Mr Trevor, inspecting the table, got onto his knees using his hand to hold on to the boy's buttock, before gliding along the crease to the inside of his nylon clad legs, all the way to his ankle, and scuffed leather school shoes. The boy's retraction was too late. It had felt like an eternity, but it had happened swiftly. Up until now Mr Trevor had just handled, held, cupped, caressed, patted, fondled, his bum cheeks as he stood at the whiteboard, or made his way there. The class always saw the indiscretions. It was common knowledge that it was something $\mathrm{Mr}$ Trevor did, but there were the chosen few that it happened to. That night, the boy told his parents, 'Mr Trevor... makes me uncomfortable... he comes too close'. He couldn't say the words. Not asking any more, in return, 'just keep away from him' they said.

See the boy in the school nurse's office. He's crying because he feels unwell. He's been called gay, and it hurt inside. The nurse lets him stay while he composes himself.

The men who touched the boy, as far as I know, were not openly gay. Within the school there were teachers who were out gay men, which, now that I'm older and am aware of Section 28, was pretty special. Those teachers, those men, never conducted themselves in a way which would infringe upon the boy, nor his ability to learn. In fact, they actively supported this boy to succeed and gave him care and acknowledgement to do so. They didn't know their efforts were being thwarted. They also gave the boy a valuable representation. This sight, of an openly gay man who has a partner, allowed him to see, that he, he wasn't made wrong. He could love another boy. And that it wasn't wrong, there could be a life. Just don't touch me.

I fell down and cut my knee. Mrs Penry comforted me, I could see the bone, I thought. hair.

My tired head on my mother's pillowy, warm legs, her hand stroking my

Holding my best friend's hand and, all over, feeling like we can do anything - together.

I know what comfort feels like.

How dare you.

He is a good man, a very respected teacher, they said, a glittering record, he would and could never hurt a child, they said, it was the touch of 'pastoral care' they said.

Him, that boy, he's a dreamer. A fantasist. Not to be believed!

Look! It's all over the boy's school reports, they said.

If only he didn't spend so much time looking out of the window.

It's true, I did. 
We accidentally confronted each other in the airlock between the courtroom and the hallway. This small old man cowering before me. And yet there was the boy again, scared and shaking like a leaf. My body crumbled inwards, to meet the boy's size. I was on the pavement, near the bridge, near the river, as a painful wail burst from my chest and my legs buckled. They said it would be important to confront him; they said there weren't many other options; they said the school wouldn't listen.

They didn't say it would be a public humiliation.

They didn't tell me my partner would look at me like I was diseased, his meagre grip struggling.

Why couldn't you hold me?

See the boy, he's back at school, a feeling of slimy destruction washing over him. His knees and legs are hitting each other rhythmically, spreading open and closed against his erection. He stares intensely at the physics teacher, Mr Rolands. For a brief moment the man's eyes meet the furious child's, and a sense of terror fills Mr Rolands up. The boy doesn't flinch, legs opening and closing. Mr Roland turns abruptly and goes back to work. The boy has already moved on, and is planning on dropping his pen on the floor, so that he can take a sniff of poppers under the table. He does this in chemistry too. His face would be flushed as he sat back up and his mind would be blurred and blunted.

The bus was empty on the top deck bar for one man behind the boy. Can you see the boy sitting there in his school uniform? The man undoes his belt buckle button and lowers the zip of his jeans; he pulls them down to the ground and lifts up the tabloid newspaper he has ready. It's there to cover him from being seen by the bus driver through the periscope. The boy hears, his ears pricked, his face pale, and a fearful form of arousal stirring. The man might have been looking at the boy. He doesn't know, as he brings himself to climax. The man drops the newspaper and zips up as he hurriedly leaves the bus. The boy sees the newspaper on the floor behind him and goes to look at it, he's stained a naked woman on page 3. He can smell the man's seed. He carefully closes the newspaper, to ensure it became his, to ensure no one else would know.

I'd had to run. He had chased me into the station. I was sure I had lost him, but as the doors of the train were blinking shut, he boarded. He was coming straight towards me. I found myself breathlessly cowering as this man's crotch met my body. I could feel him looking down at me, as he forced me against the glass that separates the seats from the standing area. I won't acknowledge him, this isn't happening, I look around and catch the eyes of a woman, 'help' my eyes scream... she glances away, 'I' $m$ not getting involved' they say. Facing the darkness, I close my eyes as the lights of the next station intrude. The doors of the train sweep open as he lets me run, obviously satisfied.

I won't tell anyone about this. You're the first. 
They said that maybe I wouldn't want to be present for the expected incursions; they said that maybe it would be better if I go into hiding for a while until it's safe out there. Dissociation, they have called it.

You were safe in there, then, they couldn't get to you, they couldn't take you away from me.

I'm sitting on a wooden bench in the winter sun, looking at diagrams, there's a medical model for this. He says it depends on the variable costs of the denial, avowal, and the pain. The brain can't process all of the information and so it's a form of protection. From the truth.

You needed to bide.

This word, 'gay', that had somehow attached itself to him, and felt too that it was true and real, that these necessary acts were a part of that. They had all told him it was time to grow up, that there would be a biological creation of sexuality, through puberty, and that things would change. They didn't say that there would be someone, crowbar in hand, attempting to wrench it and pry it out before it was ready. It didn't feel like an accident to him, and so he assumed it was a form of preparation for a life of loving men. Maybe these men were conducting a necessary ritual.

I loved the sound of the request as a new chat box would open. There was a sense of anticipation of meeting someone new. Starting with the compulsory 'asl', deciding how I would answer that - with honesty, or through an avatar - I could then proceed. I could play out various situations and test the water, play other people. I also remember I once activated the webcam and performed a 'show' for a number of older gentlemen in a specific group chat where this was available. It was exciting. I can still hear the thick Virginia accent, as this older man commanded my movements for him over the headset.

See the boy sitting on a plastic blue swivel chair, he is in the office of the family home; he is removing his clothes. See the boy as he is coerced into creating pornography. See the boy, saved as a file onto a hard drive, so he can be re-used and shared.

When I had come, and left the space, that brief feeling of visibility I had found was quickly lost to a tidal wave of self-disgust because it was dirty to be gay.

'Julian, that was abuse. You were a child. There should have been someone there to protect you, to stop that from happening' he said. I had been seeing Jeremy now for 6 months in this office in the old docklands.

But I would crave it, I thought, I wanted to be there, this is what I want.

See the boy, he's on his road, walking home after a party; a creature wrapped around his neck as a scarf. He is inebriated. Under the tree outside the mosque, a man steps out of the dark. The man comes in very close, very quickly, the boy's ass is already in his hand. There's a gap here, a memory loss. The man asks 'Is this where you live?', the boy has opened the gate and they're walking through into his mews, stopping by the ivy-covered wall he allows it to happen. 
This dark face, you're handsome, you must be lonely, this isn't the right way, 'what's your name' I say, as he takes my kiss, and places my hand on his cock, makes me feel him, 'do you like it?'... I like it, don't I, I like it, 'yeh, yeh I do...' you seem so sad, we can be ok, I thought, but 'this isn't the way it's done', we can do this properly, 'sorry, what's your name?'. There's a neighbour leaving his house, someone I know, he's coming, I have to cover him, I will make it look real, like I want you. I do, I want you, I'm kissing you now, I'm holding you now... he's gone, why... neighbour didn't I... 'What's your name?'.

'It doesn't matter', the man says. 'Let's go to your house, I want to fuck you'.

The boy finds himself down the road again, in front of the $24 \mathrm{hr}$ Turkish restaurant. His face is wet, and he's struggling for breath.

I'm sitting in a large room, with five other men, and two therapists. I'm becoming euphoric as one my group describes how he met strangers in public toilets, older men who would ritually degrade him, or how he would do drugs with younger men and be treated roughly and left, feeling worthless, how he wanted to be, how he thought he should be. His cousin had raped him repeatedly, he was made to feel like he wanted it. I looked around the room at these men, overjoyed to know that they would understand. How relieving, I thought, to have a symptom and not a character flaw.

It was the lack of an available aggressor that left a vacuum - someone needed to take on the role.

I'm used to that, taking on roles. So let me, let me tell you what to do.

Drink, I'd say. So, you can't feel it anymore.

Maybe you'll wake up on the doorstep in the rain. Or maybe, maybe if you drink just enough, you'll be loose enough to let someone take you. Maybe, if you let yourself go, maybe that will make it quiet.

Maybe, if you can make it quiet, maybe then he'd love you.

Can you see the boy, he's sitting in a small red Volkswagen, with another boy called Leon, a friend from school. They are on a wet leafy road under the light of sulphur lamps. The boys are kissing, whilst music, a cd the boy had made, plays on the stereo. They would stay like this for a while, tasting each other, or maybe smoke a cigarette together or a joint, maybe they would hold hands, maybe they would just drive.

Maybe we could disappear together, steal your dad's fast car again, do you remember? That was fun. I remember that afternoon before the antiwar march where you told me I was the brains, and you the brawn. We were lying in that part of the heath which is a bit cruisey. It was a beautiful day. We felt ok there, I remember, I felt like we fit. It was near the end of school and maybe it would carry on; I hoped it would. I think I loved you terribly; I think you did too; I think you loved me terribly.

With Leon? Leon isn't gay, he has a girlfriend; I think you're imagining it.

I had a relationship with him, I would say I did. 
Leon had soft features, light dusty cropped hair, a rounded but pronounced jaw, sharp blue eyes receded into a rugged eye line, and a muscularity he would later attribute to steroid use. They just wanted to be close to each other. The boy felt safe in Leon's strong hands. There was one time, after they'd drunk a fair amount of tequila together, and then and only then, did they try and see if it might work sexually, but it was a mess, so mostly they just held each other, and that felt enough.

You can't even hug me in public, I told him. I'm finding it hard to be silent about this. Maybe we can go to a gay club or a bar where no one will know us, maybe we can find a way, maybe you can do that for me?

When school ended, they went on their individual travels and left things open. The boy began an arts foundation course in London, and, on a visit from Leon after his trip to the Caribbean as a ship hand, Leon revealed that he had slept with and lost his virginity to a female prostitute.

Why are you telling me this? He just looked at me blankly.

It culminated in a painful 5 days at Glastonbury Festival where they shared a tent, but Leon spent most of the time ignoring Julian. Leon was moving on, growing up. This was a childhood exploration, it didn't mean anything anymore. They would hold each other one last time in the tent, feeling the warmth of each other's fading bodies. But as Leon threw himself into a cocktail of party drugs, the boy, who was starting to look like a man, was ultimately forgotten and gave whatever feelings he had left into his job at the welfare tent. He gave strangers tea and comfort, after their tents had been lost in flash flooding.

Later that summer, the boy would accidentally escort himself to an older American gentleman in Tallinn, Estonia. A few weeks later, a guesthouse owner in Bosnia plied the boy with beer in his private living space, and then tried to accost him. It would be somewhere on a train, in the endless sunflower fields of eastern Hungary, where the boy decided that he didn't want to be like this anymore, and decided that he would have to go.

The boy sacrificially cut his hair to concrete this, removing the gay one snip at a time. He thought whilst he did so of his old queer piano teacher, who had once called him and his curly locks 'Samson'. He thought that maybe the power would leave with his hair. In this dingy guesthouse, he watched on the screen of his Sony DVCam as he tried to become more manly for the camera.

He knew where he was meant to go. He had seen the men whilst still at school, standing behind trees and looking wistfully out for another set of eyes. He had also come here recently in the search of the 'sex tree' and found a leafy sheltered arch where the ground was littered with used condoms. He wasn't sure this was the spot, but desperately masturbated on the leafy ground alone, longing for an intruder.

He would be grabbed by the wrists and forced down. Entering him they would whisper 'dirty faggot' before kissing his ear. He might cry out, but would be joyful for getting what he deserved. 
He awoke a couple of hours later on this bench; the sun poking its head through the pine that sits above the small pond. The iridescent colours, the pink and orange of a new day, were beginning to creep with early morning commuter traffic. He would walk down the hazy, dewy steps behind Jack Straws Castle and experience an immediate wave of acknowledgement, followed by eyes weighing up possibility. A dark builder in his fluorescents and steel toe caps moved out of his way. A burlier older gent, in a maroon v-neck jumper and barely concealed comb over, passed a glare. A younger lad in trackies and a buzzcut, probably high, walked decisively past. And that seemed to be it. The other men and faces became blurs, as he walked out of their world and onwards home. He was surprised at how many men there were at that time of the morning. He wondered why no one would just take him, and why he couldn't surrender.

Can you see the boy, he's still there, dancing in Heaven nightclub, on a Monday night. He's made it to the grimier top floor. His arms are up to the ceiling revealing his bare abdomen, his head is flinging side to side with his hips grinding to the dirty bass-line. Eyes are spitting everywhere, waiting for a glance, lights spinning. He looks across and someone catches it. That brief glimmer is all it takes, and spinning around they're suddenly dancing, crotch to crotch, the man's arms around the back of the boy's body holding him. The boy's hands feeling under the man's shirt, at the body hair, reaching up to his face and his stubble, before they kiss. Their arousals united, the man puts his hands down the boy's bulging trousers and pleasures him on the dance floor. The boy feels it like communication, an innate understanding of his longing. 'It's possible, here' he thinks, 'in this space'.

On the rowdy bus home, the boy's face is still tingling from the rubbing stubble, the taste of manliness lingers on his tongue. As the next day arrives, the sensations start to disappear with the enveloping hangover, and the details fade even faster than the feeling of his childhood being rubbed away.

We had just had intercourse; it was the second or third time. I don't know how we decided who would take it and who would receive, but I suppose I just let these things happen, so fell into the roll of receiving. I waited for Peter to come, I couldn't, I didn't want to. He knew this about me. I cleaned myself up with a towel, put on my T-shirt and trousers. I felt cold, and after giving Peter a kiss, I went downstairs, three flights down, through the kitchen he shared with his father, which was littered with trinkets and paperwork and out into the walled and damp garden. I wanted to have a cigarette alone, away from Peter.

Peter was kind and fun and loving. He had allowed me to walk gently into his life and was bursting to share it all with me. He had seen this young man on the fence and felt it was worth the effort to try. I'm grateful he did. He had pulled me out of four years of enforced celibacy, after that melodramatic haircut. Peter took Julian dancing at Duckies, in the Vauxhall Tavern, and spun the queer back to life amongst the disco of hairy men, vaudeville, and cheap drinks. 
Things would eventually end, and Peter would move far away to Vietnam for work. On a rash visit to see him, I would try and explain to him, that I was 'dealing with something', I wanted him but 'maybe those experiences at school... with the teacher' had something to do with it, maybe if he could try and help, maybe I could move forward and we would work. Our intimacy issues weren't his fault, he said. I had made him feel poisonous, and it was clear my actions had broken what we had.

I fell off my chair after I asked Edwin to kiss me. He looked down and laughed before helping me up. 'Let's go' he said, as we grabbed our stuff and sneaked out of his friend's house party. We made it to the outstretched, concrete balconies of these 1950s estates before our lips awkwardly fell over each other's faces, and we grappled with desperate, boyish fumbling towards the stairway and down onto the damp street.

This messy one-night stand turned into brunch the next day, and then into a few weeks of togetherness. He touched me with care, and a deep and honest longing; I trusted him with my body. This all surprised me because it was Edwin's first real relationship with a man, and so this freshness became a new start for me too. The first three weeks flew by in a haze of wild teenage exploration before that man, whose name I can't remember, assaulted me outside my house. The aftermath of the assault revealed an infected rash of memories, some of which you've read here. I said to Edwin, 'you can still be having fun, you don't need to take this, me, on'. But he wanted to stay. I wanted him to stay too.

I would hide the worst under meditation and yoga, which I found lifted me up to a level zero. I was also in therapy and just trying not to be the worst that I felt, at least with him. But sometimes I would disappear - no hearing, feeling, or loving, unwilling to have sex. Sometimes the touch of Edwin's hand on my waist, a kiss on my cheek, would make me jump.

I knew he was there; I knew he was right there next to me, why had he scared me?

There would be a public trial against my teacher, in which I had to stand as a witness. I would become consumed. Edwin found it increasingly hard to look me in the eye and, unconsciously or not, tried to escape. This life we were living was a secret life from his family, and it was perhaps suddenly becoming all too real; my bravery in the face of very real demons shamed him further. I would ultimately go through the process alone, whilst also having to care for him.

Even though I craved visibility without the restraint and shame of secrecy, I also wanted to preserve the relationship. It had taken me so long to get here, that I refused to give it up. I would end up facilitating our lives so that our difficulties couldn't become real - I micromanaged our pain until neither of us could breathe anymore. On the seventh anniversary of our meeting to the day, even though we still loved each other, we left each other and went our separate ways. 
I had only seen him as a series of torso and leg shots, obviously from the gym, on the app - he had a toned physique, with some hair, potentially early 40s, not street-savvy as his trainers weren't trendy at all. I met his eyes across the keyboard in the darkness of my bedroom. His face was withdrawn, and pale, and his voice soft, timid, and expressed his Italian heritage; his hair was shaved back to the same length as his stubbly beard. 'Tomas' he said his name was, he worked in IT for the NHS. He had asked me what I was into earlier, on the app, and I had said I'm not sure, I asked him what he was into - 'Oh, I like fucking, sucking, kissing, rimming, blow jobs...' I like that stuff too, I responded. We would spend an intimate 15 minutes masturbating together, him intimating penetrative sex with me and making sounds to inform me of him getting close to climax. He wouldn't come though, and didn't want to, but he was happy I did. I thanked him. Our eyes met briefly. He hoped that one day maybe we could meet when the lockdown was over, and we said goodnight.

\section{Two-way mirror}

I would describe this text as a portrait of a fractured self, a self in conflict (Krishnamurti, 2018). A self that has been forced to live multiple lives - to find safety, protection, and understanding. It's an experience that I know many gay men go through with or without CSA (childhood sexual abuse). This opportunity to normalise my experiences of CSA in the context of my life as a gay man, to see my experiences as one road that a gay man might (sadly) have to take as something not normal, but ordinary, has given me the bravery to explore it openly. Edgar and Jason gave me the permission I needed to feel that my experience is not irrelevant or obsequiously unique.

During my MA in 2018, I suddenly had university access to a world of medical journals. I would read a lot (e.g. Dare, 1993; Schwartz \& Galperin, 1993; Cromer \& Goldsmith, 2010, Friedrichs, 2014) to try and find answers, to find routes out of what sometimes feels like a perpetual purgatory of reexperience. Although not always helpful, it showed me that some of my actions were indicative of overcoming the shame surrounding the abuse the two films I would make were a public opening, but also a necessary creative expulsion. It hasn't been conducted in isolation. My self-care includes psychological personal and group therapy alongside a consistent personal practice in meditation, breath work, and yoga. These practices have been vital in my healing and, I realise now, are also recommended for the effects of trauma and dissociation ( Draucker et al., 2011; Van Der Kolk, 2015). It has been a process of creating safety in my body whilst learning agency, taking back what has been lost.

Writing as candidly as I have here about my past might seem brutal, perhaps uncaring. I have actually found it necessary and vital. It has been about reclaiming my sexuality proudly (away from the abuse) and exploring 


\section{Julian Triandafyllou}

it vividly; the writing process has been another act of agency. I have had to be careful; I have had to change details to protect myself and others. I have also had to confront the fact that those mentioned may read this one day. This has forced me to be as honest as I possibly could with the result.

Through each of these voices represented, I have learnt and grown and lived maybe many more lives than I would have liked to, but they have made my life and understanding much richer than someone without the difficulties of being born other (Odet, 2019) in what Derek Jarman would call 'heterosoc' (Jarman, 1993). I feel grateful to be able to offer these words to a stranger's eyes, to see if perhaps we might meet and understand each other.

'I don't know your name', one of the films mentioned in this text, is available to view via this link: https://www.julianpericles.com/IDKYN

\section{Acknowledgement}

With thanks to Jaap Van Der Schaaf for his support and encouragement.

\section{References}

Christopher Dare (1993) Denial and childhood sexual abuse, The Journal of Forensic Psychiatry, 4:1, 1-4, DOI: 10.1080/09585189308407786

Lisa DeMarni Cromer \& Rachel E. Goldsmith (2010) Child sexual abuse myths: Attitudes, beliefs, and individual differences, Journal of Child Sexual Abuse, 19:6, 618-647, DOI: 10.1080/10538712.2010.522493

Claire Burke Draucker, Donna S. Martsolf, Cynthia Roller, Gregory Knapik, Ratchneewan Ross \& Andrea Warner Stidham (2011) Healing from childhood sexual abuse: A theoretical model, Journal of Child Sexual Abuse, 20:4, 435466, DOI: $10.1080 / 10538712.2011 .588188$

Jörg Friedrichs (2014) Useful lies: The twisted rationality of denial, Philosophical Psychology, 27:2, 212-234, DOI: 10.1080/09515089.2012.724354

Mark F. Schwartz \& Lori D. Galperin (1993) Reenactment and trauma, Eating Disorders, 1:3-4, 315-320, DOI: 10.1080/10640269308251170 


\title{
10 Testing proximity and intimacy An everyday reappropriation of private and public space
}

\author{
Edgar Rodríguez-Dorans
}

It's the early 2000s and I'm in a navy-blue Chevy with Julio. We're in the middle of insufferable traffic in Mexico City's periférico sur. It's supposed to be a highway, but often the traffic moves at such a slow speed that sometimes we come to a complete stop for various minutes. This is not an extraordinary occurrence. It's my first car ever, and it doesn't have air conditioning, but it has a sunroof that we love because through it we can see the sky. It's a small utilitarian car that originally didn't even have a radio, but a nice sound system was installed as an add-on. It also has tinted window film that was added for safety and sun control, which also affords us paradoxical privacy to be alone in the middle of a crowded city. The car is important because it was one of the spaces where we have had the chance to explore our intimacy in many ways: with music, with conversation, with our bodies and selves. The heat is intense, but we sing out loud to Robbie Williams and Blondie songs even though we only know half of the lyrics. We are hot and sweaty and stuck in traffic, but we are happy and together. We kiss when we come to a complete stop.

We are in our late teens or early 20 s and we both live at our respective family homes. Sometimes after finishing our classes at university, we go to my house and we continue what we started in the car. We spend hours in my bedroom, exploring our intimacy even more and having a nap afterwards. Sometimes our explorations and naps are interrupted by an unexpected arrival to the house. We set off in trepidation when my grandmother enters the kitchen adjacent to my bedroom, my mother comes home early from work, or my grandfather visits for some unknown reason. We get dressed and pretend that we are studying. We often find interruptions to our passions and experiments. Still, we manage to enjoy ourselves. The bedroom feels spacious; it has high ceilings, a door with a lock, a big window and an en-suite bathroom. Those details afford us a degree of privacy that we appreciate immensely. They also play a crucial role in our starting to understand the power that we could generate through our togetherness. José Esteban Muñoz (2007) wrote about how sleeping during the day disrupts the capitalistic wheel of productivity. This was true for us, as our afternoon joy seemed to put university coursework, our duties, and all the outside 
world on hold. We would enjoy being together in the afternoon, having sex, but also talking, laughing, listening to music, and daydreaming about plans, projects, and our present and future. We created a relational space beyond the established codes of sex and generated a narrative of gayness in relaxation mode, being at ease, in a frequent state of oneiric pleasure.

While we would often find various gradients of public oppression and violence against gay people, that public experience would contrast radically with our experience of being alone with each other. The intimidating public space attuned us to pay attention to the opportunities and spaces of privacy and intimacy that perhaps we would not have seen in a more accepting environment. In a more inclusive scenario those opportunities would not have been necessary. Harshness helped us see softness in places perhaps we would not have searched for it and allowed us to create an intimacy organised around fleeting opportunity, the unexpected place. It was an intimacy that differed from the normative idea that love should be restricted to the confines of private life. While sexuality in general has been an area of human life that has been the object of social regulation, gay sexualities have been disproportionately oppressed in a way that both public and private lives have been punished. Gay relationality itself has been disciplined, prohibited as if society wished it to be ceased. I believe that these persecutory dynamics made us more inclined to discover opportunities to explore our affects wherever we could. Thus, we discovered the thrill of holding hands in the empty football fields at university, gently touching our waists when we were queuing for lunch at the cafeteria, subtly rubbing our legs in the dimmed light of big lecture theatres, and multiple intimate ways of showing each other that we were 'there'. We would seek each other's hands and each other's gaze in the classroom; a way of subtle communication amidst the presence of everyone else.

People have bodies, and these occupy a physical space; this fact does not seem to attract much attention when the bodies in question fit within a standard of normality or uniformity in a particular context. However, when that sense of the normal is disrupted, the space occupied for those bodies seems to be excessive and unwarranted. Our gay bodies did not attract much attention when we were alone, but when we were together, there would be an enhanced sense of awareness in ourselves and in others. Julio and I would sit close to each other in our psychology classes, and that was already a peculiar event to a degree because it was populated mostly by women. Our closeness would sometimes be noticed and disliked in subtle and sometimes overt ways. On one occasion, a fellow student sitting directly behind us in the classroom commented to her friend about how 'homosexuality wasn't natural and that's why God didn't allow homosexuals to make love looking at each other's faces'. We were not sure whether she intended for us to hear her comment, but we made sure that she listened to us when we said that we could think of a dozen positions to make love while looking each other in the eye. With hindsight, I know that we could have confronted her 
differently, but at the time it was all that we could think to do. Our response created momentary tension in the classroom as a classmate applauded and cheered our response, while others remained in silence and showed some expressions that could be interpreted as disgust. On another occasion, in a class about adolescent development, the expression of disgust came from the teacher as he directed a narrative exercise in which we needed to write a story in response to a theory of psychosexual development. We wrote a story based on a gay relationship, and when we read it out loud - like everyone else in the class - we could see the abhorrence in the teacher's face. His only feedback was that homosexuality was a peripheral topic to the theory, a stage of underdevelopment, and then moved on. We were an annoyance, an undesired noise. Warner (1991) writes: 'Historically we might say that queer sexuality is like gender or race in being a political form of embodiment that is defined as noise or interference in the disembodying frame of citizenship' (p. 12). Our presence, our togetherness, seemed to create some minor, yet persistent, tension - a noise - amongst some people in our classes. It is important to note that many people expressed their acceptance of our relationship, and many more did not seem to care. This realisation was very important because it helped us to understand that, at least in that environment, our closeness was more powerful than we had initially imagined. We started to question why, if heterosexuality was presented as the 'natural' and default constitution of humanity, some people seemed to be so troubled by our presence? Surely a couple of youths in a state of 'underdevelopment' could not cause them such anxiety. Or could they?

In the early 2000s, in our cultural context, we would not have dreamt of studying queer theory as part of the curriculum. It was only when a lecturer pointed us in the direction of Michel Foucault's (1979b) 'History of Sexuality' for a research project that we started to find support in our academic and, consequently, personal lives. Our personal research led us to texts such as Marina Castañeda's (1999) 'La Experiencia Homosexual' and Urvashi Vaid's (1995) 'Virtual Equality'. Then, on one occasion, we were at a birthday party for one of our friends. She introduced us to an older gentleman who was very worldly and very kind to us. Even though it was not our birthday, at that party, he gave us a copy of the book 'Loco Afán' (2000) by Pedro Lemebel, which presents a collection of stories of homosexuality from a Latin-American - particularly Chilean - perspective. We believed this gentleman to be gay, but he had never spoken about it with us, so, in a way, we interpreted the gift as a sign of friendly unspoken recognition, one in which he told us that he 'saw' us. This event stayed in our memories and we would talk about it in times to come. We understood that there was a rich message in his act; one in which he was showing us there were other men out there who were like us, that we recognised each other, and that we could communicate amongst us, even without speaking overtly.

These books were crucial in our lives because we engaged with the ideas of authors who had travelled the paths that we were currently travelling, 
and they had been successful in the process. They were very articulate, intelligent, and sensitive people whose ideas were robust, sensible, and current - certainly more than some of the texts we would review as part of our degree. Julio and I would often talk about these books and reflect on our own experiences and how the ideas they presented applied to our relationship. In the early years of the internet in Mexico, these seminal texts opened a world of ideas that was only accessible because we sought it fervently. Our experiences of being gay sparked in us the interest of investigating and understanding ourselves. These authors' ideas encouraged us to believe our experiences were valid and that the heteronormative knowledges that had been presented to us could be contested and scrutinised. The scarcity of gay literature in our immediate social context meant that our journey was slower than it could have been if only we had been aware of LGBTQIA+ studies, queer theory, and their scholars.

The books and articles we found - even if they were not numerous - provided a haven and source of stimulation in our lives. However, this engagement with the literature was possible - I think - because we had our love life, to some extent, sorted. Julio and I had each other, which meant that we were not concerned with the idea of loneliness that we had envisioned in our lives in earlier years. He told me that as an adolescent he had thought of becoming a priest, as he never conceived himself pursuing the heteronormative route that was predetermined and seen as the only option. It was his way of escaping what Michael Warner (1991) called a 'repro-narrativity: the notion that our lives are somehow made more meaningful by being embedded in a narrative of generational succession' (p. 7). In contrast to Julio, I had not contemplated the religious 'escape'. Instead, as an adolescent, I had imagined a worse alternative, as I pictured myself following the heteronormative path while secretly experiencing desire for men without acting upon it. Lies and repression would have been my way to escape. Since models of gay life were nearly non-existent, it was not surprising that as young men we were thinking of a future in which our desire was avoided and supressed. Fear has been instilled in gay people by constant acts and discourses that reinforce the notion that living a gay life is dangerous, tragic, and conducive to dissatisfaction. Like the comments from our classmate and teacher (and many others we have experienced throughout our lives), heteronormativity works as a constant policing of nonconforming identities. In the form of hostile actions, harmful discourses, and oppressive institutions, heteronormativity presents an undesirable image of LGBTQIA+ lives. Julio and I were exposed to these harmful representations of gay life that still persist and affect many other gay men nowadays (see, for example, Bradlow et al., 2020; Liu, 2020; Newman et al., 2018). It quickly became apparent, however, that those bleak depictions of gayness were not an omnipotent force from which there was no escape. We debunked that narrative the moment we reciprocated each other's feelings, as we realised that we could be gay and live a fulfilling life because we started, at that very moment, living a 
fulfilling life. We experienced a protective relationality; a way of being with each other and supporting each other that afforded us access to a state of mind that perhaps we would have not been able to achieve individually. For example, we would go to cafés and restaurants together and we would gauge our proximity and affection, testing how close to each other we could be, how openly we could talk, and how much we could be ourselves. If you have not experienced 'minority stress' - 'the excess stress to which individuals from stigmatized social categories are exposed as a result of their social, often a minority, position' (Meyer, 2003, p. 675) - the act of going to a restaurant with your partner might not seem like a great achievement. For us, however, it was a reclamation of space that had a personal impact on our everyday lives. While I do not believe that we felt at risk of being verbally or physically abused or attacked, at least not constantly, we would have a somewhat constant sense of awareness and vigilance that did not allow us to be at ease. We would test our proximity in different spaces and our observations gradually showed us a sense of confidence to be in the world, a feeling that goes beyond a sense of safety.

Self-vigilance was an important coping mechanism for us. Members of the LGBTQIA+ population have experience in developing protective mechanisms to be safe from abuse (Armstrong et al., 2020; Nadal et al., 2011) and we were no different. By being aware of others and their potential hostile responses to our presence, we tried to remain safe. However, at the same time that our self-vigilance was a protective mechanism, it also prevented us from engaging fully in life. Julio and I coped well with everyday challenges to our togetherness, but this was partly because we took on the challenges that we sensed we could take on and discarded the ones that felt unattainable. In this constant process of assessment, we perhaps let opportunities of self-affirmation pass, some of which could have been within our reach. There were people to whom we never revealed we were a couple and there were situations in which we did not challenge heteronormative assumptions. We did this because although we had a political commitment - we did not call it 'political' at the time - to raise awareness about gayness and heteronormativity - we did not know it was called 'heteronormativity' either - sometimes we had to choose between calling out some people's assumptions and microaggressions or getting on with our lives. Many times, we chose to get on with our lives. There needs to be a delicate balance between the agency and resilience with which LGBTQIA+ individuals are asked to respond to a hostile environment and the responsibility being placed on individuals alone.

One of the challenges that we did take on most of the time was the reappropriation of the space; a space from which we did not know we were excluded, until we realised we were. Julio and I loved dancing. We met in a dance class and dancing was an important part of our everyday lives. We liked to go to gay clubs too, where we would be able to dance together. There were various gay night clubs we liked, but we would not always go 
to those venues because we also wanted to go meet our non-gay friends who would often want to go to 'mainstream' night clubs. They would go to gay clubs with us on occasion, but we wanted more; we wanted to go there all the time, not necessarily because we did not like other night clubs, but because we wanted to experience the feeling of being at ease and seeing other people like us; and it was only in the gay scene that we could experience that casualness, that lack of inhibition. There was an evident contrast between our experience on a Friday night in the gay scene, all dressed up, feeling gorgeous and feeling free and our experience outside of that scene, where some people responded to our clothing, our demeanour and our conversations in a negative way. Although we loved the gay clubs and the gay scene, it would have been a high cost to only live for the Friday and Saturday nights and put the rest of our existence on hold. It would have been an even higher cost to restrict ourselves to live freely only in the gay scene. So, instead of limiting our gayness to the gay scene, we brought our gayness to the rest of the world and, in doing so, we discovered that while there are many vigilantes of the heterosexual regime, some of them were not as well-equipped to defend their position as we were.

From mild reaffirmations of our right to be ourselves to more forceful reappropriations of the space, we had our fair share of acts of resistance and most of the time we succeeded. There was one time when we went on holiday to Ixtapa, a seaside town in Mexico, and the hotel receptionist insisted on giving us a room with two single beds. When we asked for a double bed instead, she said she would have to check whether that was possible. There is an important difference between the Spanish and English words for 'double bed': while in English it is just a 'double-sized bed' intended for two persons, in Spanish it is called a 'cama matrimonial', the literal translation of which is a 'matrimonial bed'. This might indicate a broader issue with the old-fashioned way of the Spanish language when it comes to naming beds in particular (and the material world more broadly, but that is another topic). When we asked whether it was a question of the tariff or availability, the receptionist evasively said she would need to check with her manager. We were determined to not let that discriminatory act pass and we eventually got our room with a 'matrimonial bed'. On another occasion, we went to the police station to report that we had been robbed on our way to the club. As we were giving our narrative of the events to a few police officers who were on duty, Julio and I saw in the reflection in the window that an officer behind us was mocking our clothes and his perception of our apparent effeminate behaviour. Probably believing that we could not see him, he completed his derision by mouthing the word 'puñales' - 'faggots' - and making a vulgar gesture. The officer who wrote down our statement did not do anything to stop the mockery, nor did anyone else in the room. Julio and I exchanged looks in silence, and while it was an intimidating experience that made us feel like we were the wrongdoers there, we continued with our testimony with determination. We were asked to come back on 
a couple of occasions to finalise the process and, in spite the intimidating feeling of being in a room where public servants were against us, we wanted to demonstrate we would not allow their harassment to obstruct our access to a public service. As I write about it now, I find it pathetic that a group of grown men in a position of power would try to ridicule a couple of youths half their age. This is what I consider to be the fragility of heterosexuality: if it requires an army of soldiers to defend what is supposedly a powerful force of nature, how powerful is that force really? Why would something that is portrayed as the only natural and legitimate developmental path of humanity need to be protected so fiercely? Why were they so anxious and perturbed by people who supposedly did not represent a threat?

Having realised that we had some kind of power - the power to disturb with our sole presence - we continued testing it, not because we wanted to disturb people but because we understood we had the right to live and inhabit the world like anyone else. Our protective relationality paid off as we expanded the spaces in which we could be ourselves. Public gardens, national parks, shopping malls, the sports club we attended, cinemas, theatres, museums, the streets. Our appropriation of these spaces led to further changes. We did not want to just change our relationship with the materiality of the space and dare to be 'there', we also wanted to feel good about ourselves and have an experience that did not feel like we were foreigners in our own land. And we would experience an ephemeral bliss that led to a more continuous happiness. Although some of those states would be brief, they would occur often, and we discovered that we could recreate them not only in the intimacy of the car, or the bedroom, or at clubs, or just the two of us in isolation, but also in other public spaces. Foucault (1979a) wrote about the panopticon effect, in which people who have been under surveillance under punishing regimes experience the feeling of being constantly seen, even when such surveillance is not constant, nor infallible. Julio and I gradually discovered that heteronormativity was at the same time a powerful regime and a fragile collection of practices which could not invigilate us permanently. We wanted to feel good regardless of where we were, not only in venues advocated to the LGBTQIA+ communities. Thus, family celebrations, social gatherings, and academic appearances were events we attended together as an act of self-assurance and visibility. Friends, university staff, family members, acquaintances, and strangers would see our togetherness and this contributed to the destigmatisation and de-exoticisation of gayness in our immediate circles.

A few years ago, a person who knew us both in some capacity told me that her son had come out as gay and while she confessed with tears in her eyes that it had not been an easy topic to handle nor an immediate cause of celebration for her, the fact that she had known Julio and I together, as a couple, had helped her to see the ordinariness of gayness and embrace her son's gay identity. That conversation came as a pleasant surprise to me, as I had not imagined that our presence could have helped someone else in such a way. 
We hoped - when we wrote our undergraduate thesis on gay men's relationships, when we chose academic projects on gay topics, when we created theatre projects that represented gay characters - that the work we were creating was helping some people. We hoped, but we did not know. At the time, we probably did not realise that our everyday presence in the world would have a positive impact on others as well but, with hindsight, it is evident that our ordinary lives were putting some changes in motion. Like Kathleen Stewart (2008) writes: '[the ordinary] can become a vague but compelling sense that something is happening, or harden into little mythic kernels' (p. 4). We were probably just trying to live our lives, but along the way we were creating kernel moments that would transform ourselves and others in the process.

In the small, interior space of an unassuming car, we discovered the power and beauty of our intimacy. We would close the windows, open the sunroof, play our music, sing along, and lose ourselves in the intimacy of our time together. We would enjoy our sense of mobile intimacy, and, at some point, we realised that the intimacy and the power was in the bond between us and the feeling within us; a portable intimacy that travelled with us, one that we brought with us and shared as we moved in the world.

\section{Postscript: On relationships that transcend space, time, and kinship}

Throughout this chapter I have used mostly the first-person plural, 'we', to describe my experiences. While this might raise some questions regarding the ownership of the narrative and the fusion of two voices into one story, this was a deliberate move for which I take full responsibility. Julio is not here to respond or corroborate this narrative. He died in 2019. However, over two decades of shared history as lovers, friends, and family - the type of family Tony Adams writes about in this collection - we had mutual, implicit, and unconditional trust in each other. We knew each other's passwords, PIN numbers, bank details, and other far more important secrets like our fears, anxieties, pains, and also the joys we experienced throughout our lives. I am not saying that it was an idyllic relationship in which everything was easy and open; we had our individual struggles that needed solitary processing, but we would always - eventually - share them with each other, even when this implied truths that were difficult to hear. We worked and wrote together for several collaborative projects and had the confidence of saying that, while we were separate individuals with our own personalities, we could effortlessly become one voice. Acknowledging and defending this unified voice is not a small act, especially in societies that encourage individuality and an increased sense of independence and personal achievement. Many of our achievements were only possible because we were together, and this I want to emphasise. Against the many people that might not have wanted us to be together or believed in the validity of our connection, insisting on our unity is essential. 
In a society that has conceptualised 'homosexuality' around a sense of deviancy (see, for instance, Frederick, 2014; Woods, 2014), it is still common to find the historic legacies of these oppressive discourses and practices. Early on in our identity exploration, we distanced ourselves from the 'homosexual' label and opted for the 'gay' label. Although this might seem like a small move, we saw this as a parallel process to our resistance to being relegated from the spaces we inhabited; we also wanted to resist the social institutions that insisted on defining our subjectivities. Over the years, Julio and I encountered many people - gay and non-gay - who held those views that portrayed relationships between men as deviant and even as impossible. Being together in a queer type of relating that transcended definitions of friendship, family, and romantic attachment has been our most extraordinary deed; one that we cherished and one whose ordinariness never deceived us. We knew we were everyday fixtures in each other's lives, but we also knew that what we had found was marvellous.

\section{References}

Armstrong, R., Silumbwe, A. \& Zulu, J. M. (2020) Mental health, coping and resilience among young men who have sex with men in Zambia. Culture, Health \& Sexuality, 1-15. DOI: 10.1080/13691058.2020.1788726.

Bradlow, J., Guasp, A., Cooke, V., Wicks, H., Bush, L., Douglas, R., Langdale, E. \& Aberdeen, C. (2020) Shut out: The experiences of LGBT young people not in education, training or work. London, UK: Stonewall.

Castañeda, M. (1999) La experiencia homosexual: para comprender la homosexualidad desde dentro y desde fuera/M. Castañeda; presen. de Ignacio Maldonado Martínez. México: Paidós.

Foucault, M. (1979a) Discipline and punish: The birth of the prison. Harmondsworth: Penguin.

Foucault, M. (1979b) The history of sexuality. Translated from English by Hurley, R. London: Penguin.

Frederick, B. J. (2014) "Delinquent boys": Toward a new understanding of "deviant" and transgressive behavior in gay men. Critical Criminology (Richmond, B.C.), 22(1), 139-149.

Lemebel, P. (2000) Loco afán. Barcelona, Spain: Editorial Anagrama.

Liu, X. (2020) 'But if Taiwan legalizes same-sex marriage ...': Discourses of homophobia and nationalism in a Chinese antigay community online. Critical Discourse Studies, 1-16. DOI: 10.1080/17405904.2020.1724809.

Meyer, I. H. (2003) Prejudice, social stress, and mental health in lesbian, gay, and bisexual populations: Conceptual issues and research evidence. Psychological Bulletin, 129(5), 674-697.

Muñoz, J. E. (2007) The sense of watching tony sleep. The South Atlantic Quarterly, 106(3), 543-551.

Nadal, K. L., Wong, Y., Issa, M.-A., Meterko, V., Leon, J. \& Wideman, M. (2011) Sexual orientation microaggressions: Processes and coping mechanisms for lesbian, gay, and bisexual individuals. Journal of LGBT Issues in Counseling, 5(1), 21-46. 


\section{Edgar Rodríguez-Dorans}

Newman, P. A., Fantus, S., Woodford, M. R. \& Rwigema, M.-J. (2018) "Pray that god will change you": The religious social ecology of bias-based bullying targeting sexual and gender minority youth-A qualitative study of service providers and educators. Journal of Adolescent Research, 33(5), 523-548.

Stewart, K. (2008) Ordinary affects. Translated from English. Durham, NC: Duke University Press.

Vaid, U. (1995) Virtual equality: The mainstreaming of gay and lesbian liberation. New York: Anchor.

Warner, M. (1991) Fear of a queer planet. Social Text, 9(4), 3.

Woods, J. B. (2014) The birth of modern criminology and gendered constructions of homosexual criminal identity. Journal of Homosexuality, 62(2), 131-166. 


\title{
11 In my Latinx gay shoes \\ Work, discrimination, immigration, and polyamory
}

\author{
Oscar Pantoja Guzmán
}

\section{My personal story and context}

My name is Oscar Pantoja Guzmán. I'm originally from Mexico City, where I lived for most of my life. A few years ago, I graduated from university with a Bachelor of Science in psychology. I studied this discipline because, for me, psychology is a way in which society explains itself and its social and cultural phenomena. It is a way in which human beings study themselves as individuals and as the cornerstone of society. I identify as part of the LGBTQ communities and have done so since I was 18 years old. Today I have a strong sense of belonging to this group, and sometimes I am an advocate for its causes.

As I write this chapter, I'm living in California. The adaptation and acculturation processes have been a challenge. As part of my life here I give pastoral and counselling support to members of the Latinx community. ${ }^{1}$ Something I would like to achieve in this country, the USA, is to build the foundation for a career in the arts and humanities. Considering that before coming to the USA I worked in Human Resources for three years, my career seemed to be going towards organisational psychology, but I think there's more to life than having only one career choice. Perhaps, in the same way that I see my community, life is a full spectrum of colours.

\section{At work}

In the professional arena, I've had the chance to provide psychological support to people in need. This was as part of my training as a psychologist in the last stages of my degree. After that, I went into recruitment and selection. The highest post I got was senior recruiter for a company in Mexico City, in which the organisational chart indicated that the only people more senior than me were the manager and the vice president of the company. I 


\section{4}

used to cover all stages of the hiring process, from recruitment to selecting staff at executive and managerial levels. This was one of the most fulfilling, thrilling, and demanding experiences I've had as a professional - there were occasions when I would work seven days per week - as I even developed induction and basic training programmes for new members of staff.

\section{Being a gay man}

For me, being gay is a great responsibility, as I know I have to double my efforts so that my actions speak louder than my sexual orientation. I feel that it's a luxury to belong to this LGBTQ group in this cultural context, as even nowadays there are places in the world where displays of affection between people of the same sex can put your life at risk. For me, being gay, being Latinx, and being Mexican means doing things in the best way possible - it means everything I do needs to be high quality and I can't give up. Ever. Being gay is a challenge. Just like being a woman - cis and trans, gay, or bisexual. I feel that being gay is a luxury that combines the sensitivity of my emotions, the strength traditionally associated with my gender - 'el sexo fuerte' as they say in Mexico - and the social expectations of what being a man represents. I have to be the best of the best, without transgressing other people's rights. For me, being gay is being a common man but with the privilege of loving freely. For me, being gay is being able to love who I want to love (respectfully), love them like I want to love them (respectfully), and wherever I want to love them (respectfully).

\section{Migration and culture}

My trajectory and development as a social being has been marked by the culture of the country I grew up in. However, now that I'm living in California, I can say that culture is a fascinating phenomenon, as it changes from person to person; it is inherited, it is taught, it is learnt and it can be unlearnt at every opportunity and in relation with the social circles to which we are exposed. Culture can be a very small circle that doesn't offer opportunities for development and growth. Culture can be a big circle in which development is promoted and fostered in every sense. My first job in California was at a Mexican restaurant which employed fellow Mexicans. I want to mention that I never felt the activities of a restaurant were alien to me, even if I had never worked in one before. Without being arrogant, I thought to myself: 'if I was able to complete a degree and work in other settings, I'll be able to do this, it's all about the attitude'. It was an important and exciting challenge as all my skills and previous learning were at play. It was in California that I've learnt the most (not even the seven-day work week as an HR executive could compare). I was so mentally busy, I had just arrived in a different country, I was getting used to a job with which I wasn't familiar, and I felt I needed to play with the new environment before the environment 
played with me. A year went by like this until I was able to regularise my immigration status from tourist to resident.

Not everything was 'miel sobre hojuelas' - 'honey over cornflakes' - as I would say in Mexico. It was working at that restaurant that I experienced one of the first acts of discrimination by the Latinx community. It was then that I understood the reasons why people who come here looking for new opportunities struggle to move forward, as discrimination towards Latinx people sometimes is exercised from within, the rejection comes from within (Moraga, 2015), from other Latinx like ourselves. I'll soon tell you what happened at the restaurant.

\section{My everyday}

This was in 2017, when I was working in Human Resources in Mexico City. I remember a specific occasion when I had to recruit to fill a vacancy for an accountant post. It wasn't a particularly complex profile, but for some reason I was having problems finding the right person. Then one day I was reading the $\mathrm{CV}$ of a candidate and I was in awe. I conducted a telephone interview to confirm that his skills and experience were what I was looking for, which I did. He seemed to be right for the job and I could even forecast his growth within the company. I immediately arranged an interview with the candidate and, knowing his potential, I arranged an interview with my line manager as well, so he could evaluate him too.

The day of the interview arrived and everything seemed to go as planned - honey on cornflakes. I didn't have a doubt that the candidate was right for the post. I went to my line manager's office and from the door threshold I announced I had the candidate's CV and documents so he could interview him. I even said, 'the candidate is so good, I think you'll be impressed'. At that moment, my boss checked the documents and very briefly, without much attention, he raised his gaze and asked: 'is "that" him?' 'Yes, it's him', I replied. Through the glass walls of his office, my boss looked at the candidate for one second and - like in 'The Devil Wears Prada' - he said: 'Do you know what type of company are we? We're not "that" type of people, Oscar, we're different, so don't make me waste my time with that fat, Brown candidate'. I was shocked, and I couldn't believe what I was hearing. Especially because my boss and I, myself, are Brown - morenos. He was overtly discriminating against someone in front of me based on their appearance. From the shock, I didn't know what to think or how to act. I went to speak to the candidate and said there had been an unexpected situation and we couldn't continue with the process, but that I was hoping for a positive response. I don't know why I told him that, and I felt awful for doing so. Those comments made my enthusiasm and passion for that company crumble. I quit days after I had a conversation with my boss about the discrimination I had witnessed. Notwithstanding what I said and with no sign of remorse, his last words before I left were: 'You can call it 
discrimination or whatever you want, but I don't want a fat, Brown candidate for this position; we're more than that, we're a different company, Oscar'. What I felt that evening was pure and blatant racism, which was even more hurtful because my boss was also gay, and I would've expected more understanding from him, considering he is part of a population that has experienced such discrimination first-hand.

After that experience, I decided to travel and try my luck in a different context, where I could live with my particular traits, like being gay. Although to some people it might sound strange, being gay is something that is present in every part of my everyday self. Being gay sometimes manifests itself in simple ways like when I'm driving or when I go to buy groceries. Maybe others don't notice, but when my personhood interacts or performs a specific role in this social machinery, it is when all the components of the self shine in all their splendour.

Let me cite an example. When I arrived in California and had just recently started working for the Mexican restaurant, my boss hadn't noticed I was gay, but after a few days, I could perceive how his approach towards me had changed. When this type of change happens, I start questioning, 'What should I do? Should I express my gayness overtly? Should I let people assume what they want to assume? How far can I go in expressing my gayness? To what extent is it "right" to do so?' If you are reading this text and are heterosexual, and you're wondering whether even in the 21 st century gay people still experience discrimination for our identity, the answer is yes. A month after I started working at the restaurant, my boss was making fun of me with two of my co-workers. They were seated at a table; my boss was doing the cashing-up for the day and my colleagues by his side were counting money. I approached my boss and asked whether I could have a 10-minute break, as I had been working for about 12 hours. Since one of my colleagues had told me that having a work break is a right of all workers in California, I felt empowered to do it. So, I asked. His puzzled expression seemed to show incomprehension about my request, as if I asked in a foreign tongue. He asked me: 'Why are you tired?' I responded that I was also working for the 'Restaurante Flores' - Flowers Restaurant, which he knew. He burst into laughter and said: 'Ya todos sabemos que haces flores!', which translates as 'We all know you do flowers'. Trying to overlook his prosaic remark, I emphasised that I was talking about the restaurant. At that point, one of the waiters - my colleague - seconded him and said: 'Aquí vienes a chingarle ¿o a qué creías que venías?' - 'You came here to work your ass off, or what do you think you came for?' and he kept counting money while sharing a complicit look with a waitress who was in front of him. She nodded while continuing to count money. I was angry as all I was doing was asking for something that was my right as a worker. I went back to my activities without my break. When I finished my shift, I left without saying a word to anyone. A week later, it was brought to my attention that I had been fired and nobody had told me. 
Losing jobs for being gay and asking for something within your rights is not sustainable in a capitalist system. This is the second or perhaps third time that being gay has put me in a position in which I have to choose between my dignity and paying the rent. When this happens to me, I feel powerless and I experience a sense of wrongdoing for being who I am.

On a different occasion, I was working for Apple. I had a female colleague, and we had friendly interactions in which we would talk about trivial things like the weather, traffic, and our respective countries of origin. One day she asked me about my wife and my children, as she had assumed I was married to a woman, had a house, two kids, a mortgage, etc. Since this wasn't the case, I said I wasn't married, to which she responded with incredulity - 'How is that possible?' I just laughed the comment off and changed the topic. The question came back again and again in the following days until I said, in a kindly manner, that I was gay and that I wasn't married to anyone. She laughed, perhaps thinking that it was a joke, and left. Minutes after that incident, her approach towards me changed, and then she told me: 'Being gay is the most stupid decision you've made'. But things didn't stop there. She said repeatedly, perhaps ten times, that she couldn't believe I was gay. I was fed up with the situation, so I asked my line manager to move me to a different branch, explaining what had happened. I didn't want to report her to the authorities because she would lose her job, and, since in California you get benefits when you're unemployed, I didn't want her to go home with that reward. I asked her to abstain from making those comments, or I wouldn't hesitate to protect my rights. I went as far as saying that, if she was living on the American continent, she should respect sexual diversity in any country of the Americas - from Canada to Argentina. I experienced a strange feeling and a phrase - the Americas for the Americans - came to mind, but I didn't express it. In retrospect, I think that for one moment, her ignorant comment almost pushed me to be like the people from the Mexican restaurant, like the oppressors who had offended me in the past. But this didn't happen, I rose above the situation and just left. I understood that from her position, she didn't understand what sexual diversity is, and it was sad for her - not for me.

\section{Love in Mexico City}

The definitive factor that pushed me to start my journey to a different country was love, but not love like some would think, Hollywood-style, from a romantic, poetic point of view. Instead, it was the rupture of love. After breaking up with my partner of nearly three years, I found myself struggling to find a place where I could work. I was doing badly financially and I experienced the loss of friends in the earthquake of 19th September 2017. I remember how everything was suddenly shaken when the seismic alarms warned. I recall how I hit the wall to try to protect myself when suddenly through the window I saw a three-story building disappear in a cloud of 
dust and the walls of another building fell apart but the skeleton remained. I could see people on the other side of the wall without using $\mathrm{x}$-ray vision.

So, without a concrete plan, I took a plane in the hope that I would distract my heart from the events I had experienced. I assumed my troubles would be left behind in Mexico.

Back to the story of my ex. One day I went to Zona Rosa - the gay district in Mexico City - to celebrate a work achievement. I invited my then-boyfriend, but he didn't want to go. He preferred to have some beers somewhere else with his best friend. I need to mention that I always knew he was in love with his best friend, which I respected because for me it wasn't an issue that he was in love with someone else while he was in love with me. From my experience, the 'nature' of man tends to be more polyamorous than monogamous. However, because of my ex-partner's conservative education, I never wanted to confront him with this question. He wasn't 'out' with his friends nor with his family. Before me, he had been in a relationship with a woman, and it seemed he found sexual fulfilment with her. It seemed like there was something about his sexuality he needed to demystify.

So, I was at the bar, celebrating with my colleagues, and I had had a few drinks. A very handsome guy approached me, we talked, and I gave him my number. The following day he sent me a few messages, which were read by my partner. He snapped and gave me the keys of the flat where we lived. With a severe and angry tone, he told me he had been clear about how much he hated unfaithfulness. I was in shock, and I couldn't speak. So, I only admitted my misdemeanour, gave him a hug, and thanked him for the time spent together. I knew him as an arrogant person, so I didn't want to go through the pain of demonstrating that nothing else had happened and gaining his trust again. I was so exhausted by my job at that point, and I knew he had someone else in his plans, so I chose the easiest path. I thanked him without arguing, and he left. That's the last time I saw him, but I knew he started a new relationship a couple of months after that. I, on the other hand, was about to start a journey full of ups and downs.

\section{Love in California}

Towards the end of 2018, I met my current partner. From the beginning I held up my hands and stated clearly that, before entering into a problematic situation, I didn't want a 'traditional' relationship. I'm a gay man who feels more polyamorous than monogamous. He accepted that proposition.

My current partner comes from a family of Mexican immigrants established in Los Angeles. Alcoholism and 12-hour shifts marked his upbringing. In spite of the difficulties, he completed his studies to become a pharmaceutical doctor. He's self-made, as he didn't have much support from his family, and, although it is not my story, I feel very proud of him.

For reasons I won't address in this chapter, I have never felt comfortable entering into arguments and fights with people. I feel this is unnecessary, so I 
avoid confrontations as 'negative' emotions overwhelm me. I think if I allow my negative emotions to run free, I might transform into a monster, which wouldn't make me feel proud. Thus, I do everything I can to avoid fights. One day, my current partner told me we were six months into our relationship and we had never had a fight - that I either say yes to things or take time-off to collect my thoughts and reset. I hadn't realised this. I responded that that was my usual way of being and that it was an ideal sign that we were not arguing. He debated and said that 'ideal relationships' don't exist and that he didn't feel loved by me if there wasn't tension every now and then. That comment opened a new world for me. As I write this text, we have been living together for a year-and-a-half and I still find it hard to express what bothers me without offending him. I try to find the most gentle, balanced way to communicate how fantastic it would be if my boyfriend thought and acted like I do, but since that doesn't exist, I've entered into his world and I've learnt to raise my voice and say 'no' when I don't want to do something just because he has a whim. This doesn't make me feel good, I feel uncomfortable. I tend to imagine an idealised world. Even from a sexual point of view, I'm like a vampire: you know, in vampire novels, vampires need to ask for permission to enter someone's space. So, I'm like that. Even when there is sexual tension between me and someone else, I don't proceed until the person gives me their permission, their consent. I was sexually abused when I was eight, so for me it's crucial that the person gives me their consent before I express my wildest desires - within my conception of what 'wild desire' is. I would say I'm very vanilla when I'm with someone in bed, without being boring. For me it's difficult to say whether I would still be gay if I could remove the sexual abuse from my childhood history. For me, that event, in combination with my upbringing, brought me to identify as gay.

My current partner is a mentor because he is taking my hand and helping me explore aspects of my experience that I never thought I would, had I stayed in Mexico. With him I have found, little by little, a way to be myself without a happiness mask; I now can better express my anger towards people. This change has been 'therapeutic', but it hasn't been easy. I've even stopped using social media because I don't want to portray a false image of 'everything is fine' with a well-rehearsed selfie. Animals, such as dogs and cats, have many things in common with humans but social media is not one of them. In social media, representations of our lives are often sanitised, our human mistakes omitted. When I was invited to write this chapter, the first thing that came to mind was all the times I've screwed up in my professional life, my family life, my relationships, my friendships, etc. Although I had many ideas, I didn't start the writing process straight away because I think that being gay - and being a person - is not easy. After I make a mistake, I look for a guidebook, a magazine, a book, a group, an online platform where I can find an answer. A great thing in life is that while there is so much written about it, there's still room to write my own story. My mistakes reveal part of myself and I shouldn't feel embarrassed or ashamed 
of them. I make mistakes, and I'm happy about them because otherwise I would still wear that sanitised mask and have that deep need to control the visual narrative I project in an aim to make my Instagram look pretty. I feel it's difficult to be gay in times of Instagram and Facebook because it's tempting to apply makeup to the wounds made by families who are not equipped to raise gay kids and create an illusion that everything is fine. I feel in these times of social media, we forget the fights of our gay, lesbian, trans, and queer grandparents who faced incredible challenges. What filter can I use for the deaths of my loved ones? What filter can I use for the deaths of my fellow gays who died while listening to the word 'puto' (fag)? There's no filter that can conceal the pain in those moments.

I don't ask you to see things the way I see them. In the world, there are still way too many deaths associated with gender violence and sexual orientation, and there is blatant discrimination towards people who don't fit into the established moulds. Trans identities are an example of this. Outside our LGBTQ communities, there is a constant fight we are exposed to; we are free, but we are vulnerable. We love, we want to love as equals, but there are people who want to suppress equality, just because it seems different to what they know. It is the third decade of the 21st century and there are still countries where women are subjected to genital mutilation, and men risk their lives just for exploring their sexuality with other men. It seems we must behave according to established norms.

\section{Love in times of polyamory}

When I was working for Apple in California, there were two colleagues who joined the branch. One was Latino, and the other was Asian-American. The Asian-American guy would wear a black hat and thick-framed black glasses. I could barely see his eyes behind them. I don't know how to explain it, but for some reason, there was something lurking between the Asian-American guy and myself. A few days after he joined the company, we were assigned to work together. We became friendlier and one day he asked me: 'You're Mexican, right?' and I said yes (as if I could hide my thick Mexican accent). He nodded, and I asked him: 'You speak Spanish, right?' He looked at me with puzzled eyes, smiled for a second, and responded: 'Perhaps'. I switched immediately to my native tongue and asked: '¿Me puedes entender? - Can you understand me?' I don't know how I knew it, but I sensed he would speak Spanish. As we chatted, he told me his mum is Mexican and his father Japanese. We became friends very quickly and we talked a lot about his cultural background, as I was very interested.

Shortly after, I discovered I was in love with him. In an attempt to be honest with my current partner, I told him how I felt towards this guy. We agreed that the three of us would try to get to know each other. There were various reasons why this didn't work: my maturity, the brief time I had known this new friend, the brief time my partner and I had been together. And 
there were even external factors, such as living abroad and the disparities in our financial situations, that played part in this unsuccessful attempt at a polyamorous relationship. I couldn't understand what this new friend was experiencing. The line between friends and lovers was becoming thinner, so out of respect to my partner, I started to question the agreement. I wasn't able to think clearly. Everything seemed confusing. Things became tortuous for the three of us, so for the sake of everyone's wellbeing, we decided to finish the polyamorous relationship. However, it was strange to grieve the loss of a lover while being in a relationship with another lover who wanted the best for me. With hindsight, I think I was trying to help and mentor the Asian-American guy, who seemed to be disoriented by a troubled family life. Something ironic about the 'first world' is that while there might be wealth and financial resources, the basic problems, such as raising a child and nourishing self-acceptance, cannot be solved with money - at least, not that easily. As I write this text, I don't know where this guy is, and I don't know what he's doing; but I wish him the best, as he meant something positive for me. The few memories we created together are something I'll always remember.

\section{Love after Oscar Pantoja Guzmán, reflections on this story}

In a not-too-distant future, I imagine human relationships will acquire peculiar qualities, some in which the concept of faithfulness towards your partner or loved ones will change. I also envision the lines between being gay, straight, and other attractions will blur, as they're blurring already. I envision people will understand that loving someone and being in a relationship with someone doesn't mean restricting the couple's sexuality, nor the couple's freedom; and, instead, they'll share the power that Audre Lorde (1984) writes about: 'the power which comes from sharing deeply any pursuit with another person' (p. 56). We will walk towards tolerance, respect, and the acceptance of our connectedness. Steph Grohmann (2020) writes that western individuals are rarely confronted with the reality of our interdependence; we might believe in autonomy and are only confronted by our interconnectedness when the structures that mediate our relationships fail (Grohmann, 2020, p. 75). Then we realise we co-exist, and we need to cooperate. I want to contribute to constructing relationships that acknowledge and celebrate our interdependence. I want to construct workspaces free of discrimination, where we recognise that multiple sexualities, identities, faiths, and peoples can co-exist, because we always have and always will. From my point of view, many of the social issues we face, namely economic, political, gender-, work-, or family-related issues, come from the limited ways in which we conceive love - love for the self and others. We should acknowledge our interrelatedness; we should respect others regardless of ethnicity, culture, identities, sexualities, or religions.

What is it like to be gay in my everyday? It is very similar to your life in many ways. There are no clear boundaries about how humans experience 


\section{Oscar Pantoja Guzmán}

the world; we might be able to separate and dissect people's experiences for analytic, academic purposes, but in practice, in our everyday we wake up, we live, we work, we feel in similar ways. Thus, what I have experienced as a gay man - the discrimination, the broken hearts, the migration - does not have to do with who I love; it is associated with the denial of our interconnectedness between individuals and between the rest of other living beings. I envision a future in which being gay, lesbian, bisexual, transgender, queer, and other identities become historic and obsolete concepts because we no longer need to explain and defend our identities.

For now, being gay for me is a privilege that allows me to love beyond the illusory regime of heterosexuality. And on that note, I shared with you my experiences of discrimination and polyamory attempts because I want to invite you to reflect on the idea of challenging the practices that police who we love and think generatively about the question: what do we do with the love we feel?

\section{References}

Arredondo, P. (2018). Latinx Immigrants: Transcending Acculturation and Xenophobia. Cham: Springer International Publishing AG.

Grohmann, S. (2020). The Ethics of Space. Chicago, IL: Chicago HAU Books.

Lorde, A. (1984). Sister Outsider: Essays and Speeches. Trumansburg, NY: Crossing Press.

Moraga, C. (2015). La Güera. In Cherríe Moraga and Gloria Anzaldúa (Eds.), This Bridge Called My Back: Writings by Radical Women of Color (4th ed., pp. 22-29). Albany, NY: SUNY Press. 


\title{
12 Planetary times and queer times \\ A critical planetary romanticism for the earth
}

\author{
Whitney A. Bauman
}

If nothing else, 2020 forced many of us (western modern types) to take stock of our lives and to examine the worlds in which we live. I use 'worlds' in the plural to conjure what Walter Mignolo and other decolonialists/postcolonialists call the 'multiverse' or the 'pluriverse'. We live in multiple worlds on a daily basis; furthermore, there are multiple worlds across the planet that, at any given moment, make up the planetary community. (Mignolo, 2011) This essay, for instance, was written between worlds: writing sometimes from Berlin, Germany and sometimes from Miami, FL, USA, I am aware of the ways that the contours of these two places and the shifting between them, shape the tone and insights of what is to follow; not to mention all the places that I have lived in, visited, loved and hated, and how these multiple places have shaped my person and drawn-out different identities. All of these worlds, and many more, go into this essay. Our worlds provide the habits and discourse for how we think about ourselves, other humans, and the rest of the natural world. We have no access to ourselves or others outside of a particular world. The pandemic has thrown our worlds into disarray.

The dominant voice in most of the worlds that make up the planetary community - the fossil-fuelled reality of the modern, western reductive, productive, and progressive model of science - has begun to show its many flaws. This world-making and world-destroying fossil-fuelled reality really got going during the period that some sociologists call 'The Great Acceleration', beginning after World War II (McNiell and Engelke, 2016) The increase in the speed of communication, transportation, and production technologies and the increase in life spans due to medical technologies, have enforced a fast-paced chronological time over the face of the planet. This unified chronos, emanating from the prime meridian and enforced by the GMT (an atomic clock with links to atomic energy that will enable fossil-fuelled speed to increase and continue well beyond the decline of fossil fuel production) is necessary for living at such a fast pace. We must be 'on time', and we must measure time in days, weeks, months, and years in order to make the fossil-fuelled reality work. This fossil-fuelled chronos also makes possible the idea of progress: that we are moving towards something, 


\section{Whitney A. Bauman}

building up on the past into a 'better' future: hence the productive, progressive model of knowledge and science.

The problem is, as the Covid pandemic has revealed perhaps in new ways, the fossil-fuelled time of chronos is an anthropic imposition upon the world; and not just any old anthropos, but the modern, western European anthopos. This standardisation of time paves over all the other times that exist within the planetary community. The different times of different peoples, animals, plants, systems, and places are all made to conform to this single sped up, progressive reality. This process began long ago with the most recent bout of European colonisation in the 15th century: as European elites and intellectuals began to travel and be exposed to new landscapes and cultures, everything had to be ordered into a single (European-centred) history - and a progressive one at that. Native peoples and Africans were considered so primitive they didn't have 'culture' and/or were subhuman, and either could be treated as subhuman or had to be educated/cultivated in the image of European history and culture and/or eliminated in some way. Other places were Orientalised, written into the single history of western Europe, with ancient Aryan roots in Indic cultures, Ancient Greece, and Rome; then a period of darkness and a Renaissance that coincided with European colonisation. China and India become sources for fuel for renaissances and romantic movements, and the entire Muslim world was written as a passive receptacle that simply preserved knowledge during the dark ages for the real agent of history, western Europe (Said, 1978; Mignolo, 2011).

The torch of progress was passed to Christian Europe and, later, to the USA, and was taken up with gusto by modern science. Whereas Christianity was the colonising force that brought light to the dark masses, the emerging scientific method and scientific mentality would become the new bearer of light, creating technologies that would make some human lives better and longer. The sciences and scientists would become the new agents bringing about a New Eden on Earth (Merchant, 2003).

The current fossil-fuelled reality, which emerged out of this western, materialistic, and reductive scientific worldview, is now finally outstripping the carrying capacity of so many humans and the rest of the natural world. From genocide, to slavery, to black lives matter, MeToo, mass extinctions, and climate change fossil-fuelled reality is beginning to act as the ouroboros, eating its own tail. This brief essay argues that the current pandemic has enabled many people to open up to the problems of fossil-fuelled time and open onto the multiple times of the planet. Queering the times of the planet is key, I argue, to re-attuning to the multiple bodies of the planetary community that make up our worlds at any given moment. And this re-attuning is the ground from which we can begin to co-construct new worlds that promote the flourishing of and justice for a broader population of the planetary community. This process will never be 'for all' and final, but rather a continual process of critique, deconstruction, re-attunement, 


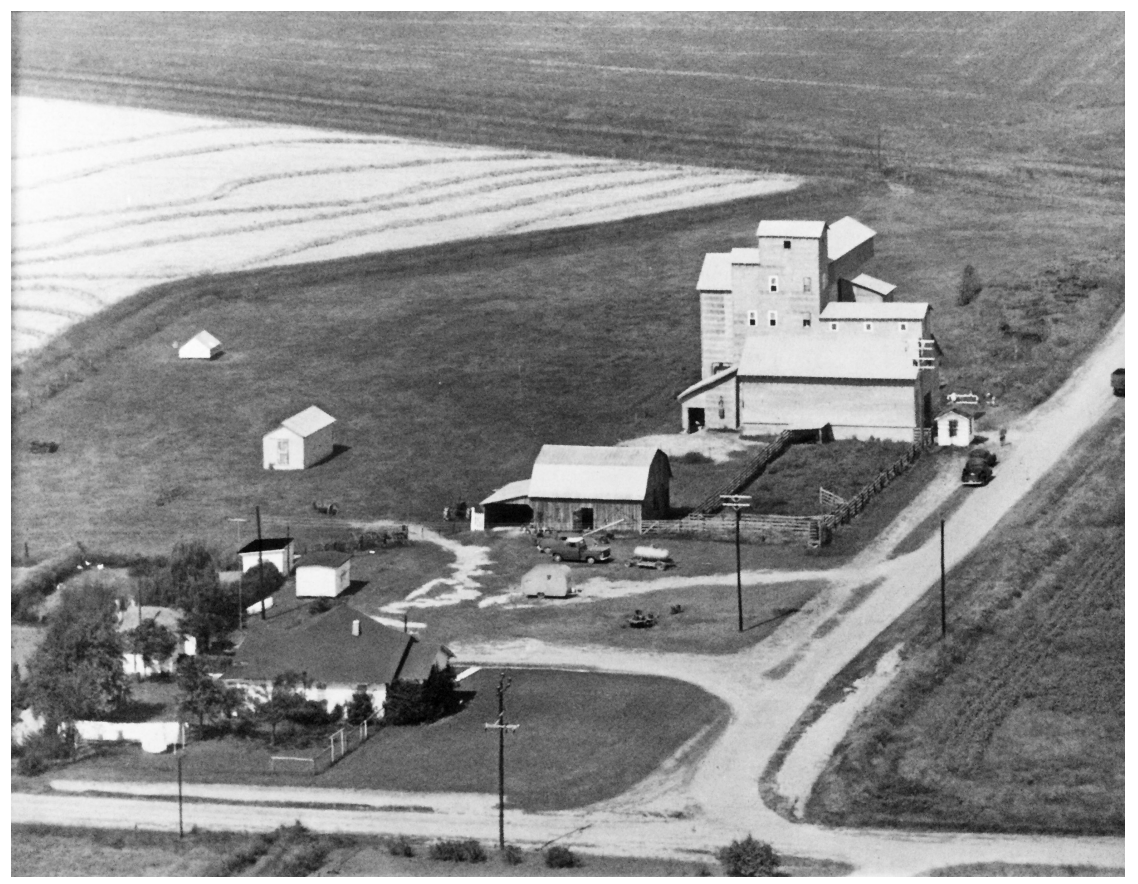

Figure 12.1 The Goodwin-Bauman family farm (Photo courtesy of James Walsmith)

and co-constructing. I begin first with my autobiographical roots, which have shaped my understanding of fossil-fuelled and planetary times. I then move on to what religion as 're-attuning' might look like in the context of developing what I am calling a Critical Planetary Romanticism (CPR) for the earth. Finally, I end where I began, with a small autobiographical reflection on planetary possibilities for the future (Figure 12.1).

\section{From uncertainty to certainty: The story of one family farm}

This is my family's old farm in Stuttgart, Arkansas, USA. ${ }^{1}$ I lived in that little house in the front left corner for some time, and I grew up playing on that farm, helping out around the farm with our family garden plot, shucking corn and hulling peas, riding in combines with my grandfather, and hunting and fishing in many different wooded areas and reservoirs that made up that unique landscape. All of this gave me embodied knowledge

1 I took this autobiographical excerpt and the closing excerpt from an article I published in the journal, Religions (Bauman, 2020). 
about human-earth relations: predator-prey, the importance of 'listening' to the land, the type of 'balance' that one had to make in terms of how much land should be under production at any given time, etc. It also gave me a sense of what it meant to live in faith and hope: every year, farmers take out loans for the crop they are putting in the ground in hopes that the yield will be enough to pay off the loan with some profit. This is not guaranteed, and it takes the 'cooperation' of many different entities within the natural world to make it happen. This cooperation - between humans and the rest of the natural world - is something that was always open-ended (never certain). Furthermore, we (my family) were a part of this unique landscape and ecosystem. Nature was, then, never for me a wilderness devoid of human life, nor was it just mere resource for human projects: rather, we (humans) are a part of nature and whatever culture, language, and human knowledge and technologies are, they are a part of nature as well.

During the 1980s, as some readers will recall, the deregulation by the Reagan administration put huge strains on smaller family farms like ours. I watched over a period of 10-15 years as this farm, under economic pressures, changed from a multiple-use (hunting, fishing, rotating crops of corn, soy, rice, sunflowers, and milo, mostly, and family garden plots) family farm into a mono-cropped Monsanto soybean farm. The forested areas where we went hunting were cut down for more production area, and the reservoirs were not maintained as an ecosystem (with a focus on the game and wildlife) but were turned into mere sources of water for the crops. This is the reductive-productive model that I critique in this article, along with its fossil-fuelled time and assumptions about truth, nature, and human beings. The transformation of my family farm by this reductive and productive, fossil-fuelled model is a microcosmic experience of what living in the Anthropocene is like. The fossil-fuelled pace of life changes the geography of specific places to be uniform and efficient towards (some) human ends.

In contrast to these fossil-fuelled, productive and reproductive times, I want to argue for a different sort of time. It is both queer- and pandemicrelated (Halberstam, 2005); pandemics, after all, remind us of the porous boundaries between inside and outside and our entanglement with other creatures, not to mention how pandemics jolt us out of the 'normal' everyday routines of life. On that farm, the poisonous snakes, mosquitoes, and (sometimes) dangerous farming equipment, along with the plants and animals that became part of me and through my waste I of them, kept me constantly aware of the porosity of my body. From this porous perspective, we might become more attuned to the multiple times of the planetary communities and more attuned to the multiple places that make up the planetary at any given moment. Let's just call this 'pandemic time and places' for short. 


\section{Pandemic times and places}

Perhaps one of the silver linings of the pandemic of 2020 is that it jolted many of us fossil-fuelled western types out of the 'business as usual' in our daily lives. From social distancing, to economic shutdowns, to the end or severe decrease in the amount we travel, there was nothing 'normal', about 2020. But then again, as many in the BLM and MeToo movements have pointed out, what 'normal' is it that some of us long for? The continued system of structural and institutional racism and sexism that kills and abuses black and brown bodies and the bodies of women? The continued fossil-fuelled reality that is literally outstripping the carrying capacities of the planet? The continued neoliberal globalisation that we call 'progress' but that places billions of people in the world into poverty and degrades their local environments? The same system of fossil-fuelled reality that has brought about what scientists refer to as the sixth mass extinction event? If this is normal, then who in their right mind would want to return to it?

These pandemic times have uncovered the seeping wounds of the racist, anthropocentric hetero-patriarchal body of the so-called 'western world'. It is this same world that saw my family farm turned into a mono-cropped culture of death. As Carolyn Merchant suggests, one way of understanding the transformation of the world that took place during the so-called 'scientific revolution', is as the transformation of matter into dead stuff (Merchant, 1980). In addition, this was coupled with the idea that humans alone are made in the image of God (from Christian monotheism) (White, 1967). Thus, agency and value lie with humans alone (hence the Cartesian cogito). The scientific revolution, was, in part, enforcing the idea that humans alone (and to be sure, only some humans) contain all agency and value, and the rest of the natural world was mere dead matter for use towards the human (western, Christian, white, male) ends of progress. This same reductive and productive system is also caught up in the reproduction of 'compulsory heterosexuality' and gender and sexual dimorphism. Humans, too, get reduced to (nuclear) family-making, economic units. In retrospect, as I will discuss more below, the violence of the fossil-fuelled time and that of heteronormativity were forever linked for me as a result of growing up on that family farm.

The problem is, of course, this productive and reductive model of naturalism (and heternormativity) never really fully caught on. What I want to suggest here, however, is that during the 19th century, there were still a few scientists who fought against this type of necrophilia (the making of matter dead stuff). In a sense, they understood the queerness of evolutionary times, planetary times, and the importance of the multiplicity of place.

The culture wars in Europe of the 19th century are not unlike the culture wars in western democracies today. There was a battle over competing authorities and a growing sense of nationalism as economies became more and more entangled and transportation allowed more and more people to 
travel to different places. Furthermore, the first effects of the fossil-fuelled industrial revolution on the rest of the natural world were coming into focus. Enter Ernst Haeckel. Haeckel, the so-called German 'Darwin' and 'father' of ecology, fell on the rhetorical side of the emerging sciences. He was one of the first to construct a full-blown naturalistic worldview, but it was not a reductive vision. All of nature was 'alive' for Haeckel, and the human cultural sciences were yet another level of the natural sciences in general: humans and all things human emerged from the rest of the natural world (Richards, 2008). He called his naturalistic worldview monism, but it was not of the reductive Spinozian type of monism. Rather, it was an open and evolving monism (Rubenstein, 2018).

Haeckel, perhaps more than any other scientist of his time, did more to place humans and all things human within an evolutionary perspective. This had some serious consequences. First, the idea that there was anything like a priori knowledge or a 'thing in itself', was out the window for Haeckel. If humans emerge from the entangled evolving process of life, there is no point at which something could be totally separate. Every individual entity is itself a community of processes and other entities, an ecosystem, so to speak (Haeckel, 1992). He, in other words, recognised the porosity of all bodies. Second, if humans emerge from evolutionary processes along with all other things on the planet, then humans cannot have an objective, nonlocated perspective on reality. Rather, we are 'in the mix'. All knowledge and thought is thus contextual, and hermeneutics and interpretation matter. There is no universal view of truth or experience of time, but a plurality of truths and experiences. Third, if humans are a part of the rest of the evolving planet, species distinctions become nomenclature in the end, and there are no essences or forms for living entities, including humans. This latter point led Haeckel to support the work of Magnus Hirschfeld at the Institute for the Study of Sexuality in Berlin (Hirschfeld, 2000). Haeckel knew that there was a variety of sexes and sexualities throughout the natural world, so if humans are part of the rest of the natural world, there must be a variety of sexes and sexualities in human beings as well. In this sense, evolutionary theory is a queer science. In a similar way, my own recognition of being part of nature from my experiences on the farm that I grew up on, somehow connected to a queering of time, and forms, and possibilities for what it meant to be 'human' outside of the reductive, (re)productive, fossil-fuelled model that was being enforced upon bodies regardless of context: cultural or ecological.

Ecology is also a 'queer' science, and Haeckel was the one who named it. I say it is queer because ecology is, if nothing more, about blurring boundaries, or at least about admitting that boundaries between entities and systems are porous and shifting (Morton, 2010). All living (and nonliving) things are, in a sense, shape-shifters. For Haeckel, the surrounding ecology of an organism is that which drives evolutionary adaptations. Different biological communities lead to the highlighting of different 
aspects of a given entity, and over time, this leads to shifts in ontogeny. Furthermore, for Haeckel, an individual organism, and that which marks all living things from non-living things, is produced when the exterior of that organism is internalised. Said another way, the surroundings of an organism are internalised, and this is what makes up a unique individual. No single organism will internalise its surroundings in the same way. This has some interesting connections with E.O. Wilson's links between biodiversity and human creativity. The landscapes shape the innerscapes, and then the innerscapes return to shape the landscapes of which they (we) are a part (Wilson, 1984).

In the fossil-fuelled times of neoliberal globalisation, in which a reductive and productive science understands nature as dead stuff for use towards human 'progress', what happens to our innerscapes as the outerscapes are diminished. German biologist and philosopher Andreas Weber suggests that we internalise 'dead nature' and become, ourselves, dead on the inside. (Weber, 2017, p. 70) In fact, a whole host of psychological disorders, he suggests, stem from trying to anaesthetise the internal decay of internalising a dead planet. In terms of my own family farm, the internalisation of the necrophiliac industrialised landscape turned into feelings of loss, despair, grief, and longing. Weber suggests that whereas the Enlightenment mentality leads to pushing out vitality and affect for cold, calculating reasons, what we need now is an 'enlivenment'. Some type of re-animation, or neoanimism, or what I will call a critical planetary romanticism (CPR) that understands the entire planetary community (nature, culture, technology, etc.) as a living, evolving, and open process.

It is perhaps during these pandemic times, peering through the cracks of reified fossil-fuelled worlds that we can begin to find ways to let more life into our worlds, and to see that we are entangled with all other bodies evolutionarily, ecologically, and on a planetary scale. Perhaps we can begin to think in terms of queer times and places (Halberstam, 2005). From my understanding, this means recognising that the times and places of the planet are multiple. Planetary times queer our understandings of chronological time because it forces us to recognise deep cosmic, geological, and evolutionary times. It is also helps us to recognise the multiple times of different bodies: the times of bees, goshawks, lemurs, sloths, humpback whales, redwood forests, canyons, dung beetles, and the seasonal times of the planet itself. The time of winter in the northern hemisphere is the time of summer in the southern one: these times exist together in one planetary community. The times of duck migration, and the times of crops from seed to harvest, are multiple and do not conform to human, fossil-fuelled technological time. All of these times make up the planetary community at any given point, and no time scale can be collapsed into the other. We live in the multiple times of the planetary community. And, since time and place are intimately connected, we should also pay attention to the multiple places of the planet. 
Whereas fossil-fuelled reality, with its smooth chronological time, paves over places with disregard, opening up to planetary places leads to a polyamory of place (Bauman, 2014). Places unfold at their own paces, but entangled with the planetary flows of energy, information, materials, and bodies. That is, no place is in isolation; rather, each place is made up of a unique set of planetary flows that makes it that unique place. My own person is played by and carries the multiple places that I have lived within: the family farm, Little Rock, Arkansas; Nashville, Tennessee; Berkeley, California; Miami, Florida; Jogjakarta, Indonesia; Berlin, Germany; and all the places I have visited for short periods in between. These places call out different parts of me because I am in an open evolving relationship with them. It is a polyamorous affair with multiple planetary places.

Rather than holding on to one place at the costs of all others (nationalisms, parochialisms, etc.), a type of monogamy of place, perhaps we could practice love for multiple places and how they are entangled into a planetary community. This recognises that we can love multiple bodies in different ways, and that we are entangled with all other bodies. It also undermines the monogamous way in which private property, the individual, and humanity itself is construed under fossil-fuelled neoliberalism. Private property is an extractive practice that claims ownership of what is entangled. The isolated individual is an extractive practice that backgrounds the entangled connections that make up any given organism. Finally, anthropocentrism, or human exceptionalism, is an extractive practice that suggests ethical and moral concern should be held for one species (and who gets counted as human here has mattered dearly over the centuries).

Maybe, just maybe, there is some hope in the cracks of fossil-fuelled time that will begin to open up spaces internally and externally that let more vitality back into the entire planetary community. This will take processes of re-attunement and ones which I think can be guided by something like a critical planetary romanticism. It is to a discussion of CPR (for the Earth) that I now turn.

\section{Re-attunements: Developing a critical planetary romanticism}

If anything, I would argue, religion (re-reading and/or gathering together in its Latin roots) is about re-attuning to the worlds in which we live. In fact, I argue that re-attunement is one way to define what religions actually do (at their best). Moses re-attuning to a world in which an empire depended upon slavery and then working to create a new world that let more life thrive; Jesus re-attuning to a world of injustice by the Roman Empire and understanding that male and female, Jew and gentile, rich and poor were all deserving of basic human decency and dignity; Sufi's whirling to re-attune to the spinning of the planet; the Buddha, peering through the cracks of a caste system and re-attuning to a world in which all things were ultimately interconnected and separation was a lie; trickster figures that break 
up strict boundaries and help humans re-attune to the worlds around them; Ghandi's anti-colonial movement and MLK Jr.'s movement for civil rights: all of these depend upon re-attuning to the worlds in which we live because the worlds have become ossified and unjust to many bodies. Religion, then, is a queer affair: breaking open the boundaries of identity that have become ossified and allowing us to open on to a host of bodies and ways of being in the world: ways that pay attention to how we enter into and are entered by multiple bodies on a daily basis (human and non). The process of nature naturing, or life living, is, it seems, an erotic affair and religions can help us re-attune to these planetary bodies when they are not used in the service of harnessing and hoarding power.

Such re-attuning depends upon paying deep attention to earth bodies; it depends, in other words, on some sort of earthly erotic desire. In the recent Netflix documentary on Walter Mercado, Mucho Mucho Amor (Tabsch 2020), there is a moment where the documentarian asks Mercado about his sexuality and Mercado responds (and I paraphrase): 'my whole body is sexual, I am making love to everything around me on a daily basis'. Mercado here is asking us to re-attune our bodies to the world. It is odd that the sensual desires we modern western humans are allowed to experience are reduced to functions: sex and eating, basically. Our sexual desires are more often than not relegated to the regions that we keep covered; our eating desires are shamed and shaped into all sorts of pathological habits. Not to mention, the violence surrounding these two ways of interacting with other bodies. How is it that our most intimate contact with other bodies has been reduced to either fucking or eating? What if, as Mercado suggests, our whole body is the site of eros, and all bodies are sites of eros. What types of engagement might we have with human bodies and all other earth bodies if we were to see our entire bodies as sites of intimate connection?

The porosity of the body is such that we have microorganisms crawling in and out of our skin daily; the air we breathe comes in and out and is recycled from other breathing bodies over millennia; the atoms that make up our bodies are recycled from stars; the microbiome of our gut that is part of the ecosystem of our bodies; AND the viruses and bacteria and germs and infections that can kill us are also part of this ongoing orgy of earthly bodies. It is not that all this entanglement is 'good' for individuals, humans, or any other species. This planetary orgy will eventually kill us all.

As our ancestors well know, porosity is a double-edged sword. It allows for the possibility of connection and life, but also for returning to equilibrium with the entities around us, or death. When the extant world religions were emerging onto the scene some 4000 years ago, life was short. There was no modern medicine and living until 40 or 50 was a big deal. It made sense that religious and philosophical narratives and cosmologies gave humans a special place in the world. It helped to know that one was part of a larger cosmos and that he/she/they would have something to look forward to after a relatively short life on earth. Though the life span of many peoples today 


\section{2}

is still less than those of modern, more economically privileged societies, the modern world has made great strides in sealing the human individual off from the rest of the planetary community. Modern western architecture, transportation, medicine, agriculture and consumption systems, and education all suggest that we humans can live as if we were isolated individuals and not dependent upon the earth systems. We have extended life into the 80 s and 90s, and there are many trans/post humanists who think eventually we humans will be able to 'beat' death. The problem is that this reifies the human, making the 'human' another unit of the efficient calculations required of fossil-fuelled time and technologies. Life is much queerer, much messier.

This illusion, that we can wall ourselves off and escape the interrelatedness that will eventually lead to our death, has caused social injustice and ecological degradation. In fact, climate change and pandemics both remind us that we are, indeed, porous entangled bodies within an evolving planetary community and that we are not in control. The earth is not made for humans alone, rather the earth made it possible for we humans to exist: the earth gifted us our very existence. This gift only requires that we learn to live within the wider planetary community rather than as if we were the only things that matter. Part of living with, means accepting finitude, uncertainty, and ambiguity in terms of our own life. Indeed, all things living are justified in trying to continue living! Part of what it means to be nature naturing, is to bridge the gap from moment to moment and continue on into the future as an organised entity. That is not a crime. We have to eat, sleep, defecate, create, love, feel, mourn, and rejoice. We ought to be able to carve out spaces to live as humans within the rest of the planetary community in all the queer forms that we humans might take, without assuming that human forms are isolated or the only ones that matter. Let millions of relations and connections bloom. As humans, specifically, we might be able to carve out dwelling spaces for our own individual existences for about 80 years, but we can't expect to live forever without also realising that in order to do so we will give up the very thing that makes us human: our entanglement with the planetary community. Our dwelling here is, as Thomas Tweed argues, just for a time; life is on the move and our bodies move and change along with it, crossing from youth, to middle age, to old age (if we are lucky) and death. (Tweed, 2006) We ought to build institutions and systems that recognise our need to dwell in our diverse interrelated forms, but also pay deep attention to the needs of the ever-changing planetary community. In order to pay deep attention to and constantly re-attune ourselves to the needs of this ever-changing planet, we need to develop something like a critical planetary romanticism (CPR) for the Earth. I will spend the rest of this essay reflecting on each of these terms.

I want to start my reflections with the last of the three terms of a CPR for the Earth. What do I mean by romanticism in this context? If the problem with the fossil-fuelled, reductive and productive model of 'nature' is that the 
rest of the natural world is treated as 'standing reserve' for human 'progress', (Heidegger, 1977) then a romanticism seeks to correct that understanding of nature. Romanticism here becomes our ontology (so to speak). We are entangled with the evolving and living bodies of the rest of the planetary community. All of the world is vital and contains value (Bennett, 2010). This matches up well with understandings from the new materialisms. The vitality and value of the entities and bodies that make up the planetary community become the basis for thinking about what is 'good' and what is 'bad'. Goodness and badness are not imposed upon the planetary community from above, but rather emerge from our entangled relations. How ought we live, given our porous entanglements with all other life on the planet? Such reflection must be done not just with humans, but with nonhuman participants as well.

Romanticism cannot be tied to local places alone. A romanticism that is tied to local places alone can easily turn into parochialism or nationalism; this was part of the problem with the German romantics of the 19th century, for instance. Instead, we must extend that romantic concern towards the connections of local places and bio-regions that together make up the entire planetary community at any given moment. The planetary, then, provides us with our aesthetics, our understandings of beauty and ugliness. This is our imaginative boundary for thinking about what types of worlds we want to help co-create; and I do mean worlds in the plural: at any given time, the multiple worlds that are co-constructed help to make up the planetary community. Again, this can't be just from a human perspective, but must be co-constructed together with other planetary citizens.

Finally, we need critical theories to help remind us of our multiply embodied realities, and the multiplicity of perspectives that make up our worlds and the planetary community. There is no naïve, direct, unfiltered connection to 'nature'. Rather, our different embodiments lead to different experiences of the planetary. And, due to the ways in which worlds are constructed, different bodies experience the planetary community differently. We need critical race theory, queer theory, disability studies, critical animal studies, post-colonial and de-colonial studies, feminist theories, and more to help remind us of the ways in which worlds are experienced differently depending on embodiment. And, we ought to listen to the bodies that are most adversely affected by a given construction of the world so that we can begin to co-construct worlds in ways that include those abject bodies in ideas of flourishing, goodness, and beauty. These critical theories are central to helping us understand that truth is multi-perspectival, shifting, and more about ethics and aesthetics than ontology and metaphysics ( Figure 12.2).

\section{Coda: From top-down monocrops to passive solar fields}

Actions that don't seem so obvious or possible from the present moment can emerge in the processes of building different worlds. When I think about 


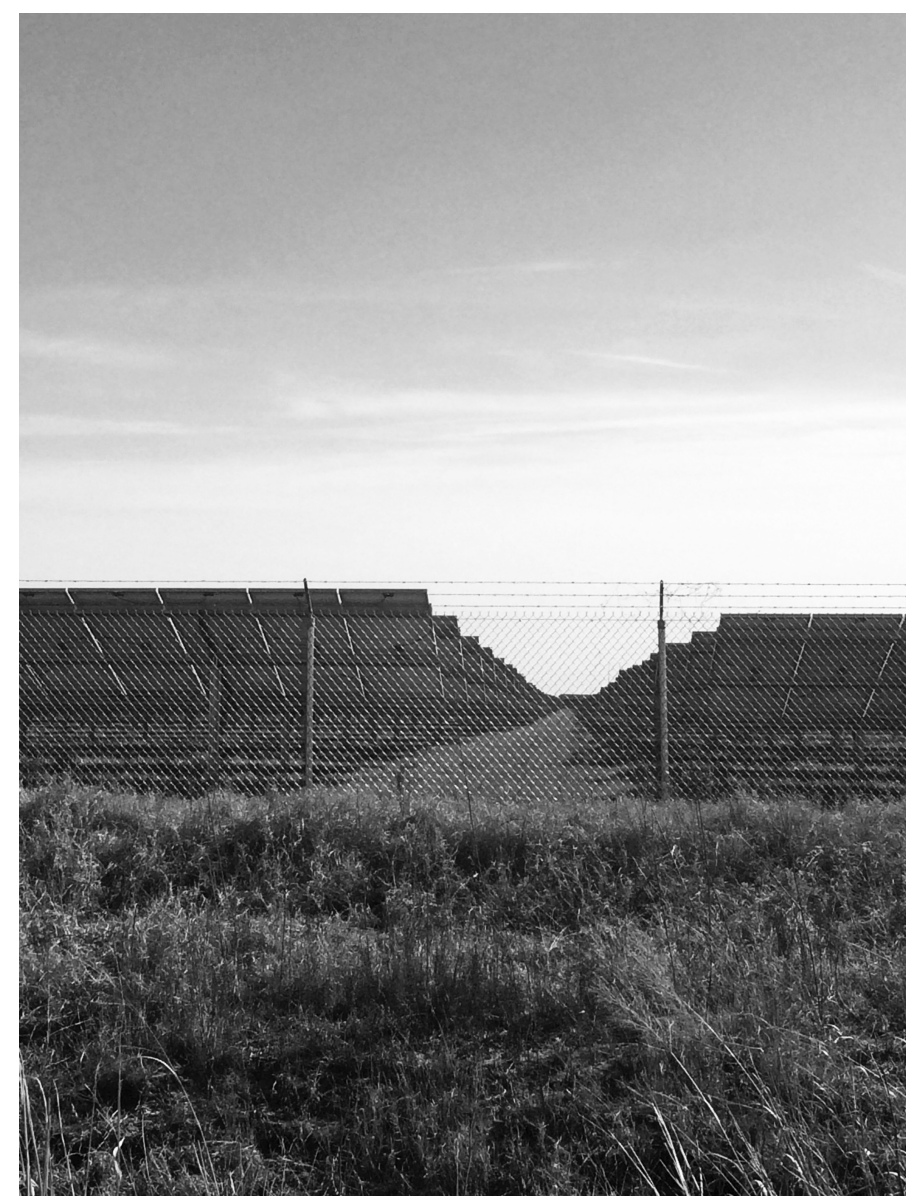

Figure 12.2 Solar fields on the former Goodwin-Bauman farm (Photo courtesy of James Walsmith)

growing up on that family farm in Stuttgart, Arkansas, as a child, I could have never imagined that it would one day be a solar field, nor that I would be writing about it from Berlin, Germany. This is part of what it means to live in faith and hope for a 'different' (and hopefully better) planetary future. This is no return to paradise, nor is it 'business as usual'. There is technology involved, but it is renewable technology that listens to the demands of those voices who have been destroyed by fossil fuels. There is also technology involved in my ability to develop a polyamory of multiple places around the planet (but still to this point, it is that fossil-fuelled technology that has allowed for this). Am I loving multiple places at the peril of the planet? That is, indeed, a conundrum, and there is no Utopic world possible in which all 
will be well and there will be no more violence; but I do think we can develop planetary technologies of polyamory that promote the love of multiple places without threatening the future of the planetary systems that keep life living.

A planetary technology that feels the erotic connection between earth bodies and understands its entanglement with the planetary community is possible. Any technology, even passive solar ones, will come with its own problems, such as the destructive mining of lithium needed to power the green, renewable revolution. But an earthly erotic, critical planetary romanticism for the Earth, might enable us to hear the suffering of bodies that results from our co-constructed worlds. And perhaps, the suffering that results from solar is already less than the suffering that results from fossilfuelled technologies; perhaps, we can continuously find ways to reduce the impacts of our own lives on others in ways that we share in the flourishing and the suffering together. Perhaps in this small transition from industrial monoculture to solar fields lies hope for a different possibility for living that may bring about more justice and flourishing for, and solidarity with the bodies that will make up our planetary future. The fact that solar fields exist on a former soybean farm in Stuttgart, Arkansas (USA) is a major reattunement that has taken place in my lifetime. It may be too little too late for many of our extant worlds, but the fact that this former unimaginable has now been made not only possible but real, gives me faith and hope for a different, even a queer, planetary future.

\section{References}

Bauman, W. (2014) Religion and ecology: Developing a planetary ethic. New York: Columbia University Press.

- (2020) Returning faith to knowledge: Earthlings after the anthropocene. Religions, 11(4), 169.

Bennett, J. (2010) Vibrant matter: A political ecology of things. Durham, NC: Duke University Press.

Haeckel, E. (1992) The riddle of the universe. Buffalo, NY: Prometheus Books.

Halberstam, J. (2005) In a queer time and place: Transgender bodies, subcultural lives. WB: New York, New York: NYU Press.

Heidegger, M. (1977) The question concerning technology, and other essays. New York: Garland Publishing.

Hirschfeld, M. (2000) The homosexuality of men and women. Amherst, NY: Prometheus Books.

McNeill, J. R. \& Engelke, P. (2016) The great acceleration: An environmental history of the anthropocene since 1945. Cambridge: Harvard University Press.

Merchant, C. (1980) The death of nature: Women, ecology, and the scientific revolution. 1st ed. San Francisco, CA: Harper \& Row.

Merchant, C. (2003) Reinventing eden: The fate of nature in Western culture. New York: Routledge.

Mignolo, W. D. (2011) The darker side of western modernity: Global futures, decolonial options. Durham, NC: Duke University Press. 


\section{Whitney A. Bauman}

Morton, T. (2010) Queer ecology. PMLA, 125(2), 273-282.

Richards, R. J. (2008) The tragic sense of life: Ernst Haeckel and the struggle over evolutionary thought. Chicago, IL: University of Chicago Press.

Rubenstein, M.-J. (2018) Pantheologies: Gods, worlds, monstrosities. New York: Columbia University Press.

Said, E. W. (1978) Orientalism. New York: Pantheon Books.

Tabsch, K. Director. (2020) Mucho Mucho Mucho Amor: The Leged of Walter Mercado. Netflix.

Tweed, T. A. (2006) Crossing and dwelling: A theory of religion. Cambridge: Harvard University Press.

Weber, A. (2017) Matter and desire: An erotic ecology. White River Junction, VT: Chelsea Green Publishing.

White, L. (1967) The historical roots of our ecologic crisis. Science, 155(3767), 1203-1207.

Wilson, E. O. (1984) Biophilia: The human bond with other species. Cambridge, MA: Harvard University Press. 


\title{
13 Notes on the contributors' experiences
}

\section{Insights into autoethnographic research}

\author{
Edgar Rodríguez-Dorans and \\ Jason Holmes
}

Reflexivity and writing are integrated into autoethnography as skills that allow researchers to make sense of their personal experiences at the intersection of social and cultural phenomena. The private nature of writing can make its process inaccessible and mystified. To offer an insight into this personal process, we wanted to provide the reader with notes that would address how it was to write this book. We wrote these notes based on the contributors' reflections on the writing process. Throughout the edition of the book, we invited the contributors to have a conversation with us via video conferences to better understand their engagement with the topics they wrote about and their methods of inquiry.

Some of them preferred to meet with us individually; some others took part in small group conversations. The objective of the meetings was to demystify the writing process and learn more about it by asking contributors to speak about the difficulties and concerns they faced and the times when it went with ease. We wanted to present readers with the process of finding personal space and voice and how authors might have solved potential struggles to find the message they wanted to distil and reflect on those times when they asked themselves, 'what is this about?' All authors were at different stages of the writing process; some were at the conceptualisation phase, where there are ideas, but there is nothing really on the page. Others had already provided the first draft, while some others had already completed their text. The different stages of writing reflected in their comments about what it was like to write autoethnographically.

These conversations had the purpose of exploring three key aspects: how they conceptualised 'the everyday' in their own chapters, which was especially important given the scarcity of research about ordinary aspects of gay life; we also explored ethical concerns during the writing and how they resolved them; and, finally, we were interested in aspects of craft, or in other words, how their writing looked in practice. While we had these themes as a guideline for the meetings, these were an organic engagement with the contributors. As we wrote in the introduction, we knew some authors beforehand, but in other cases, these online meetings were the first time that we had spoken to them. 
Perhaps these conversations spoke to our need - as editors - to know more about the contributors and to establish a personal connection with them. Since we were asking them to share with us aspects of life that had personal significance, we wanted to make sure that authors were 'comfortable' with the project. The word 'comfortable' proved to be a difficult one, as many of the writings exposed the 'relational ethics' Carolyn Ellis (2007) writes about, in which autoethnographers need to: 'act from our hearts and minds, acknowledge our interpersonal bonds to others, and take responsibility for actions and their consequences' (p. 3). Envisioning that some aspects of engaging with personal narrative could elicit some distress in contributors, we wanted to provide an outlet where they could express any concerns that they may have.

We knew this section was asking authors to access vulnerable parts of themselves outside of the written-based work. A conversation is 'immediate' and might not always offer the opportunity to leave the writing and come back to it to edit. In a conversation, one might express things differently than they would in writing. To create a sufficiently 'safe' space for these men to talk about what went on for them while writing their chapters, and for the right to process this material away from the anxiety of being named, in this section we withhold the contributors' identities.

Finally, we also wanted these live conversations to be an opportunity to bridge potential disciplinary and methodological divisions in what was a diverse group of writers. Thus, we conceptualised these conversations around reflexive practices, writing process, and support sessions to promote writers' involvement with their inquiry throughout the prewriting, during, and post-writing stages. We used Zoom recording capabilities to record the conversations with authors. We used ELAN to transcribe the audio-recordings and make sense of the discussions with contributors.

\section{Conceptualising and operationalising 'the everyday'}

Because 'the everyday' is highly personal, conceptualising it was a complex task for authors. Indeed, there were various ways the everyday was conceived in different chapters. One of these ways of understanding the everyday was through 'everyday memories'. For example, one author rooted his chapter in someone else's statement, a powerful phrase that had stayed in his memory. Others engaged with thoughts, images, happenings, or certain relationships that were constantly on their minds, and therefore, were an essential part of their identities. These kernel moments offered a powerful focus point that elicited the start of a 'self-search' process.

Some aspects of their writing came about as epiphanies, a moment in which they realised that what they saw as ordinary, perhaps was not ordinary for everyone. An author told us about how his idea for the chapter emerged when standing in a room, staring at a wall, thinking about the writing. He needed something event-driven that would pull out his emotions, something that added colour and texture to the writing. 
For other authors, the development of the chapter was strongly associated to a sense of place. For example, some authors talked about how being about to have a shower, or about to travel, or while doing chores - space where they do a lot of thinking - helped them engage with a profound sense of loss, insight, loneliness, love, and confusion that were later reflected in their chapters. One author expressed how the writing experience helped him realise he had not fully accepted his gayness and the realisation made him feel 'fresh and liberated'.

For several contributors, the papers they wrote for this book were part of larger projects and they used this opportunity to focus on the everyday as a novel angle. One author described:

'I've been working on theorising this topic for a couple years, and in this case, I used 'the ordinary' to think about intimacy. So this chapter will contribute to a larger exploration. I work out complex concepts in different venues. However, this one allows me to deep dive into the notion of intimacy from a personal and cultural perspective'.

\section{The need to write about a topic}

The idea that the topic finds the author and not vice versa is a discussion that has taken place in academic writing: for example, writing as a method of inquiry, autoethnography, poetic inquiry, and research as activism are some of the disciplines that have presented alternatives to research that resist prescriptive methodologies (see Gale and Wyatt, 2017; Wyatt, 2019; Richardson and St. Pierre, 2005; St. Pierre, 2017; Prendergast et al., 2009; Galvin and Prendergast, 2016). The notion that the topic finds the writing suggests that the theme of discussion is so pressing, momentous, and timely that it is almost 'inevitable' or 'necessary' to write about it. One author commented that the question of deciding on the topic of his chapter posed an ontological challenge for him, as he did not think he had had any agency in writing about it. He said:

Part of my experience was of this chapter coming to me, almost as if it was a life of its own, almost as if it needed to be written or it wanted to be written, which is very unusual for me. But that's what the experience was like. I'm not claiming any kind of belief in spirituality or anything like that, or in life outside of us - living creatures on this planet - but something quite remarkable happened in the construction of this chapter. In my experience of it ... I was clear from the beginning that I needed to write about it.

Similarly, other contributors were clear on what topic to write about from the beginning, which suggests a sense of certainty about their choices. Looking back at the abstracts they provided when the book was in its proposal stage, these confirmed a certain stability about the topics the author's wanted to address. They took their work in progress to retreats, on their travels, to their everyday spaces; they 'carried' their inquiries with them wherever they were - running in the hills, in their visits to home towns; and 
when abroad, at home and elsewhere, spending time by themselves thinking, working, writing, processing. They wrote notes and started writing and reading along with ideas of what it means to be gay. They 'wrote and wrote and wrote'. Because they had this inner certainty about what they needed to write about, the chapters came about with a sense of promptness. One author expresses that the chapter 'wrote itself', to convey it flowed really quickly. It was the same for another writer who said he was not worried about things to write, he just needed to find the time to write them.

As an explanation to the notion that they developed their chapters as an inner need or urgency to write them, one contributor explained he saw in his chapter the opportunity to ask questions that others like him may struggle to ask. His aim was to give tools and resources to those traumatised by abandonment, exclusion, and ostracisation. This experience was like other contributors' narratives of engaging with their own chapters in which their writing was responding to a stimulus that came from a deep and continuous immersion in their experiences and the contexts in which they inhabited. Their writing would reveal to them the extent to which they felt their need was not only a personal quest for meaning, but it was also a call to interrogate certain aspects of their lives that at first glance could be considered 'ordinary', but upon reflection, they revealed problematic dynamics, inequalities, and broader issues rooted in the social and cultural milieus they inhabit.

\section{The symbolic presence of community in the writing}

The importance of a community of gay men - real or symbolic - was a crucial theme in the authors' writings. The idea of 'community' was complex, and it differed between authors, but in all cases, it was expressed as essential because it represented connection in four major aspects: to learn about gayness, to feel at ease and write freely, to feel understood, and to mentor other gay men. Authors expressed how having a sense of a gay community during their process of inquiry helped them to engage in discussions that otherwise would be difficult to address.

One expressed they had an imaginary LGBTQIA+ audience in mind, and they intentionally 'wrote for them' and for queer people whose voices have been lost. They worried their writing may be 'too much', perhaps 'too queer', but if they didn't express it, if they 'didn't tell their truth, it was never going to get out there'. They are part of a culture that is expressive, yet queer people in that culture are not expressive of their emotions and feelings. They wanted to pave a way so other queer people like them can speak about themselves, because in doing so, more queer connections may occur.

As the contributor said:

I want people in the queer community back home to read this stuff, a piece from my fairly unknown hometown, and realise: 'Oh my god! This exists!' It fills me with inspiration. I haven’t met anyone from my hometown 
telling this type of story. The exposure would be great not only for me, but others like me that have these stories, but didn't think their stories mattered.

For this contributor, writing was an act of advocacy. They really wanted something - loss of family, loss of community and rejection - that could connect with others in LGBTQIA+ communities. They felt their motivation, but also that they wanted their writing to be raw and emotional. They sought to write about experiences that no one spoke about. Growing up, they felt everyone was closed and didn't express their truths, so they sought to do the complete opposite. They wanted to be a representative of their culture and share their heart and mind with the world.

Other authors reported their work with gay men extends beyond this book and is an integral part of their professional lives. Reflecting on this work, one narrated: 'Why do I work with gay men? It is about motivation and personal commitment to contribute to a community to which I feel I belong.' He wanted this to be reflected in his chapter. So, as part of his writing process, he wrote about this motivation. He continues: 'And tracing that back to discovering being gay in the first place and then almost telling a life story of discovering right up to today and working in this field.' This continuous reflective process helped him realise he wanted to write about his work itself and more about what it means to belong to a community or to have a sense of belonging to a community.

\section{Ethics and unexpected issues in writing these autoethnographies}

As researchers, mental health practitioners, and gay men ourselves, we (Edgar and Jason) were aware of the caveats of editing a collection of texts that would deal with intimate aspects of everyday life, potentially sexual themes, and mental health issues. We were conscious of various ethical deliberations to which we would be exposed. Accordingly, we aimed to base our decisions and actions on ethical values, decision-making models, and ethics codes. Equally important, we were in continuous reflection and discussion between us as editors about potentially difficult content. Collecting these autoethnographic stories resembled the research process of working with participants in a research study. We understood contributors are familiar with academic practices when conducting research, and some of them deal with ethical concerns regularly, so they would be conscious of managing difficult disclosures.

However, we also knew that most contributors would not have the privilege of anonymity to protect them from painful revelations. Autoethnography is an approach to research in which ethics take an unexpected turn: researchers are well-trained in the ethics that take care of participants, but taking care of the self can be a more sinuous trail. Having your name attached to a text that can put you in a precarious position is a decision that requires an ongoing assessment. In one instance, we talked with one contributor about 


\section{Edgar Rodríguez-Dorans and Jason Holmes}

how his concerns about his chapter were conveying a sense of vulnerability that was making us feel worried. This was a process that we observed throughout the course of two years and led the three of us - editors and contributor - to finally agree that it was in his best interest to not take part in the collection. Although we believe it would have been an important contribution to this book and those who read it, the value of non-maleficence and the question 'how does writing this chapter benefit the contributor?' helped us decide that the concerns outweighed the benefits.

We want to clarify that this decision was not associated with the topic of the chapter; it was the contributor's response to the topic that guided our decision. This means that there were not 'untouchable' topics, but there were personal responses that made specific vulnerabilities emerge. Throughout the book there are diverse themes writers address and, while some of them might be upsetting to read, we always tried to ensure that writers took a reflective stance with their chapters - for example, throughout the period in which writers developed their chapters, we conversed with them over email and video calls at various points and asked whether they felt certain about the contents and disclosures in their respective texts. We wanted to ensure they were conscious and felt supported in the decisions they made within their writing.

These ongoing conversations with authors led us to categorise the ethical concerns into three main groups: (1) inclusion of other people's narratives into the author's writing; (2) concerning disclosures; and (3) contributors' wellbeing. These domains contemplated concrete questions we needed to consider as part of the publication process.

\section{Affective responses to the autoethnographic process}

This section highlights how the stories that authors shared in this book sometimes elicited a difficult process and how they managed those unexpected affective responses. The writing became an opportunity to foster selfunderstanding, and, most times, participants came out of them with a sense of being transformed, with a different understanding of who they were. One autoethnographer shared how, in the prewriting process, he dealt with ideas and experiences that he needed to process before he could express them publicly. Some feelings were still raw, some experiences were still confusing, and he needed to understand his feelings for those experiences before he could say something about them.

Another contributor described uncomfortable emotional states that he experienced during the writing. As he is a theatre artist, he described how writing is an opportunity to do similar emotional work to when he creates a character. Yes, he experienced anxious states during the writing, but he narrated how, as an actor, he has learnt that that can be the premise that underlies his artistry and his craft, and he could apply for that work in performance to his autoethnographic research. 
For one autoethnographer, writing this piece brought him into really 'dark places'. He narrated how he wrote and left the text for some time, then went back, looked at it, and 'stayed with it'. He was not sure whether that was a 'healthy practice', but he recognised that the act of re-reading his writing had a desensitising component that helped him cope with the difficult content. He continued: '[My writing] will go into very dark spaces. If it's too tricky a space, either I will stay there or quit, I come back to it later, find another way to say it. Or I just won't go there'.

Some contributors felt apprehensive about writing about their gayness. One was disclosing his gay identity in writing for the first time and revealed that this raised significant boundary issues and dilemmas about disclosure that were not straightforward to address. He said: 'If you'd asked me last year or the year before (our invitation to contribute), my answer would have been "no". This piece of work is highly revealing'. His dilemma evoked a period of reflection. Talking about different issues, sometimes having dialogues with himself, conversations with others, posing questions about boundaries and imaginary scenarios of 'how much should I reveal?' These considerations, which responded to ethics of selfcare, were the most difficult part of the process, more than the writing itself.

He was not alone in reporting that once early hesitations or decisions had been resolved, a quick flowing process ensued. Three other contributors spoke about writing a rough draft - 'a vomit', 'an expulsion of information' very quickly. These early drafts were just for their personal use, only to see where the writing process took them. They 'slept on these drafts', maybe only working on them two days a week, sometimes the writing was considered terrible (e.g., 'I can't believe I said that') and led to changes in structure or voice.

\section{Over-exposure}

Historically, gay men's lives have been open to scrutiny. This has generated what Frederick (2014) calls 'gay discontent'. He writes: '[Men who have sex with men] - and more recently "gay" men-have been stigmatised by the oppressive and marginalizing policies of numerous systems of social control (criminal law, canon [church] law, medicine, public health, behavioral sciences, etc.)' (p. 141). As editors, we were concerned that this book could, inadvertently, expose the narratives of contributors to forms of scrutiny that could reproduce these harmful practices of control of policing. Throughout the course of the edition of manuscripts, we were aware that a book that uses autoethnography as its method will always have an element of vulnerability that comes from self-exposure. With this in mind, we had the principles of non-maleficence and benefit as our guideline to make sure that the writings presented here did not come at the detriment of the contributors' wellbeing. 


\section{Edgar Rodríguez-Dorans and Jason Holmes}

One writer, whose text focused on sexuality and eroticism in digital platforms, asked at various points of the process 'how revealing' he needed to be in his disclosures. We explored the reasons he felt the need to be 'revealing'. These conversations brought about topics of the exoticisation and marginalisation of gay men's relationships that have permeated into mainstream idiosyncrasies. It became apparent how the contributor was comfortable discussing these topics of gay eroticism in the safety of the conversations with editors, but he realised it was something that he did not want to share with the readers. He decided he would not share that aspect of life at this point.

Other authors also expressed similar views about how gay men's lives have been poorly studied in the sense that research on gay men's lives is scarce, and the studies that exist have centred primarily on gay men's sexualities. This brought about whether they would want to contribute to that sex-centred discourse. One way in which contributors reached a compromise with themselves was by emphasising that the parts of their writing that centred on sex are told in their own terms and by remembering that the book was a space that offered an opportunity for other gay men to read about content that applies to their own lives.

One author expressed how this opportunity was profoundly important because, throughout his life, he had already been working on lots of boundary issues regarding: 'What am I prepared to say about myself? I come from a culture where it was almost impossible to be gay, through the 1970s and 80 s, and the idea of being open and disclosing especially in publication has always been there for me, and now it was time to take that opportunity'.

While the above account suggests the positive impact of disclosing aspects of their lives, we were mindful that some contributors were in a fragile or precarious position. One was anxious about the readership of the book and felt unprepared for the exposure it would offer. He expressed concerns about writing about certain parts of his intimate life and made a conscious decision not to address those issues in the light of negative consequences he could face in the geographical context he lives in. He expanded on this and spoke of wanting to protect his current relationship from public scrutiny. He has made past relationships open; he has even written for different platforms. Now, he does not want to write about his relationships, because he knows what he has done to himself in the past. He said:

'I have the power to do something different, to own my sexuality, my pleasures, and try different things. I don't regret writing about them in the past, it was fine, I liked it. But now, I know things I didn't know before, and I want to value that. Is not a question of being brave, but more a question of "it's my right not to disclose about my sexual life",

To understand how autoethnographers negotiate difficult disclosures in their writing, we asked them: 'How do you decide what to include and what is just for you?' They shared how, for some difficult content, it becomes a desensitising process. One of them discussed how autoethnography brings 
about: 'very uncomfortable writing that has caused me concerns, especially when using "I" as the main voice. Writing about serious mental health issues for the first time sucked, but it happened. I puked what I knew. I wrote around the situation. I don't like it; I'm going to flip it at you. Keep working on it, until I think: "great, I think it matters, and I want to include my story here". I could write it without the serious mental health issues, but I think that, out of honesty and commitment to readers, I want to be a bit more vulnerable'.

The theme of over-exposure revealed that the autoethnographic writing process was an ongoing negotiation with the self and others to decide what needed to be written and what would be detrimental to their own welfare.

\section{Writing in a pandemic}

As stated in the introductory chapter, some parts of this book were written during the COVID-19 pandemic. During this time, the lives of many took an unusual domestic focus, and the ordinary was highlighted. The 'everyday' angle of this book had been planned in pre-pandemic times, but the series of lockdowns, travel restrictions, and social distancing measures that took place around the world made the ordinary more evident for contributors.

For one of them, the pandemic created the 'occasion', a 'horrible, painful time' that is constantly traumatic about which he writes in his chapter. $\mathrm{He}$ said:

'We are experiencing multiple pandemics in which [we] are situated differently. People experience them differently because our privileges and disadvantages made some more vulnerable than others. And we are in the intersections of those multiple pandemics; even though we are not necessarily impacted by them in the same way, we are in the middle of them'.

During this horror, one contributor said he was forced everyday to look inwards for resources to get through it. The relationship he writes about has been his lifeline, and it has given him the faith and strength to look inside his own emotionality in these multiple pandemics and to sit in his place. Without the pandemic, he would have been distracted.

For another contributor, enforced solitude of his pandemic afforded him the time and space to sit with his piece long enough to decide it was ready to be read. He found writing during the pandemic a much-needed distraction that allowed him to get something moving and motivating and that took him away from the current situation.

It was the same for another contributor who saw the writing as a productive exercise in stepping outside this pandemic time. For him the pandemic was an everyday personal and ecological trauma, and he sought ways to deal with the grief that different people are being treated differently in what is a renewed time of violence. 


\section{Aspects of 'craft' in autoethnographic research: Autoethnography as a method}

In response to the question: 'What do you think autoethnography does as a method that other methods don't or can't?' One contributor responded that it's a method that 'draws out the human soul [...] it's almost magical'. For him, autoethnography pulls out understanding from experience and connects it to the broader human shared experience. He finds it elusive, like looking in a mirror: 'Sometimes you are comfortable with what you are looking at, others you are not'. He continued:

'Autoethnography is flexible, but it's also a hard truth. It's a very careful process; you have to check in with your emotions and reflections. Feeling okay to write about the contents of this chapter was a process that took years. Before now, my capability to write about that experience was limited.'

Another author coincided with the notion of autoethnography being a flexible but hard method. He believes autoethnography benefits from disclosing aspects of relationships that are only accessible to the self, and although he really wanted to do that, he felt he could not do that completely, as he is in a relationship with someone who is really private. His writing became risky.

As editors, the tension between making private aspects of relationships public became a battle of forces in which our primary concern was the mental and professional wellbeing of the contributors. During the writing process, our ongoing relationship with them and the private conversations therein could manage this tension. However, we knew once the book was published, our ability to do so became limited. On this basis, and given that some were new to publishing autobiographical material, our dialogue with contributors on what aspects of relationships they were comfortable disclosing represented an important part of our relationships with these men. One author who was new to autoethnography narrated:

'I used a lot of personal experience in processing and managing my academic work, but I've not done autoethnographic work. This is the first time that I've written for an autoethnographic collection. However, I wouldn't say that it's hugely different from past work that I've done that has been published in other contexts. It's very, very personal, but it wasn't framed as autoethnographic'.

Some authors reflected on the scope, limits, and defining qualities of autoethnography. There seemed to be a consensus that what makes these texts autoethnographic is that they are all about the contributors' experiences and they are honest and open texts about culture - the culture that they come from, the culture that they live in, and the culture of their own disciplines.

\section{Sources to aid autoethnographic writing}

One contributor described how he always approaches his autoethnographic work by situating his own life, body, and experiences in the research. For him, 
that is the lens through which he can understand others. Autoethnography is a deeply personal process that requires a level of vulnerability, an evolving process that as a writer allows him to get closer to this representation of his own interiority and understand how this interiority can reflect or be useful to others.

Some contributors played with sources early in their writing process; others did so retrospectively once their autobiographical material had been generated. After writing their autobiographical material, some contributors were left with thinking about how they brought in broader cultural concepts and narratives and, as one contributor put it: 'the LGBTQ stuff'. In other words, there was an intentional and conscientious use of resources that were seen as potentially aiding the writing.

For one contributor, one of their main sources is 'a sister document', which they open in their computer and fill it with raw ideas. They often revisit that sister document and use it to find a focal point of their writing. Like many of the contributors, their focal point was a kernel scene, which served as an anchor where the writer could come back to - a focal point from where they could look at themes and 'connect with foreign ideas'. Once the focal point was established, the writing came together. As they said:

'Once I have an idea, other ideas come in rapidly. I wrote to see where these ideas were going, and, if I have a document where I can put them raw, then I can go through picking out these ideas'.

One contributor explored papers and online libraries seeing what material spoke to him. He used a filtering process in which he asked if the material helped to get his point across. In doing so, he concentrated on papers which explored human experience. He said: 'I am exploring myself and I connect to those [papers] more, which feel they are discussing real human experience'. For him, positivist papers didn't feel like 'real life'.

Other contributors knew they wanted to incorporate certain other works from the onset. These works were usually an area of long-term interest, such as certain theoretical concepts or an individual's body of work. They started the writing process with these works in mind. For these authors, the process was different from the free flow of autobiographical material about which the others spoke.

Sometimes the sources the authors used were acknowledged explicitly; sometimes they were more implicit. In these instances, their references to broader culture hung around their texts more subtly. These were things the contributors had read or assimilated throughout their lives. Put another way, the references are present in their writing but not so much they had them in mind; rather they are immersed in them, they are a part of them. Implicit acknowledgement of resources is illustrated for example in the following exchange between four of the contributors:

Contributor 1: 'It's what we do in life. I often talk about the book "The Velvet Rage" (Downs, 2006), it is part of my everyday'. 
Contributor 2: 'For me, it's Lorde (1984) when I think about desire and the erotic, I cannot help, but thinking about Lorde. I carry her with me. She opened my eyes to an important idea'.

Contributor 1: 'These books are part of us, and even if we don't quote or cite them directly when we talk about these issues, they are part of our embodied processes. We are thinking through the lens of the literature we have read'.

Contributor 2: 'Yes. I am not a Foucault expert, but his ideas have allowed me to write about the things I do. So, even though I am not using his theory or concepts for this piece, they are there. For example, I am sick of people saying monogamy is heteronormative. Why do you say that? Monogamy is not a straight privilege; anyone can be monogamous if they want. So it's something that sits perfectly with feminist thinking and queer theory and Foucauldian thinking and regulatory power, even though I am not quoting that in my discussions with people who criticise my relationship for being monogamous'.

The literature as a source was fundamental in autoethnographic writing. One author commented about his uncertainty about how open to be in his text, which led to him seeking reassurance from published articles where, as he said:

There are these guys talking openly about $[\ldots]$ the work and what happens in the work. And they offered me reassurance that we have to think about these delicate matters.

Reading what others had written gave contributors permission to write openly about their experience, albeit still with apprehension because other scholars might not sympathise with the ideas presented in their chapters:

I don't know the readership of this book, and some people reading this book might not be on the same page. I'm on that page and these other guys that think and work along the same lines as me, they're on that page, but we might get this book reviewed and someone might think completely different and might attack me for this.

The literature on gay men's studies was a crucial resource for many contributors, especially the literature that uses first-person accounts as a focal point because it encouraged authors to write about their own experience, which would give them a level of understanding of the vulnerability that comes when using personal experience as the main source to construct an argument. As one contributor put it:

I felt it was hypocritical of me to ask others in my professional life to do this type of self-disclosure work, but for me never to do it. I felt it was time to 'come out from behind the professional facade' to be more directly open and engaged in the work of research and what it means to be a gay man working in his field. For me, this literature gave me the permission, strength, and courage to do it. We all stand on the shoulders of others in this work, and my little chapter could not have been created hadn't it been for those other guys who had come before and had the courage to publish what they published and to say what they said. 

resources

For some contributors, everyday conversations and situations became a domain of analysis. These were conversations with themselves, with other specific people, dead or alive, or wider imaginary audiences. They used these conversations and situations as analytical tools to help them process the emotional aspects of the relationships about which they wrote. They gave information on how people interacted and the impact those interactions had on the contributor and how they see the world. As one contributor said: 'I engage in situations with different categories - sexual difference, masculinity, deep intimacy, vulnerability - core features of my work. I use other literature and theory to unpack these in the everyday'.

All the contributors used memories, dreams, and flashbacks as data. These embodied ways of knowing also included sources such as sensorial data - smells, flavours, tactile stimuli - and their association's responses to those. The difference in data sources spoke about how each contributor conceptualised data and their philosophical stance on what data is. One contributor used previous research interview transcripts as a source of material. He recalled moments that have stayed with him for ten or 15 years snippets of research data that his thoughts meandered too. Emotional points - a reaction - where he could stick a mental note. He used these as starting points of reflection. He reported:

'And it's really interesting to see what is revealed when you change the perspective from looking at the participants. I've built my research career by talking to others and trying to understand what others have to say. And what I am looking at this time is inside me'.

Using self as a source for the research generated a sense of alertness amongst contributors. It was a point of reflection about what constitutes data in research and how evidence is conceptualised in their respective disciplines. One author was concerned about the validity of quoting himself or using his own memory, because in the discipline he works in, the convention is that data is provided only by research participants' input. At first, it was difficult for him to locate himself as the researcher and as a source of the data. His dilemma speaks not only to him as an individual, but to the whole discipline of the natural sciences. How is knowledge constructed? Whose voices have validity? These and other questions emerged from the disciplines contributors worked in, and these concerns were not exclusive to the natural sciences. One contributor recalled how a friend of his, a literary academic who uses books and novels as sources of analysis writes about them all the time. He recalled:

[My friend] wrote an entire critique of 'Giovanni's Room' (Baldwin, 1990), which deals with gay characters, and he wrote it effortlessly, and I've read many other of his reviews on queer topics. But when I told him I was writing an autoethnography, he said he would struggle to write about his 
own experience. And he said: 'Why would I write about my own life?' There was something about the first-person experience that seems perplexing for him, but perhaps it's even something more fundamental, like he wasn't seeing his own experience as a valid source of data'.

\section{Audiences as sources for the writing}

Writing with an audience in mind was an important source for some contributors. We asked them: 'How do you think these imaginary audiences influenced your processes?'

Some authors expressed how writing with a particular reader in mind was helpful in finding their focus and developing their writing. For example, that other gay people who find themselves reflected in the narration might read their chapter was an important motivation to write. Imagining other people's responses to their writing also functioned as an 'ethical compass', which helped them imagine possible scenarios and make decisions on selfcare and confidentiality. For example, that people from certain professional bodies or academic organisations would read their chapters was a common concern amongst contributors. They negotiated this type of concern by referring to ethical principles of their own disciplines. A common way to resolve ethical tensions was by thinking of the potential positive impact that the writing would bring to people who are beneficiaries in their respective disciplines. As one author expressed:

If this text helps some people [in my academic discipline] see the need to develop more refined interventions for LGBTQ people, if someone says: 'oh, I hadn't thought about things this way, maybe I need to revisit my assumptions', then I'll feel that this was worth the risk.

However, having an audience in mind was not always a helpful occurrence. One writer described he had 'too many people in his head'. During the writing process, he kept thinking of former research participants, his research topic, and he tried to squeeze and stretch his story so it appealed to them all. He found the thought of others reading his personal story anxietyprovoking. At the stage of journaling for himself, the autoethnographic process felt good and appropriate, but when thinking that others were going to see his writing, he struggled. He dealt with the multiplicity of voices in his head by reducing his imagined audience by initially writing only for himself and for his partner. He found the writing a way of putting into words what he struggled to say to him in person.

Following the previous author's comments about a reduced audience, another contributor also found it difficult to write when there were many people in his mind. He explained that in his approach to autoethnography, if he pre-defines an audience for his text, he gets into a problem of blockage in his work that does not move him to write. Instead, he got into writing about the everyday by a recurrent conversation that he had or he wished he could have had with someone who is no longer here; these imagined 
conversations led him to engage in moments of everyday interactions that scarred him, marked him, or changed how he acted - and then he wrote about them. These thoughts generated some affective states that he then used as resources for his writing too. The thought that the person in his thoughts will never know certain aspects of his life elicited a profound sense of loss that was difficult to deal with. Both the affective states and this person as his primary audience served as a motivation for his piece, manoeuvring through everyday turbulence and longing.

In starting with an imaginary conversation, other contributors developed their chapters from 'writing small snippets of experience' before branching out into the wider cultural conversations associated with their topics. By asking 'What have other people said about these themes?' they identified concepts on which they later conducted further research. This strategy helped them to ask broader questions and incorporate these into autobiographical material before finishing their piece by returning to micro moments.

\section{Voice}

For many contributors, particularly those writing about mental distress, their writing was very personal, very difficult, and very raw. That meant, for some, playing with the voice in which they wrote the piece as a way to manage their emotions. One contributor spoke of using different voices as a way throughout various stages of the writing. Using different voices allowed him to take his text into different directions and to experience different feelings, which helped him to 'get into spaces' his other voices could not.

The option to use first-, second-, and third-person voices was an important resource to protect authors from the potential harm emerging from disclosing intimate parts of their lives. For some authors, writing their chapters in the first person from the start was too painful. As one of them said:

"Using "I" is the most difficult thing [...] using the second- or third-person voice throws the text onto the reader and off me [...] it allows me to share different things safely, [using the first-person voice] makes it too personal and can affect me more than I am prepared for'.

Some authors tried writing in the second- and third-person voice and others used the plural as well to take pressure from themselves and explore different affective responses. However, they also were conscious that as autoethnographers, switching voices was allowed, as long as the narration was still rooted in personal experience.

\section{Creating the conditions for the writing process}

Writing can be a mystified practice, as it is a personal and normally solitary experience. When discussing the actual writing process, something that can be an ordinary, everyday practice, some authors had to delve deep into their experience to clarify how they approach the task. 
As one contributor said: 'I fucking hate writing. I just need to write', which revealed an apparent straightforwardness of the process, as if they just need to 'do it'. In trying to unpack what happens in the writing process, we spoke with authors about the conditions that favour this activity. One of them, who has a background in music and is 'very music orientated', narrated how he uses playlists associated with his writing, and how he writes on an evening, after a few beers, which elicits a space that he associates with writing.

Another author describes an initial writing phase that is messy and confusing - 'a beautiful mess'. They wrote all their ideas in a blank document which was 'very rough' and helped them get significant content on the document. That document became 'a companion paper' to their main chapter. The concept of a companion paper was a messy, disorganised paper, with thoughts roughly laid out, and 'bullet point after bullet point' that is developed along the main chapter. The companion paper was made from pure and powerful personal content the contributor used as a reflective paper and from which they could either pull ideas or sections of text to incorporate into his main body of work or use them as a personal, reflective space. This was an approach that was used by at least one other contributor. $\mathrm{He}$ described how he works with multiple documents in which he puts a collection of thoughts and narratives. These narratives or seminal ideas felt powerful for him, but the meaning of them was still unknown.

The unknown or unprocessed quality of the contents in those companion papers was not concerning to the authors, as they used them as potential content for future writing, something that could mature and develop into something else.

\section{Entangled ideas and fragmented texts}

A sense of entanglement was a common occurrence in the authors' experience of writing their chapters. They described how the complexity of their lived experiences was reflected in their writing. The many angles to approach their narrations could mean that their writing could become confusing and their arguments could weaken.

For one contributor, 'too much reading' meant he went off on a tangent. He felt pulled from too many directions, which led to difficulty in structuring his work. He was feeling 'like headphone cables all tied up in knots and trying to untangle them'.

In trying to work out what the issue was, he reflected on the possibility that the entanglement could be part of the text that needed to be there. Maybe a sense of entanglement was what the chapter was about. This sense of an entangled text was experienced by other authors as well, so we invited them to leave their texts like that and share them with us to see how they worked. In reading their texts, part of our feedback as editors consisted in embracing the complexity and discussing with them that some texts benefit from not 
having a clear and linear narrative. We encouraged them to 'stay with' their texts and offer them as expressive texts that allow the reader to experience with them part of the affective states that impregnated the narrative.

When providing this feedback to one contributor, he commented:

This reminds me of the text, Ordinary Affects (Stewart, 2008), which brings tangled narratives that then leaves for readers to interpret and moves onto another. It's not linear, and in appearance, it does not have a narrative arch, but it does when you finish the book, or at least I made sense of it that way.

We reflected on how, perhaps, it was best to leave the entanglement there. For one author, that became an opportunity to think about using form in unique ways and reflect on his 'fragmented' writing, his sense of not knowing where he was going as the main offering. Perhaps, in some ways, that sense of not knowing where he was going was the story.

Other contributors embraced a sense of fragmentation in their work. One of them explained how a sense of apparent fragmentation makes sense once the author and the reader allow themselves to enter the text with freedom. He said:

In some work, using fragments or notes is the methodology. For example, Susan Sontag's wonderful work 'Notes on Camp' (1966). All she uses is 47 notes. That's the essay. There are no linear arguments, just 47 notes which are profound. Similarly, Peggy Macintosh, on white privilege (1989), she created lists of white privileges, not so much as content but as form to generate ideas.

One contributor likened his writing process to constructing a brick structure. Each brick was separate in that it represented an account, a tale, a reflection, or an extract from a research interview. But each brick was necessary to build the structure. There was no attempt at making sense. Each brick had to be read separately for you to get a sense of the experience.

These examples of fragmented and entangled ways of writing suggested a way to get us into writing spaces, to spark curiosity, and to engage in different ways to approach work. These conversations between editors and contributors became on some occasions an opportunity for peer mentoring. From one of these exchanges, two contributors used the genre of performative autoethnography to do their storytelling work. The performative aspect helped to invite a sense of seeing the scenes and being in conversation with the authors. They used the performative qualities of their work to evoke feelings in the readers to witness closely the experiences they were reminiscing through their writings - a co-sharing of feelings and experiences.

\section{Sharing their work in progress}

Each author had their own personal approach to sharing their work in progress. One contributor did not share early versions of his work; he shared only the abstract, as he wanted his text to be a surprise: 'like a movie trailer'. 
Others volunteered their work to be shared with other contributors to get an understanding of what others were doing and generate intertextuality. One contributor, however, did not want to see other contributions, as he did not want other people's writing to impact or influence his work at an early stage of its development.

In contrast, for another author, receiving feedback from us, Edgar and Jason, was an important part of their writing process. The editorial comments meant they could dive deeper into their exploration of ideas. Feedback helped them to 'flourish', and 'gave more life' to the writing. They said getting consistent feedback from us was crucial and emphasised the need not just to send one near-complete draft for comment but various versions before reaching the final chapter. For them, a steady flow of comments and responses helped them polish their piece.

For another contributor, seeing what others were writing allowed him 'to see how brave they have been and that allows me to be brave too'. Other contributors too spoke of feeling apprehensive about their work. They worried if their piece was a good fit for the book. They questioned the extent to which their piece spoke to the everyday and mundane and how much other gay men and academic readership would relate to their piece. For one this process was reminiscent of times when he has been part of special issues for different journals in which sharing work in progress has not been a common practice and, from the experience of collaborating in this book, he felt it is a beneficial practice for him to see what other people are working on.

\section{Final thoughts and advice for others}

When asked what advice they had for others writing autoethnography, authors reflected on their experiences of writing for this and other projects and shared the following.

One contributor reflected it is important to:

Let yourself go into the process; you learn as you do. Don't walk in knowing the scene. Ah, this is going to happen [...] stuff happens in writing. You don't know what you are going to say until you start saying it.

Another advised others to be reflective of themselves and the process:

Understand and feel your emotions as autoethnography can be an emotional process, write rough ideas in a notepad - because you can get a really good piece from a rush of ideas and save unused writing for another project.

Finally, another author reminded autoethnographers to practice self-care during the writing process when he said:

Be kind to yourself. Nothing is perfect, and sometimes it's the imperfections that give birth to a perfect piece. Be keenly aware of your emotions when writing and what that does to you. Autoethnography pieces can be emotionally driven, but sometimes you don't need to be so immersed. It's just a written piece and not what's happening right now in the moment. It's part of your everyday life, but it's not the emotion that's present every 
minute or every hour. Give yourself breath, give yourself space and time to recover from this piece.

Wise words, that as editors of this collection, we echoed.

\section{References}

Baldwin, J. 1990. Giovanni's room, London: Penguin.

Downs, A. 2006. The velvet rage: Overcoming the pain of growing up gay in a straight man's world, Cambridge, MA: Da Capo Press.

Ellis, C. 2007. Telling secrets, revealing lives: Relational ethics in research with intimate others. Qualitative Inquiry, 13, 3-29.

Frederick, B. J. 2014. "Delinquent boys": Toward a new understanding of "deviant" and transgressive behavior in gay men. Critical Criminology (Richmond, B.C.), 22, 139-149.

Gale, K. \& Wyatt, J. 2017. Working at the wonder: Collaborative writing as method of inquiry. Qualitative Inquiry, 23, 355-364.

Galvin, K. T. \& Prendergast, M. 2016. Poetic inquiry II - Seeing, caring, understanding: Using poetry as and for inquiry, Rotterdam: Brill.

Lorde, A. 1984. Sister outsider: Essays and speeches, Trumansburg, NY: Crossing Press.

Macintosh, P. 1989. White privilege: Unpacking the invisible knapsack, Wellesley, MA: Wellesley Centers for Women.

Prendergast, M., Leggo, C. D., Sameshima, P. \& Brill, E. J. 2009. Poetic inquiry: Vibrant voices in the social sciences, Rotterdam: Sense Publishers.

Richardson, L. \& St. Pierre, E. A. 2005. Writing: A method of inquiry. In J. Van Maanen (Ed.), The Sage handbook of qualitative research, 3rd ed. Thousand Oaks, CA: Sage Publications Ltd.

Sontag, S. 1966. Against interpretation: And other essays. New York: Farrar, Straus and Giroux.

St. Pierre, E. A. 2017. Writing post qualitative inquiry. Qualitative Inquiry, 24, 603-608.

Stewart, K. 2008. Ordinary affects, Durham, NC: Duke University Press.

Wyatt, J. 2019. Therapy, stand-up and the gesture of writing: Towards creativerelational inquiry, New York: Routledge. 


\title{
14 Conclusion
}

\author{
Edgar Rodríguez-Dorans and Jason \\ Holmes
}

This edited collection supports the view that being gay is a personal, social, and cultural phenomenon that has multiple implications in people's lives. The essays featured in this book demonstrate that being gay goes beyond discourses of sexuality and gender and reaches to realms of political, socioeconomic, religious, legal, psychological, and global significance. The closeup narratives presented by the contributors show how their/our everyday lives are entangled in powerful structures, regimes, and dynamics that inform and restrict a gay man's existence.

Presenting a gloomy view of gay life was not our intention, and we believe that despite the sometimes-difficult subjects that were addressed throughout the chapters, the collection as a whole presents the reader with a variety of narratives of diverse affective content. Indeed, we hope the reader finds sparks of joy in the kinship and shared experiences expressed in the texts. Either way, we are confident that even when in the middle of forceful dynamics, the contributors have taken a step back to identify restrictive social apparatuses and have shown agency in resisting and challenging them.

The narratives of our now friends, Ken, David, Randall, Panu, Cináed, Tony, Seamus, Willem, Yasin, Julian, Oscar, and Whitney with regards to how we make sense of our everyday lives as gay men emerged from our past and present experiences, but also looked into the future to imagine where our lives are heading. Our written words were generated in a specific sociohistoric and personal time, which must be taken into consideration as our writings are contextual and, therefore, are shaped by particular (and some extraordinary) circumstances.

As such, this edited collection does not attempt to generalise gay men's lives. Nor does it attempt a reductionist thematic analysis of the issues raised in the chapters. Instead, the collection aims to evoke the voices and words of other gay men - and individuals from other LGBTQIA+ populations - who feel, experience, describe, and write similar narratives about their experiences. In particular, some stories narrated here might resonate with other LGBTQIA+ people's experiences of feeling, exploring, and struggling for being part of a population that has been discriminated against, disadvantaged, colonised, and often oversimplified and understood only in terms of 
our desire. The history of colonisation of gayness by powerful institutions - medical organisations, governments, religious organisations, companies that profit from our identities - is one of the reasons we invited contributors to look deep into, but also beyond, our desire.

\section{Gay life through an everyday prism}

Why is it important to think about gayness from an 'everyday' perspective? Because the current state of knowledge on LGBTQIA+ studies is at a relatively advanced stage and yet, we know little about intimate aspects of gay life; because looking at gayness through an everyday-ordinary lens shows us that the existing research and public knowledge of gayness is limited to a few aspects of gay existence. As individuals, gay men often find ourselves in the middle of grand narratives that give much attention to certain aspects of life, but ignore entire areas that are important to us. Approaching gayness with an everyday lens required us to pay attention to those people, relationships, activities, feelings, and thoughts that catch our attention and show the disparity between what matters to us gay men and what has been portrayed in public and academic knowledge. A focus on the everyday requires us to see that, in many cases, being gay means to the individual much more than the gender of the person to whom we feel attracted and much more than our sexuality - without denying the importance of our sexuality. Similarly to the question 'Can work be regarded as queer if it's not explicitly "about" sexuality?' posed to contributors of the book 'After Sex?' (Halley and Parker, 2011), we wanted to explore what it is like to think about gayness from a personal, everyday perspective, regardless of its subtle or overt relation with sexuality.

The personal nature of the stories that emerged from this writing exercise was a crucial move in response to the work that still needs to be done to reduce systemic inequalities for gay men, wider LGBTQIA+ populations, and other marginalised groups. These first-hand narratives emphasised the need to represent gayness in a fair way. The word 'fair' calls out to the numerous times and instances in which gay men have not had a say in matters that concern and affect us directly. These autoethnographies reclaim our authority to talk about our own experiences and recognise the knowledge generated through inhabiting our own skins. In 1972, during the convention of the American Psychiatry Association, an anonymous gay psychiatrist - Dr Anonymous - addressed the audience but concealed his identity by wearing a mask and using a microphone that distorted his voice (Glass, 2018). The reason for his address was to speak against the pathologisation of homosexuality and the biased representation of homosexual individuals as inherently dysfunctional and mentally ill. It was an urge to 'look carefully at the power which lies in [psychiatrists'] hands to define the health of others around us' (Scasta, 2003). The anonymous psychiatrist, later identified as John E. Fryer, and his speech at the conference have been deemed 
a crucial factor that contributed to the removal of homosexuality from the Diagnostic and Statistical Manual of Mental Disorders. John E. Fryer's act of resistance - defined by himself as 'probably the central event in his career' (in Scasta, 2003) - is an example of the great value of personal voice in identifying, communicating, and challenging discourses that still persist due to unchecked power.

Fryer's life circumstances put him in a position in which he took the opportunity to speak at a place where a pivotal shift of power benefitted - and continues to benefit - uncountable numbers of people. While not all of us have the same access to such circles of power, we do not underestimate nor undervalue the value of personal story nor 'the power of the small' (Harris, 2020) to transform and to create new realities. The gay men contributing to this book also took the opportunity to voice those structures, discourses, and dynamics that need to be discussed, critiqued, and changed. We wrote from our respective fronts and disciplines with the skills and power we have. We wrote about specific concerns, but with confidence that some of these are likely to be relevant to your own interests and circumstances, regardless of whether you identify as LGBTQIA+ or not. In a book that has the everyday as its focus, it might be seen as contradictory to finish with a paramount story instead of an ordinary story. However, we want to emphasise that, as the contributors have illustrated, the extraordinary inhabits within the everyday; those paramount moments lurk within the happenings of our ordinary existence.

We are aware of some of the privileges we have by writing this. For example, we did not have to wear a mask - like Fryer had - to write about our gay lives: we live in socio-historic contexts in which we have certain protections to address the issues we still face as a population, and we benefit from specific opportunities that many fellow gay men do not have. We are also aware that there are aspects of LGBTQIA+ lives in urgent need of address, and this book might have not touched upon them; we are aware that there is still much essential work to do. However, we believe that the book pivots us in that direction. We continue reflecting on our own lives as a way to identify the beliefs we live by and continue examining their provenance, their validity, and their role in our existence. We continue examining our own circumstances, including our biases, prejudices, and privileges.

\section{A sense of an ending and a desire to continue: Suggestions for further research}

This book aims to speak to different readerships. We invite you to think of the forms in which you can use its contents to take action in whatever capacity that feels generative. Whether its contents speak to you from a methodological perspective and inspire you to explore uses of personal story and autoethnography; a professional interest in LGBTQIA+ lives or perhaps you identify as LGBTQIA+, and some of the narrated experiences in this 
book resonate/contrast with yours; or perhaps it is 'the everyday' and 'the ordinary' that has caught your attention; perhaps it is something else that motivated you to read this collection; in whatever way, we hope that you found it stimulating. As a way of an ending and also as a way of continuing the 'conversation', we want to ask you: What does your everyday say about you? What are the grand narratives you live by? And do they need revising?

This book was intended as a counterbalance to the research that has centred on the colonial approach that powerful forces, such as the state and medical and religious organisations, have taken in defining and regulating our lives. The contents presented here were heterogeneous in terms of the disciplines and socio-historical and political contexts of the individuals that featured in them. That heterogeneity responds to the multiple angles from which gay lives can be seen, but overall, the essays presented and discussed them from two overlapping angles: gay men's lives from an interpersonal, relational perspective and from a macroscopic, cultural perspective. The issues that affect gay life are many; the fragile state of marriage equality in some states and the decriminalisation of same-sex relationships in others are only two of the most researched and well-known challenges. However, we know less about the individual challenges we face in our quotidian lives in the different cultural contexts we inhabit. What some gay men may consider ordinary, others might consider as an extraordinary occurrence. As demonstrated by the different chapters of this collection, the challenges and opportunities we face are associated with our age, cultural backgrounds, geographical locations, our mobility and trajectories, religious backgrounds, relationships with partners, friends, and family; our education, and our occupation. Some of us face individual problems associated with health, relationships, finances and even the concept of time itself. On the surface, these issues could be seen as personal issues. However, some of our personal issues are social and political issues.

The intertwinement of personal and social dimensions of everyday life shown through the narrated experiences of the authors in this book illuminate some useful directions for future research. It is clear that we still experience significant challenges rooted in prejudice, discrimination, inequality, and misrepresentation of gay men's lives. In his chapter, Oscar Pantoja described how he witnessed and experienced discrimination in the workplace in different settings, which has led him to question: 'What should I do? Should I express my gayness overtly? Should I let people assume what they want to assume? How far can I go in expressing my gayness? To what extent is it “right" to do so?' In trying to understand what he can do with the love he feels, his chapter suggests a future line of inquiry could be the experiences of LGBTQIA+ people, and furthermore, LGBTQIA+ people of underrepresented groups at work. With the advancement in the pursuit of equality, there might be a false impression that we have achieved an acceptable level of equality, and Oscar's essay clearly shows what is written in an organisation's equality policy may not be reflected in the thoughts and 
actions of its employees. This narrative shows with great detail how society continues to discriminate against LGBTQIA+ people in subtle, yet brutal, ways and how this identity intersects with aspects of ethnicity, class, and culture.

Showing us another possible avenue of inquiry, Tony Adams, Panu Sahassanon, and Cináed Thomas, questioned how we respond to the preestablished narratives of human development that we are presented with over our lifetimes. Tony asked: 'What do gays (and straights) do if these narratives don't fit?' This question suggests that, despite decades of academic and non-academic work, we still know very little about the trajectories of human development amongst gay men and LGBTQIA+ populations in general. While we carry on with our everyday lives, and through narrating our experiences of the unexpected and the unknown, we try to make sense of different events in our lives and create our own meanings around them - we create our own life story. As editors, we see these narrative acts as an opportunity to document significant events, analyse the circumstances in which these happen, and interrogate whether there are needs and opportunities for change. Some of these interrogations can only be made if we have an insider's perspective to engage with the dynamics that sustain those happenings. Besides questioning the status quo, these narratives implicitly suggest the need for a specialist understanding of the development of gay men and other LGBTQIA+ lives. The scripts that LGBTQIA+ people live their stories by can be fertile soil for further research as these scripts - or lack of - may spark the curiosity of researchers who search for answers to their whys. Whys that attempt to understand those Selves that act and feel; Selves that look for sex; Selves that want to feel ontologically secure; Selves that want to love and be loved; those Selves that, after being misplaced, misled, and misconstrued, just want to experience the feeling of truly being.

In this book, some of the disciplines that are prominent in the study of gay life bring our attention to the area of mental and physical ill health - see, for instance, the essays by Yasin Koc, Willem J. Stander, Cináed Thomas, and Seamus Prior. These works were valuable because they voice important mental and physical health challenges faced by gay men and those who support them. These corroborate that there is a myriad of aspects that account for the uneven social field that contributes to perpetuate challenges for gay men and LGBTQIA+ populations in general. The need for studies that do substantial work to identify specific issues in a more nuanced way becomes apparent when we read about the 'lack of ordinary privileges' - chapter by Yasin - who highlights aspects of geography, multiculturalism, and intersectionality.

In terms of the region, the chapters are contextualised around aspects that might be particular of certain geographical areas, which is indicative of how different the social realities gay people experience in different countries can be. It is also important to note that the chapters are written in a context in which, although challenging, it is still legal to be gay (although we 
do acknowledge that at the time of writing, not every contributor's country of birth legally recognises gay partnerships). This poses the question of how LGBTQIA+ peoples experience their everyday lives when living in areas of the world where there is no rule of law that protects them. The book 'Gay Life Stories, Same-Sex Desires in Post-Revolutionary Iran', by Jón Ingvar Kjaran (2019) is a good example of how much we ignore about how LGBTQIA+ people live their lives in contexts in which the historic, legal, and social challenges threaten what in other contexts we have learnt to consider our individual rights.

One of the most important points we can draw from this collection is that although we share certain commonalities, the everyday lives of gay men vary significantly, and there is no single trajectory or course of development of gay life. Studies that used to see gay life as a progression of stages with particular milestones and used those models to explain and predict gay men's sexual behaviour are now finding in qualitative studies - particularly in autoethnographies - voices from the inside; voices from the native experts who might not find themselves represented in those studies. Autoethnographic research has added nuances to the understanding of gay identities and has even given an 'anti-rhetoric', namely 'a rhetoric that always simultaneously promotes and disavows itself renouncing its intent even as it amuses audiences and advances agendas' (Gilbert, 2004, cited in Fox, 2010, p. 137).

Relational life, intimate relationships, and the pursuit of intimacy, as addressed in the essays by Julian Triandafyllou, Edgar Rodríguez-Dorans, and Randall C. Lopez suggest that our relational life is one of the most important issues in research into gay men's lives. Relationships seem to be central to the understanding of how gay men make sense of who they are and how these identities are represented at a collective level. In his book on gay male identities, Andrew Cooper (2013) discusses how the vast majority of participants emphasised the significance of their partners and relationships in general as important part of their lives. His work showed that participants found in their relationships a 'safe space' and a source of confidence within a homophobic environment. He asserts that for gay men, relationships are an important part of their lives. His findings highlight how gay men look for love, intimacy, and commitment. His work is relevant to this collection because we observe in it the suggestion that those relationships and encounters, those civil unions, romantic dates, and sexual partners - those 'safe spaces' - play a part not only in how gay men negotiate their relationship agreements but also in how those relationships 'shape' the way in which gay men make sense of themselves and highlight the need for further study on the relational life of gay men.

Finally, we want to draw the reader's attention to some not-so-obvious suggestions for future research. Whitney Bauman's queering of time and his experiences of farming life could speak to those interested in artificial intelligence and agricultural studies. Cináed Thomas' refusal of treatment should 


\section{Edgar Rodríguez-Dorans and Jason Holmes}

he become terminally ill and Randall C. Lopez' experiences surrounding his father's death could resonate with those involved in cancer and palliative care. Furthermore, David Lowbridge-Ellis' painful experiences in a card shop that could connect with to people involved in the retail sector, and Tony Adams' yearning for close gay friends to be located nearby as they age, could be of interest to those involved in housing. The possibilities for broader LGBTQIA+ research ideas are boundless, and we urge the reader to take whatever sparks their interest and run with it.

In conclusion, the chapters included in this collection constitute a diverse body of work. We hope this body of work will serve as an opening to future studies that spotlight the insider/expert voices of gay men and other LGBTQIA+ people who explain what being LGBTQIA+ means to them and, when dealing with the experiences of others, researchers need to offer transparency about our interpretive voices.

We finish with a proposal - possibly even a demand - to shift the focus from being gay as an identity that is conceptualised around desire and sexuality to an identity that is conceptualised around the larger aspects of an ordinary, everyday life. And we humbly ask you to consider that a whole world of meanings and stories is contained in the voice of someone who shyly, proudly, firmly, utters: 'I'm gay'.

\section{References}

Cooper, A. 2013. Changing Gay Male Identities, Abingdon, Oxon: Routledge.

Fox, R. 2010. Tales of a Fighting Bobcat: An Auto-archaeology of Gay Identity Formation and Maintenance, Text and Performance Quarterly, 30, 122-142. DOI: 10.1080/10462931003650153.

Gilbert, J. R. 2004. Performing Marginality: Humor, Gender, and Cultural Critique. Detroit, MI: Wayne State UP.

Glass, G. 2018. Doctor anonymous: Creating contexts for homosexuality as mental illness. Journal of Medical Humanities, 39, 101-109.

Halley, J. \& Parker, A. 2011. Introduction. In: Halley, J. \& Parker, A. (eds.) After Sex?: On Writing since Queer Theory. New York: Duke University Press.

Harris, A. M. 2020. Creative-relational inquiry. Departures in Critical Qualitative Research, 9, 16-25.

Kjaran, J. I. 2019. Gay Life Stories Same-Sex Desires in Post-Revolutionary Iran, Cham: Springer International Publishing.

Scasta, D. L. 2003. John E. Fryer, MD, and the Dr. H. Anonymous episode. Journal of Gay \& Lesbian Psychotherapy, 6, 73-84. 


\section{Index}

Note: Italicised folios indicates figures and folios with " $n$ " indicates endnotes in the text.

acceptability/acceptance xiv, xix, 17; for aging gays 64; non-acceptance 37; self-acceptance 94-5, 131; social $28 \mathrm{n} 7$

Act Up xvii, xix

Adams, T. E. 7, 58-67, 120, 170, 172; cultural narratives 61 ; dating cisgender men 58 ; death of partner 59-60, 64; families-of-origin $60-1,63,65$; gay aging 59-60, 67; gayness 62; homophobic and heteronormative religious discourse 61 ; intimate relationship 59; samesex relationships 65 ; suicide scare 63 ; 'survivor's guilt' 63

AIDS xvii, 62-3, 62n10

alcoholism 128

American Psychiatry Association 167

anthropocene/anthropocentrism 136,140

anti-gay $61 \mathrm{n} 8$; attitudes 98 ; hate crimes 63; religiosity 63

Arceneaux, M. 61n6

Arredondo, P. 123n1

Asian-American 130-1

Austin, Texas 33-4

autoethnography $7-8,147$; affective responses to process 152-3; audiences 160-1; ethics and unexpected issues in 151-65; everyday encounters 159-60; research 156-65; sharing work in progress 163-4; sources to aid writing in 156-8; thoughts and advice for others $164-5$; voice 161 ; writings 70
Bangkok 39, 41-2, 45-6

Barak, A. 3

Bauman, W. A. 133-45, 171; Coda 143-5; critical planetary romanticism 140-3; monocrops to passive solar fields 143-5; one family farm 135-6; pandemic times and places $137-40$; re-attunements 140-3; uncertainty to certainty $135-6$

being a gay man 124

being gay $8,10-11,129,131,167$, 172 ; everyday 7,126 ; mean to gay men 8 ; minority identity of 98 ; political 7; sense of identity 48; social privileges 64

Berry, K. 62n10, 64, 65n17

Blondie (rock band) 113

Bochner, A. P. 7

Brommel, B. 66n21

California 14, 124, 126-30, 140

Calvin Klein 46

Cambridge University 21

Castañeda, M. 115

Catholic education 58, 63

chemsex 24-5

Cher, k.d. lang 58

childhood sexual abuse (CSA) 111

China 134

Christian 39-41, 48, 137

Christmastime: in 2009 41-2; in 2010 $42-3$; in $201442-3$; in $201743-4$; in 2019 39-41, 45-6; in 2020 46-7

cisgender 11, 58, 61, 62n13

Civil Partnership Bill 47

cognitive energy 28 


\section{Index}

cognitive load theory $28 \mathrm{n} 5$

Cohen, S. xvi

coming out xiii, xvii, xix, $6,11,15$, 23-4, 31, 37, 52, 59, 62n11, 64, 83, 94-5

communication 9, 35-6, 89, 114, 133

community: biological 138 ;

discrimination 100; gay 33-5, 37, 62n13, 95, 100; Latinx 123, 123n1, 125; LGBT 100, 130; LGBTQ 83, 123; LGBTQIA+ 119; non-gay 7; planetary 133-4, 136, 139-40, 142-3, 145; presence in writing 150-1; psychology 83 ; religious 98 connective humanity $\mathrm{xx}$

Cook, M. 4

Cooper, A. 171

Coronation Street 21

Corpus Christi, Texas 31

cosmopolitan sexualities $\mathrm{xx}$

COVID-19 2-3, 33, 36, 46, 63, 66, 134, 155

critical planetary romanticism (CPR) 14, 135, 139-43, 145

Critique of Everyday Life (Lefebvre) 2, 8

Cunningham, S. $61 \mathrm{n} 6$

Daddies I'd Like to Fuck (DILFs) 64

David L.-E. 17-28; everyday thought after waking up 17-18; expressing personal experience to an assembly 21-2; feeling when someone says, they knew he was gay 23-4; holding hand of partner 25-6; kiss by husband 26; making a child realise about his wrong comment about being gay 23; The Nook 19; public display of affection 21; questioning self about everything 20-1; recalling husband after receding of waking thoughts 18-19; responding to a student about query regarding badge with rainbow 22-3; responding to colleague who comments "you don't sound gay" 24; sex education question 24-5; shower gel 19-20; thinking of adopting 19

Davies, R. T. xvii

depression 85

DiFranco, A. 92

discrimination 7, 14, 99-100, 125-6, 130-2, 169 diversity 10-11, 127

Donna Bella 83

'Drag Race' (RuPaul) 96, 101

Eguchi, S. 7

Ellis, C. 7, 148

Enfield College xvi

entangled ideas 162-3

eros $75-7,141$

eroticism 14,154

ethics 74, 143, 148, 151-65

Europe 134, 137

everyday: conceptualising and operationalising 148-51;

conversation 62; gay hope xix-xx; gay life 167-8; gay reality xviii; life of the gay male therapist; presence 120 ; sexual acts 77 ; social and economic inequalities 79; transformative gay life xvii-xix

Facebook 130

Faith, P. 8

families of choice $52,60 \mathrm{n} 4$

families-of-origin 60-1, 63, 66

Families We Choose (Weston) 60n 4

fear 71-2, 94; anxiety and 33; avoidance and 75 ; shame and 54

finding self $\mathrm{xv}-\mathrm{xvi}$; politically xvi-xvii; through others xiv-Xv

Fingerhut, A. W. 48

Fisher, C. 64

Foucault, M. 115, 119, 158

fragmented texts 162-3

Frederick, B. J. 153

Freud, S. 76

Frommer, M. 75

Fryer, J. E. 167-8

Garland, J. 58

Gaultier, J. P. 20

gay: aging $62-3$; bars xv, 5, 66, 83; celebrity 41; clubs 117-18; community $33-5,37,62 \mathrm{n} 13,95$, 100; culture 7, 12-13, 34, 52, 62; dating apps 33; death 59n1; discontent 153; disease 62; eroticism 154; gaze 9; genocide xvii; identity 6, 13, 32, 37, 94, 153; kiss 4; life everyday 167-8; male model magazines xv; marriage xvii, xix; men 1, 3-10, 12-14, 34, 51, 53-4, 56-7, 60, 60n3-4, 65, 71, 76-8, 
88-9, 95-8, 104, 111, 150-1, 154, $158,164,166$; music 10 ; people 6, 13, 23-4, 27n2, 41, 45, 47-8, 114,116 ; relational analysts 75 ; relationality 114 ; romances 21 ; sex 54; years $59 \mathrm{n} 1$

Gay Liberation Front (GLF) xvii-xviii, xix

'Gay Life Stories, Same-Sex Desires in Post-Revolutionary Iran' (Kjaran) 171 gayness 3-4, 47, 57-8, 62; autoethnography 7-8; colonisation of 167 ; heteronormativity 117 ; sexuality 77

gender: binary 44 ; identity $10,33,43$, $47-8$; sexuality and $12,82,115$; violence 130

Gendlin, E. T. 5

generational hope xviii

Generation X 54

Genesis 40

genital mutilation 130

Golden Girls, The 65

Goltz, D. B. 59n1, 61n9

Goodwin-Bauman family farm 135,144

grand narratives 4-6, 8-11, 14, 169

Greenwood, R. M. 92

Grey, A. xvii

Grindr (gay app) 33, 50-2, 56, 64, 95

Grohmann, S. 131

Growlr (gay app) 33

Guzmán, O. P. 123-32; being a gay man 124; culture 124-5; everyday life 125-7; love in California 128-30; love in Mexico City 127-8; love in times of polyamory $130-1$; migration 124-5; reflections 131-2; at work $123-4$

habitual repetition 6

Haeckel, E. 138

Harris, W. C. $61 \mathrm{n} 8$

Harrison, D. A. 10

hate $61,63,71-2,78,93,96,162$

help-seeking 88-9

heteronormativity $7,17,44,54$, 62n10-11, 89, 117; knowledges 116; marriage 72; religious discourse 61

heterosexuality/heterosexuals 10,60n3, 132; compulsory 137 ; homosexuality 94; men 53; purity pledges 61 ; sexuality 95 ; whiteness and 13
Highmore, B. 3-4, 8

Hirschfeld, M. 138

'History of Sexuality' (Foucault) 115

HIV xvii-xviii, 62-3, 62n10-11

Hobby, R. 27n1

homophobia $61,67,77,83,89,94,97$

homosexual/homosexuality 77-8, 92-4, 121, 167; behaviour 45; exclusively 20; law xvi; paedophilia and 98

Homosexuality: Its Nature and Causes (West) $\mathrm{xv}$

Homosexual Law Reform Society (HLRS) xvi, xviii

hyperarousal 76

identity: culture and 3 ; gay 6,13 , 32, 37, 94, 153; gender 28n6; intersectional 97; queer 30-1, 37; queer teacher 27; sexual 32

India 134

Instagram 35, 130

International Lesbian and Gay Movement xx

intersectional identity 97

intimacy $2,4,9,13,37,41,47,58$, 76-7, 113-14, 120, 149, 159, 171

It's a Sin (Davies) xvii

Jacobs, M. 96

Jaenicke, C. 69, 78

Jarman, D. 112

Jesus Christ 39, 140

John, E. 64

Kjaran, J. I. 171

Klein, K. J. 10

Koc, Y. 92-101, 170; bullying 94; homosexuality/homosexual 92-4; identity 94, 96-7, 101; ordinary privilege 92; self-acceptance 94-5; sexual orientation 96; social exclusion 96; stigmatised minorities 93, 98

Kuchuck, S. 75

Kungfu Tootsie 44

Lady Gaga 65

'La Experiencia Homosexual' (Castañeda) 115

Lalor, K. 6

Last Song, The 44

Latinx communities 123, 123n1, 125

Lefebvre, H. 2, 8 


\section{Index}

Lemebel, P. 115

LGBT 6, 9, 24, 27n1, 28n6

LGBTI Namibia 83

LGBTQ 64, 83-4, 88, 123-4, 160

LGBTQIA+ 2, 6, 9-10, 116-17, 151, 166-8

Living Sexuality (Berry) 64, 65n17

'Loco Afán' (Lemebel) 115

London School of Economics (LSE) xvi-xvii

loneliness 12, 30, 33, 35-6, 50-7, 61-2, 116

Lopez, R. C. 30-8, 171-2; break up with partner 32-3; father's death 31-2, 37; perception 33; shower thoughts $30-1$

Lorde, A. 131, 158

Los Angeles 128

Lowbridge-Ellis, D. 172

\section{machismo 37}

Macintosh, P. 163

Madonna 58

Mamma Mia 64

masturbation 58, 70-1, 111

McIntosh, P. 92, 99

McQueen, A. 96

Mead, M. xviii

Mellors, B. xvii

Mercado, W. 141

Merchant, C. 137

meta-analyses 99

Metropolitan Community Church 61n8

Mexico 4, 11, 116, 118, 124-5, 129

Mexico City 113, 127-8

Meyer, I. H. 100

Michael, G. 64-5

Mignolo, W. 133

migration 99, 124-5, 132, 139

Minority Stress Model 100

modernism 3

monogamy 14, 61-2, 140, 158

Mucho Mucho Amor (Mercado) 141

Muñoz, J. E. 113

Namibia 11, 81-4

narrating 'the everyday' 4-7

narrative resistance xviii

necrophilia 137, 139

neoliberal globalisation 139

Netflix 9

New Testament 40

New York 59 night clubs 9-10, 117-18

non-gay 118,121 ; assisted living facility 65; communities 7

non-White gay man 97

Northern Ireland 71-2

'Notes on Camp' (Sontag) 163

Nuñez, C. 38

Old Testament 40

Oliver, Jamie 50

oral sex 45

Ordinary Affects 163

ordinary privileges $13,92,94-5$, $100-1,170$

Organisation for Economic

Co-operation and Development 28n7

Orlando, Florida 63

over-exposure 153-5

paedophilia 98

pandaka 45

Pantip (Thai internet forum) 42

Pantoja, O. 169

personal space $3,5,56,147$

phenomenology of everyday life xviii

physical relation 74

physical space 114

physiological examination xvi

planetary community 133-4, 136, 13940, 142-3, 145; see also community

polyamory $14,130-1,140,144-5$

polymorphous perversity 69,76

Princes Street 45

Prior, S. 69-78, 170; eros 75-7; fear 71-2; hate 71-2; homosexuality 77-8; purity and dirt 73-4; sexuality rampant and relinquished $72-3$; sexual life 77; shame 71-2

private property 140

pro-gay stories 64

Protestant Christian 39

psychiatric hospital xvi

psychological health 73-4, 77

psychosexual theory 76

purity and dirt 73-4

Queen's Vernacular: A Gay Lexicon (Rodgers) 60-1n5

queer 3,7 ; artist $63 \mathrm{n} 14$; identity $30-1,34$, 37; men 4; sexuality 115 ; studies 10 ; teachers $27,28 \mathrm{n} 6$; theory 115-16, 143, 158

Queer Aging (Ramirez-Valles) 65n18 
Queer Domesticities (Cook) 4

'Queer Eye' (RuPaul) 96

racial prejudice 99

racism 34, 83, 97, 126, 137

Ramirez-Valles, J. 62n11, 65n18

Rantzen, E. 57

Reagan administration 136

relational ethics 148; see also ethics

religious freedom 65

risks: being gay 9; of losing everything

94; of resting on laurels 70

Rocket Man (John) 64

Rodgers, B. 60-1n5

Rodríguez, F. 3

Rodríguez-D. E. 4, 9, 113-21, 171; being gay 116 ; gay relationality 114; intimacy 113-14, 120; minority stress 117 ; protective relationality 117 ; public oppression and violence 114; public space 114; reappropriation of space; self-vigilance 117 ; space, time, and kinship 120-1

Roman Empire 140

romanticism 14, 143

RuPaul (drag queen) 96, 101

Sahassanon, P. 39-48, 170;

Christmastime in 2009 41-2;

Christmastime in 2010 42-3;

Christmastime in 2014 42-3;

Christmastime in 2017 43-4;

Christmastime in 2019 39-41, 45-6;

Christmastime in 2020 46-7; making sense $47-8$

same-sex: attraction 58; marriage xix,

15; partner/partnerships 30, 47;

relationships 2, 65; sexual activity 61

Sant, Gus Van 58

Santa Claus 42

Schmitt, M. T. 99

scientific revolution 137

Scofield, M. xvn4

secrecy xix, 71, 110

Secret Love, A 65n19

Sedgewick, E. 83

self-harm 64,74

self-vigilance 117

sex education 24-5

sexual arousal $45,72,77$

sexual development 74, 77, 115

sexual gratification $76-7$ sexual identity $10,12,32-3,47,96$, 98, 101

sexuality: eroticism and 154; gayness with 77; gender and 12, 82; mental health and 14; queer 115; rampant and relinquished $72-3$; studies 2

sexual life 77,154

sexual minorities 10

sexual objectification 34,37

sexual orientations 10

sexual self xiiin 1,78

shame xix, 20, 24, 48, 54, 71-2, 75, $77-8,79,111$

Shelton, J. N. 99

Sherman, E. 75-6

Shield, A. 51, 51n1

social acceptance $28 \mathrm{n} 7$

social change 3

social class $\mathrm{xv}$

social death $62 \mathrm{n} 13$

social development 71

social distance 87

social norms 79

social realities 1,170

Sociological Aspects of Homosexuality

(Scofield) xvn4

sodomy laws 61-2

Sontag, S. 27n3, 58, 163

Spieldenner, A. R. 7

Stander, W. J. 79-90, 170; bullied 83; depression and anxiety 80; joining a gay social networking app 84; life stressors 81 ; writing difficulty 82

stereotypes 24, 99-101

Stewart, K. 120

stigma xix, 12, 36, 79-80, 88, 93, 96, 100

St. Mark's Square, Venice 21

Stonewall Liberation (1969) xvii, xix straight couples 21,42

Swift, T. 65

Tawan Church 39

Theravāda Buddhist 39, 45

Thomas, C. 46, 50-7, 170-1; feeling lonely 50-5; midlife 55-6; refusing cancer treatment 54

Tiger King 65

Tinder 64

Tommy Hilfiger 46

transformative everyday gay life xvii-xix 


\section{Index}

Triandafyllou, J. 103-12, 171; cammer 103; childhood sexual abuse 106, 111; Glastonbury Festival 108; intercourse 109; Section 28104

ubhatobyanjanaka 45 United Church of Christ 61n8 University of Edinburgh 48 U.S. National Survey on LGBTQ Youth Mental Health (2020) 64

Vaid, U. 115

Vietnam 110

Vinaya Pițaka 45

'Virtual Equality' (Vaid) 115
Walter, A. xvii

Warner, M. 116

Wayne, J. 25

Weber, A. 139

Weeks, J. xviii

West, D. J. xvn4; Homosexuality: Its Nature and Causes xv

Weston, K. 60n3-4

Wikipedia 24

Williams, R. 113

Wilson, E.O. 139

World War II 133

youthism $61 \mathrm{n} 9,62 \mathrm{n} 13$

Zona Rosa 128 